\title{
Análise não linear geométrica e física de núcleos rígidos de edifícios altos em concreto armado
}

\section{Angelo Giovanni Bonfim Corelhano}

Dissertação apresentada á escola de

Engenharia de São Carlos da Universidade de são Paulo, como parte dos requisitos para obtenção do Título de Mestre em Engenharia de Estruturas

Orientador: Márcio Roberto Silva Corrêa

São Carlos 
AUTORIZO A REPRODUÇÄO E DIVULGAÇÄO TOTAL OU PARCIAL DESTE TRABALHO, POR QUALQUER MEIO CONVENCIONAL OU ELETRÔNICO, PARA FINS DE ESTUDO E PESQUISA, DESDE QUE CITADA A FONTE.

Ficha catalográfica preparada pela Seção de Tratamento da Informação do Serviço de Biblioteca - EESC/USP

C414a

Corelhano, Angelo Giovanni Bonfim.

Análise não linear geométrica e física de núcleos rígidos de edifícios altos em concreto armado / Angelo Giovanni Bonfim Corelhano; orientador Márcio Roberto da Silva Corrêa. -- São Carlos, 2010.

Dissertação (Mestrado-Programa de Pós-Graduação e Área de Concentração en Engenharia de Estruturas) - Escola de Engenharia de São Carlos da Universidade de São Paulo, 2010 .

1. Edifícios altos. 2. Núcleo de rigidez. 3. Não linearidade geométrica. 4. Nào linearidade física. 5. Concreto armado. I. Título. 
FOLHA DE JULGAMENTO

Candidato: Engenheiro ANGELO GIOVANNI BONFIM CORELHANO.

Dissertação defendida e julgada em 20/04/2010 perante a Comissão Julgadora:

Geen ar. S.C. APROVADO Prof. Associado MÁRCIO ROBERTO SILVA CORRÊA - (Orientador)

(Escola de Engenharia de São Carlos/USP)

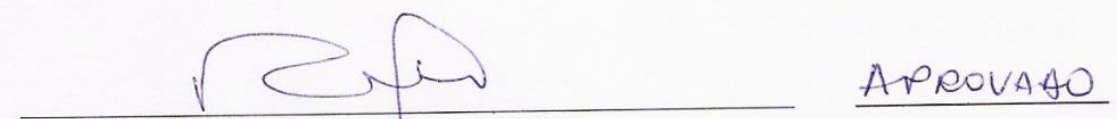

Prof. Dr. ROBERTO MARCIO DA SILVA

(Universidade Federal de Minas Gerais/UFMG)

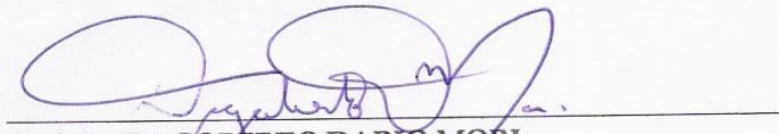

Prof. Dr. DAGOBERTO DARIO MORI

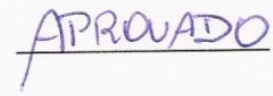

(Escola de Engenharia de São Carlos/USP)

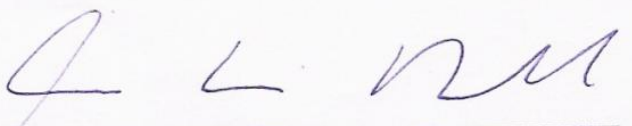

Prof. Ássociado MARCIO ANTONIO RAMALHO

Coordenador do Programa de Pós-Graduação em

Engenharia Civil (Engenharia de Estruturas)

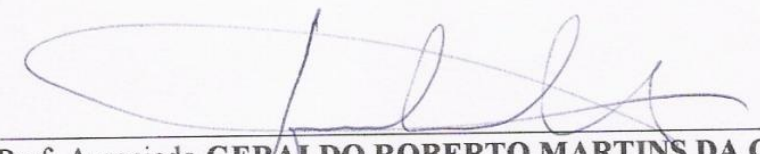

Prof. Associado GERALDO ROBERTO MARTINS DA COSTA

Presidente da Comissão de Pós-Graduação 

Aos meus pais, Antonio e Branca com amor e gratidão. 



\section{Agradecimentos}

Agradeço a Deus, meus pais e minha avó por me guiarem até aqui.

Ao excelente trabalho de orientação do professor Márcio Roberto Silva Corrêa.

Ao professor Dagoberto Dario Mori pelas orientações iniciais.

Aos meus grandes amigos de república durante os anos de graduação em Maringá: Géter, Moisés, Rodrigo (Cepa) e Walter.

Aos bacharéis e mestres: Hugo, Wanderson e Rodrigo (Mário), com quem tive o privilégio de morar durante o desenvolvimento deste trabalho.

A todos os professores que passaram pela minha formação, desde os primeiros anos de ensino fundamental até a pós-graduação.

Aos amigos do SET que foram excelentes companhias durante o desenvolvimento deste trabalho.

Aos funcionários do SET/EESC/USP.

A todas as pessoas que contribuíram de alguma forma para a realização deste trabalho A CAPES pela bolsa concedida. 


\section{Sumário}

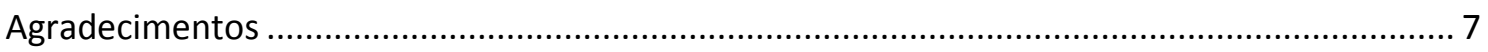

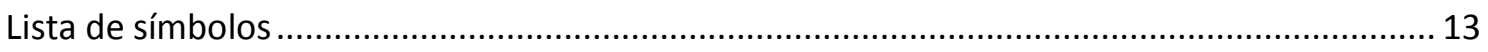

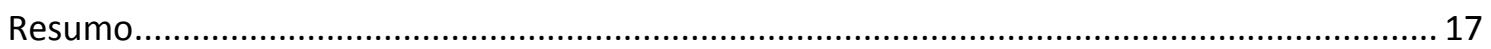

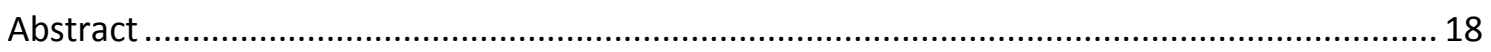

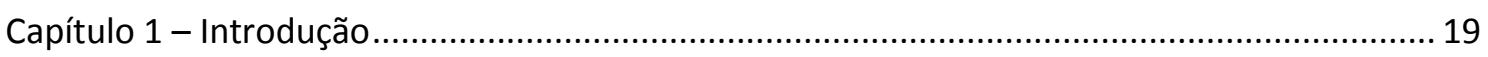

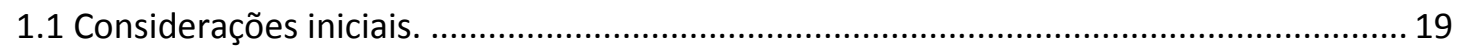

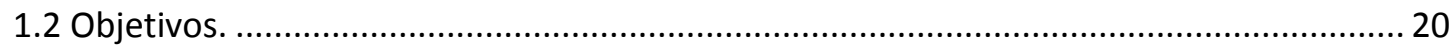

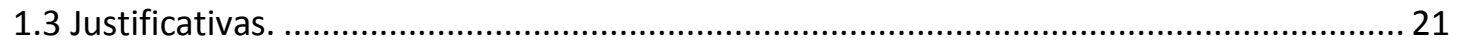

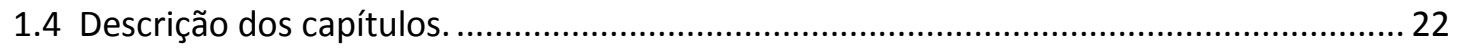

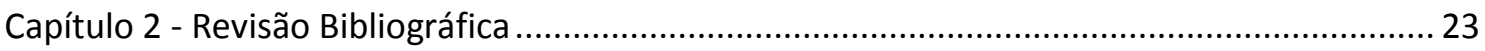

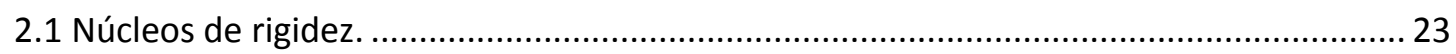

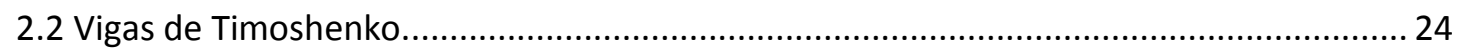

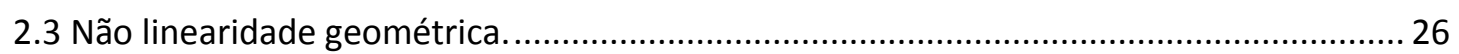

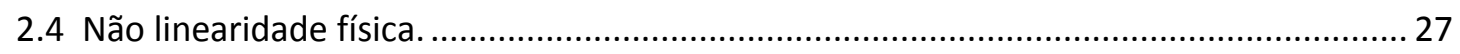

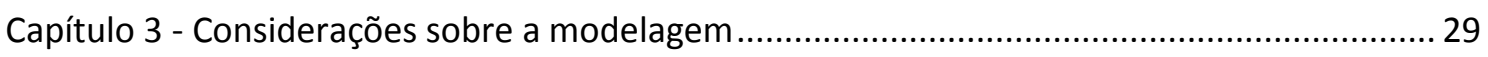

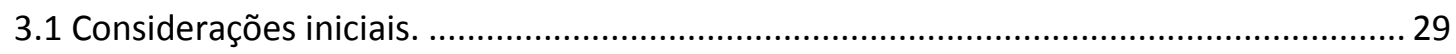

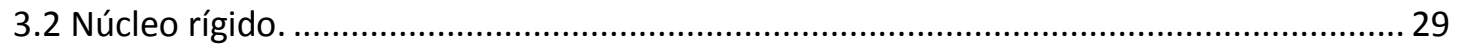

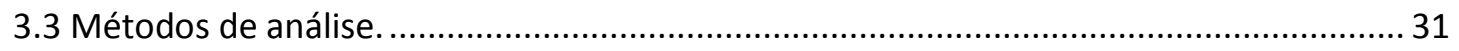

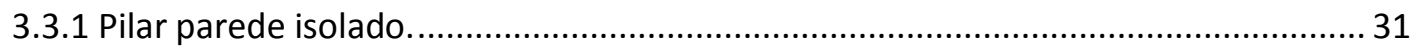

3.3.2 Barras de seção delgada sem a consideração da flexo-torção. …………………....... 32

3.3.3 Barras de seção delgada com a consideração da flexo-torção.................................. 33

3.3.4 Modelagem através de elementos de casca.............................................................. 34

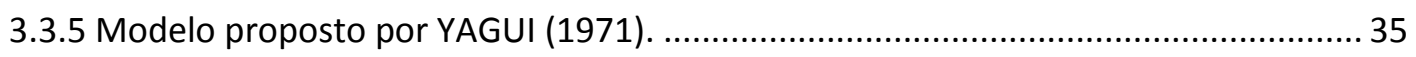

3.4 Sistema de referência local e global............................................................................ 40

3.4.1 Sistema de referência local para barra de pórtico tridimensional.............................. 40

3.4.2 Sistema de referência global e matrizes de rotação.................................................... 40

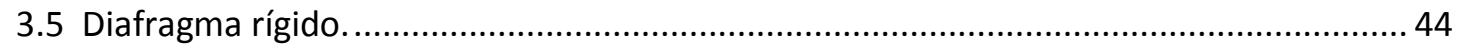

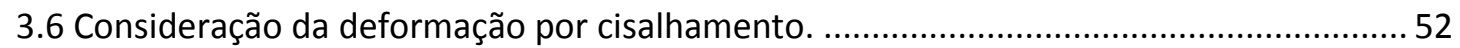

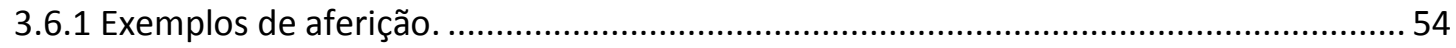

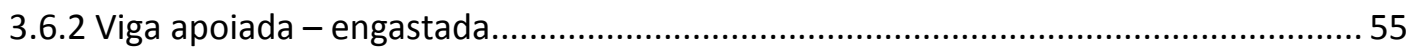

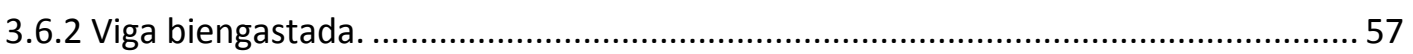

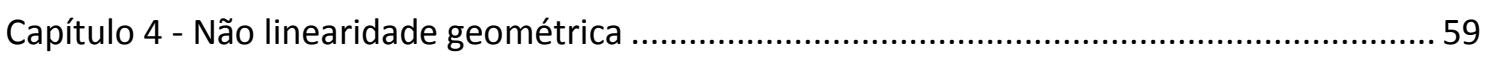

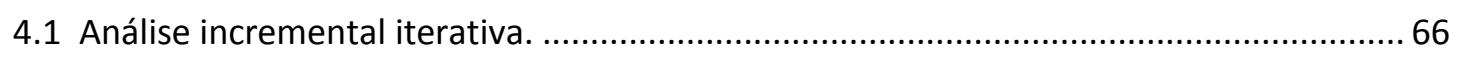




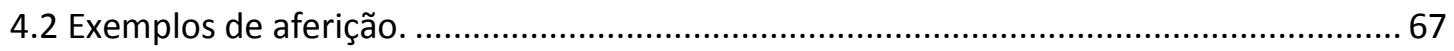

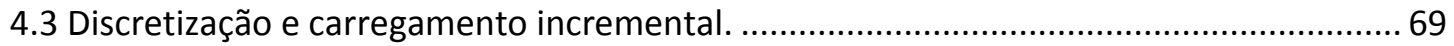

4.4 Barra engastada sujeita a momento na extremidade................................................... 72

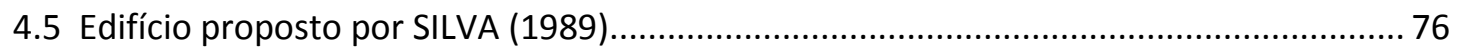

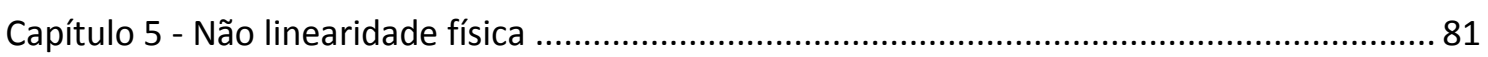

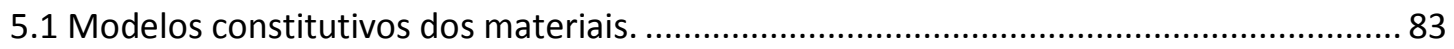

5.2 Relações entre módulo de elasticidade e deformação....................................................... 87

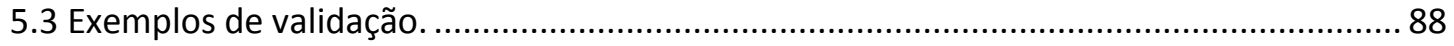

5.3.1 Pórtico simples com carregamento vertical................................................................. 89

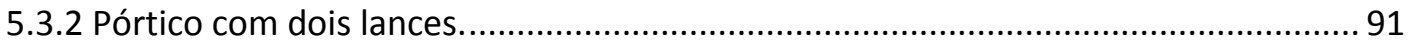

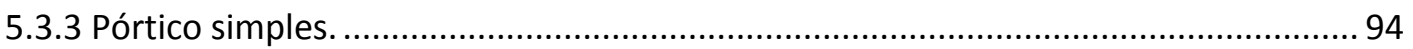

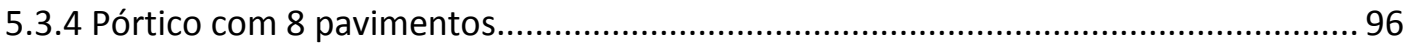

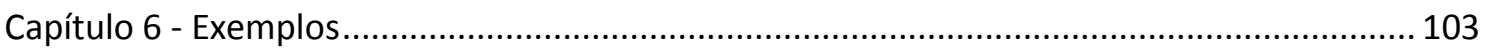

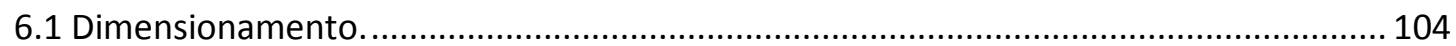

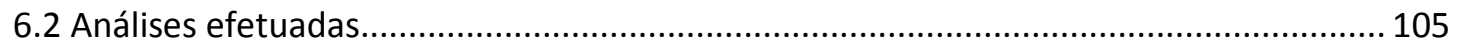

6.3 Coeficiente redução de inércia das paredes dos núcleos. .............................................. 106

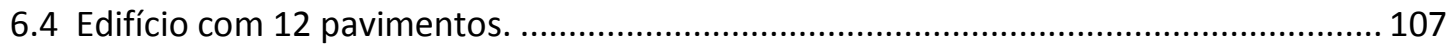

Sugestão para coeficiente redutor de inércia..................................................................... 114

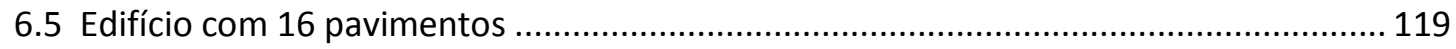

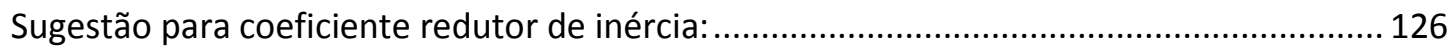

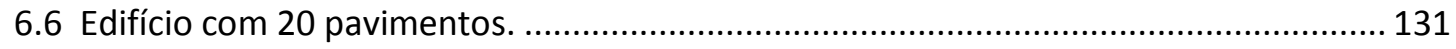

Capítulo 7 - Conclusões e sugestões para trabalhos futuros ................................................. 145

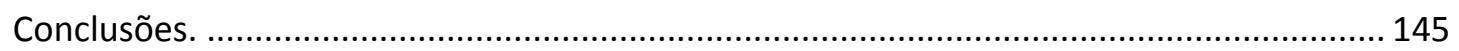

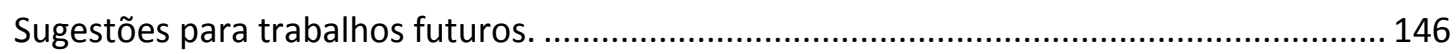

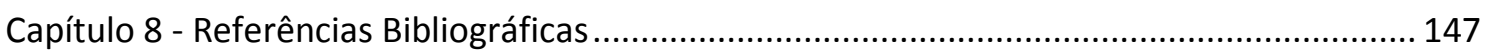

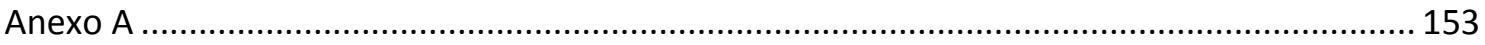

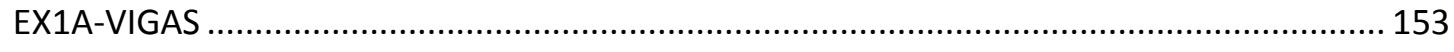

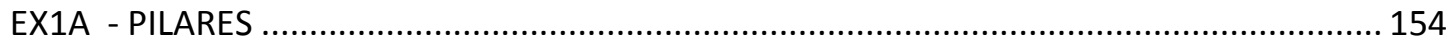

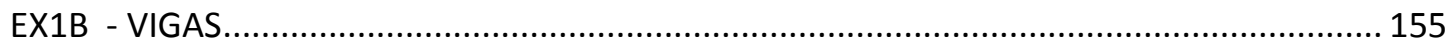

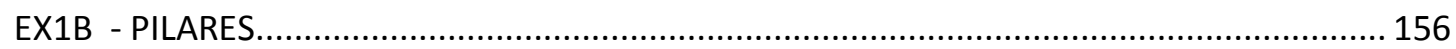

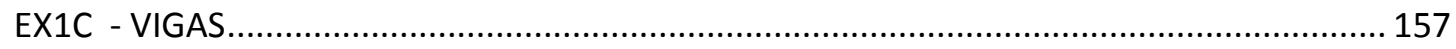

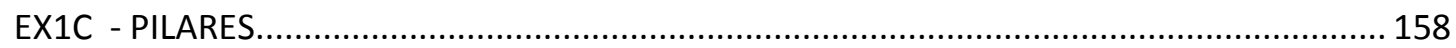

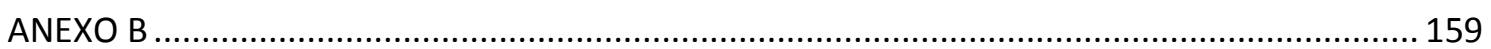

$12 \mathrm{~A}$ 
$12 \mathrm{~B}$

12 C

16A

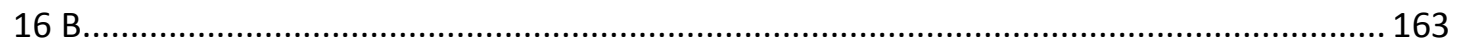

$16 \mathrm{C}$

$20 \mathrm{~A}$

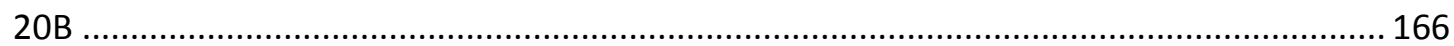

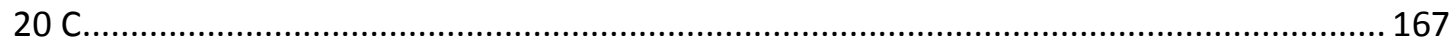

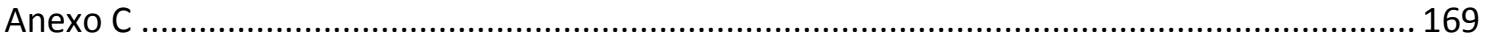

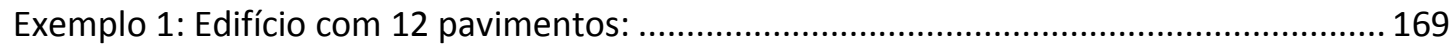

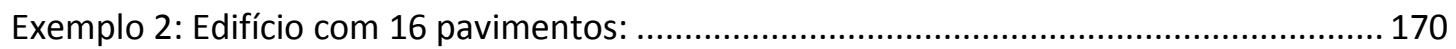

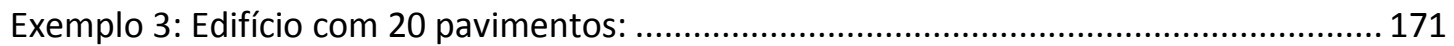




\section{Lista de símbolos}

$\boldsymbol{A}$ - Área da seção transversal do elemento

$\boldsymbol{A}_{\boldsymbol{S}}{ }^{\prime \prime}$ - Área da seção transversal dos estribos

$\boldsymbol{B}$ - Largura da seção

$\boldsymbol{b}$ " $\boldsymbol{e}$ " - Maior e menor dimensões do estribo

$\boldsymbol{C}_{\boldsymbol{x}}, \boldsymbol{C}_{\boldsymbol{y}}, \boldsymbol{C}_{z}, \boldsymbol{C}_{\boldsymbol{x} z}-$ Coeficientes de rotação

$\boldsymbol{D}_{\boldsymbol{x}}, \boldsymbol{D}_{\boldsymbol{y} \boldsymbol{k}}, \boldsymbol{D}_{\boldsymbol{z} \boldsymbol{k}}-$ Deslocamentos de um nó pertencente ao diafragma rígido

$\boldsymbol{D}_{x n}, \boldsymbol{D}_{z n}$ - Deslocamentos do nó mestre

$\boldsymbol{E}$ - Módulo de elasticidade longitudinal do material

$\boldsymbol{E}_{\boldsymbol{S}}$ - Módulo de elasticidade do aço em regime elástico

$\boldsymbol{E}_{\boldsymbol{S}}{ }^{\prime}-$ Módulo de elasticidade do aço após o escoamento

$\boldsymbol{F}^{T}-$ Vetor que reúne os esforços nodais

$\boldsymbol{f}^{\prime}{ }_{c}$ - Máxima tensão de compressão do concreto

f ck - Máxima tensão de compressão característica do concreto

$\boldsymbol{f}^{\prime}{ }_{t}$ - Máxima tensão de tração do concreto

$\boldsymbol{f}_{\boldsymbol{y} \boldsymbol{s}}, \boldsymbol{f}_{\boldsymbol{y}}-$ Máxima tensão no aço

$\boldsymbol{G}$ - Módulo de elasticidade transversa do material

$\boldsymbol{G}_{\boldsymbol{y}}$ - Produto do coeficiente de forma na direção y e o módulo de elasticidade transversal

$\boldsymbol{G}_{\boldsymbol{z}}$ - Produto do coeficiente de forma na direção z e o módulo de elasticidade transversal

$\boldsymbol{H}$ - Altura da seção

I - Inércia da seção

$\boldsymbol{K}_{\mathbf{0}}$ - Matriz de rigidez elástica do elemento

$\boldsymbol{K}_{\mathbf{1}}$ - Matriz de rigidez incremental do elemento

$\boldsymbol{K}_{\mathbf{2}}$ - Matriz de rigidez incremental do elemento

$\boldsymbol{K}_{\boldsymbol{G}}-$ Matriz de rigidez geométrica do elemento

$\boldsymbol{K}_{\boldsymbol{M}}$ - Matriz de rigidez transformada em coordenadas globais

$\boldsymbol{K}_{\boldsymbol{S}}-$ Matriz de rigidez secante da estrutura

$\boldsymbol{K}_{T}$ - Matriz de rigidez considerando deformação por corte

$\boldsymbol{K}_{\boldsymbol{T}}$ - Matriz de rigidez tangente da estrutura 
$\boldsymbol{L}$ - Comprimento do elemento

$\boldsymbol{M}$ - Momento fletor pontual aplicado

$\boldsymbol{N}$ - Esforço Normal atuante no elemento

$\boldsymbol{N}_{\mathbf{1}}(\boldsymbol{x}), \boldsymbol{N}_{\mathbf{1}}(x), \ldots, \boldsymbol{N}_{\mathbf{2}}(\boldsymbol{x})$ - Funções aproximadoras dos deslocamentos ao longo do elemento

$\boldsymbol{P}$ - Força pontual aplicada

$\boldsymbol{Q}-$ Vetor que reúne os deslocamentos nodais

$\boldsymbol{q}_{1}, \boldsymbol{q}_{2}, \ldots, \boldsymbol{q}_{12}-$ Vetor de deslocamentos nodais

$\boldsymbol{R}$ - Matriz de rotação de coordenadas

$\boldsymbol{r} \boldsymbol{x}_{1}, \boldsymbol{r} \boldsymbol{y}_{1}, \boldsymbol{r} \boldsymbol{z}_{1}, \boldsymbol{r} \boldsymbol{x}_{2}, \boldsymbol{r} \boldsymbol{y}_{2}, \boldsymbol{r} \boldsymbol{z}_{2}-$ Rotações em torno dos eixos $\mathrm{x}, \mathrm{y}$ e $\mathrm{z}$ dos nós inicial e

$\boldsymbol{R}_{\boldsymbol{x} \boldsymbol{k}}, \boldsymbol{R}_{\boldsymbol{y} \boldsymbol{k}}, \boldsymbol{R}_{z \boldsymbol{k}}-$ Rotações de um nó pertencente ao diafragma rígido

$\boldsymbol{R}_{\boldsymbol{y n}}-$ Rotação do nó mestre

$\boldsymbol{s}$ - Espaçamento entre estribos

$\boldsymbol{T}$ - Matriz de translação de deslocamentos

$\boldsymbol{U}$ - Energia de deformação das barras

$\boldsymbol{u}_{1}, \boldsymbol{v}_{1}, \boldsymbol{w}_{1}, \boldsymbol{u}_{2}, \boldsymbol{v}_{2}, \boldsymbol{w}_{2}$ - Deslocamentos nas direções $\mathrm{x}, \mathrm{y}$ e $\mathrm{z}$ dos nós inicial e final do

$\boldsymbol{u}_{\boldsymbol{x}}$ - Deslocamento nodal na direção X

$\boldsymbol{u}_{\boldsymbol{y}}$ - Deslocamento nodal na direção Y

$\boldsymbol{u}_{\boldsymbol{z}}$ - Deslocamento nodal na direção Z

$\boldsymbol{V}$ - Volume do elemento

$\boldsymbol{x}, \boldsymbol{y} \boldsymbol{e} \mathbf{z}-$ Sistema cartesiano local

$\boldsymbol{X}, \boldsymbol{Y}$ e Z - Sistema cartesiano global

$X_{1}, Y_{1} \boldsymbol{e} Z_{1}-$ Sistema cartesiano com orientação qualquer

$\boldsymbol{X}_{2}, \boldsymbol{Y}_{2} \boldsymbol{e} \boldsymbol{Z}_{2}-$ Sistema cartesiano com orientação qualquer

$\boldsymbol{X}_{\boldsymbol{K}}, \boldsymbol{X}_{\boldsymbol{K}}-$ Coordenadas de um nó pertencente ao diafragma rígido em relação ao nó mestre

$\boldsymbol{Y}$ - Coordenada Y da fibra em relação ao centróide da seção

$\boldsymbol{Y C} \boldsymbol{A}$ - Coordenada do centróide de uma camada de aço ao centróide da seção

YCC - Coordenada do centróide de uma camada de concreto ao centróide da seção 
$\boldsymbol{Z}$ - Inclinação do trecho descendente da curva Tensão versus Deformação considerando o confinamento

$\boldsymbol{Z}$ - Coordenada $Z$ da fibra em relação ao centróide da seção

$\boldsymbol{\alpha}$ - Fator de redução da tensão de tração do concreto

$\boldsymbol{\alpha}-$ Giro em torno do eixo X

$\boldsymbol{\beta}$ - Giro em torno do eixo Y

$\boldsymbol{\beta}_{\mathbf{0}}-$ Rotação da corda do elemento em torno do eixo y

$\boldsymbol{\beta}_{1}-$ Rotação nó inicial do elemento em torno do eixo y

$\boldsymbol{\beta}_{\mathbf{2}}-$ Rotação nó final do elemento em torno do eixo $\mathbf{y}$

$\boldsymbol{\gamma}$ - Giro em torno do eixo $\mathrm{Z}$

$\boldsymbol{\gamma}$ - Matriz de transformação

$\boldsymbol{\varepsilon}-$ Vetor de deformações

$\boldsymbol{\varepsilon}_{\mathbf{0}}$ - Deformação específica do concreto para a máxima tensão de compressão

$\varepsilon_{50 c}$ - Deformação do concreto correspondente a $50 \%$ da tensão máxima no trecho descendente do diagrama Tensão versus Deformação considerando o confinamento $\boldsymbol{\varepsilon}_{\mathbf{5 0 u}}$ - Deformação do concreto correspondente a $50 \%$ da tensão máxima no trecho descendente do diagrama Tensão versus Deformação desconsiderando o confinamento $\boldsymbol{\varepsilon}_{\boldsymbol{X}}-$ Vetor de deformações longitudinais

$\boldsymbol{\varepsilon}_{\boldsymbol{c}}-$ Deformação específica do concreto

$\boldsymbol{\varepsilon}_{\text {smax }}$ - Máxima deformação do aço

$\varepsilon_{t}-$ Deformação do concreto para máxima tensão de tração

$\varepsilon_{t}-$ Máxima deformação do concreto tracionado

$\boldsymbol{\varepsilon}_{\boldsymbol{y s}}$ - Deformação do aço correspondente à tensão de escoamento

$\boldsymbol{\varphi}_{1}, \boldsymbol{\varphi}_{2}, \ldots, \boldsymbol{\varphi}_{11}-$ Coeficientes das matrizes $K_{1}$ e $K_{1}$

$\boldsymbol{\psi}_{1}, \boldsymbol{\psi}_{2}, \ldots, \boldsymbol{\psi}_{11}-$ Coeficientes das matrizes $K_{1}$ e $K_{1}$

$\boldsymbol{\rho}^{\prime \prime}-$ Taxa de armadura transeversal

П - Energia potencial total

$\boldsymbol{v}$ - Coeficiente de Poison

$\boldsymbol{\sigma}-$ Vetor de tensões

$\boldsymbol{\theta}_{\mathbf{0}}-$ Rotação da corda do elemento em torno do eixo $\mathrm{z}$

$\boldsymbol{\theta}_{1}-$ Rotação nó inicial do elemento em torno do eixo z

$\boldsymbol{\theta}_{2}-$ Rotação nó final do elemento em torno do eixo $\mathrm{z}$ 
$\boldsymbol{\theta}_{\boldsymbol{x}}-$ Rotação em torno do eixo X

$\boldsymbol{\theta}_{\boldsymbol{y}}-$ Rotação em torno do eixo Y

$\boldsymbol{\theta}_{\boldsymbol{z}}-$ Rotação em torno do eixo $\mathrm{Z}$ 


\section{Resumo}

CORElhanO, A. G. B. (2010). Análise não linear geométrica e física de núcleos rígidos de edifícios altos em concreto armado. São Carlos, 2010. Dissertação (Mestrado) - Escola de Engenharia de São Carlos, Universidade de São Paulo.

Neste trabalho são abordados os aspectos inerentes à análise não linear física e geométrica de núcleos rígidos pertencentes a estruturas de contraventamento de edifícios altos em concreto armado. O trabalho foca a análise estrutural dos núcleos através do uso de uma ferramenta computacional capaz de realizar uma análise não linear rigorosa, estudando modelos usuais com o emprego do método dos elementos finitos. São avaliadas as reduções de inércia que ocorrem nas paredes que compõem os núcleos, dimensionados de forma a apresentarem três taxas de armadura, uma próxima à mínima, uma média e uma próxima à máxima permitida pela NBR 6118. São estabelecidas estimativas simplificadas para os efeitos da não linearidade física sobre esses elementos, que possam ser utilizadas em projetos usuais de maneira simples e prática.

Palavras chave: Edifícios altos, Núcleo de rigidez, Não linearidade geométrica, Não linearidade física, concreto armado. 


\begin{abstract}
CORELHANO, A. G. B. (2010). Nonlinear geometrical and physical analysis of cores of reinforced concrete tall buildings. São Carlos, 2010. Dissertation (Master)- Escola de Engenharia de São Carlos, Universidade de São Paulo.

This work deals with nonlinear geometrical and physical analysis of structural cores that take part in the bracing system of multistory reinforced concrete buildings. The study depicts the structural behavior of concrete cores by using a computational tool that performs a strict non-linear analysis, coping with usual models based on the Finite Element Method. The work evaluates the inertia reduction of concrete core's walls, considering minimum, medium and maximum geometrical reinforcement ratio prescribed by NBR 6118. Estimations of the physical nonlinearity of those elements are provided aiming at the practical use in actual structural design.
\end{abstract}

Keywords: Tall buildings, structural cores, geometrical nonlinearity, physical nonlinearity, reinforced concrete. 


\section{Capítulo 1 - Introdução}

\subsection{Considerações iniciais.}

A construção de edifícios altos tem sido uma alternativa cada vez mais atraente em grandes centros urbanos. A estrutura de tais edifícios exige grande rigidez frente ações horizontais, sendo uma das alternativas viáveis a adoção de núcleos rígidos. $\mathrm{Na}$ modelagem deste tipo de estrutura, além de certa complexidade imposta pela presença do núcleo, os efeitos das não linearidades geométrica e física têm maior relevância.

O meio científico, incentivado pelo aumento da capacidade de processamento dos microcomputadores, tem desenvolvido poderosas ferramentas computacionais de análise não linear de estruturas de concreto armado. Apesar do avanço científico, existe uma defasagem de alguns anos entre tecnologias desenvolvidas e o seu emprego no meio técnico. As razões são diversas, tais como maior complexidade das rotinas envolvidas, maior necessidade de conhecimento da teoria de análise e maior tempo de processamento.

Dado este panorama, o presente estudo fundamenta-se em dois aspectos. O primeiro deles é o de contribuir para a análise não linear física e geométrica de edifícios com núcleo de rigidez através do desenvolvimento de um código computacional que possibilite estas análises em pórticos tridimensionais. O segundo é o de buscar a evolução dos processos simplificados de análise através de parâmetros estimadores dos efeitos da análise não linear física, na rigidez dos elementos pertencentes às paredes dos núcleos. 


\subsection{Objetivos.}

A realização deste trabalho tem como objetivo principal avaliar o comportamento de edifícios altos com núcleo de rigidez considerando as não linearidades geométrica e física, com uma formulação rigorosa consistente, na qual são atribuídos modelos constituintes independentes para o concreto e para o aço. Os núcleos são modelados segundo YAGUI (1971), em que as paredes são representadas por barras verticais flexíveis ligadas ao nível do pavimento por barras horizontais rígidas articuladas nas extremidades que se conectam às demais paredes .

Para tanto, foi desenvolvida neste trabalho uma ferramenta computacional capaz de realizar análise não linear geométrica de pórticos tridimensionais considerando os pavimentos como diafragmas rígidos no seu plano, e análise não linear física de elementos submetidos à flexão composta.

Objetiva-se, também a avaliação da inércia efetiva a ser empregado nas paredes pertencentes aos núcleos para análises estruturais simplificadas, bem como o efeito da deformação por esforço cortante sobre os elementos constituintes da estrutura de contraventamento. 


\subsection{Justificativas.}

A evolução da concepção arquitetônica tem levado a soluções estruturais cada vez mais ousadas. A busca pelo equilíbrio entre segurança e economia tem exigido um grau crescente de aprimoramento dos métodos de análise empregados. Desta forma os métodos de análise de estruturas de contraventamento de edifícios altos têm evoluído de forma considerável.

Existem diversos trabalhos referentes às NLG e NLF de elementos estruturais de concreto pertencentes a pórticos planos, mas ainda há carência de estudos sobre o efeito da NLF sobre as paredes de núcleos rígidos, bem como de indicadores de inércia efetiva a ser empregada em análises simplificadas. No meio técnico, por falta de informações específicas, as paredes recebem usualmente o mesmo tratamento dos pilares quando da avaliação dos efeitos da NLF. 


\subsection{Descrição dos capítulos.}

No segundo capítulo é apresentada a revisão bibliográfica, sendo abordados os aspectos da modelagem de estruturas tridimensionais de edifícios altos e o desenvolvimento das análises não lineares simplificadas e rigorosas.

No terceiro capítulo é feita uma descrição detalhada dos aspectos considerados na modelagem elástica das estruturas de contraventamento de edifícios, bem como uma breve discussão sobre alguns dos métodos simplificados de análise não linear.

No quarto capítulo desenvolve-se a formulação empregada para o tratamento da não linearidade geométrica em pórticos tridimensionais, sendo apresentados alguns resultados para validação do modelo empregado.

No quinto capítulo é apresentada a formulação utilizada para a análise não linear física, bem como os modelos constitutivos adotados para aço e concreto. Ao final deste capítulo são mostrados, para fins de validação do modelo computacional, algumas estruturas e os correspondentes resultados numéricos e/ou experimentais apresentados por outros autores.

No sexto capítulo são apresentadas as estruturas analisadas e utilizadas para o estudo da influência da NLF sobre as paredes dos núcleos. São apresentados três edifícios iguais em planta e com números de pavimentos iguais a 12, 16, e 20.

No sétimo capítulo são apresentadas as conclusões do trabalho, bem como algumas sugestões para futuros trabalhos de pesquisa.

No último capítulo é apresentada a bibliografia consultada para o desenvolvimento da pesquisa.

No apêndice A são mostrados os detalhamentos das armaduras do pórtico de 8 pavimentos apresentado no capítulo 5. No apêndice B são mostrados os detalhamentos das armaduras dos núcleos estudados no capítulo 6. Por fim no anexo $\mathrm{C}$ são mostradas tabelas referentes aos deslocamentos dos pavimentos dos edifícios estudados no capítulo 6. 


\section{Capítulo 2 - Revisão Bibliográfica}

\subsection{Núcleos de rigidez.}

As estruturas de edifícios altos requerem do projetista grandes conhecimentos relacionados à estabilidade das estruturas, principalmente no que diz respeito ao controle dos deslocamentos e esforços provenientes das ações horizontais.

O processo discreto, apesar do grande número de incógnitas, é de grande interesse quando se analisam estruturas que apresentem variações geométricas ao longo da sua altura.

Vários pesquisadores, como HEIDEBRECHT \& SWIFT (1971), SMITH \& TARANATH (1972) e TARANATH (1975), que utilizaram a análise matricial discreta, consideraram o tramo do núcleo entre lajes como um elemento linear tridimensional, que relaciona o bimomento com a primeira derivada da torção.

YAGUI (1971), utilizando o processo discreto, tratou as paredes de seção transversal, como associações de pórticos planos formados por um conjunto de vigas horizontais, com as suas extremidades em balanço e engastadas no centro em pilares verticais. Tais vigas possuem rigidez infinita à flexão no plano dos pórticos a que pertencem.

Outro trabalho que pode ser citado foi desenvolvido por SORIANO (1971), que além de apresentar um desenvolvimento teórico, apresenta também um programa capaz de realizar o cálculo automático de estruturas carregadas lateralmente, o núcleo e os demais elementos são idealizados como um conjunto de painéis ortogonais, interagindo em suas interseções verticais através das lajes.

SILVA (1989), utilizando a modelagem para núcleos proposta por YAGUI (1971), desenvolve análise de estruturas tridimensionais formadas por pórticos e núcleos resistentes, levando em consideração a deformação por esforço cortante, trechos rígidos, e também uma análise não linear geométrica simplificada, através do método P- $\Delta$.

MORI (1992), a partir do trabalho desenvolvido por BECKER (1989), introduz a análise não linear geométrica, procedendo a alteração da matriz de rigidez dos elementos afetada pelos esforços de segunda ordem.

Baseando-se também no trabalho desenvolvido por BECKER (1989) e MORI (1992), MATIAS (1997) analisa a interação tridimensional entre núcleos e as estruturas de 
contraventamento, tais como treliças, pórticos e pilares isolados, considerando a influência das suas fundações no equilíbrio final da estrutura quando são introduzidos os efeitos da não linearidade geométrica.

TORRES (1999) objetivando considerar a deformação pelo esforço cortante nas análises estruturais de edifícios que apresentem núcleo resistente, desenvolve um programa onde o comportamento à flexão dos elementos verticais de contraventamento passa a ser regido pela teoria de barras de Timoshenko e não mais pela de Euler-Bernoulli.

PEREIRA (2000) desenvolve um estudo comparativo entre várias modelagens possíveis em barras para os núcleos rígidos, com análises feitas em primeira e segunda ordem, sendo os resultados comparados com os obtidos fazendo-se a modelagem do núcleo com elementos finitos de chapa no software Ansys 5.0

\subsection{Vigas de Timoshenko.}

A teoria tradicionalmente utilizada para a flexão de elementos de barra, conhecida como teoria de Euler-Bernoulli, data de 1705. A teoria de viga de Timoshenko, que considera a deformação por cisalhamento, foi exposta inicialmente pelo autor em 1921. Em seu artigo, já se colocava a necessidade de um fator de forma, que introduzisse os efeitos da tensão de cisalhamento.

Em TIMOSHENKO \& GERE (1984) podem ser encontrados mais detalhes e discussões sobre as vigas de Timoshenko. Vários foram os autores que propuseram elementos finitos para a viga de Timoshenko, podendo-se citar NICKEL \& SECOR (1972) e TESSLER \& DONG (1981), dentre outros. Eles diferem entre si apenas na escolha da função de interpolação utilizada para aproximar os deslocamentos transversais e as rotações.

O modelo mais simples para a formulação em elementos finitos, conforme visto em BATHE (1996) é aquele que considera interpolações lineares tanto para os deslocamentos transversais, quanto para as rotações. No entanto, este modelo se mostra muito rígido para as vigas pouco deformáveis ao esforço cortante. Este comportamento acarreta o bloqueio da solução ou travamento, conhecido como o efeito shear locking. $\mathrm{O}$ travamento acontece devido à inconsistência da ordem das funções de deslocamentos transversais e as respectivas rotações. Alguns artifícios matemáticos foram propostos para superá-lo, podendo-se utilizar uma função de interpolação de mesmo grau tanto 
para os deslocamentos quanto para as rotações, mas utilizando um polinômio de menor grau para a distorção. É também freqüentemente utilizada a integração seletiva, na qual a integração numérica em ordem reduzida é empregada para calcular os coeficientes de rigidez associados à distorção, enquanto os demais coeficientes da matriz de rigidez são determinados com uma integração precisa. A integração reduzida é feita usando-se quadratura de Gauss com apenas um ponto, o que para um polinômio aproximador de grau $\mathrm{P}=2 \mathrm{~N}-1$, corresponde a se adotar uma aproximação constante.

Através dessas técnicas, chega-se a uma nova matriz de rigidez, como mostrada em NÓBREGA (1997), onde a parcela de esforço cortante tem a sua participação diminuída, o que leva ao alívio do travamento da solução. Este procedimento deve ser utilizado com cautela, segundo RIGITANO (1998).

Uma solução bastante elegante e precisa do problema foi proposta por REDDY (1997), que emprega um elemento que se adéqua a um campo de deslocamentos com polinômios cúbicos para representar as distorções na seção transversal, admitindo que as seções não permaneçam planas. Um fator importante neste estudo é a necessidade de continuidade das funções aproximadoras. A escolha dos graus de liberdade deve levá-la em consideração, já que em um procedimento baseado em elementos finitos, as funções aproximadoras escritas em função dos parâmetros nodais devem representar grandezas contínuas.

NARAYANASWAMI \& ADELMAN (1974) concluíram que em qualquer formulação do MEF, em que as deformações causadas por esforço cortante são consideradas, é essencial que a rotação da reta normal (e não a derivada da linha elástica no ponto) seja tomada como grau de liberdade. Este problema nasce do fato de ser necessária, em um mesmo nó, a continuidade de quaisquer grandezas que se tome como grau de liberdade; se isto não acontecer, a formulação em elementos finitos torna-se inconsistente.

Já que os diagramas de esforço cortante apresentam descontinuidades em presença de cargas concentradas transversais e a distorção da seção é proporcional a este esforço, a rotação não é contínua e não pode ser utilizada como parâmetro nodal. Neste trabalho foi empregada a formulação apresentada em GERE \& WEAVER (1987), a qual leva em consideração o deslocamento total e a rotação associada exclusivamente à flexão. 


\subsection{Não linearidade geométrica.}

Com a evolução dos métodos de análise e do poder de processamento dos microcomputadores, a NLG tem sido incorporada de forma gradual aos projetos de edifícios, embora ainda haja defasagem entre as teorias já consolidadas e as efetivamente empregadas nas rotinas dos escritórios de engenharia ou em softwares comerciais de cálculo e detalhamento de estruturas de concreto armado.

Será feita uma breve discussão sobre alguns trabalhos fundamentais ao entendimento da evolução da análise não linear geométrica de elementos de barra via MEF.

O trabalho de TURNER et al (1956), considerado pioneiro na apresentação dos fundamentos do MEF aliado ao desenvolvimento da linguagem FORTRAN e a possibilidade de manipulação de um número cada vez maior de variáveis, impulsionou o desenvolvimento de trabalhos na área de engenharia de estruturas. TURNER et al (1960) publica o primeiro trabalho em que a NLG é tratada via MEF.

ARGYRIS (1965) estuda problemas relativos às não linearidades física e geométrica via MEF publicando o clássico "Continua e Descontinua".

MARTIN (1965) introduz o conceito de modelo incremental para NLG de pórticos, no qual a deformação inicial em cada incremento é considerada constante e relacionada à força normal.

MALLET \& MARÇAL (1968) desenvolvem o formalismo das matrizes incrementais, empregando o conceito de rigidez tangente e incluindo na matriz de rigidez os termos quadráticos dos deslocamentos.

JENNING (1968) emprega coordenadas eulerianas na formulação da matriz de rigidez tangente, enquanto POWELL (1969), também empregando coordenadas eulerianas, separa os deslocamentos associados às deformações e os de corpo rígido, permitindo, assim, empregar sua formulação para grandes rotações dos nós.

ORAN (1973) apresenta matriz de rigidez tangente para pórticos planos, posteriormente estendida a pórticos tridimensionais, mas alertando para a não comutatividade das rotações no espaço 3D.

ARGYRIS et al (1978) introduzem o conceito de graus de liberdade naturais, separando os deslocamentos oriundos de deformação e os de corpo rígido, estendendo a formulação às estruturas de pórticos tridimensionais mediante o tratamento do problema da não comutatividade de rotações. 
WEN et al (1983) apresentam as matrizes de rigidez tangente e secante para pórticos planos e tridimensionais baseadas em uma formulação lagrangeana para pequenas rotações, dispensando um tratamento vetorial às rotações no espaço 3D.

No SET/EESC/USP, ANTUNES (1978), empregando uma formulação para pequenos deslocamentos e rotações, estuda a instabilidade de estruturas tridimensionais de edifícios altos.

A década de oitenta, conta com inúmeros trabalhos relevantes na área de análise não linear geométrica e física. Aqui são citados alguns trabalhos que serviram como base para trabalhos desenvolvidos no SET/EESC/USP.

PIMENTA (1989) abrange vários aspectos da análise não linear de pórticos planos sem restrição à ordem de grandeza dos deslocamentos envolvidos.

SILVA (1989) emprega o método P-Delta para avaliação dos efeitos da NLG sobre estruturas tridimensionais de edifícios com núcleo de rigidez.

CORRÊA (1991) através da formulação apresentada em WEN et al (1983) desenvolve código computacional em FORTRAN para análise não linear geométrica de estruturas tridimensionais de edifícios.

MORI (1992) com a formulação desenvolvida por ANTUNES (1978) desenvolve um modelo para análise não linear de estruturas de edifícios com núcleo de rigidez, levando em consideração os efeitos do bimomento.

SOLER (1995) apresenta teoria sobre barras retas no espaço 3D, aplicável a estruturas de pórticos tridimensionais; o tratamento das rotações é feito de forma lagrangeana através da fórmula de Euler-Rodrigues, sendo a teoria geometricamente exata.

PAULA (1997) estuda, a partir do emprego do MEF, as formas lagrangeana e euleriana das expressões do equilíbrio. Questões quanto à estabilidade estrutural também são abordadas em seu trabalho

\subsection{Não linearidade física.}

A implementação de códigos que possibilitem a análise não linear física tem ganhado espaço nas três últimas décadas, sendo o seu desenvolvimento predominantemente posterior ao início das análises não linear geométricas. Desde a década de 90 existem 
vários trabalhos que contemplam o acoplamento das duas não linearidades em pórticos planos de concreto armado. A seguir são apresentados alguns trabalhos que foram referência para este, e demais trabalhos realizados no SET/EESC/USP.

BRANSON (1963) ó o autor de uma das fórmulas mais difundidas para a determinação da inércia efetiva de vigas e lajes unidirecionais.

ARGYRIS (1965) estuda a NLG e NLF de elementos pertencentes a pórticos planos.

KENT \& PARK (1971) apresentam modelo constitutivo para o concreto comprimido baseado em resultados experimentais.

O efeito tension sttifening considerando o trecho descendente da curva tensão versus deformação do concreto tracionado foi modelado por SCANLON \& MURRAY (1974). FIGUEIRAS (1983) apresenta um modelo constitutivo para o concreto no qual discute vários aspectos, tais como o tension sttifening.

PROENÇA (1988) apresenta estudos sobre modelos matemáticos para representação do comportamento não linear físico do concreto.

ALWIS (1990) sugere uma curva trilinear para a relação momento curvatura para barras de estruturas de concreto armado.

Diversos autores mais recentes desenvolveram códigos eficientes para o tratamento das não linearidades física e geométrica de pórticos planos sendo alguns deles: VECCHIO \& EMARA (1992), RASHEED \& DINNO (1994). No SET/EESC/USP podem ser citados vários trabalhos que abordam este tipo de análise, dentre eles, SILVA (1996), PAULA (2001), PINTO (2002), NOGUEIRA (2005) e VASCONCELOS (2005).

No decorrer do capítulo, foi feito um breve histórico dos trabalhos desenvolvidos na linha em que o presente trabalho está inserido. Fica claro o atual nível de desenvolvimento e grande quantidade de trabalhos referentes ao tratamento das não linearidades física e geométrica de pórticos planos e modelagem tridimensional de estruturas levando em consideração a não linearidade geométrica. A realização deste trabalho é justificada pela falta de trabalhos referentes ao tratamento da análise não linear física rigorosa dos núcleos rígidos. 


\section{Capítulo 3 - Considerações sobre a modelagem}

\subsection{Considerações iniciais.}

Para a análise das estruturas, foi desenvolvido neste trabalho um código computacional baseado no MEF. Este software denominado ao longo do trabalho por NUC NLGF possibilita a modelagem de estruturas compostas por barras de pórtico tridimensional. As considerações e métodos adotados para a modelagem das estruturas são abordados neste capítulo.

Para o tratamento da não linearidade geométrica foi adotada uma estratégia secante de resolução de sistemas não lineares. O controle da convergência é verificado em forças e deslocamentos simultaneamente. As formulações e considerações sobre o tratamento da não linearidade geométrica são abordadas no capítulo 4 .

As considerações quanto a não linearidade física são feitas no capítulo 5. Em termos de implementação, a estratégia de solução adotada é a mesma usada para a não linearidade geométrica, assim como para a consideração simultânea das não linearidades geométrica e física.

\subsection{Núcleo rígido.}

De acordo com ANTUNES, MORI e SOUSA (1995), dentre os vários sistemas de contraventamento existentes, os núcleos estruturais podem ser considerados como essenciais à estabilidade dos edifícios de andares múltiplos, pois com o seu acoplamento aos outros sistemas estruturais, consegue-se conferir à estrutura global um razoável acréscimo de rigidez.

PEREIRA (1997), através de análises de resultados obtidos em seu trabalho, conclui que a atuação do núcleo de rigidez é bastante benéfica para a estrutura de contraventamento, auxiliando na redução das translações horizontais dos pavimentos e contribuindo na redução dos esforços internos nos demais componentes da estrutura. 
A teoria desenvolvida por VLASSOV (1962) pode ser considerada de grande precisão quando se deseja analisar o comportamento dos núcleos resistentes em edifícios sujeitos torção. No entanto, para a sua utilização é necessário que se tenha conhecimento da teoria de flexo-torção, que considera, além dos esforços solicitantes tradicionais, a existência do bimomento.

Independente de toda complexidade que a análise considerando o núcleo resistente possa gerar, sua participação no controle dos deslocamentos provocados pela ação do vento é de grande interesse estrutural.

Autores como MATIAS (1997) denominam de núcleos estruturais os elementos de elevada rigidez, constituído pela associação tridimensional de paredes retas ou curvas, formando seções transversais abertas ou semi-fechadas. Suas dimensões transversais são muito superiores às dos demais elementos que normalmente compõem as estruturas de contraventamento, sendo sua rigidez à flexão responsável por grande parte da rigidez global da estrutura.

Estes elementos são usualmente posicionados nas áreas centrais dos edifícios, ou seja, em torno das escadas, elevadores, depósitos ou espaços reservados para a instalação de tubulação hidráulica ou elétrica. Ao nível das lajes apresentam seção parcialmente fechada devido à presença destas ou de lintéis.

MATIAS e MORI (1997) abordam esse fenômeno do empenamento, como sendo consequência das proporções do núcleo, ou seja, seu comportamento estrutural assemelha-se ao de um perfil delgado que, quando submetido à torção, faz com que suas seções transversais, originalmente planas, empenem, provocando tensões normais de tração e compressão. Essas tensões têm valores significativos na análise estrutural e não podem ser desconsideradas. São consequiência da atuação do momento torçor, ou ainda quando da existência de vínculos que impeçam o empenamento da seção.

O pavimento será considerado infinitamente rígido no seu plano, impedindo a distorção da seção do núcleo. As lajes são consideradas perfeitamente flexíveis na direção perpendicular ao seu plano, não caracterizando assim restrição ao empenamento das seções do núcleo.

Os lintéis, que são as vigas que promovem o fechamento parcial da seção do núcleo ao nível das lajes, podem conferir um aumento na rigidez à torção do núcleo, em especial quando engastados nas paredes do núcleo. 


\subsection{Métodos de análise.}

Utilizando o MEF, o tratamento pode ser feito de três maneiras:

a) por elementos finitos especiais

b) associação de elementos de chapa com elementos de barra, ou

c) por elementos de barra tradicionais. Nesse trabalho serão empregados elementos tradicionais de barra de pórtico tridimensional.

Por apresentar-se muito simples e eficaz, e principalmente por permitir fácil acoplamento a vários softwares de elementos finitos, o modelo desenvolvido por YAGUI (1971) foi adotado na modelagem dos núcleos resistentes de concreto armado neste trabalho.

PEREIRA (2000), em sua dissertação de mestrado, fez um estudo comparativo entre algumas das discretizações usuais para os núcleos de rigidez. A seguir é feito um resumo das características de cada modelagem, sendo que resultados detalhados podem ser encontrados em sua dissertação de mestrado. Foram estudadas as seguintes modelagens: Pilar parede isolado, barras de seção delgada com e sem a consideração da flexo-torção, elementos de chapa e finalmente o modelo proposto por YAGUI (1971).

\subsubsection{Pilar parede isolado.}

Nessa modelagem, cada parede do núcleo é tratada como um pilar parede isolado, não havendo interação com as demais. Dessa forma, as forças de cisalhamento atuantes nas ligações das paredes são desprezadas, diminuindo-se a rigidez do núcleo como um todo.

O elemento utilizado para essa modelagem é o tradicional elemento de pórtico 3D com 6 graus de liberdade por nó, sendo 3 translações e 3 rotações em torno dos eixos triortogonais do elemento. (Vide figura 3.1) 


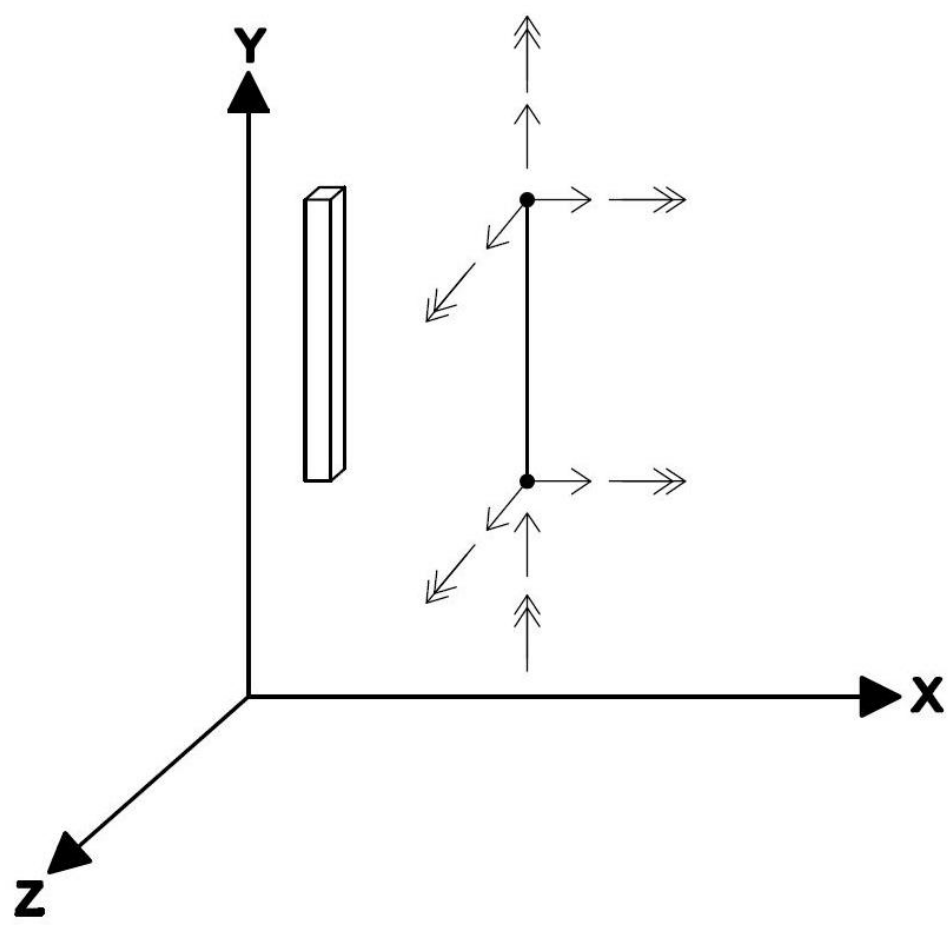

Figura 3.1: Graus de liberdade do elemento de pórtico tridimensional.

\subsubsection{Barras de seção delgada sem a consideração da flexo-torção.}

Para essa modelagem, o elemento representativo da barra é o mesmo utilizado na modelagem acima. Difere dela por reunir as características geométricas em uma única barra equivalente situada no centro de torção da seção do núcleo. Apresenta alguns inconvenientes relativos à modelagem, tais como a necessidade da determinação prévia das coordenadas do centro de torção do núcleo, e também a translação das coordenadas das extremidades das vigas solidárias ao núcleo para o seu centro de torção.

Do ponto de vista do comportamento estrutural possui o inconveniente de não ser capaz de representar de forma satisfatória os casos em que existe torção do edifício. Isso devido ao fato de não considerar o bimomento existente nesses casos. Assim, aplica-se com maior eficiência a edifícios que possuam plantas e carregamentos simétricos, os quais não apresentam torção. 


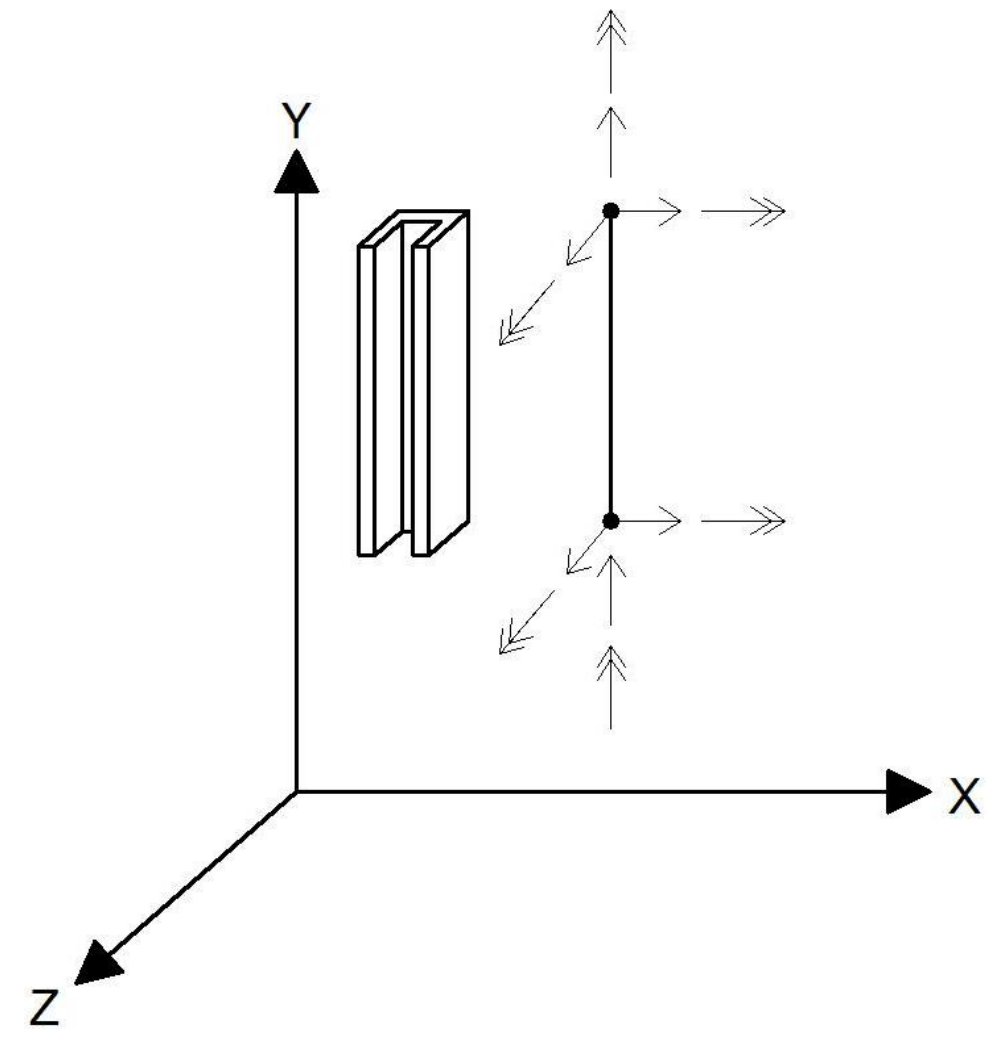

Figura 3.2: Graus de liberdade do elemento de barra delgada sem flexo-torção.

\subsubsection{Barras de seção delgada com a consideração da flexo-torção.}

Para essa modelagem é utilizado um elemento com 7 graus de liberdade por extremidade. Além dos seis graus de liberdade dos elementos de pilar tridimensional, esse elemento possui um sétimo grau de liberdade representativo do empenamento da seção.

Do ponto de vista da modelagem apresenta os mesmos inconvenientes da modelagem do item anterior, somando-se a necessidade do conhecimento da teoria de flexo-torção de VLASSOV (1962).

Do ponto de vista do comportamento estrutural apresenta capacidade de representar o comportamento de edifícios sujeitos à torção. 


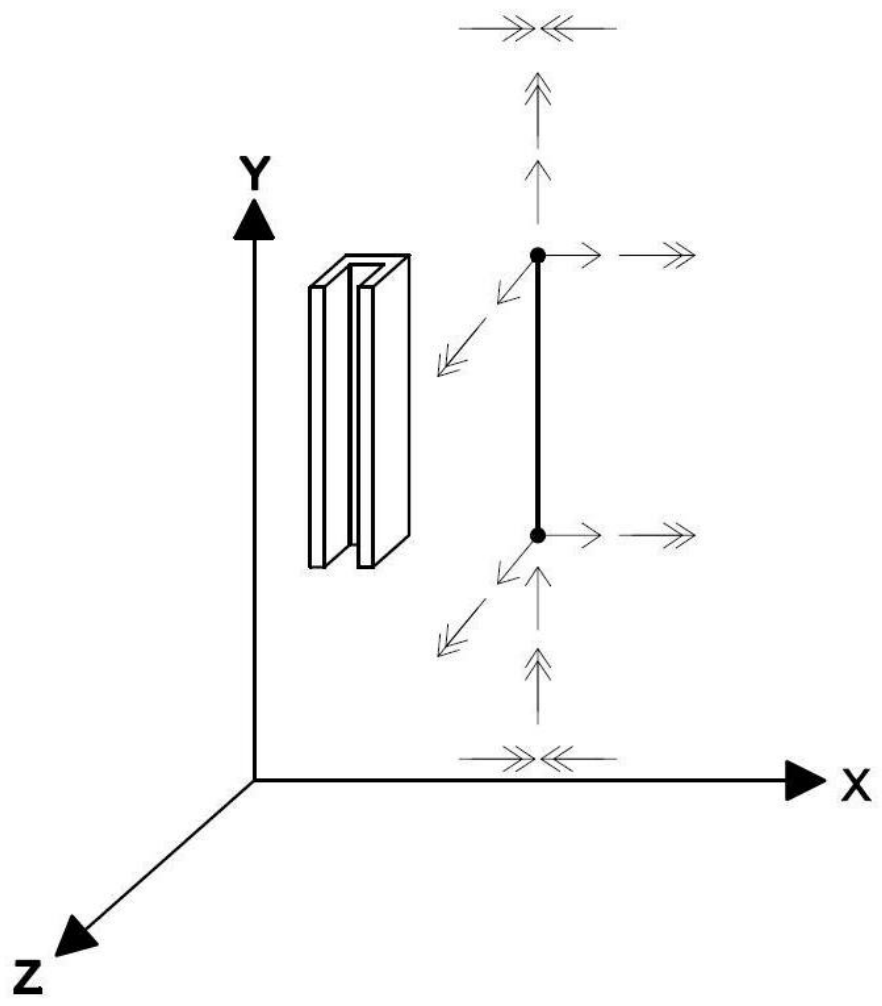

Figura 3.3: Graus de liberdade do elemento de barra delgada com flexo-torção.

3.3.4 Modelagem através de elementos de casca.

O estudo desenvolvido por PEREIRA (2000) utilizou o software Ansys para a modelagem do núcleo através de elementos de casca. O elemento utilizado foi o Shell 63. 
Esse elemento possui 6 graus de liberdade por nó: (Vide figura 3.4)

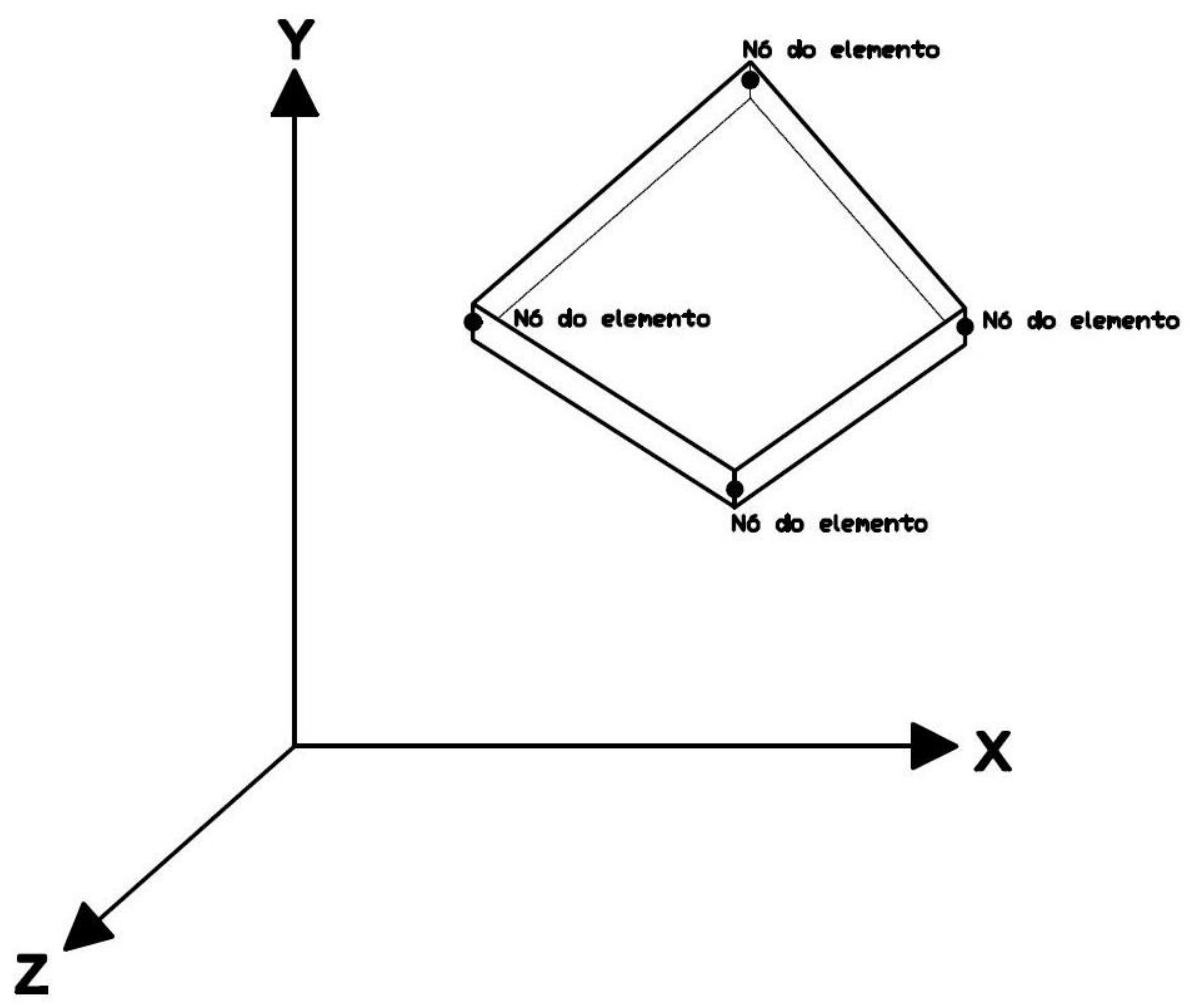

Figura 3.4: Elemento de casca Shell 63 do software Ansys 5.5.

$\mathrm{Na}$ época do desenvolvimento do trabalho um dos poucos inconvenientes dessa modelagem era a limitada capacidade dos computadores pessoais, pois, devido ao grande número de elementos envolvidos na discretização do núcleo, a solução do sistema de equações apresentava grande esforço computacional. Hoje, dada a capacidade dos processadores, esse fato não representa mais um problema tão sério nas análises lineares.

\subsubsection{Modelo proposto por YAGUI (1971).}

Consiste na modelagem de cada parede como uma barra de pórtico plano com as mesmas características da parede que representa, sendo que a interação entre as paredes é feita através de barras rígidas engastadas ao pilar e articuladas nas extremidades comuns. 


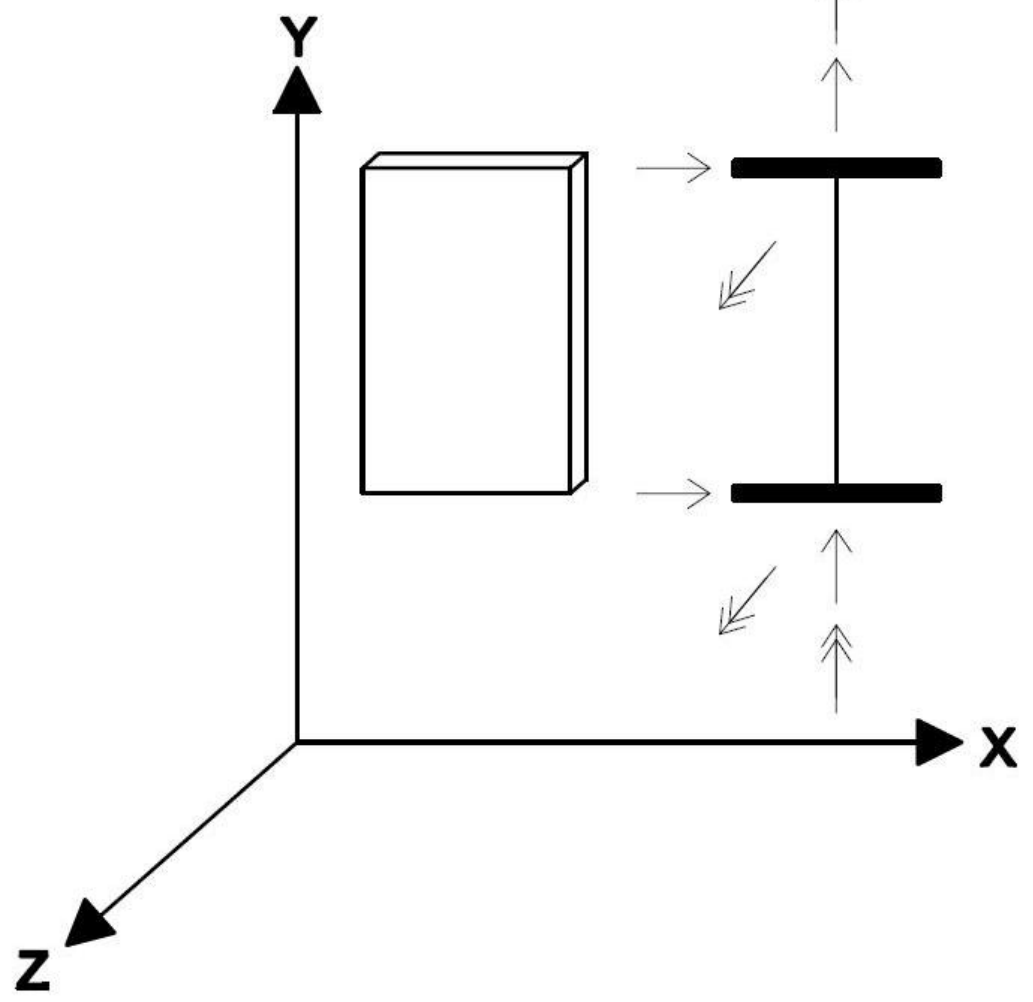

Figura 3.5: Graus de liberdade do elemento idealizado por YAGUI (1971).

Do ponto de vista da modelagem, essa discretização apresenta a vantagem de permitir a representação dos elementos que se conectem aos núcleos, sem necessidade de rotinas de translação de rigidez destes elementos.

Do ponto de vista do comportamento estrutural, apresenta capacidade de representar de forma satisfatória edifícios sujeitos à torção.

A seguir são apresentadas as principais características desta modelagem, segundo YAGUI (1971).

São as seguintes as principais hipóteses assumidas para a modelagem:

a) As paredes planas que constituem o núcleo são comumente desprovidas de rigidez à flexão atuante segundo seus planos transversais, em consequiência de suas espessuras relativamente delgadas.

b) O comprimento das paredes planas deverá ser constante ao longo de sua altura, porém a espessura poderá variar bruscamente aos níveis dos pavimentos. 
c) As únicas interações a serem consideradas entre as paredes, ao longo de suas interseções, são as forças de cisalhamento longitudinais.

d) As lajes são supostas como diafragmas rígidos, impedindo as distorções das seções transversais do núcleo.

e) Por causa de sua desprezível rigidez à flexão, as interações entre os diafragmas rígidos e as paredes planas ficam reduzidas aos esforços contidos nos planos horizontais, ao longo das interseções desses elementos.

Assim sendo, cada segmento de parede será discretizadado como se ilustra nas figuras 3.6 e 3.7 .

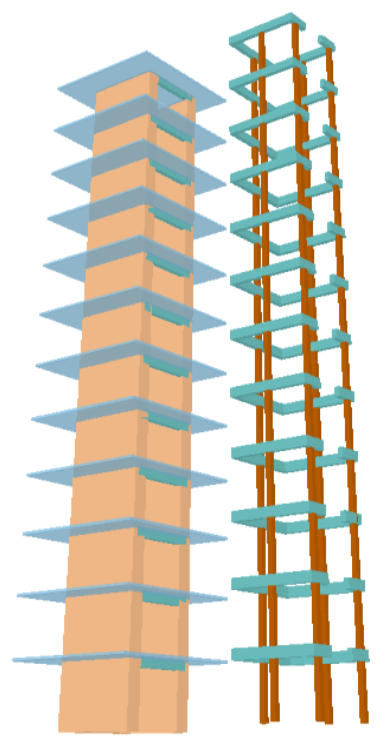

Figura 3.6: Núcleo e sua respectiva discretização em barras.

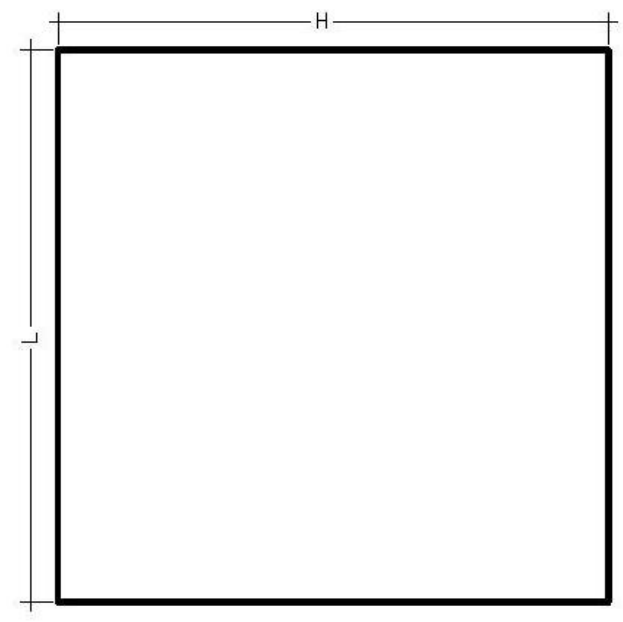

Pilar parede

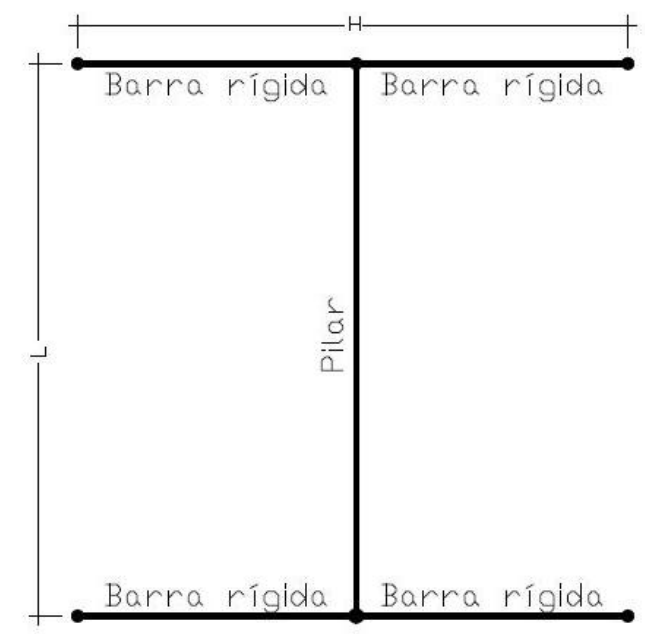

Discretização em elementos de barras

Figura 3.7: Vista lateral da discretização de cada parede em barras. 
No trabalho desenvolvido por YAGUI (1971), a matriz de rigidez do elemento de núcleo é desenvolvida considerando-se as dimensões da parede em planta, mediante o emprego de off-sets que levam em consideração a presença da barra rígida ao nível dos pavimentos.

No programa desenvolvido nesse trabalho, cada elemento pertencente à estrutura é efetivamente modelado, o tratamento das barras rígidas é feito de acordo com o proposto em CORREAA (1991), sendo as barras rígidas consideradas como se tivessem a altura do correspondente pé direito e a espessura da parede. Essas dimensões conferem rigidez suficiente para a consideração de "infinita" rigidez, sem o inconveniente de gerar perturbação na solução numérica.

Embora cada parede de núcleo tenha comportamento de pórtico plano, no programa desenvolvido foi utilizado o elemento de pórtico tridimensional, por simplicidade na montagem da matriz de rigidez global do sistema. Obviamente o elemento tridimensional reúne as características do elemento de pórtico plano, ou seja, tem rigidez nula segundo seu eixo de menor inércia.

Dessa forma, tem-se para um tramo de núcleo a seguinte discretização em paredes e eventual lintel:
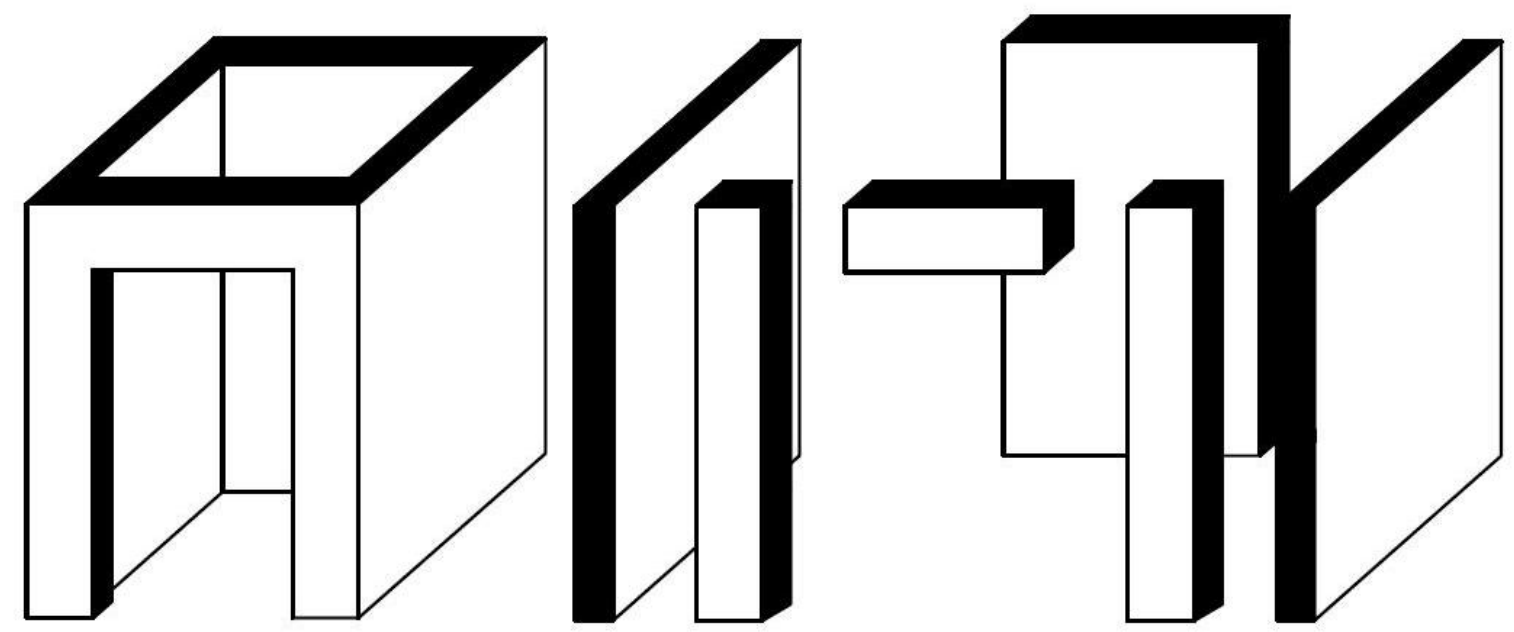

Figura 3.8: Divisão da seção do núcleo em paredes. 
Após a divisão em paredes, a discretização em elementos finitos é feita conforme a figura 3.9.

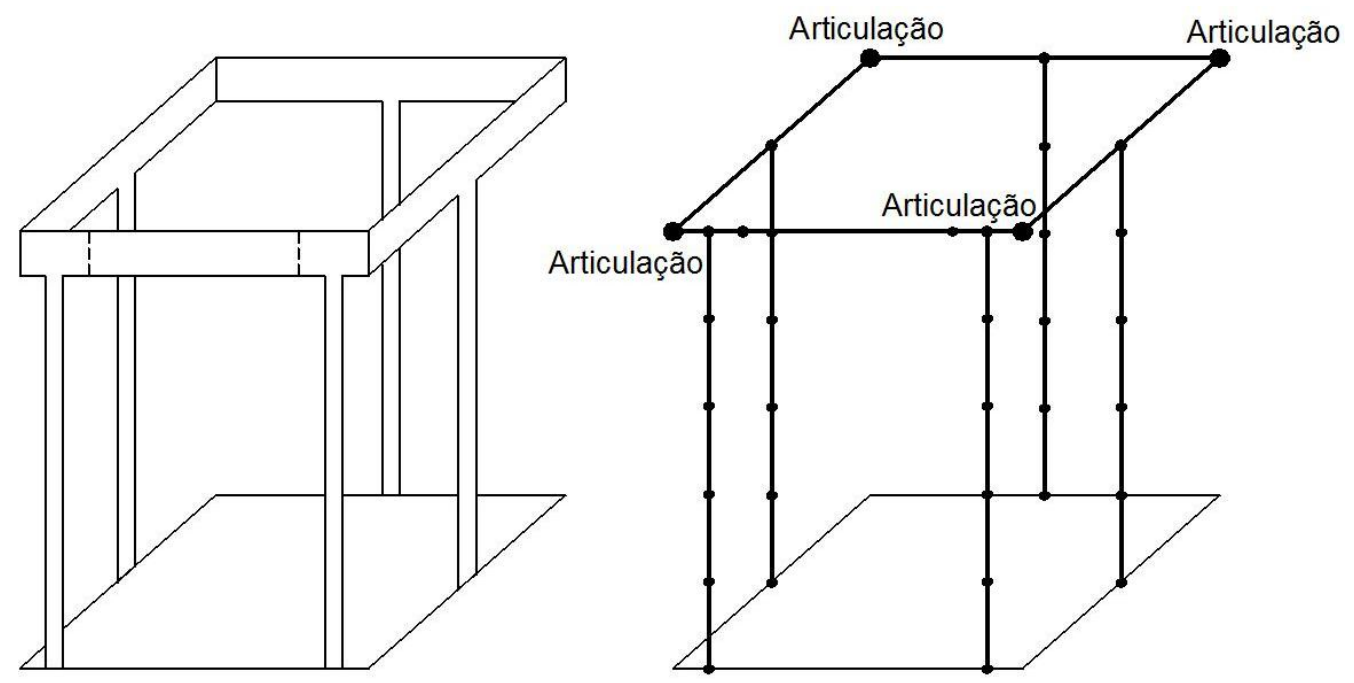

Figura 3.9: Discretização das paredes em elementos finitos.

Para os pilares, foram adotadas divisões em 5 elementos em cada tramo, suficiente para o tratamento da não linearidade física, como se explica no capítulo 5. As vigas rígidas, como citado acima, e os lintéis são modelados como viga com sua seção real. 
3.4 Sistema de referência local e global.

3.4.1 Sistema de referência local para barra de pórtico tridimensional.

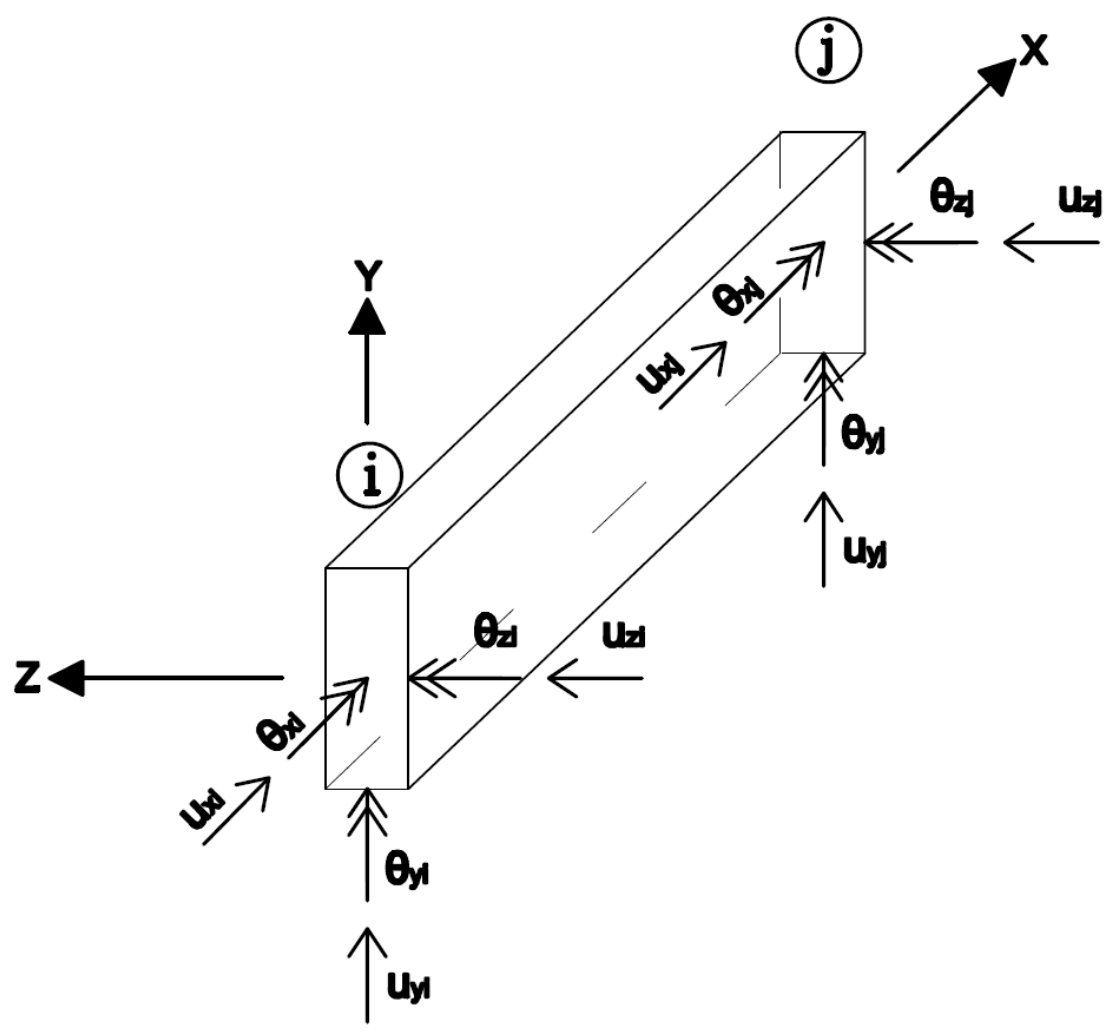

Figura 3.10: Coordenadas locais e graus de liberdade do elemento de pórtico tridimensional.

3.4.2 Sistema de referência global e matrizes de rotação.

A determinação da matriz de rigidez e do vetor de cargas de cada elemento no sistema global a partir do sistema local requer uma transformação de coordenadas. Como todos os elementos usados no programa são elementos clássicos de pórtico tridimensional são necessárias matrizes de rotação no espaço tridimensional. 
Tomando o eixo X como o eixo longitudinal do elemento, e sendo $\alpha, \beta$ e $\gamma$ os giros em torno dos eixos $\mathrm{X}, \mathrm{Y}$ e Z, respectivamente, conforme as figuras 3.11, 3.12 e 3.13:

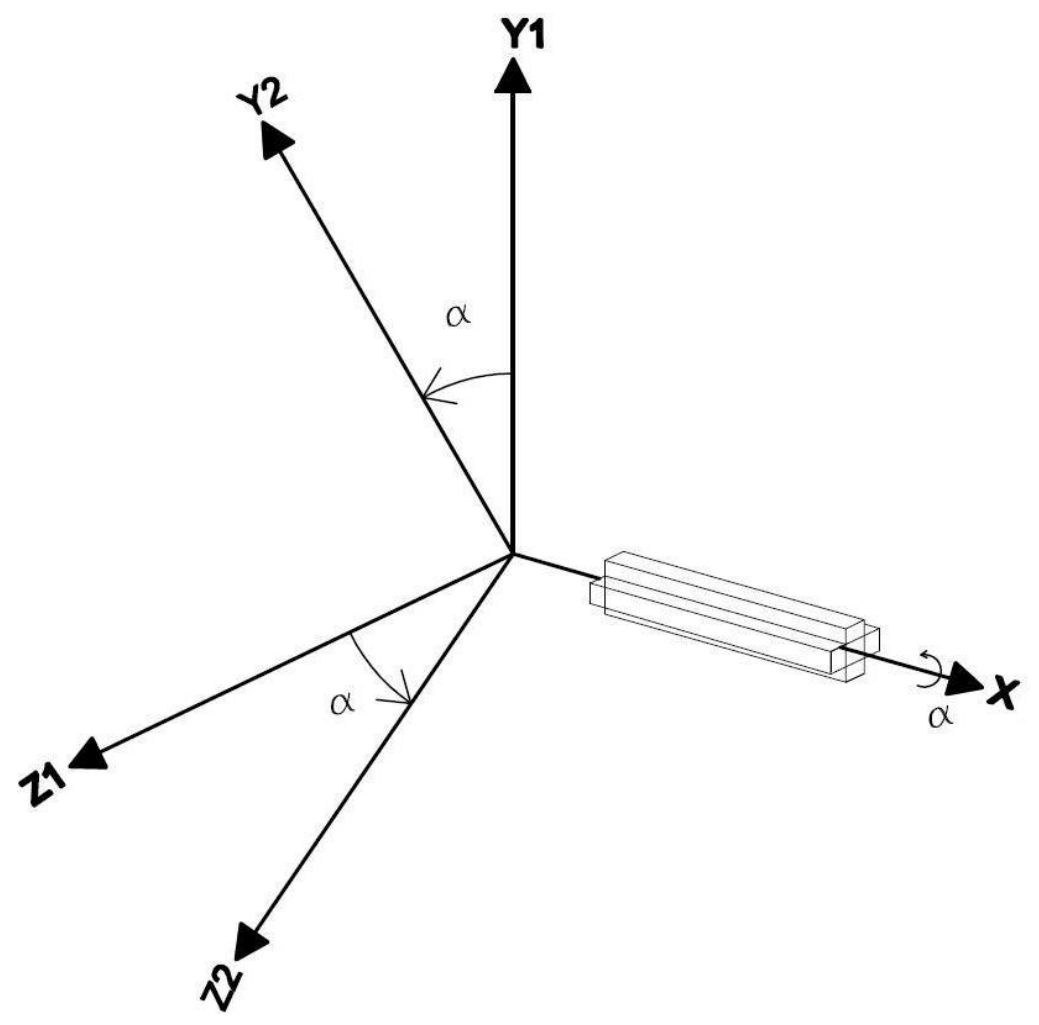

Figura 3.11: Giro do elemento em torno do eixo X.

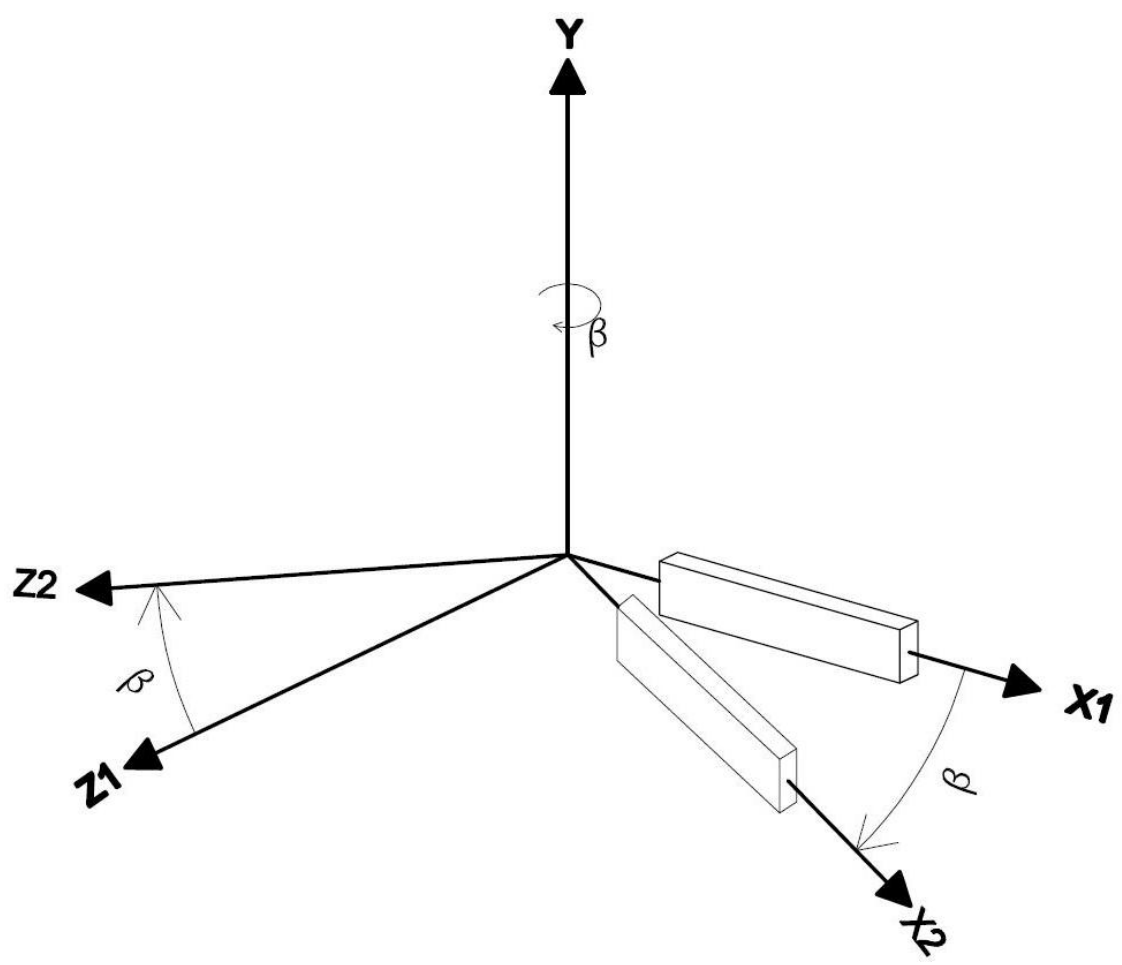

Figura 3.12: Giro do elemento em torno do eixo Y. 


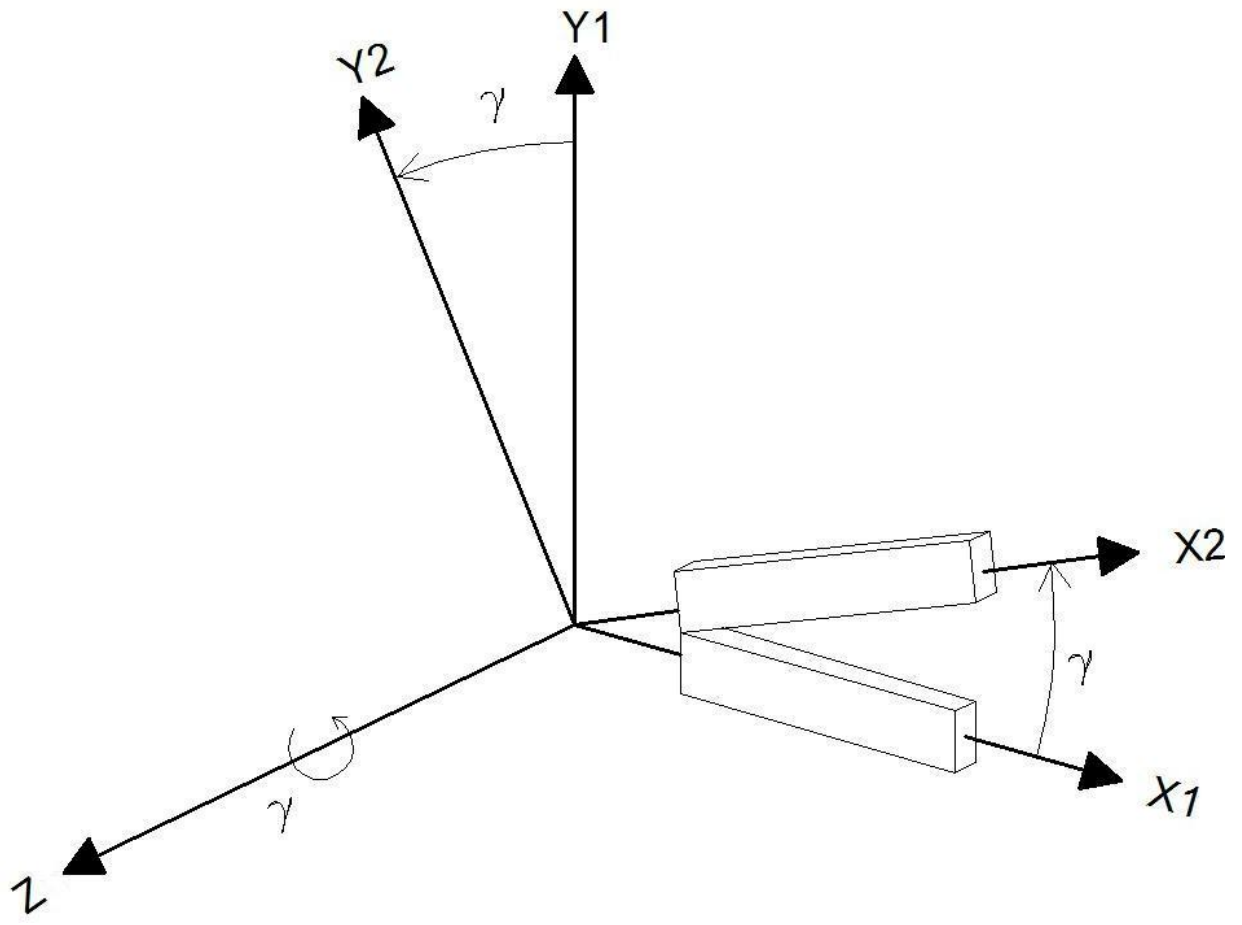

Figura 3.13: Giro do elemento em torno do eixo $\mathrm{Z}$.

Sendo as coordenadas dos extremos de cada elemento dadas por:

$x_{i}-$ Coordenada X inicial

$x_{f}-$ Coordenada X final

$y_{i}-$ Coordenada $Y$ inicial

$y_{f}-$ Coordenada $Y$ final

$z_{i}-$ Coordenada Y inicial

$z_{f}-$ Coordenada $Z$ final

Assim, o comprimento L é dado por:

$$
L=\sqrt{\left(x_{f}-x_{i}\right)^{2}+\left(z_{f}-z_{i}\right)^{2}+\left(z_{f}-z_{i}\right)^{2}}
$$


Os coeficientes $C_{x}, C_{y}, C_{z}$ e $C_{x z}$ são dados por:

$C_{x}=\frac{x_{f}-x_{i}}{L}$

$C_{y}=\frac{z_{f}-z_{i}}{L}$

$C_{z}=\frac{z_{f}-z_{i}}{L}$

$C_{x z}=\sqrt{C_{x}{ }^{2}+C_{z}{ }^{2}}$

A matriz de transformação R é dada por:

$\mathrm{R}=\left[\begin{array}{llll}{[\gamma]} & {[0]} & {[0]} & {[0]} \\ {[0]} & {[\gamma]} & {[0]} & {[0]} \\ {[0]} & {[0]} & {[\gamma]} & {[0]} \\ {[0]} & {[0]} & {[0]} & {[\gamma]}\end{array}\right]$

Sendo $\gamma$ dada por:

$\gamma=\left[\begin{array}{ccc}C_{x} & C_{y} & C_{z} \\ \frac{-C_{x} \cdot C_{y} \cdot \cos \alpha-C_{z} \cdot \operatorname{sen} \alpha}{C_{x z}} & C_{x z} \cdot \cos \alpha & \frac{-C_{y} \cdot C_{z} \cdot \cos \alpha+C_{x} \cdot \operatorname{sen} \alpha}{C_{x z}} \\ \frac{C_{x} \cdot C_{y} \cdot \operatorname{sen} \alpha-C_{z} \cdot \cos \alpha}{C_{x z}} & -C_{x z} \cdot \operatorname{sen} \alpha & \frac{C_{y} \cdot C_{z} \cdot \operatorname{sen} \alpha+C_{x} \cdot \cos \alpha}{C_{x z}}\end{array}\right]$

Para barras verticais, por exemplo, a matriz de transformação $\gamma$ é dada por:

$\gamma=\left[\begin{array}{ccc}0 & C_{y} & 0 \\ -C_{y} \cdot \cos \alpha & 0 & \operatorname{sen} \alpha \\ C_{y} \cdot \operatorname{sen} \alpha & 0 & \cos \alpha\end{array}\right]$ 


\subsection{Diafragma rígido.}

Segundo CORRÊA (1991), na modelagem de edifícios de andares múltiplos é razoável admitir o pavimento como infinitamente rígido em seu plano e perfeitamente flexível em sua direção normal, desde que as lajes não apresentem aberturas muito grandes ou o pavimento não apresente em planta uma das dimensões muito maior que a outra.

O pavimento considerado como um diafragma rígido (comportamento de chapa), que distribui as ações horizontais entre os vários painéis de contraventamento existentes na estrutura. Assim, a modelagem da laje na estrutura de contraventamento pode ser dispensada, uma vez que esta é considerada infinitamente rígida e compatibiliza as translações e rotações do pavimento.

Adotado esse comportamento para a estrutura, a solução do sistema de equações fica simplificado, com a possibilidade de vinculação de três graus de liberdade de cada elemento ao nível dos pavimentos ao nó mestre. A seguir são mostradas as etapas para a implementação do nó mestre na estrutura.

Para barras de pórtico 3D com 6 graus de liberdade por nó, ao nível dos pavimentos, tem-se 3 graus de liberdades dependentes do movimento de corpo rígido da laje, que são as translações nas direções $\mathrm{X}$ e $\mathrm{Z}$ e a rotação em torno do eixo Y. A figura 3.14 ilustra a situação de um nó K pertencente ao pavimento: 


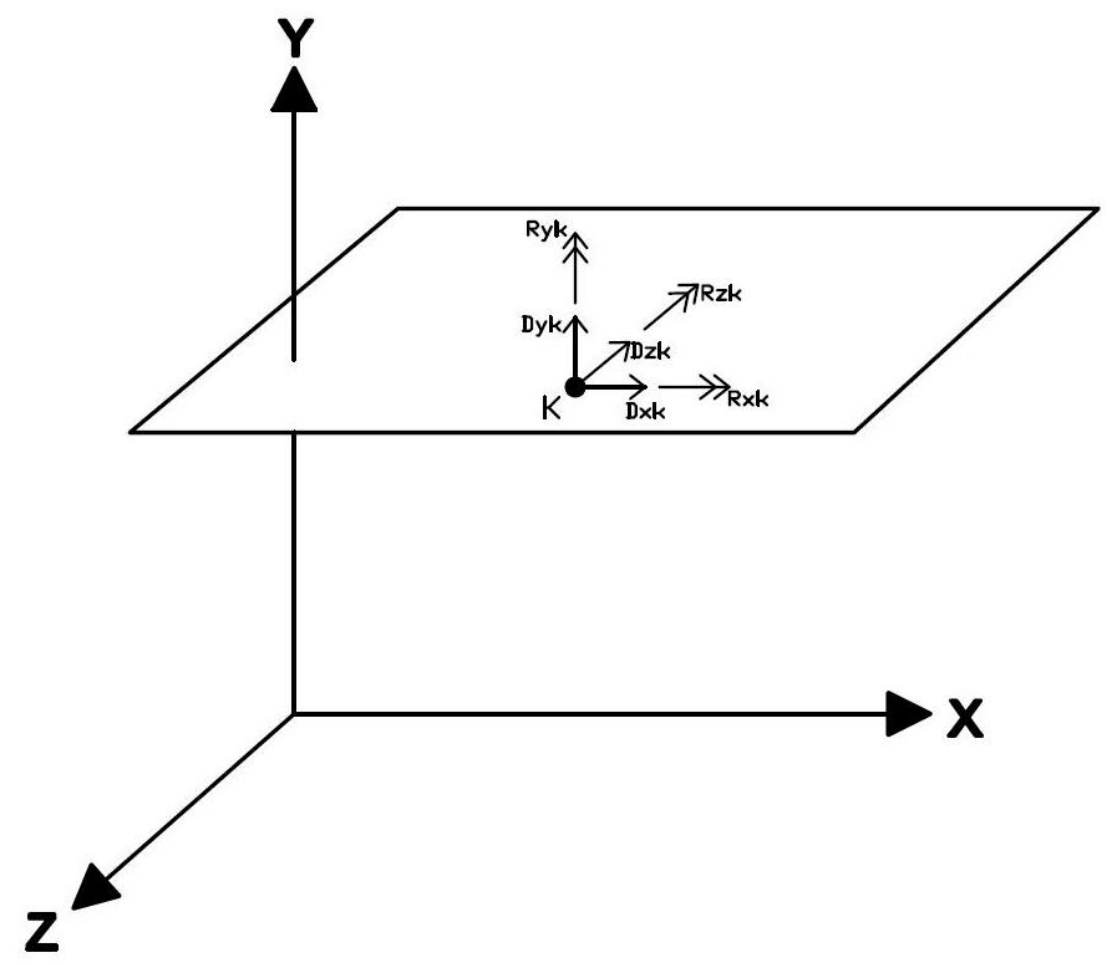

Figura 3.14: Nó pertencente ao pavimento e seus graus de liberdade dependentes e independentes.

Os demais deslocamentos do ponto $\mathrm{K}$, que são as rotações em torno dos eixos $\mathrm{X} \mathrm{e} \mathrm{Z}$, e o deslocamento na direção Y, são deslocamentos independentes.

\section{Hipótese do diafragma rígido:}

Sendo K um nó pertencente ao pavimento que tem como nó mestre o nó N, a figura 3.15 mostra os deslocamentos dependentes do movimento de corpo rígido do pavimento: 


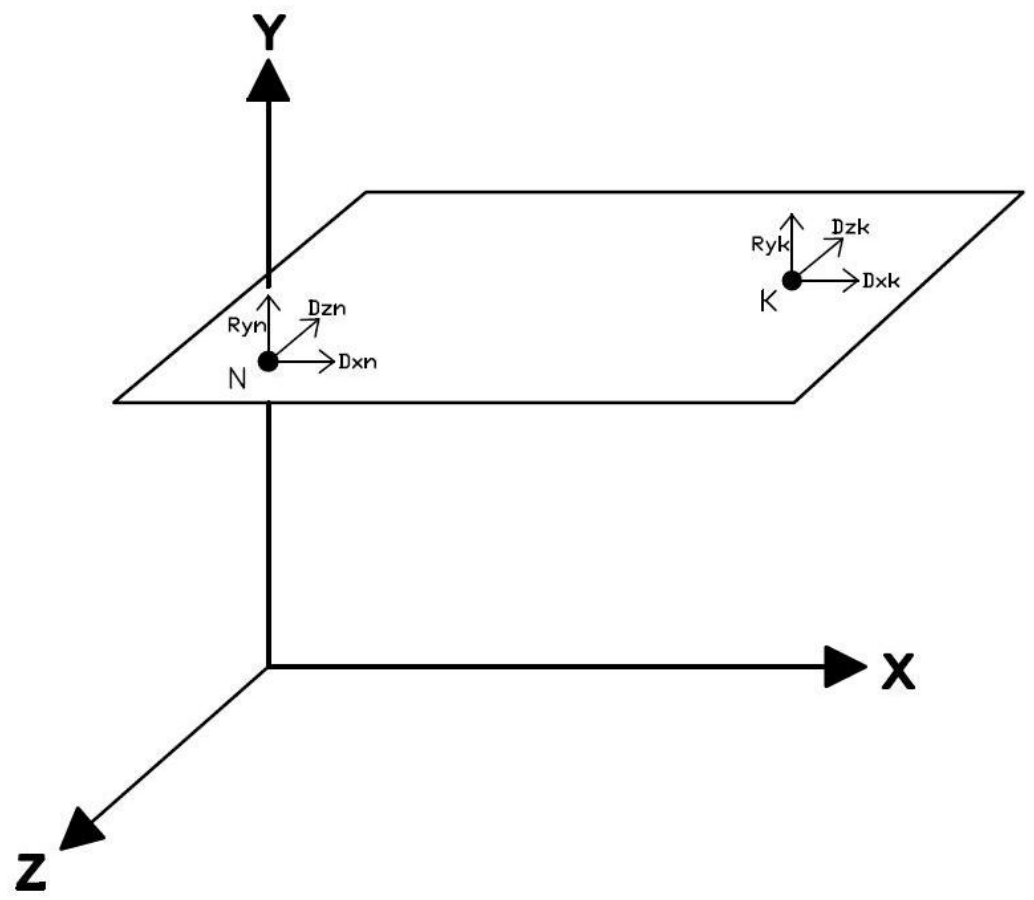

Figura 3.15: Nó mestre N, e nó K, pertencentes ao pavimento.

$\mathrm{Na}$ figura 3.16 os deslocamentos do nó mestre $\mathrm{N}$ têm o índice $\mathrm{n}$, enquanto os deslocamentos dependentes de um nó K qualquer, possuem o índice k.

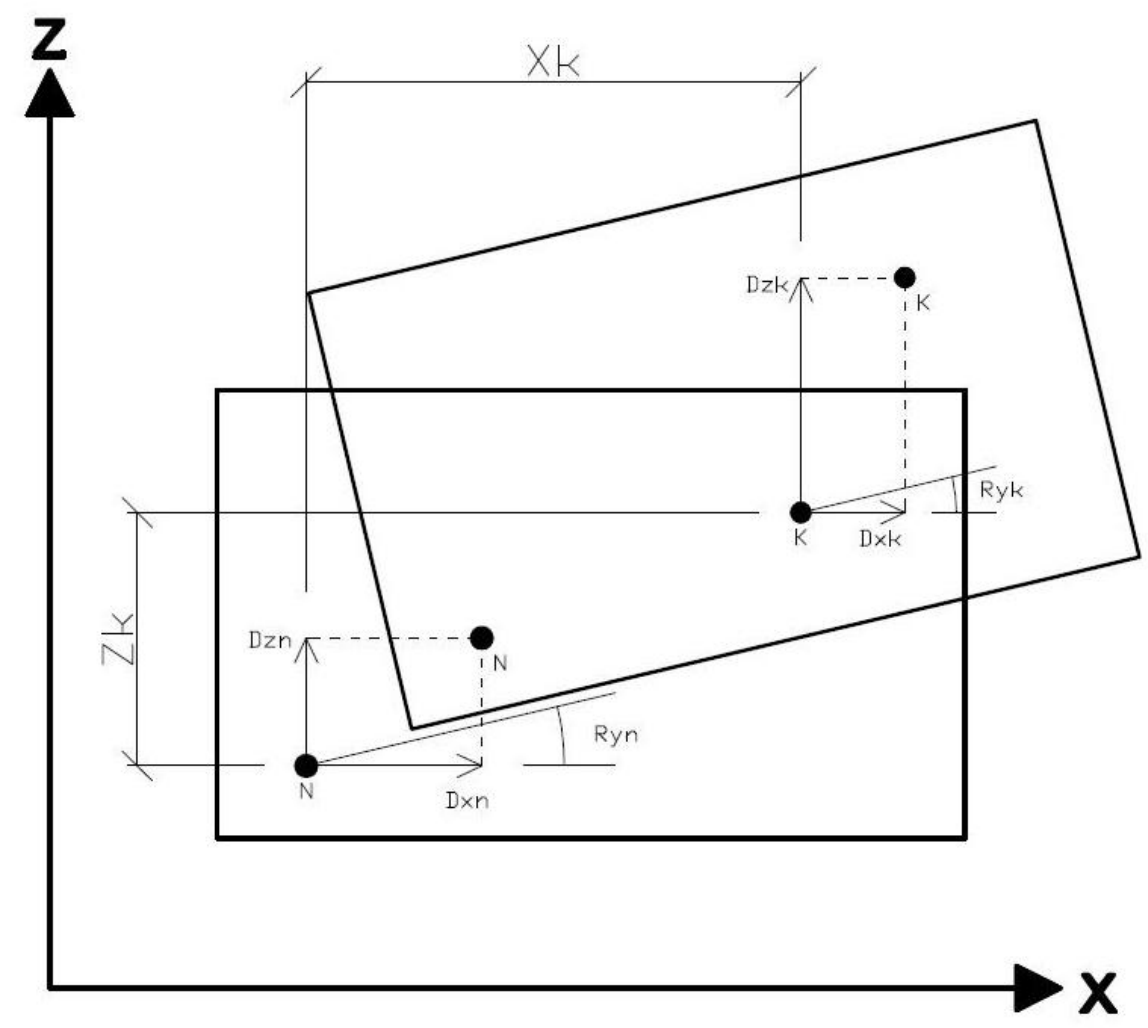

Figura 3.16: Movimento de corpo rígido do pavimento. 
Os deslocamentos do nó $\mathrm{K}$ podem ser escritos a partir dos experimentados pelo nó mestre de acordo com as equações a seguir, que admitem a geometria dos pequenos deslocamentos:

$D_{x k}=D_{x n}-Z_{k} \cdot R_{z n}$

$D_{z k}=D_{z n}+X_{k} \cdot R_{z n}$

$R_{y k}=R_{y n}$

Matricialmente tem-se:

$\left[\begin{array}{c}D_{x k} \\ D_{z k} \\ R_{y k}\end{array}\right]=\left[\begin{array}{ccc}1 & 0 & -Z_{k} \\ 0 & 1 & X_{k} \\ 0 & 0 & 1\end{array}\right] \cdot\left[\begin{array}{c}D_{x n} \\ D_{z n} \\ R_{y n}\end{array}\right]$

$\left[\begin{array}{c}D_{x k} \\ D_{z k} \\ R_{y k}\end{array}\right]=[T] \cdot\left[\begin{array}{c}D_{x n} \\ D_{z n} \\ R_{y n}\end{array}\right]$

$\left[\begin{array}{c}D_{x k} \\ D_{z k} \\ R_{y k}\end{array}\right]=[T] \cdot\left[\begin{array}{c}D_{x n} \\ D_{z n} \\ R_{y n}\end{array}\right]$

Levando-se em conta que as barras de pilares são dotadas de 6 graus de liberdade por nó, tem-se:

$$
\left[\begin{array}{l}
q_{1} \\
q_{2} \\
q_{3} \\
q_{4} \\
q_{5} \\
q_{6} \\
q_{7} \\
q_{8} \\
q_{9} \\
q_{10} \\
q_{11} \\
q_{12}
\end{array}\right]=\left[\begin{array}{l}
u_{1} \\
v_{1} \\
w_{1} \\
r x_{1} \\
r y_{1} \\
r z_{1} \\
u_{2} \\
v_{2} \\
w_{2} \\
r x_{2} \\
r y_{2} \\
r z_{2}
\end{array}\right]
$$


Assim, para um pilar que tem sua extremidade inferior (nó um) em uma laje n e sua outra extremidade (nó dois) na laje $n+1$, tem-se que a matriz de transformação é dada por:

$\left[\begin{array}{c}q_{1} \\ q_{2} \\ q_{3} \\ q_{4} \\ q_{5} \\ q_{6}\end{array}\right]=\left[\begin{array}{c}D_{x n}-Z_{k} \cdot R_{z n} \\ v_{1} \\ D_{z n}+X_{k} \cdot R_{z n} \\ r x_{1} \\ R_{y n} \\ r z_{1}\end{array}\right]$

$\left[\begin{array}{c}q_{7} \\ q_{8} \\ q_{9} \\ q_{10} \\ q_{11} \\ q_{12}\end{array}\right]=\left[\begin{array}{c}D_{x n+1}-Z_{k+1} \cdot R_{z n+1} \\ v_{2} \\ D_{z n+1}+X_{k+1} \cdot R_{z n+1} \\ r x_{2} \\ R_{y n+1} \\ r z_{2}\end{array}\right]$

Assim para o nó um:

$\left[\begin{array}{l}q_{1} \\ q_{2} \\ q_{3} \\ q_{4} \\ q_{5} \\ q_{6}\end{array}\right]=\left[\begin{array}{cccccc}1 & 0 & 0 & 0 & -Z_{k} & 0 \\ 0 & 1 & 0 & 0 & 0 & 0 \\ 0 & 0 & 1 & 0 & X_{k} & 0 \\ 0 & 0 & 0 & 1 & 0 & 0 \\ 0 & 0 & 0 & 0 & 1 & 0 \\ 0 & 0 & 0 & 0 & 0 & 1\end{array}\right] \cdot\left[\begin{array}{c}D_{x n} \\ v_{1} \\ D_{z n} \\ r x_{1} \\ R_{y n} \\ r z_{1}\end{array}\right]=\left[T_{k}\right] \cdot\left[\begin{array}{c}D_{x n} \\ v_{1} \\ D_{z n} \\ r x_{1} \\ R_{y n} \\ r z_{1}\end{array}\right]$

Para o nó dois:

$\left[\begin{array}{c}q_{7} \\ q_{8} \\ q_{9} \\ q_{10} \\ q_{11} \\ q_{12}\end{array}\right]=\left[\begin{array}{cccccc}1 & 0 & 0 & 0 & -Z_{k+1} & 0 \\ 0 & 1 & 0 & 0 & 0 & 0 \\ 0 & 0 & 1 & 0 & X_{k+1} & 0 \\ 0 & 0 & 0 & 1 & 0 & 0 \\ 0 & 0 & 0 & 0 & 1 & 0 \\ 0 & 0 & 0 & 0 & 0 & 1\end{array}\right] \cdot\left[\begin{array}{c}D_{x n+1} \\ v_{2} \\ D_{z n+1} \\ r x_{2} \\ R_{y n+1} \\ r z_{2}\end{array}\right]=\left[T_{k+1}\right]\left[\cdot\left[\begin{array}{c}D_{x n+1} \\ v_{2} \\ D_{z n+1} \\ r x_{2} \\ R_{y n+1} \\ r z_{2}\end{array}\right]\right.$ 
Assim, reunindo-se os 12 graus de liberdade em um só vetor:

$\left[\begin{array}{c}q_{1} \\ q_{2} \\ q_{3} \\ q_{4} \\ q_{5} \\ q_{6} \\ q_{7} \\ q_{8} \\ q_{9} \\ q_{10} \\ q_{11} \\ q_{12}\end{array}\right]=\left[\begin{array}{cc}{\left[T_{k}\right]} & {[0]} \\ {[0]} & {\left[T_{k+1}\right.}\end{array}\right] \cdot\left[\begin{array}{c}D_{x n} \\ v_{1} \\ D_{z n} \\ r x_{1} \\ R_{y n} \\ r z_{1} \\ D_{x n+1} \\ v_{2} \\ D_{z n+1} \\ r x_{2} \\ R_{y n+1} \\ r z_{2}\end{array}\right]=[T] \cdot\left[\begin{array}{c}D_{x n} \\ v_{1} \\ D_{z n} \\ r x_{1} \\ R_{y n} \\ r z_{1} \\ D_{x n+1} \\ v_{2} \\ D_{z n+1} \\ r x_{2} \\ R_{y n+1} \\ r z_{2}\end{array}\right]$

A matriz de rigidez transformada é dada por:

$K_{M}=T^{T} \cdot K \cdot T$

Assim, para um elemento de pilar em que apenas a sua extremidade inferior seja vinculada, tem-se:

$\left[\begin{array}{l}q_{1} \\ q_{2} \\ q_{3} \\ q_{4} \\ q_{5} \\ q_{6} \\ q_{7} \\ q_{8} \\ q_{9} \\ q_{10} \\ q_{11} \\ q_{12}\end{array}\right]=\left[\begin{array}{cc}{\left[T_{k}\right]} & {[0]} \\ {[0]} & {[I]}\end{array}\right] \cdot\left[\begin{array}{c}D_{x n} \\ v_{1} \\ D_{z n} \\ r x_{1} \\ R_{y n} \\ r z_{1} \\ D_{x n+1} \\ v_{2} \\ D_{z n+1} \\ r x_{2} \\ R_{y n+1} \\ r z_{2}\end{array}\right]$

Dessa maneira a matriz de transformação T é dada por:

$[T]=\left[\begin{array}{cc}{\left[T_{k}\right]} & {[0]} \\ {[0]} & {[I]}\end{array}\right]$

Onde $[I]$, é uma matriz identidade $6 \times 6$. 
De maneira análoga, para elementos de pilar em que somente a extremidade superior seja vinculada ao diafragma, obtém-se:

$[T]=\left[\begin{array}{cc}{[I]} & {[0]} \\ {[0]} & {\left[T_{k}\right]}\end{array}\right]$

Para elementos de viga pertencentes ao pavimento em que se considera a existência de diafragma rígido, como os dois nós estão contidos nesse pavimento, basta montar a matriz de transformação T com a transformação nos nós inicial e final da barra referidos ao mesmo nó mestre.

Assim:

$[T]=\left[\begin{array}{cc}{\left[T_{k}\right]} & {[0]} \\ {[0]} & {\left[T_{k}\right]}\end{array}\right]$

Sendo cada nó dotado de 6 graus de liberdade, então os nós vinculados ao pavimento que tiveram suas rigidezes transferidas ao nó mestre ficarão destituídos destas, enquanto o nó mestre contará apenas com as rigidezes referentes aos deslocamentos de corpo rígido do pavimento. Desta forma o sistema fica indeterminado. Uma forma muito simples de se contornar este problema, mostrado em CORRÊA (1991), é a vinculação dos deslocamentos nas direções destituídas de rigidez após a transformação e translação de rigidezes. O procedimento é o mesmo empregado para entrada da vinculação exterior da estrutura. A seguir (Vide figura 3.17), são mostrados alguns exemplos de vinculação de nós participantes da estrutura. 


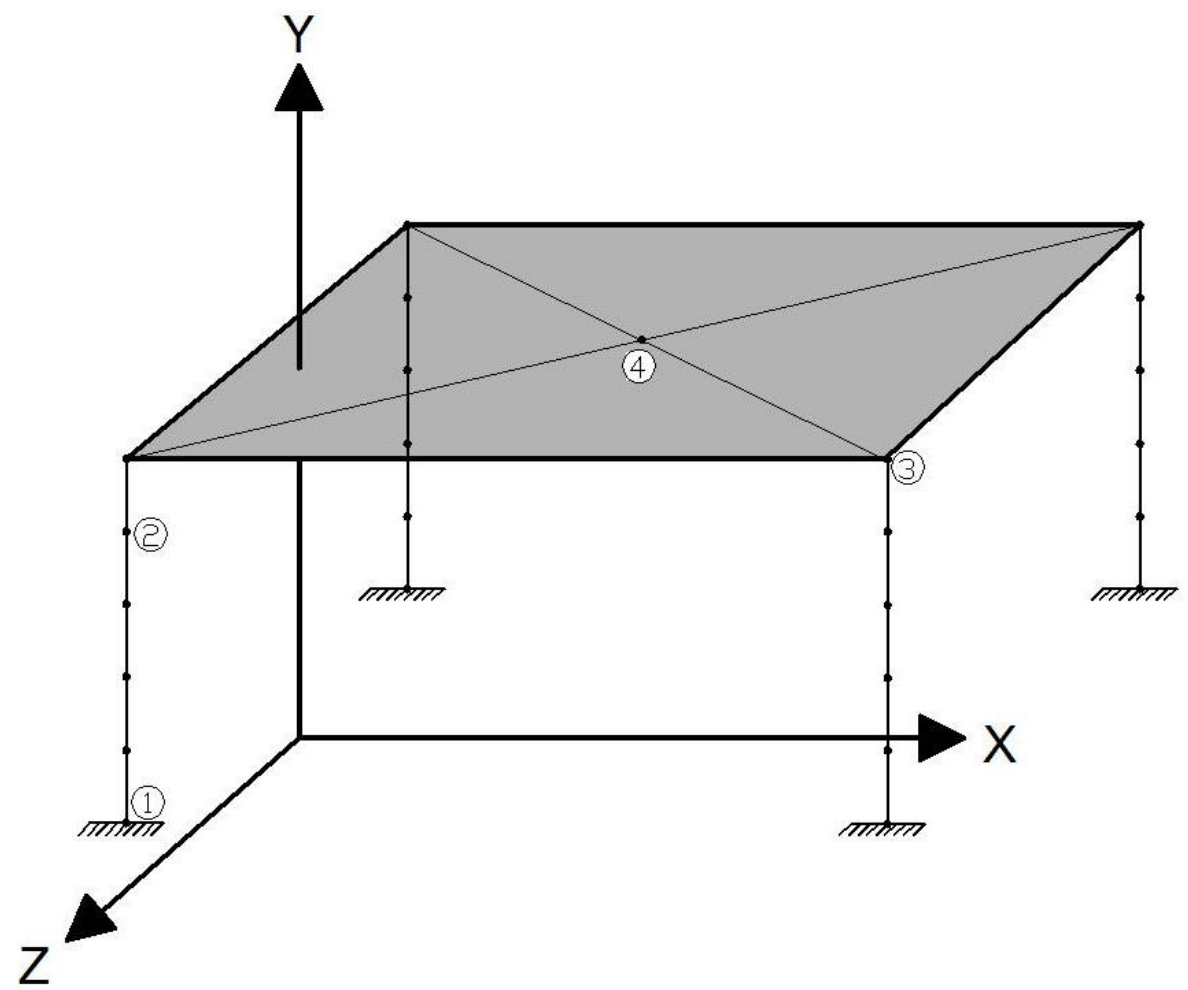

Figura 3.17: Identificação de nós pertencentes ao diafragma rígido.

Na tabela 3.1 é exemplificado o esquema de restrição nodal dos nós da estrutura da figura 3.17, considerando a hipótese de diafragma rígido para os pavimentos.

Tabela 3.1 - Vetor de restrições nodais para consideração do diafragma rígido.

\begin{tabular}{|c|c|c|c|c|c|c|}
\hline \multirow{2}{*}{ Nó } & \multicolumn{7}{|c|}{ Restrição } \\
\cline { 2 - 7 } & $\mathbf{u}$ & $\mathbf{v}$ & $\mathbf{w}$ & $\mathbf{r x}$ & $\mathbf{r y}$ & $\mathbf{r Z}$ \\
\hline 1 & 1 & 1 & 1 & 1 & 1 & 1 \\
\hline 2 & 0 & 0 & 0 & 0 & 0 & 0 \\
\hline 3 & 1 & 0 & 1 & 0 & 1 & 0 \\
\hline 4 & 0 & 1 & 0 & 1 & 0 & 1 \\
\hline
\end{tabular}

As validações da modelagem tridimensional da estrutura e a consideração do diafragma rígido serão mostrados no quarto capítulo, utilizando-se uma estrutura proposta por SILVA (1989) e posteriormente estudada por vários outros autores. 


\subsection{Consideração da deformação por cisalhamento.}

A princípio a teoria de vigas de Timoshenko é a extensão da teoria de Euller Bernoulli, levando em consideração o efeito da deformação por esforço cortante. Assim, a hipótese de que as seções planas permanecem planas após a deformação é mantida, mas a perpendicularidade com o eixo não é mais imposta. Admite-se, então, uma deformação adicional à curvatura de flexão, sendo, portanto a distorção diferente de zero, conforme está indicado na figura 3.18 .

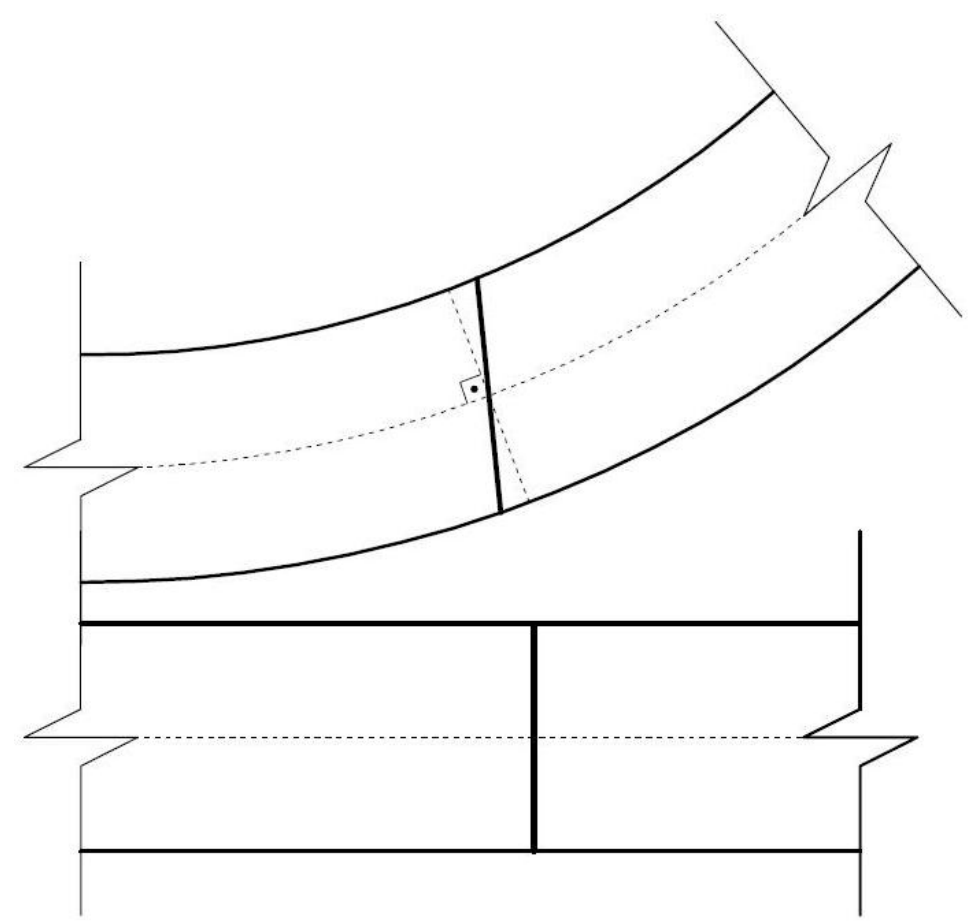

Figura 3.18: Viga de Timoshenko deformada.

$\mathrm{Na}$ hipótese de Euler-Bernoulli admite-se que todas as deformações causadas por tensões de cisalhamento nas seções transversais são nulas o que não pode ser negligenciado quando se tratam de elementos curtos.

Para contornar os problemas de travamento de solução e a não continuidade das rotações totais das seções, este trabalho contempla a flecha total correspondente aos esforços de flexão e cisalhamento e a rotação devida apenas à flexão, que são graus de liberdade contínuos em todo o intervalo do problema. $\mathrm{O}$ acoplamento da deformação por esforço cortante é introduzida somente sobre a parcela linear da matriz de rigidez 
dos elementos, considerando que não existam maiores implicações sobre o comportamento não linear físico ou geométrico dos elementos.

A matriz de rigidez do elemento de barra é a apresentada em GERE \& WEAVER (1981). Como a dedução desta matriz é amplamente conhecida, no SET/EESC/USP há vários trabalhos que mostram sua dedução, optou-se por apenas apresentá-la estendida para elementos de pórtico tridimensional.

$K_{\mathrm{T}}=\left[\begin{array}{ll}K_{\mathrm{T}_{\mathrm{AA}}} & K_{\mathrm{T}_{\mathrm{AB}}} \\ S I M & K_{\mathrm{T}_{\mathrm{BB}}}\end{array}\right]$

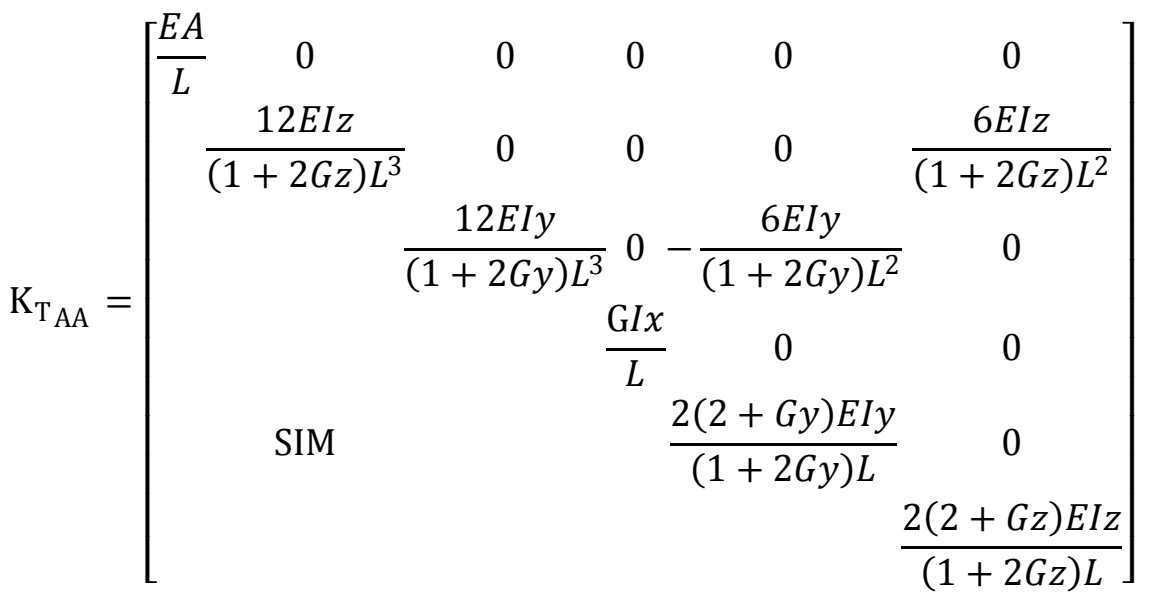

$$
\mathrm{K}_{\mathrm{T}_{\mathrm{AB}}}=\left[\begin{array}{cccccc}
-\frac{E A}{L} & 0 & 0 & 0 & 0 & 0 \\
0 & -\frac{12 E I z}{(1+2 G z) L^{3}} & 0 & 0 & 0 & \frac{6 E I z}{(1+2 G z) L^{2}} \\
0 & 0 & -\frac{12 E I y}{(1+2 G y) L^{3}} & 0 & -\frac{6 E I y}{(1+2 G y) L^{2}} & 0 \\
0 & 0 & 0 & \frac{-G I x}{L} & 0 & 0 \\
0 & 0 & \frac{6 E I y}{L^{2}} & 0 & \frac{2(1-G y) E I y}{(1+2 G y) L} & 0 \\
0-\frac{6 E I z}{(1+2 G z) L^{2}} & 0 & 0 & 0 & \frac{2(1-G z) E I z}{(1+2 G z) L}
\end{array}\right]
$$




$$
\mathrm{K}_{\mathrm{T}_{\mathrm{BB}}}=\left[\begin{array}{cccccc}
\frac{E A}{L} & 0 & 0 & 0 & 0 & 0 \\
\frac{12 E I z}{(1+2 G z) L^{3}} & 0 & 0 & 0 & -\frac{6 E I z}{(1+2 G z) L^{2}} \\
& \frac{12 E I y}{(1+2 G y) L^{3}} & 0 & \frac{6 E I y}{(1+2 G y) L^{2}} & 0 \\
& 0 & \frac{\mathrm{GI} x}{L} & 0 & 0 \\
\mathrm{SIM} & & & \frac{2(2+G y) E I y}{(1+2 G y) L} & 0 \\
& & & & \frac{2(2+G z) E I z}{(1+2 G z) L}
\end{array}\right]
$$

\subsubsection{Exemplos de aferição.}

Os exemplos a seguir são resultados de análises lineares de vigas para aferição dos resultados obtidos com o programa desenvolvido neste trabalho considerando a deformação por esforço cortante. Os resultados de referência são chamados BERNOULLI, sem consideração de deformação por esforço cortante, e TIMOSHENKO, considerando a deformação por esforço cortante. Os exemplos desenvolvidos são oriundos de livros de Resistência dos Materiais e WANG (1995). Os resultados obtidos com o programa considerando a deformação por esforço cortante são chamados NUC NLGF.

As vigas analisadas são de concreto com as seguintes características mecânicas:

Módulo de elasticidade longitudinal: $E=25000000 \mathrm{kN} / \mathrm{m}^{2}$

Coeficiente de Poisson: $v=0.2$

Módulo de elasticidade transversal: $G=10420000 \mathrm{kN} / \mathrm{m}^{2}$ 
3.6.2 Viga apoiada - engastada.

Neste exemplo é apresentada uma viga curta, com geometria e carregamento mostrados na figura 3.19. Em termos de discretização, foram tomadas barras de $1 \mathrm{~m}$ de comprimento, resultando em 5 nós. As dimensões estão em cm.

$$
M=100000 k N \cdot m
$$
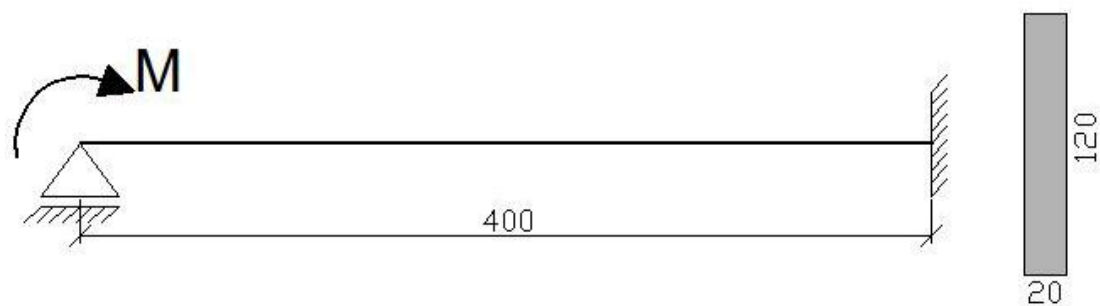

Figura 3.19: Geometria e carregamento da viga apoiada engastada, WANG (1995).

Tabela 3.2 - Deslocamentos e rotações dos nós da viga apoiada engastada.

\begin{tabular}{|c|c|c|c|c|}
\hline \multicolumn{5}{|c|}{ Viga apoiada engastada } \\
\hline GDL & Nó & TIMOSHENKO & NUC NLGF & BERNOULLI \\
\hline \multirow{3}{*}{ v } & 1 & 0,00000 & 0,00000 & 0,00000 \\
\cline { 2 - 5 } & 2 & $-0,08605$ & $-0,08605$ & $-0,07813$ \\
\cline { 2 - 5 } & 3 & $-0,08212$ & $-0,08212$ & $-0,06944$ \\
\cline { 2 - 5 } & 4 & $-0,03713$ & $-0,03714$ & $-0,02604$ \\
\cline { 2 - 5 } & 5 & 0,00000 & 0,00000 & 0,00000 \\
\hline \multirow{3}{*}{$\theta$} & 1 & $-0,16420$ & $-0,16420$ & $-0,13889$ \\
\cline { 2 - 5 } & 2 & $-0,04987$ & $-0,04981$ & $-0,02640$ \\
\cline { 2 - 5 } & 3 & 0,01570 & 0,01570 & 0,03470 \\
\cline { 2 - 5 } & 4 & 0,03230 & 0,03231 & 0,04340 \\
\cline { 2 - 5 } & 5 & 0,00000 & 0,00000 & 0,00000 \\
\hline
\end{tabular}




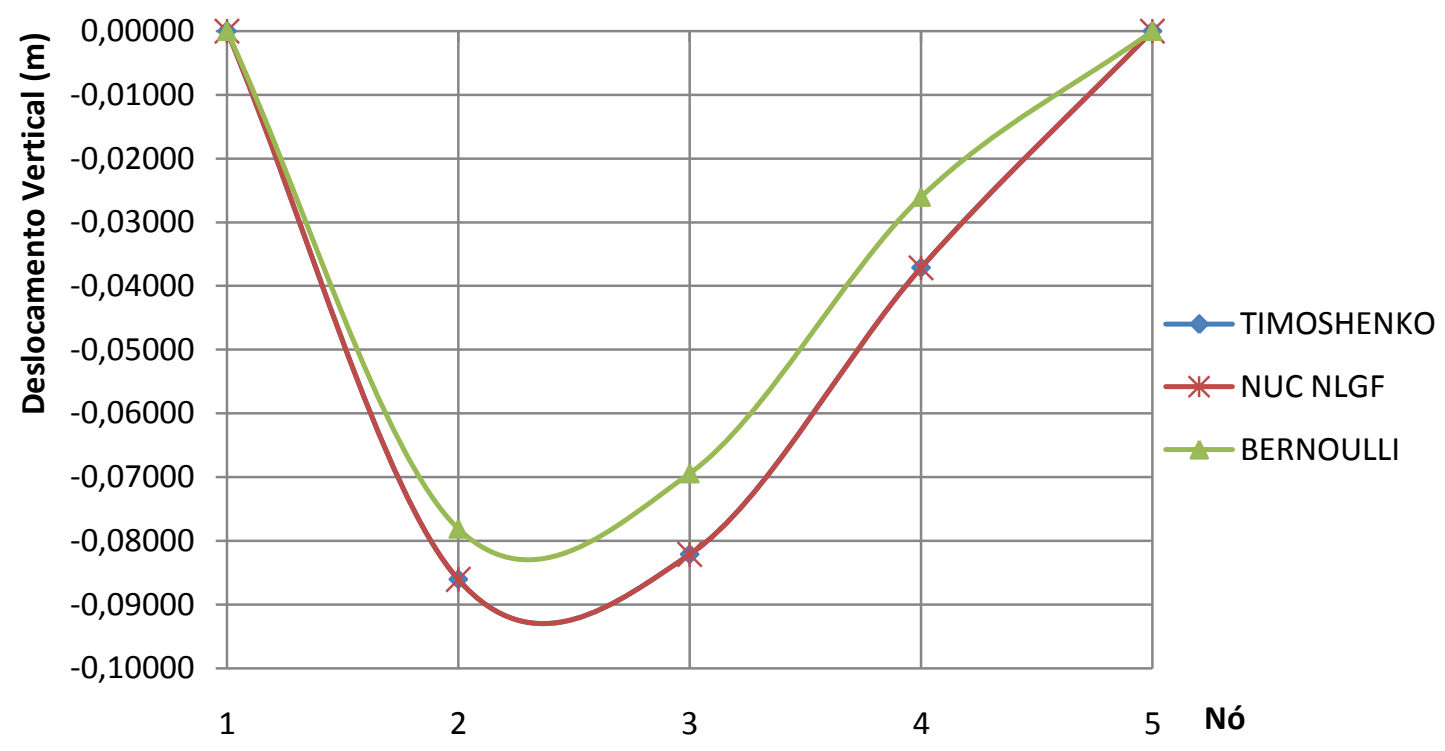

Figura 3.21: Deslocamentos verticais ao longo do eixo da viga apoiada engastada.

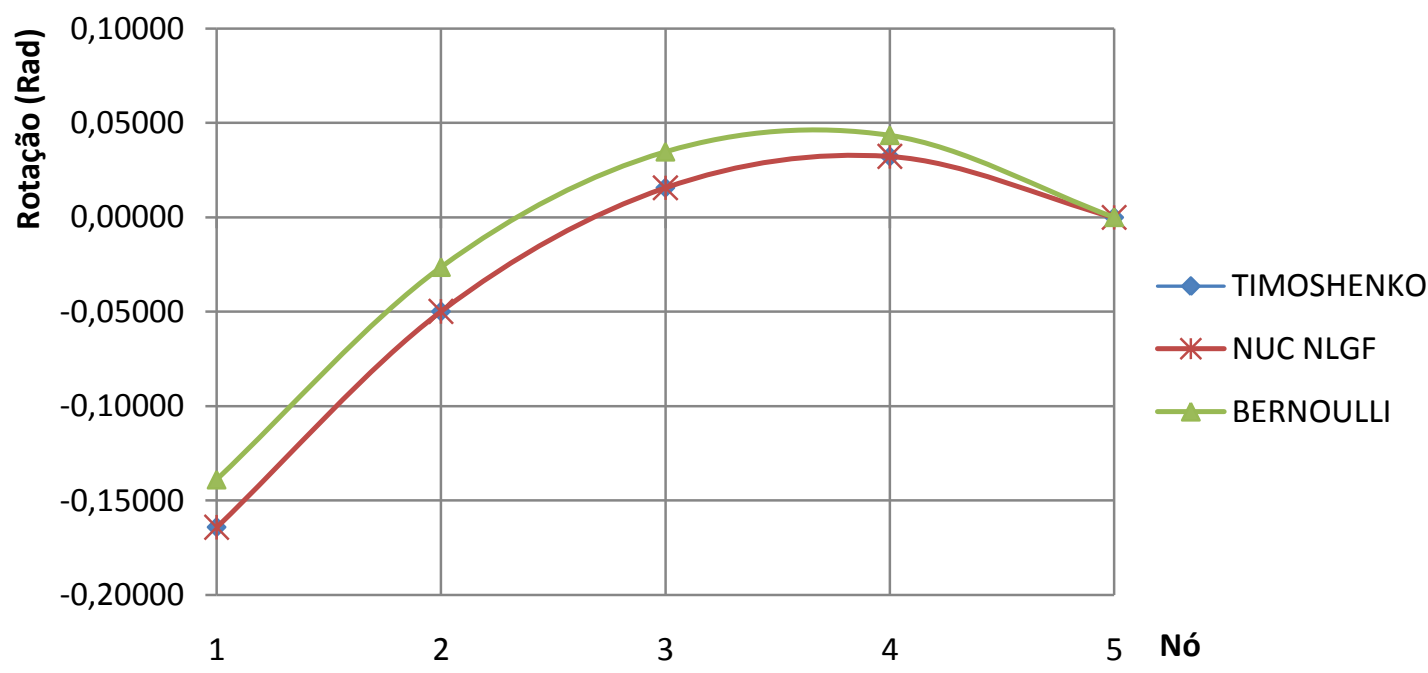

Figura 3.22: Rotações ao longo do eixo da viga apoiada engastada.

Conforme mostrado nas figuras 3.21 e 3.22 , os deslocamentos obtidos pelo programa desenvolvido neste trabalho apresentam se muito próximos aos adotados como referência. 


\subsubsection{Viga biengastada.}

Neste exemplo é apresentada uma viga muito curta, com geometria e carregamento mostrados na figura 3.23. Em termos de discretização, foram tomadas barras de $1 \mathrm{~m}$ de comprimento, resultando em 5 nós. As dimensões estão em cm.

$$
P=100000 k N
$$
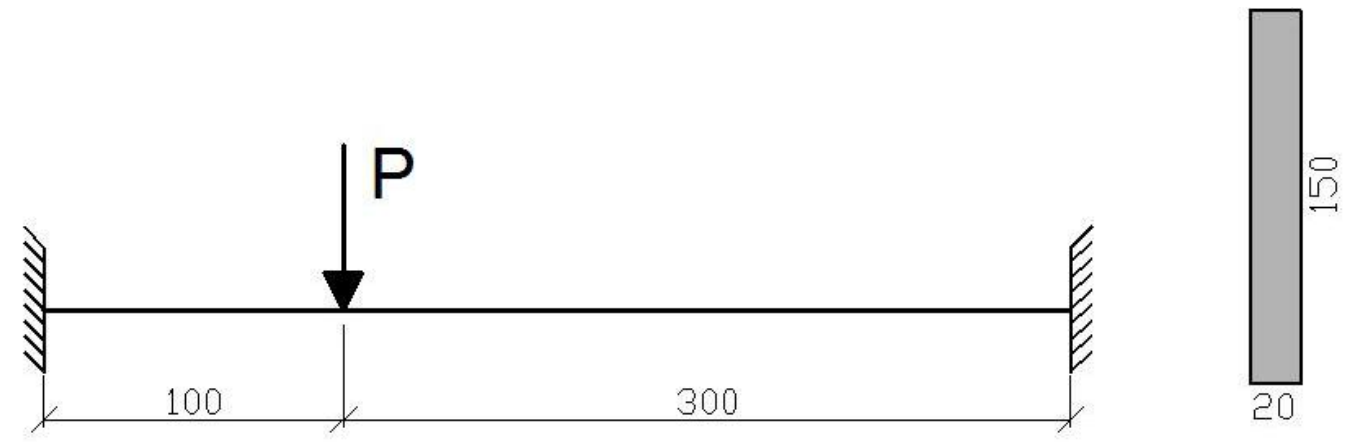

Figura 3.23: Geometria e carregamento da viga biengastada, WANG (1995).

Tabela 3.3 - Deslocamentos e rotações dos nós da viga biengastada.

\begin{tabular}{|c|c|c|c|c|}
\hline \multicolumn{5}{|c|}{ Viga biengastada } \\
\hline GDL & Nó & TIMOSHENKO & NUC NLGF & BERNOULLI \\
\hline \multirow{4}{*}{$\mathbf{v}$} & 1 & 0,00000 & 0,00000 & 0,00000 \\
\cline { 2 - 5 } & 2 & $-0,03975$ & $-0,03976$ & $-0,01000$ \\
\cline { 2 - 5 } & 3 & $-0,03105$ & $-0,03105$ & $-0,01185$ \\
\cline { 2 - 5 } & 4 & $-0,01345$ & $-0,01345$ & $-0,00482$ \\
\cline { 2 - 5 } & 5 & 0,00000 & 0,00000 & 0,00000 \\
\hline \multirow{4}{*}{$\boldsymbol{\theta}$} & 1 & 0,00000 & 0,00000 & 0,00000 \\
\cline { 2 - 5 } & 2 & $-0,00712$ & $-0,00712$ & $-0,01000$ \\
\cline { 2 - 5 } & 3 & 0,00829 & 0,00829 & 0,00444 \\
\cline { 2 - 5 } & 4 & 0,01066 & 0,01066 & 0,00777 \\
\cline { 2 - 5 } & 5 & 0,00000 & 0,00000 & 0,00000 \\
\hline
\end{tabular}




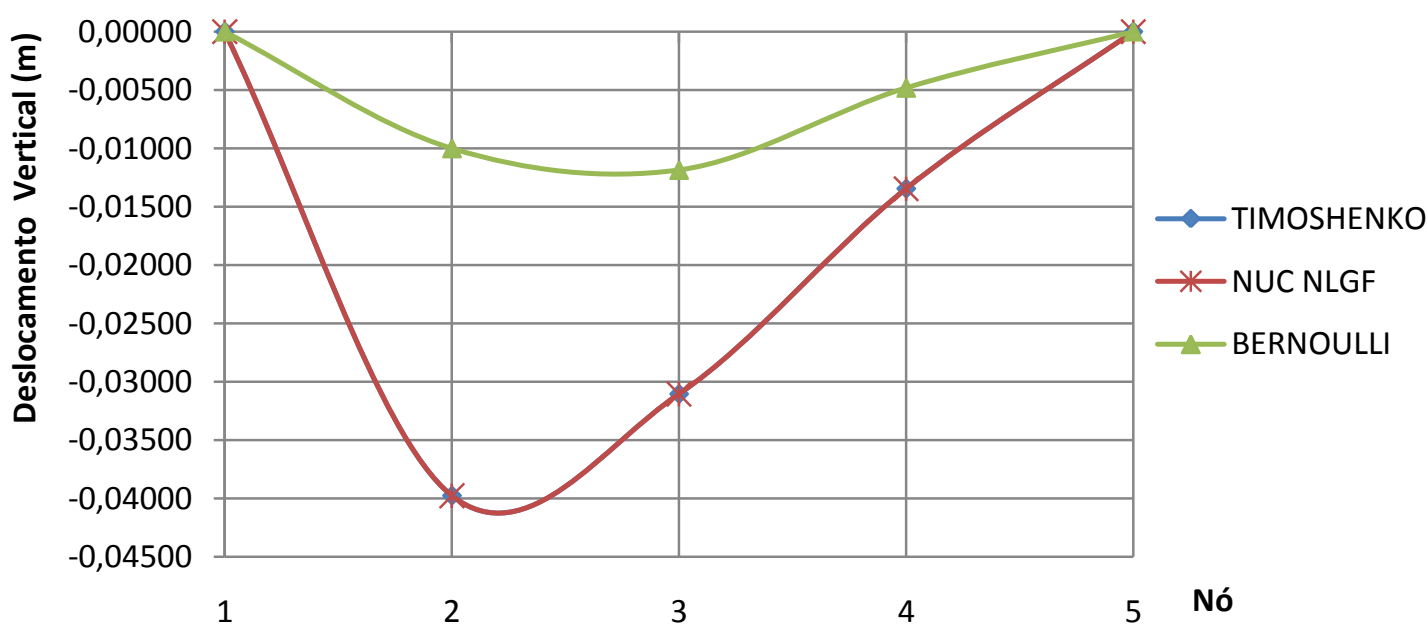

Figura 3.24: Deslocamentos verticais ao longo do eixo da viga biengastada.

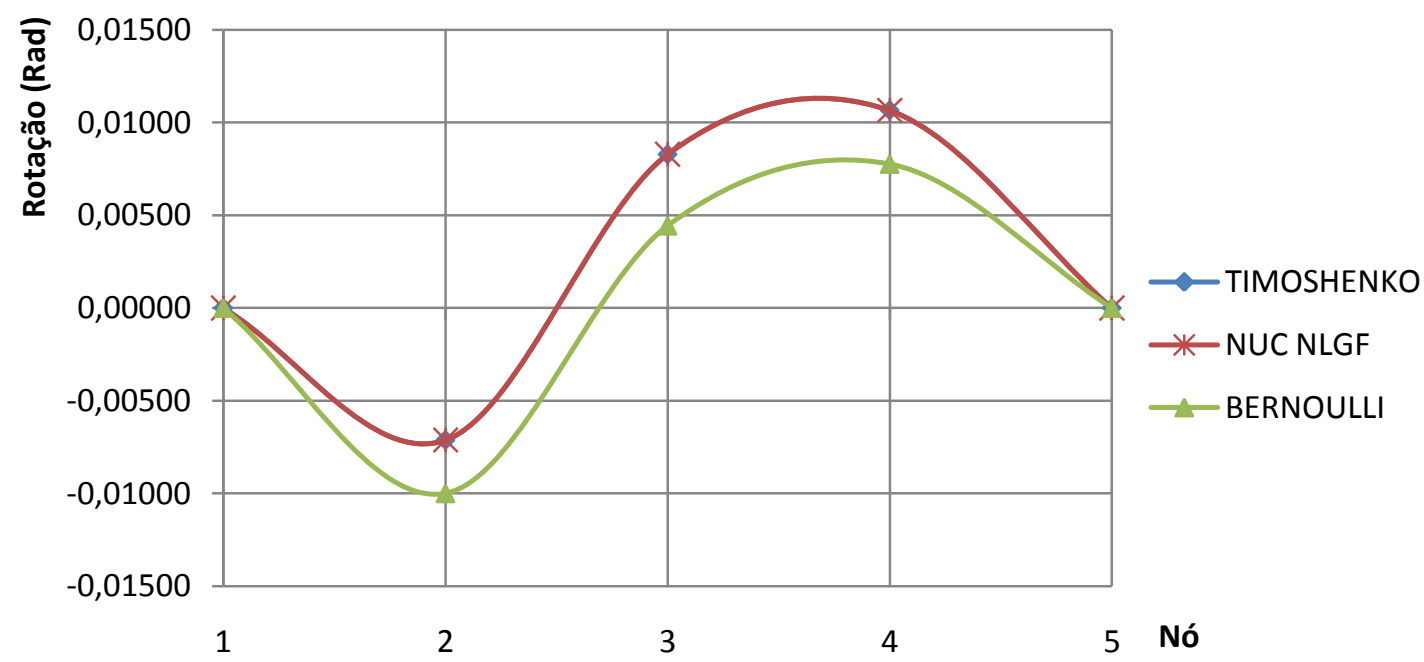

Figura 3.25: Rotações ao longo do eixo da viga biengastada.

Neste exemplo também é verificada ótima correspondência entre os resultados de referência e aqueles obtidos com o programa desenvolvido neste trabalho.

Neste capítulo foram discutidas as considerações sobre a modelagem das estruturas a serem estudadas. Os modelos e considerações adotadas são baseados em teorias bem consolidadas por vários autores. São, também, usadas na maioria dos trabalhos do SET/EESC/USP nesta mesma linha de pesquisa.

As considerações sobre as não linearidades, e a forma em que estas são acopladas ao modelo são mostradas nos dois próximos capítulos. 


\section{Capítulo 4 - Não linearidade geométrica}

Neste capítulo, será desenvolvida a teoria que descreve o comportamento não linear geométrico das estruturas compostas por barras. O tratamento da não linearidade geométrica feito conforme o apresentado em CORRÊA (1991), no qual são adotados o tensor de tensões de Piola Kirchhoff de segunda espécie e o tensor de deformações de Green-Lagrange.

Dentre as várias possibilidades de estratégia de solução do problema não linear será adotado o método da iteração direta, o qual faz uso das matrizes de rigidez secantes.

Seja uma estrutura constituída por barras interconectadas pelas suas extremidades (nós), em regime elástico, a energia potencial da estrutura é dada por:

$\Pi=U-F^{T} Q$

Onde:

$\Pi=$ Energia potencial total

$\mathrm{U}=$ Energia de deformação das barras

$F^{T}=$ Vetor que reune os esforços nodais

$Q=$ Vetor que reune os deslocamento nodais

A energia de deformação é dada por:

$\mathrm{U}=\frac{1}{2} \int_{V} \varepsilon^{T} \sigma d V$

$\mathrm{U}=\frac{1}{2} \int_{V} \varepsilon^{T} E \varepsilon d V$

$\varepsilon=$ Tensor das deformações

$E=$ Módulo de elasticidade do material

$\sigma=$ Tensor das tensões 
$V=$ Volume do elemento de barra

Usando um vetor B que relacione as deformações aos deslocamentos, a equação da energia pode ser representada por:

$\Pi=\frac{1}{2} \sum_{e} \int_{V e} Q^{T} B^{T} E Q B d V_{e}-F^{T} Q$

Onde:

$e=$ Número de elementos

$V_{e}=$ Volume de cada elemento

$B=$ Vetor que relaciona as deformações aos deslocamentos

Devido ao vetor de deformações adotado, a energia de deformações passa a ter uma relação não linear com os deslocamentos:

$\Pi=\frac{1}{2} \sum_{e} \int_{V e} Q^{T} B^{T} E Q B d V_{e}-F^{T} Q$

$\Pi=U(Q)-F^{T} Q$

Como o equilíbrio da estrutura ocorre na condição em que as derivadas parciais do funcional em relação a cada deslocamento são nulas, tem-se:

$\frac{\partial U}{\partial Q}-F=0$

Ou, ainda, matricialmente:

$\mathrm{K}_{\mathrm{s}} U=F$ 
Os deslocamentos axiais são admitidos lineares e os deslocamentos transversais cúbicos. Assim, as funções aproximadoras dos deslocamentos são do tipo:

$u_{i}(x)=\mathrm{N}_{1}(x) \cdot q_{1}+\mathrm{N}_{7}(x) \cdot q_{7}$

$v_{i}(x)=\mathrm{N}_{2}(x) \cdot q_{2}+\mathrm{N}_{6}(x) \cdot q_{6}+\mathrm{N}_{8}(x) \cdot q_{8}+\mathrm{N}_{12}(x) \cdot q_{12}$

$w_{i}(x)=\mathrm{N}_{3}(x) \cdot q_{3}+\mathrm{N}_{5}(x) \cdot q_{6}+\mathrm{N}_{9}(x) \cdot q_{9}+\mathrm{N}_{11}(x) \cdot q_{11}$

A medida de deformação de Green é dada por:

$\varepsilon_{\mathrm{x}}=\left(u_{0}{ }^{\prime}-Y \cdot v_{0}{ }^{\prime \prime}-Z \cdot w_{0}{ }^{\prime \prime}\right)+\frac{1}{2}\left(u_{0}{ }^{\prime}-Y \cdot v_{0}{ }^{\prime \prime}-Z \cdot w_{0}{ }^{\prime \prime}\right)^{2}+\frac{1}{2} \cdot\left(v_{0}{ }^{\prime}\right)^{2}+\frac{1}{2} \cdot\left(w_{0}\right)^{2}$

Como a parcela $\frac{1}{2}\left(u_{0}{ }^{\prime}-Y \cdot v_{0}{ }^{\prime \prime}-Z \cdot w_{0}{ }^{\prime \prime}\right)^{2}$ é muito pequena em comparação com as demais parcelas, ela será desprezada. Adicionalmente será utilizada a média ponderada da derivada do deslocamento transversal e não o seu valor pontual,assim como feito em WEN et al (1983), dessa forma, a deformação passa a ser dada por:

$\varepsilon_{\mathrm{x}}=\left(u_{0}{ }^{\prime}-Y \cdot v_{0}{ }^{\prime}-Z \cdot w_{0}{ }^{\prime \prime}\right)+\frac{1}{\mathrm{~L}} \int_{0}^{\mathrm{L}} \frac{1}{2} \cdot\left(v_{0}{ }^{\prime}\right)^{2} \cdot \mathrm{dx}+\frac{1}{\mathrm{~L}} \int_{0}^{\mathrm{L}} \frac{1}{2} \cdot\left(w_{0}{ }^{\prime}\right)^{2} \cdot \mathrm{dx}$

Definido o tensor de deformações, o cálculo da energia de deformações é dado por:

$\mathrm{U}=\frac{1}{2} \int_{V} \varepsilon_{\mathrm{x}}^{2} E d V$

$\mathrm{U}=\frac{1}{2} \int_{V}\left[\left(u_{0}{ }^{\prime}-Y \cdot v_{0}{ }^{\prime \prime}-Z \cdot w_{0}{ }^{\prime \prime}\right)+\frac{1}{\mathrm{~L}} \int_{0}^{\mathrm{L}} \frac{1}{2} \cdot\left(v_{0}{ }^{\prime}\right)^{2} \cdot \mathrm{dx}+\frac{1}{\mathrm{~L}} \int_{0}^{\mathrm{L}} \frac{1}{2} \cdot\left(w_{0}\right)^{2} \cdot \mathrm{dx}\right]^{2} E d V$ 
Os desenvolvimentos subseqüentes até a determinação das matrizes de rigidez secante e tangente são mostrados em detalhes na tese de doutorado de CORRÊA (1991). As matrizes secante e tangente são dadas respectivamente por:

$K_{\mathrm{S}}=K_{0}+\frac{1}{2} K_{1}+\frac{1}{3} K_{2}$

$K_{\mathrm{T}}=K_{0}+K_{1}+K_{2}$

Sendo as matrizes $K_{0}, K_{1}$ e $K_{2}$ iguais a:

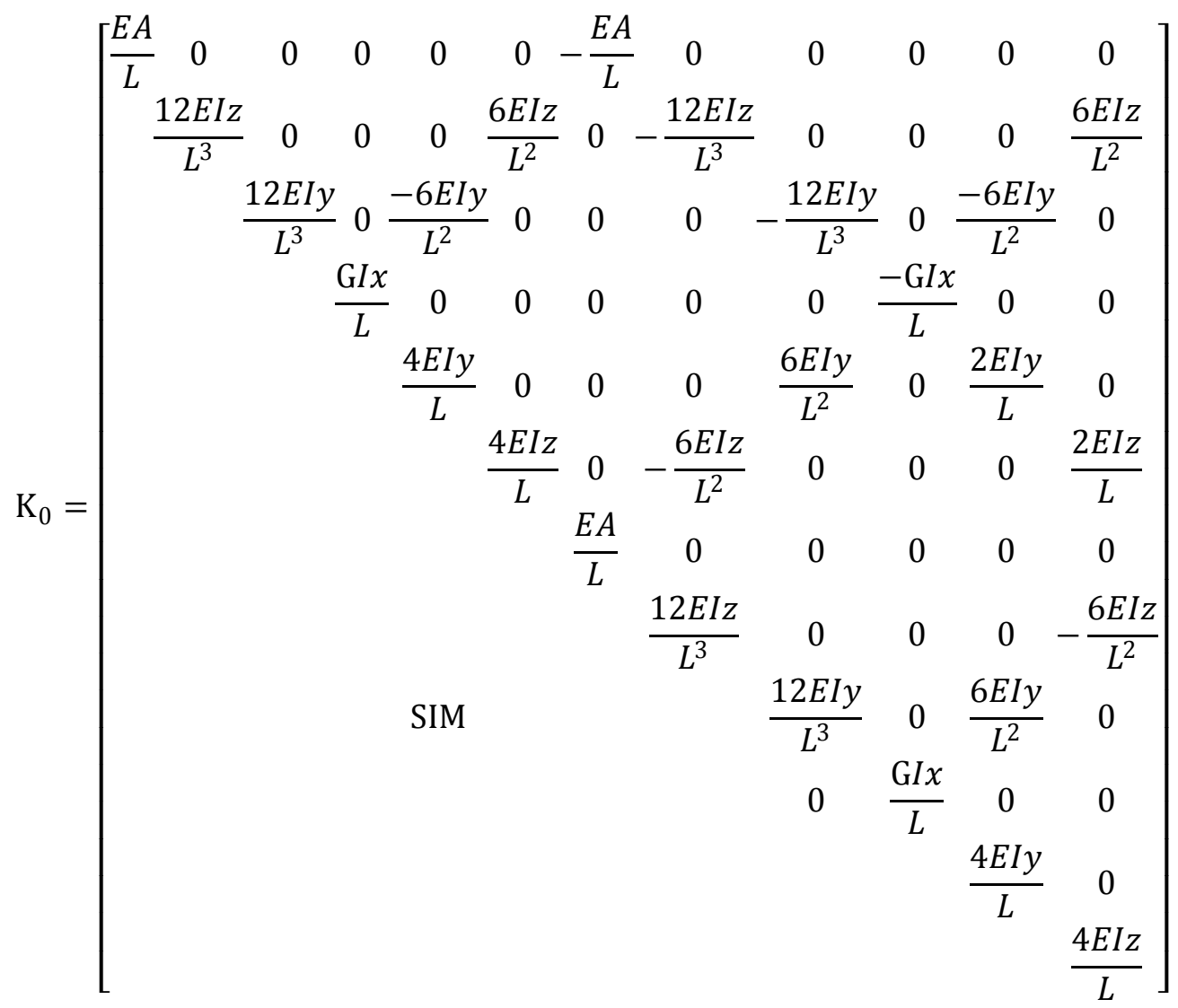




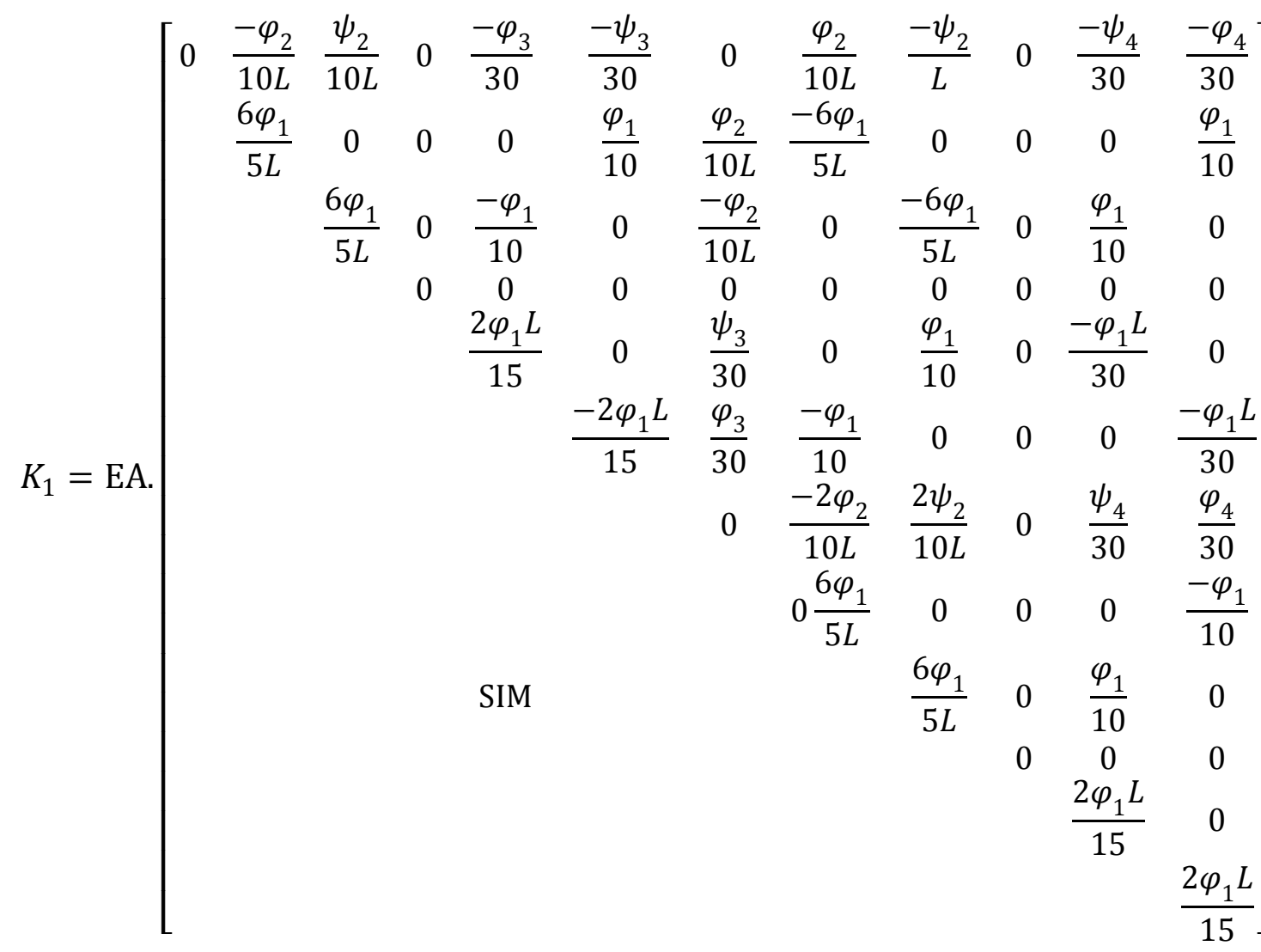

$K_{2}=\left[\begin{array}{ll}K_{2 \mathrm{AA}} & K_{2 \mathrm{AB}} \\ S I M & K_{2 \mathrm{BB}}\end{array}\right]$

$K_{2 \mathrm{AA}}=\mathrm{EA} .\left[\begin{array}{cccccc}0 & 0 & 0 & 0 & 0 & 0 \\ & \frac{\varphi_{5}+\psi_{11}}{L} & \frac{-\varphi_{2} \psi_{2}}{100 L} & 0 & \frac{\varphi_{2} \psi_{3}}{300} & \varphi_{6}+\frac{\psi_{11}}{12} \\ & \frac{\varphi_{5}+\psi_{11}}{L} & 0 & -\psi_{6}-\frac{\varphi_{11}}{12} & \frac{\psi_{2} \varphi_{3}}{300} \\ & & 0 & 0 & 0 \\ & & & \left(\psi_{8}+\frac{\varphi_{11}}{9}\right) \mathrm{L} & \frac{\varphi_{3} \psi_{3}}{900} \mathrm{~L} \\ & & & \left(\varphi_{8}+\frac{\psi_{11}}{9}\right) \mathrm{L}\end{array}\right]$

(4.20 a) 
$K_{2 \mathrm{AB}}=\mathrm{EA} .\left[\begin{array}{cccccc}0 & 0 & 0 & 0 & 0 & 0 \\ 0 & \frac{-\varphi_{5}-\psi_{11}}{L} & \frac{\varphi_{2} \psi_{2}}{100 L} & 0 & \frac{\varphi_{2} \psi_{4}}{300} & \varphi_{7}+\frac{\psi_{11}}{12} \\ 0 & \frac{\varphi_{2} \psi_{2}}{100 L} & \frac{-\psi_{5}-\varphi_{11}}{L} & 0 & \psi_{7}+\frac{\varphi_{11}}{12} & \frac{\psi_{2} \varphi_{4}}{300} \\ 0 & 0 & 0 & 0 & 0 & 0 \\ 0 & \frac{-\varphi_{2} \psi_{3}}{300} & \psi_{6}+\frac{\varphi_{11}}{12} & 0 & \left(\psi_{9}-\frac{\varphi_{11}}{36}\right) \mathrm{L} & \frac{\varphi_{4} \psi_{3}}{900} \mathrm{~L} \\ 0 & -\varphi_{6}-\frac{\psi_{11}}{12} & \frac{\psi_{2} \varphi_{3}}{300} & 0 & \frac{\psi_{4} \varphi_{3}}{900} \mathrm{~L} & \left(\varphi_{9}-\frac{\psi_{11}}{36}\right) \mathrm{L}\end{array}\right]$

$K_{2 \mathrm{BB}}=\mathrm{EA} .\left[\begin{array}{cccccc}0 & 0 & 0 & 0 & 0 & 0 \\ & \frac{\varphi_{5}+\psi_{11}}{L} & \frac{-\varphi_{2} \psi_{2}}{100 L} & 0 & \frac{-\varphi_{2} \psi_{4}}{300} & -\varphi_{7}-\frac{\psi_{11}}{12} \\ & \frac{\varphi_{5}+\psi_{11}}{L} & 0 & \psi_{7}+\frac{\varphi_{11}}{12} & \frac{\psi_{2} \varphi_{4}}{300} \\ & & 0 & 0 & 0 \\ & & & \left(\psi_{10}+\frac{\varphi_{11}}{9}\right) \mathrm{L} & \frac{\varphi_{4} \psi_{4}}{900} \mathrm{~L} \\ & & & & \left(\varphi_{10}+\frac{\psi_{11}}{9}\right) \mathrm{L}\end{array}\right]$

(4.20 c)

Onde:

$\theta_{0=}\left(v_{2}-v_{1}\right) / L$

$\theta_{1=} r z_{1}$

$\theta_{2}=r z_{2}$

$\beta_{0=}\left(w_{1}-w_{2}\right) / L$

$\beta \theta_{1=} r y_{1}$

$\beta_{2=} r y_{2}$ 


$$
\begin{aligned}
& \varphi_{1}=\left(u_{2}-u_{1}\right) / L \\
& \varphi_{2}=\theta_{1}+\theta_{2}-12 \theta_{0} \\
& \varphi_{3}=4 \theta_{1}-\theta_{2}-3 \theta_{0} \\
& \varphi_{4}=4 \theta_{2}-\theta_{1}-3 \theta_{0} \\
& \varphi_{5}=\left(9 \theta_{1}{ }^{2}+9 \theta_{2}{ }^{2}-2 \theta_{1} \theta_{2}-36 \theta_{1} \theta_{0}-36 \theta_{2} \theta_{0}+216 \theta_{0}{ }^{2}\right) / 100 \\
& \varphi_{6}=\left(6 \theta_{1}{ }^{2}+\theta_{2}{ }^{2}-2 \theta_{1} \theta_{2}-54 \theta_{1} \theta_{0}+6 \theta_{2} \theta_{0}+54 \theta_{0}{ }^{2}\right) / 300 \\
& \varphi_{7}=\left(6 \theta_{2}{ }^{2}+\theta_{1}{ }^{2}+2 \theta_{1} \theta_{2}-54 \theta_{2} \theta_{0}+6 \theta_{1} \theta_{0}+54 \theta_{0}{ }^{2}\right) / 300 \\
& \varphi_{8}=\left(8 \theta_{1}{ }^{2}+3 \theta_{2}{ }^{2}-4 \theta_{1} \theta_{2}-12 \theta_{1} \theta_{0}-2 \theta_{2} \theta_{0}+27 \theta_{0}{ }^{2}\right) / 300 \\
& \varphi_{9}=\left(-2 \theta_{1}^{2}-2 \theta_{2}^{2}+6 \theta_{1} \theta_{2}-2 \theta_{1} \theta_{0}-2 \theta_{2} \theta_{0}-3 \theta_{0}{ }^{2}\right) / 300 \\
& \varphi_{10}=\left(8 \theta_{2}{ }^{2}+3 \theta_{1}{ }^{2}-4 \theta_{1} \theta_{2}-12 \theta_{2} \theta_{0}-2 \theta_{1} \theta_{0}+27 \theta_{0}{ }^{2}\right) / 300 \\
& \varphi_{11}=\left(2 \theta_{1}{ }^{2}+2 \theta_{2}{ }^{2}-\theta_{1} \theta_{2}+3 \theta_{1} \theta_{0}-3 \theta_{2} \theta_{0}+18 \theta_{0}{ }^{2}\right) / 25 \\
& \psi_{1}=\left(u_{2}-u_{1}\right) / L \\
& \psi_{2}=\beta_{1}+\beta_{2}-12 \beta_{0} \\
& \psi_{3}=4 \beta_{1}-\beta_{2}-3 \beta_{0} \\
& \psi_{4}=4 \beta_{2}-\beta_{1}-3 \beta_{0} \\
& \psi_{5}=\left(9{\beta_{1}}^{2}+9{\beta_{2}}^{2}-2 \beta_{1} \beta_{2}-36 \beta_{1} \beta_{0}-36 \beta_{2} \beta_{0}+216 \beta_{0}{ }^{2}\right) / 100 \\
& \psi_{6}=\left(6{\beta_{1}}^{2}+{\beta_{2}}^{2}-2 \beta_{1} \beta_{2}-54 \beta_{1} \beta_{0}+6 \beta_{2} \beta_{0}+54 \beta_{0}{ }^{2}\right) / 300 \\
& \psi_{7}=\left(6{\beta_{2}}^{2}+{\beta_{1}}^{2}+2 \beta_{1} \beta_{2}-54 \beta_{2} \beta_{0}+6 \beta_{1} \beta_{0}+54 \beta_{0}{ }^{2}\right) / 300 \\
& \psi_{8}=\left(8 \beta_{1}{ }^{2}+3 \beta_{2}{ }^{2}-4 \beta_{1} \beta_{2}-12 \beta_{1} \beta_{0}-2 \beta_{2} \beta_{0}+27 \beta \theta_{0}{ }^{2}\right) / 300 \\
& \psi_{9}=\left(-2 \beta_{1}{ }^{2}-2 \beta_{2}{ }^{2}+6 \beta_{1} \beta_{2}-2 \beta_{1} \beta_{0}-2 \beta_{2} \beta_{0}-3 \beta_{0}{ }^{2}\right) / 300 \\
& \psi_{10}=\left(8{\beta_{2}}^{2}+3{\beta_{1}}^{2}-4 \beta_{1} \beta_{2}-12 \beta_{2} \beta_{0}-2 \beta_{1} \beta_{0}+27{\beta_{0}}^{2}\right) / 300 \\
& \psi_{11}=\left(2 \beta_{1}{ }^{2}+2{\beta_{2}}^{2}-\beta_{1} \beta_{2}+3 \beta_{1} \beta_{0}-3 \beta_{2} \beta_{0}+18 \beta_{0}{ }^{2}\right) / 25
\end{aligned}
$$




\subsection{Análise incremental iterativa.}

Dado o baixo nível de não linearidade geométrica associada às estruturas usuais de edifícios, a formulação acima descrita dispensa o caráter incremental dos carregamentos, bastando um único passo de carregamento. Para análises não lineares geométrica e física, devido a um maior nível de não linearidade introduzida pelo material, há a necessidade da divisão do carregamento, tornando indispensável o tratamento incremental dos carregamentos.

Para uma análise em que o carregamento é incremental, quando se passa de um nível de carregamento para o seguinte, além da atualização de coordenadas da estrutura deve-se considerar o nível de tensões a que a estrutura está sujeita até o início do novo incremento. A informação quanto ao nível de tensões é dado pela tradicional matriz geométrica, expressa por:

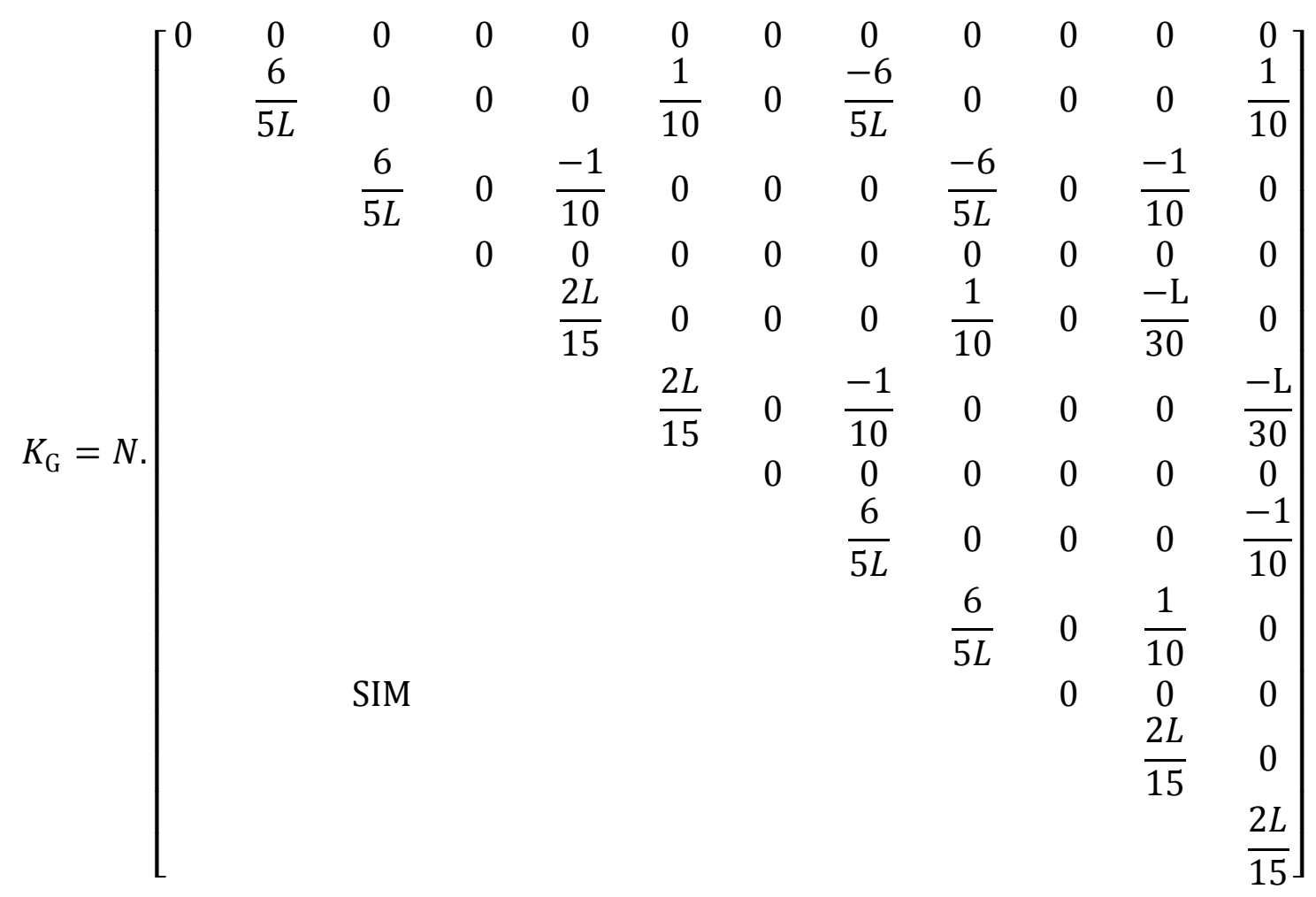


Assim para um incremento $i$ qualquer, o equilíbrio da estrutura é expresso por:

$$
{ }^{i} F+\left[{ }^{i-1} K_{G}+{ }^{i} K_{0}+\frac{1}{2}{ }^{i} K_{1}+\frac{1}{3}{ }^{i} K_{2}\right] \Delta{ }^{i} Q={ }^{i+1} F
$$

Sendo:

${ }^{i} F$ e ${ }^{i} K_{G}$ devidos às deformações até o início do incremento

${ }^{i} K_{0},{ }^{i} K_{1} \mathrm{e}{ }^{i} K_{2}$ devidos às deformações do atual incremento

\subsection{Exemplos de aferição.}

Será analisado um pórtico biengastado composto por 3 barras, sendo a barra horizontal inextensível conforme a figura 4.1 proposto por ELIAS (1986). Será comparada a curva força $P$ pelo deslocamento $u$ segundo quatro análises distintas.

A primeira delas é a apresentada em ELIAS (1986) que faz uso das funções de estabilidade do modelo viga-coluna para a solução; a segunda é a mostrada em CORRÊA (1991), que discretiza o pórtico em três barras e usa a mesma teoria deste trabalho; a terceira é mostrada em PAULA (2001), que usa o tensor de deformações de Green completo e divide cada barra em 6 elementos; e por último a análise realizada com o código desenvolvido neste trabalho (NUC NLGF), que deve mostrar resultados idênticos aos de CORRÊA (1991). 


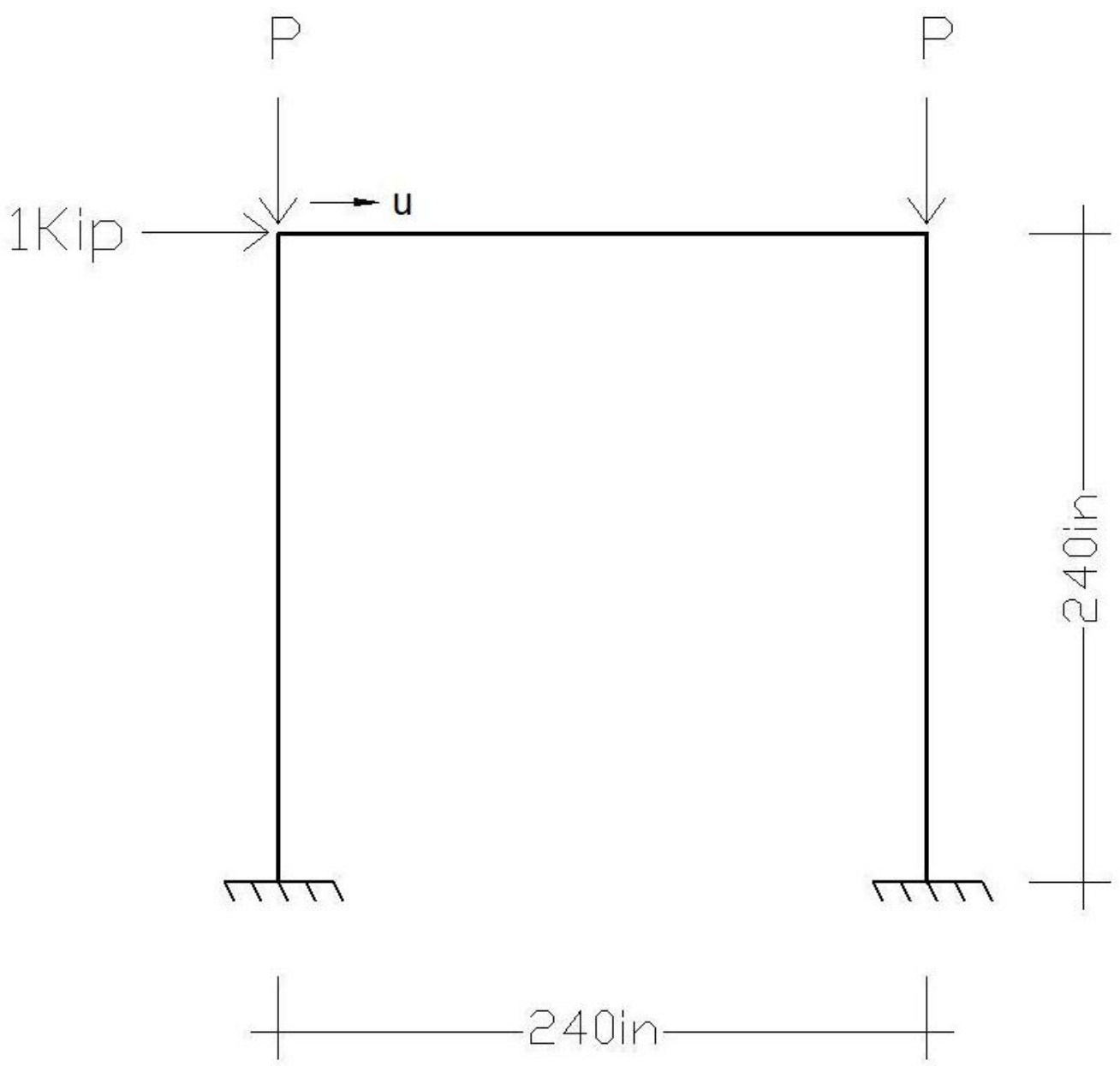

Figura 4.1: Pórtico biengastado proposto por ELIAS (1986).

$$
\begin{aligned}
& A=10 \mathrm{in}^{2} \\
& I=100 \mathrm{in}^{4} \\
& E=30000 \mathrm{ksi}
\end{aligned}
$$




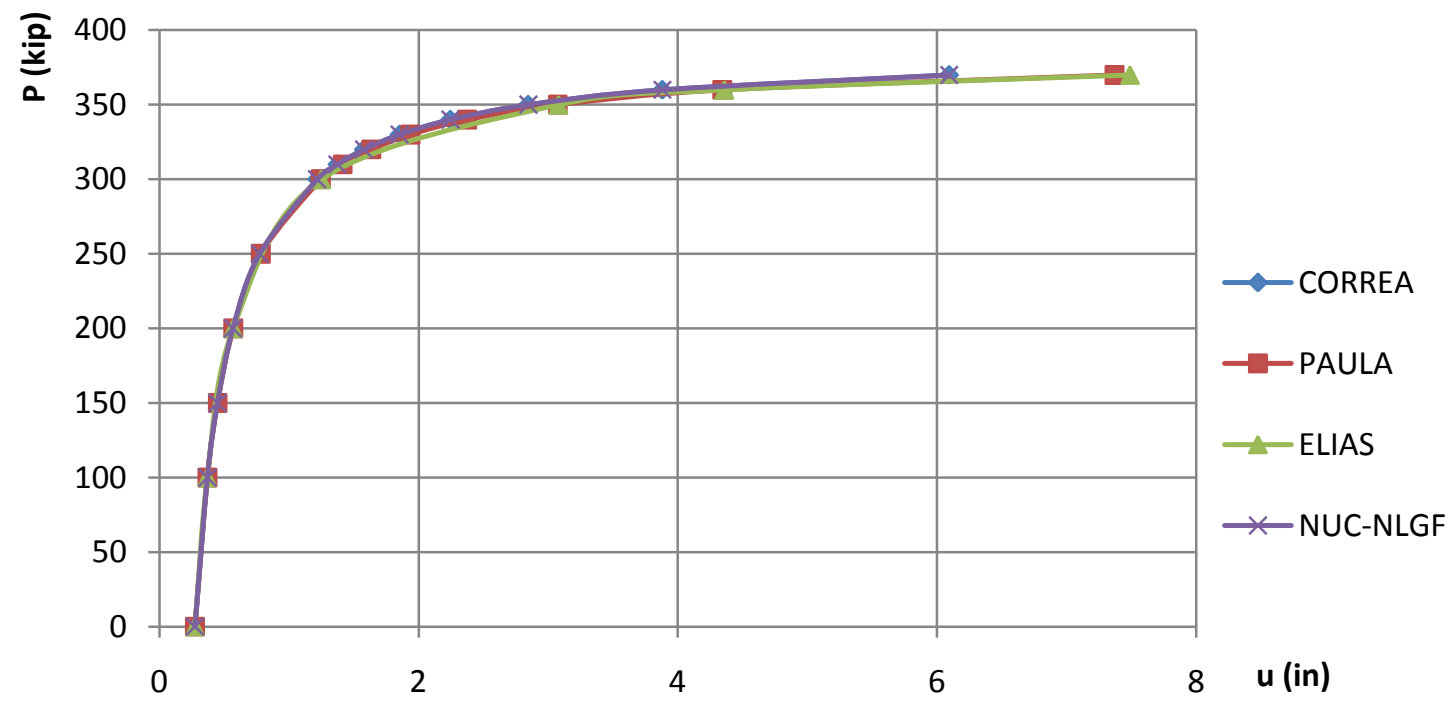

Figura 4.2: Força vertical versus deslocamento horizontal do topo do pórtico.

A análise feita com o programa desenvolvido mostra resultados idênticos aos obtidos por CORRÊA (1991). Em relação às duas outras análises, embora a carga última esteja bem representada, existe pequena diferença em relação ao deslocamento referente á perda de equilíbrio da estrutura.

\subsection{Discretização e carregamento incremental.}

Para a avaliação do desempenho do comportamento do carregamento incremental, foi feita uma comparação entre os resultados obtidos em deslocamentos e esforços e o número de incrementos de carga no mesmo pórtico do exemplo anterior. Devido à sua melhor representatividade, foi usado nesse exemplo a discretização de cada barra em 6 elementos, de acordo com PAULA (2001). 


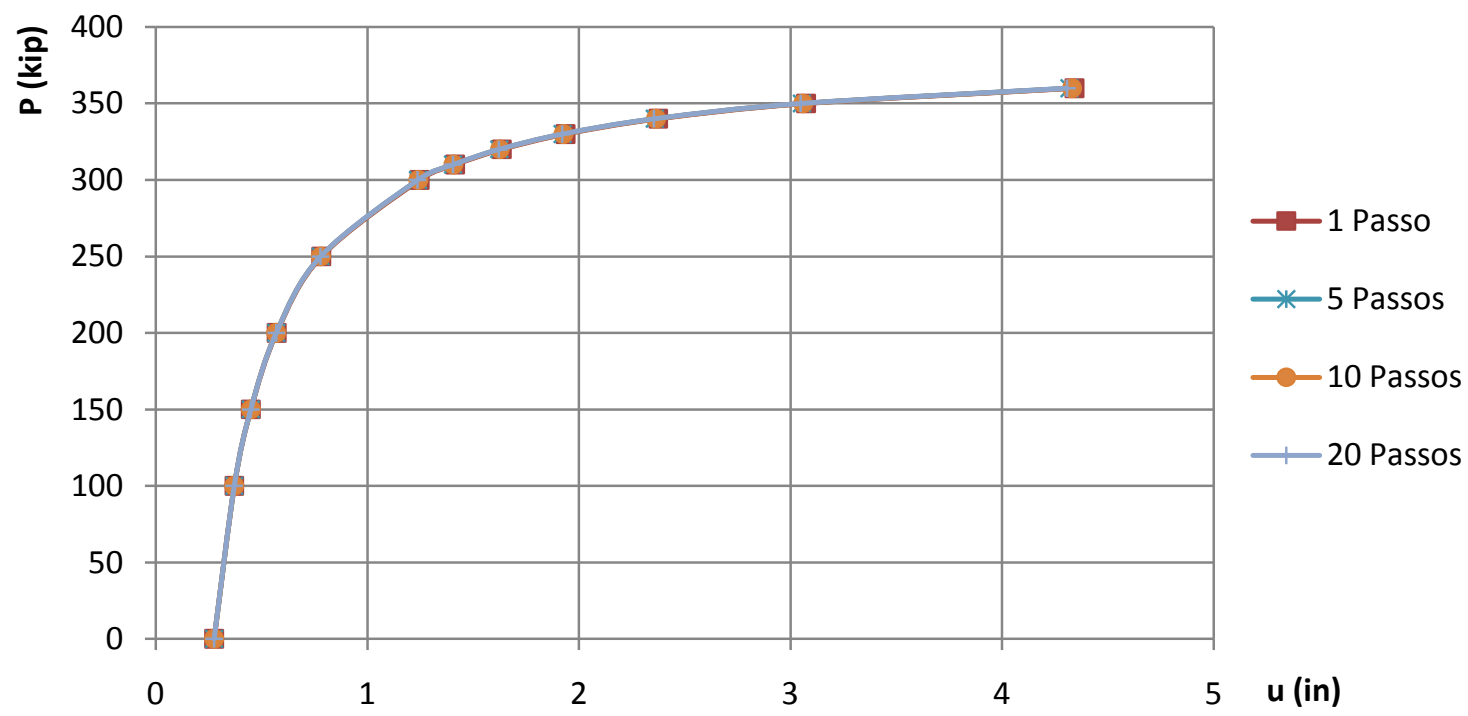

Figura 4.3: Força vertical versus deslocamento horizontal do topo do pórtico.

Como mostrado na figura 4.3, os deslocamentos obtidos nas análises com diferentes números de passos de carregamento são idênticos. Esta divisão em passos será importante para a análise não linear física, onde o grau de não linearidade imposto pelo material faz o tratamento incremental indispensável.

Objetivando a verificação do número necessário de divisões das barras para que os resultados em esforços através das integrações das tensões em cada camada fossem iguais aos obtidos através da multiplicação da matriz de rigidez de cada elemento pelos seus respectivos deslocamentos locais, fez se um breve estudo paramétrico avaliando o número de divisões pela precisão dos resultados.

As figuras 4.4, 4.5 e 4.6 mostram os resultados apresentados em função do número total de elementos distribuídos uniformemente entre os membros, usados em cada discretização. São eles o deslocamento horizontal do ponto de aplicação da carga horizontal, o esforço normal e momento fletor junto ao vínculo na base do pilar direito da estrutura. 


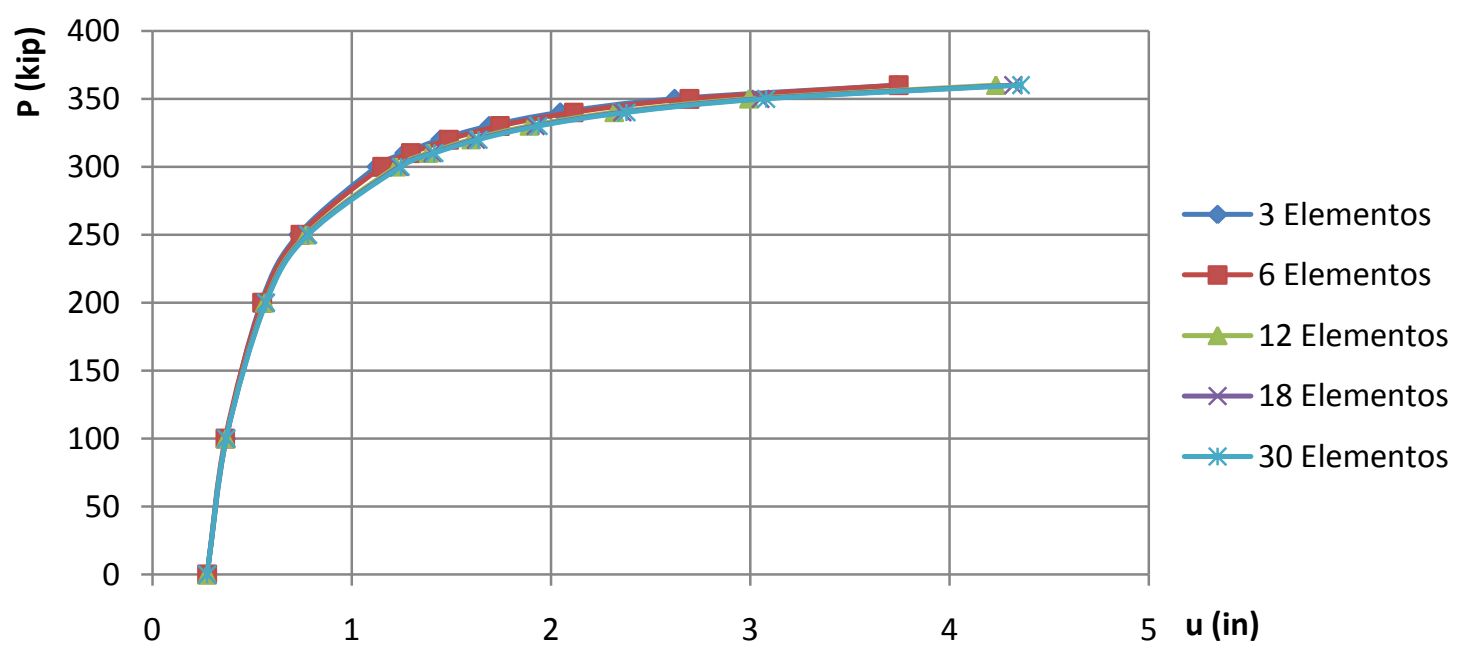

Figura 4.4: Força vertical versus deslocamento horizontal do topo do pórtico.

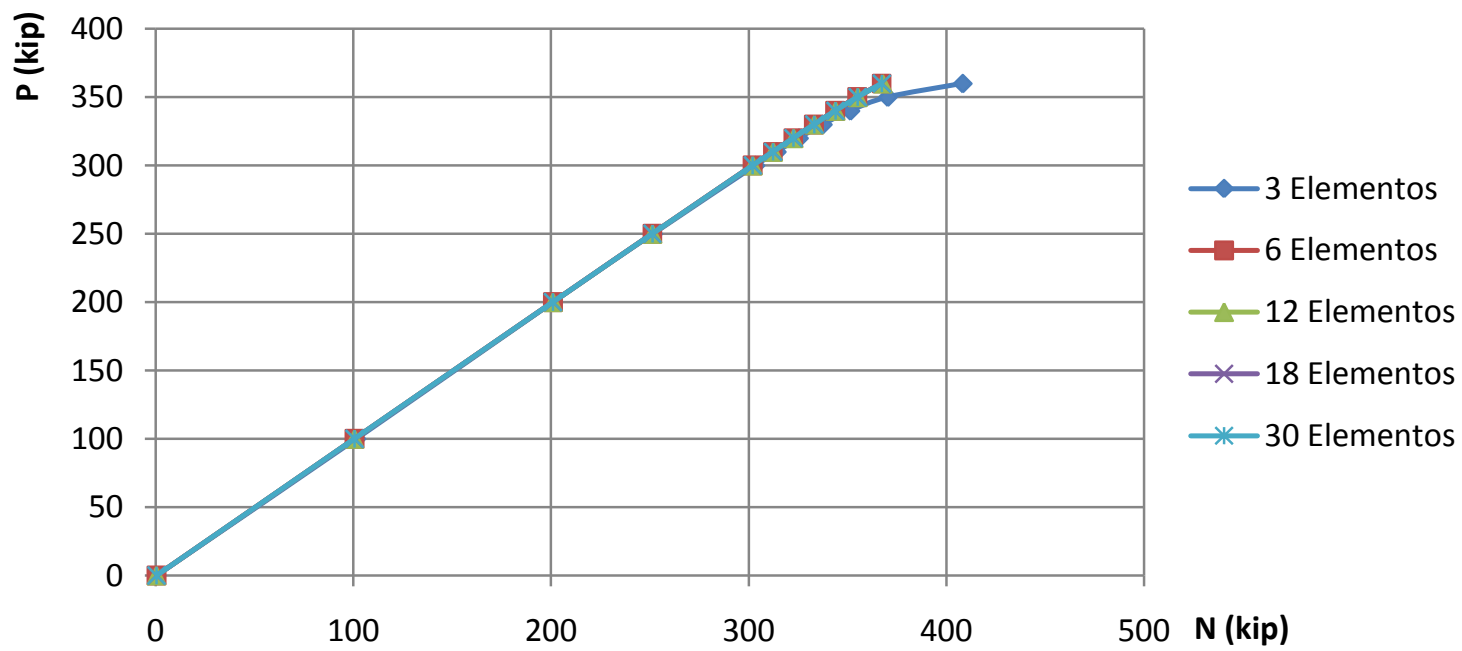

Figura 4.5: Força vertical versus Normal na barra vertical á direita. 


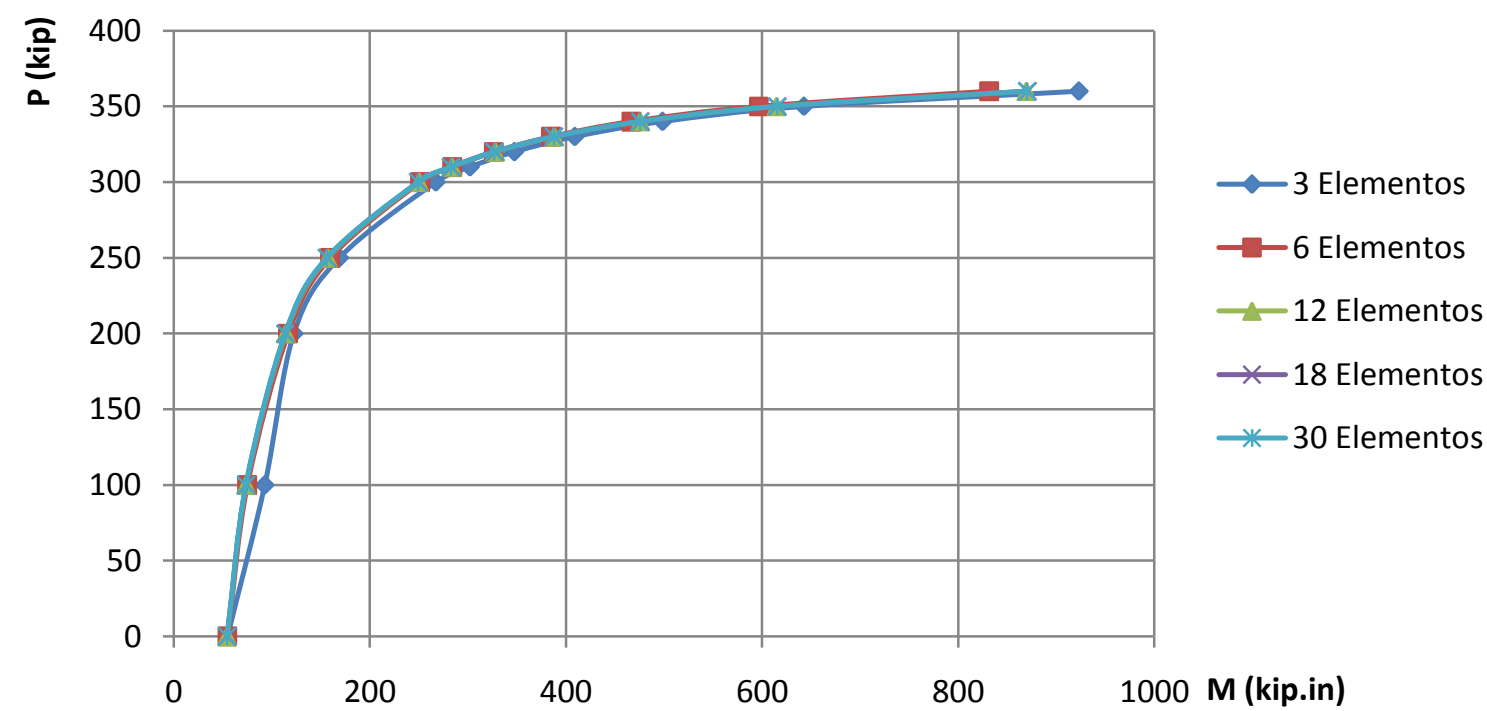

Figura 4.6: Força vertical versus momento fletor na barra vertical á direita.

Para os deslocamentos, as análises realizadas com número de elementos maior que 12 , apresentaram resultados praticamente iguais. O valor da carga última não sofreu influência da discretização. O esforço normal apresentou pequena diferença apenas na discretização mais pobre e próximo á carga última. Em relação ao momento, o número de elementos usados na discretização mostrou influência um pouco maior, embora tenha sido notada apenas para cargas próximas á carga última da estrutura.

Em geral a discretização mostrou pouca influência no comportamento da estrutura, o que mostra a eficiência da formulação mesmo para discretizações pobres.

\subsection{Barra engastada sujeita a momento na extremidade.}

Para mostrar a eficácia da formulação utilizada na solução da não linearidade geométrica, são apresentados os resultados em deslocamentos de uma viga engastada (figura 4.7), sujeita a um momento em sua extremidade. Para a análise, a viga foi dividida primeiramente em 20 elementos e depois em 10 elementos, sendo que a diferença entre os resultados das duas discretizações é insignificante. Optou-se por mostrar os resultados para a discretização em 10 elementos, que são confrontados com os obtidos por PIMENTA (1986). 


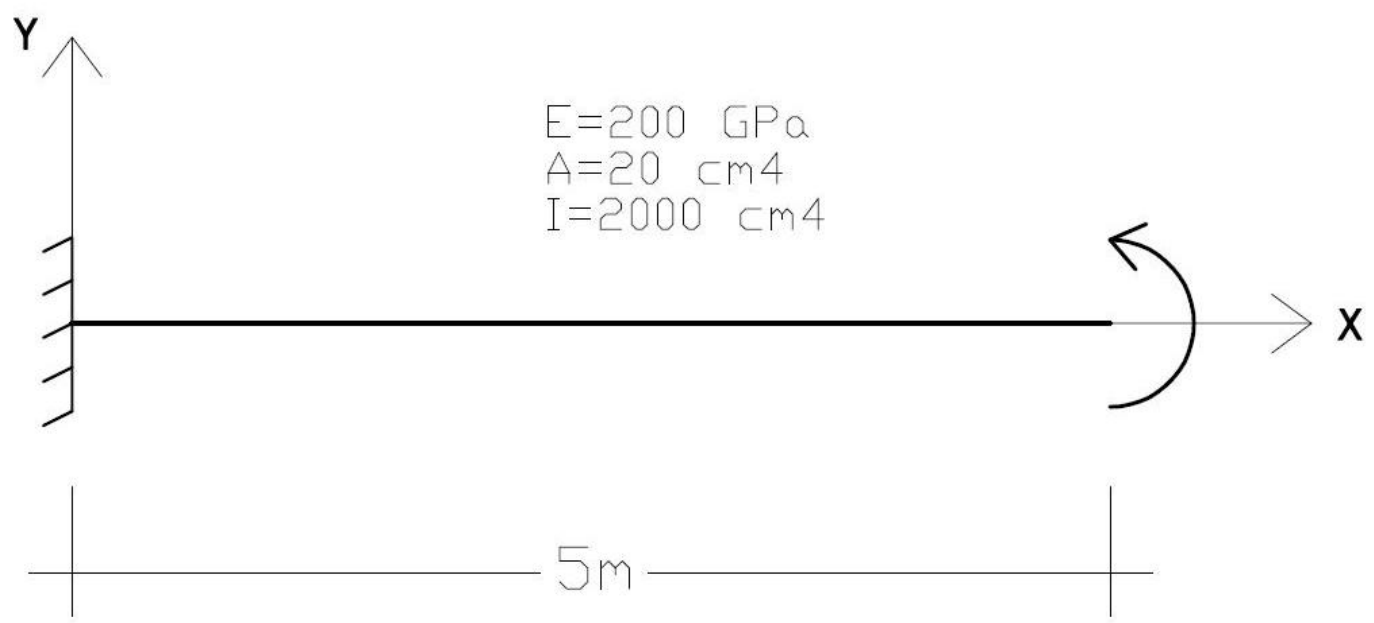

Figura 4.7: Viga engastada sujeita a momento aplicado na extremidade.

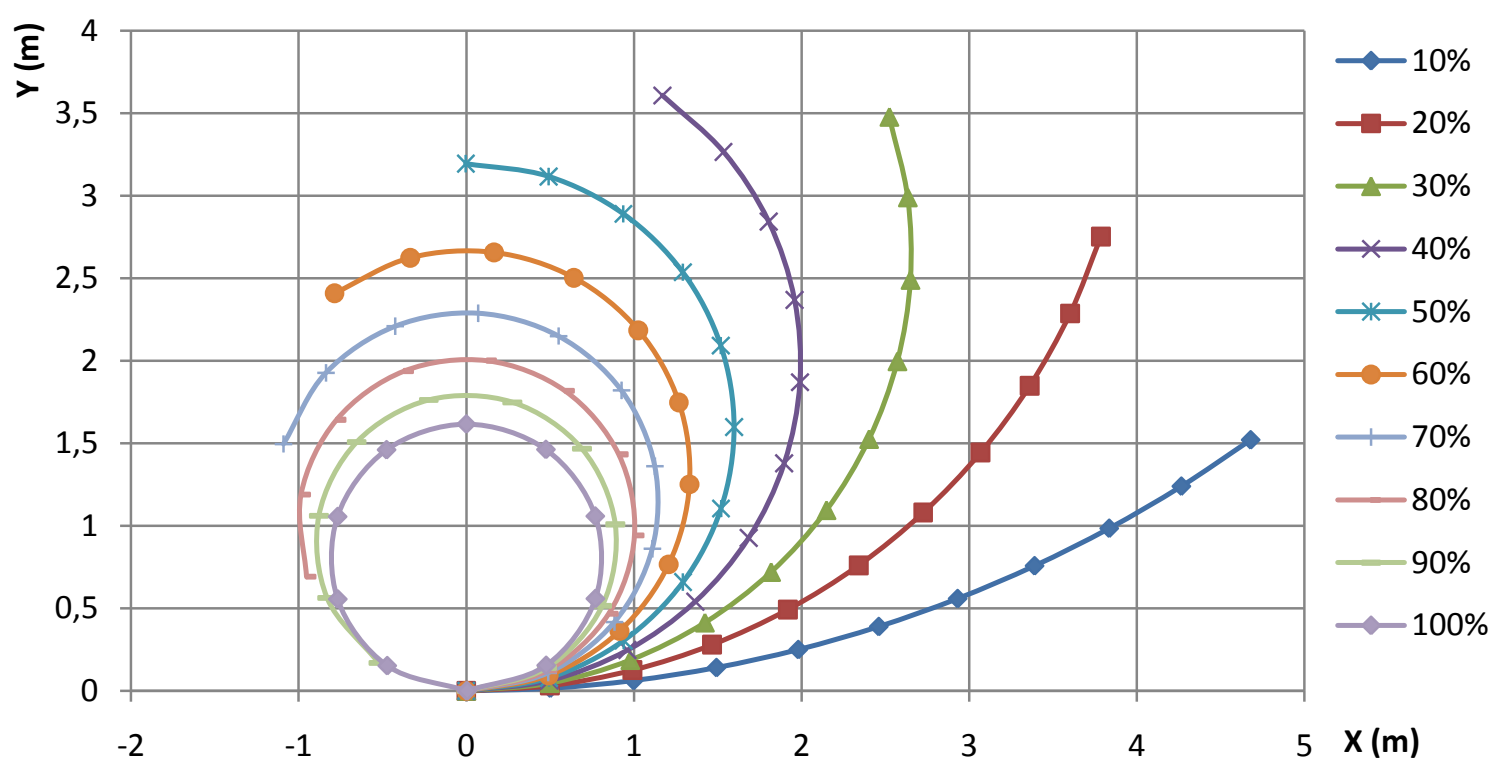

Figura 4.8: Posição dos nós da barra versus carregamento. 
Tabela 4.1 - Coordenadas e rotações do nó extremo da viga engastada.

\begin{tabular}{|c|c|c|c|c|c|c|}
\hline \multicolumn{5}{|c|}{ Coordenadas do extremo da viga } \\
\hline M & \multicolumn{3}{|c|}{ NUC NLGF } & \multicolumn{3}{c|}{ PIMENTA } \\
\hline kN.m & X $(\mathrm{m})$ & $\mathrm{Y}(\mathrm{m})$ & Rot. $(\mathrm{rad})$ & $\mathrm{X}(\mathrm{m})$ & $\mathrm{Y}(\mathrm{m})$ & Rot. (rad) \\
\hline 0,00 & 5,00000 & 0,00000 & 0,00000 & 5,00000 & 0,00000 & 0,00000 \\
\hline 5,00 & 5,00000 & 0,01563 & 0,00625 & 4,99900 & 0,01562 & 0,00625 \\
\hline 14,13 & 5,00000 & 0,04416 & 0,01766 & 4,99900 & 0,04416 & 0,01766 \\
\hline 30,80 & 4,99877 & 0,09624 & 0,03850 & 4,99800 & 0,09622 & 0,03849 \\
\hline 50,00 & 4,99675 & 0,15620 & 0,06250 & 4,99600 & 0,15620 & 0,06250 \\
\hline 502,65 & 4,67840 & 1,52000 & 0,62800 & 4,67750 & 1,51620 & 0,62380 \\
\hline 1380,29 & 2,86600 & 3,34900 & 1,72600 & 2,86340 & 3,34408 & 1,72500 \\
\hline 2909,87 & $-0,65800$ & 2,59700 & 3,63700 & $-0,65388$ & 2,58379 & 3,63700 \\
\hline 3674,91 & $-1,09000$ & 1,22200 & 4,59600 & $-1,08080$ & 1,21742 & 4,59400 \\
\hline 4439,45 & $-0,60600$ & 0,23080 & 5,55300 & $-0,60350$ & 0,23194 & 5,54900 \\
\hline 5026,55 & 0,00400 & 0,00002 & 6,28000 & 0,00000 & 0,00000 & 6,28300 \\
\hline
\end{tabular}

Na comparação com os deslocamentos apresentados por PIMENTA (1986), que utiliza uma formulação para grandes deslocamentos e rotações, os deslocamentos obtidos com a formulação empregada neste trabalho apresentam boa representatividade.

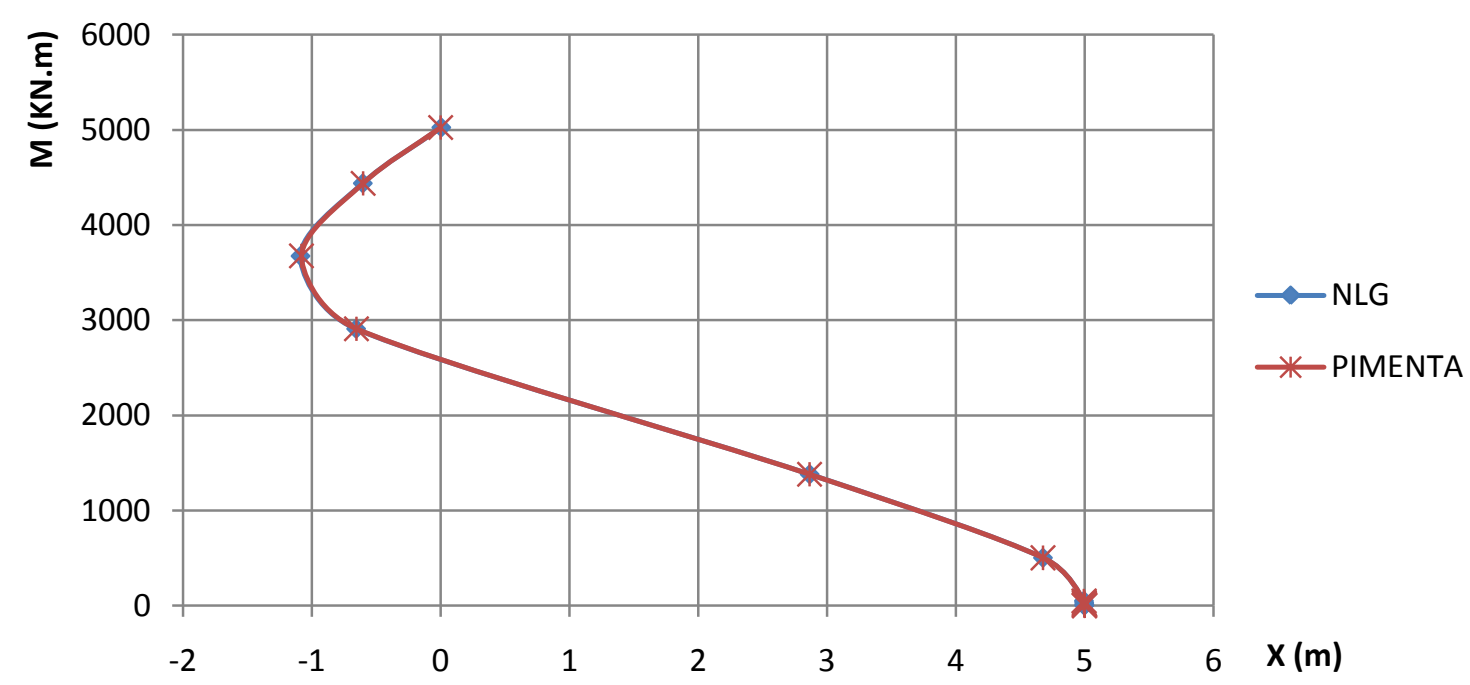

Figura 4.9: Deslocamento horizontal do nó extremo da barra versus carregamento. 


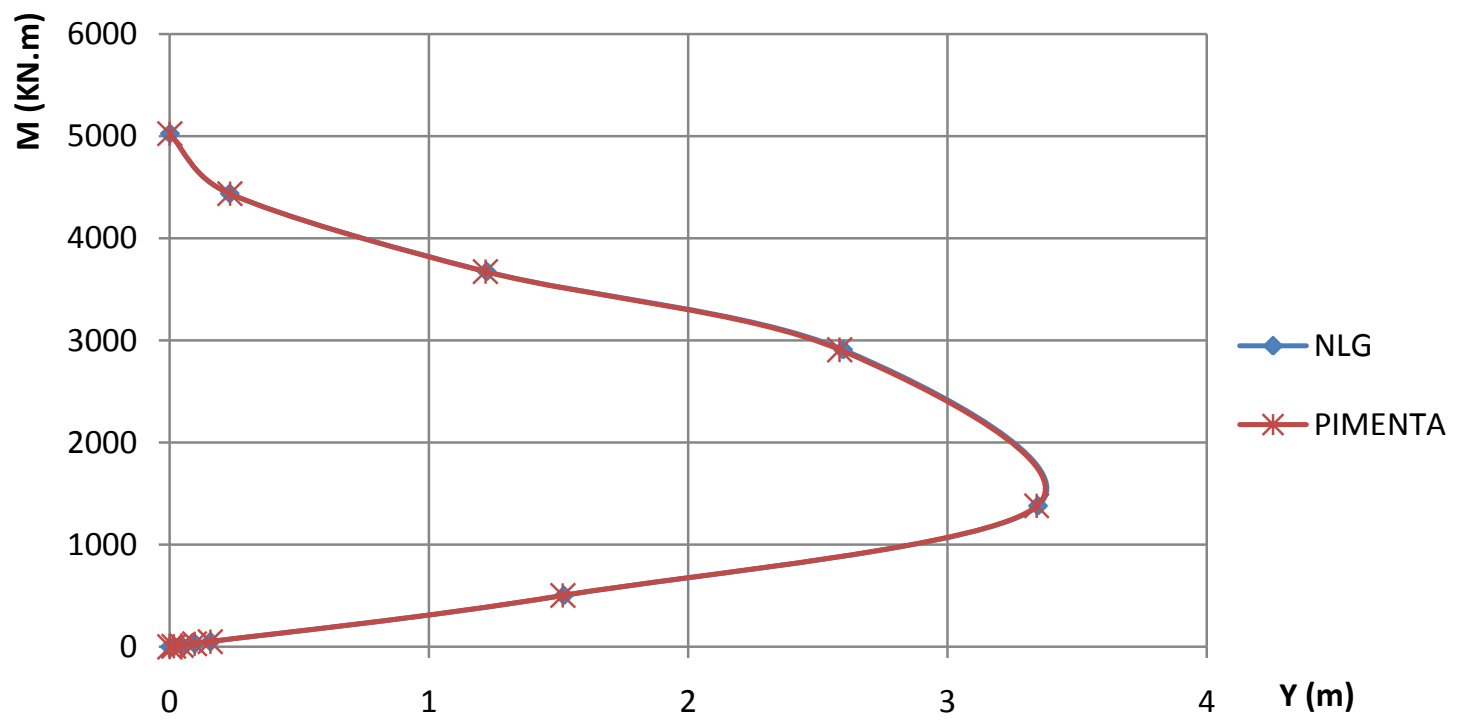

Figura 4.10: Deslocamento vertical do nó extremo da barra versus carregamento.

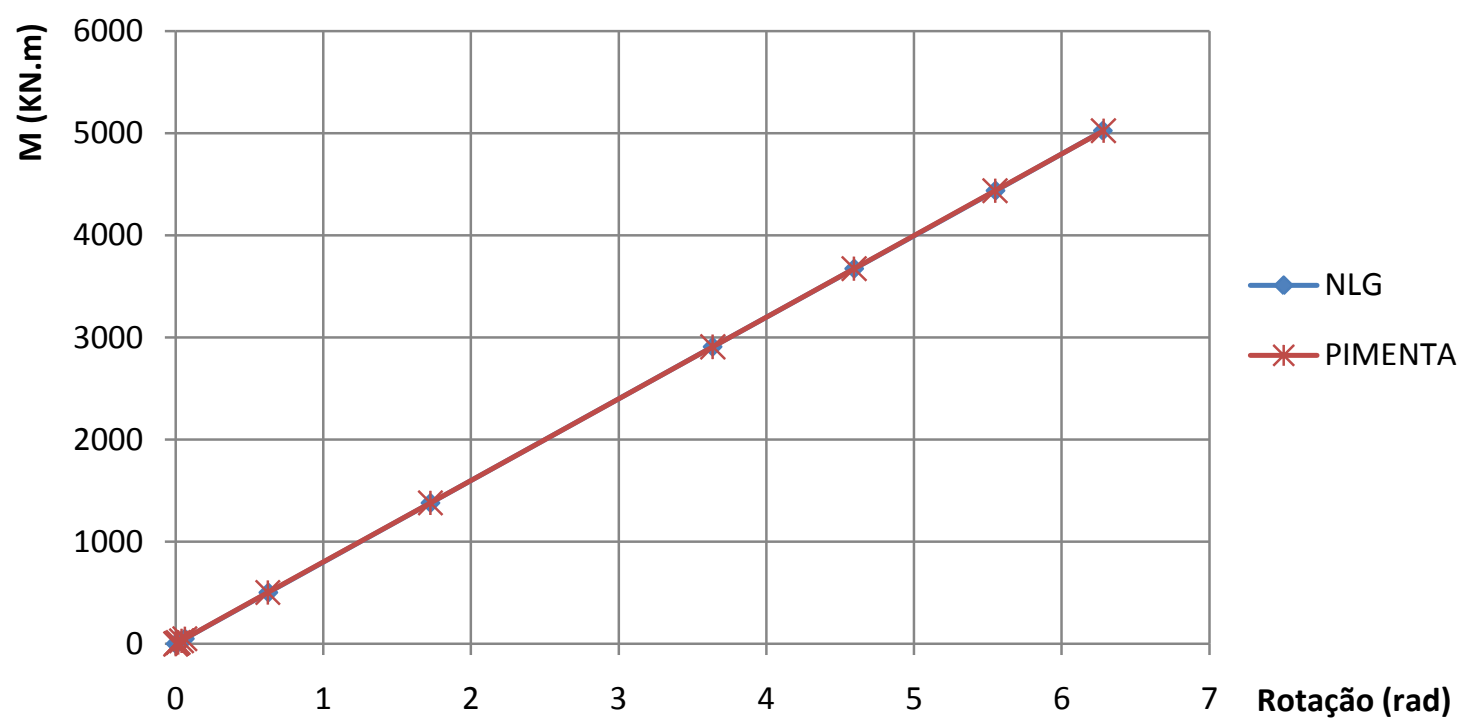

Figura 4.11: Rotação do nó extremo da barra versus carregamento.

$\mathrm{Na}$ análise dos deslocamentos do nó extremo da viga, a representatividade dos resultados é observada mais uma vez, pois são praticamente iguais aos apresentados por PIMENA (1986) 


\subsection{Edifício proposto por SILVA (1989).}

A seguir são apresentados os resultados de deslocamentos para a estrutura proposta por SILVA (1989). São mostrados os resultados de análises lineares e não lineares realizadas nos trabalhos de SILVA (1989), MATIAS (1997), PEREIRA (2000) e MARTINS (2001). Todos os pavimentos são iguais em planta conforme a figura 4.12, tendo as seguintes características:

Pé direito dos andares: $H=400 \mathrm{~cm}$

Número de pavimentos: $N=15$

Módulo de elasticidade: $2000 \mathrm{kN} / \mathrm{cm}^{2}$

Módulo de elasticidade transversal: $800 \mathrm{kN} / \mathrm{cm}^{2}$

Coeficiente de Poisson: $v=0.2$

Dimensões do pilares: $25 \mathrm{~cm}$ x $50 \mathrm{~cm}$

Dimensões das vigas: $20 \mathrm{~cm}$ x $60 \mathrm{~cm}$

Espessura das paredes do núcleo: $t=15 \mathrm{~cm}$

Para o último pavimento os carregamentos são os seguintes:

Carregamento vertical distribuído nas vigas: $Q=10 \mathrm{kN} / \mathrm{m}$

Cargas verticais aplicadas nos pontos 1, 2, 3 e 4 na seção transversal do núcleo:

Ponto1: $P=35 k N$

Ponto2: $P=90 \mathrm{kN}$

Ponto3: $P=90 k N$

Ponto4: $P=35 k N$

Ação do vento concentrada no último pavimento: $F_{Z}=25 \mathrm{kN}$

Para os demais pavimentos os carregamentos são os seguintes:

Carregamento vertical distribuído nas vigas: $Q=20 \mathrm{kN} / \mathrm{m}$

Cargas verticais aplicadas nos pontos 1, 2, 3 e 4 na seção transversal do núcleo:

Ponto 1: $P=70 \mathrm{kN}$

Ponto 2: $P=180 k N$ 
Ponto 3: $P=180 \mathrm{kN}$

Ponto 4: $P=70 \mathrm{kN}$

Ação do vento concentrada nos pavimentos: $F_{Z}=51 \mathrm{kN}$

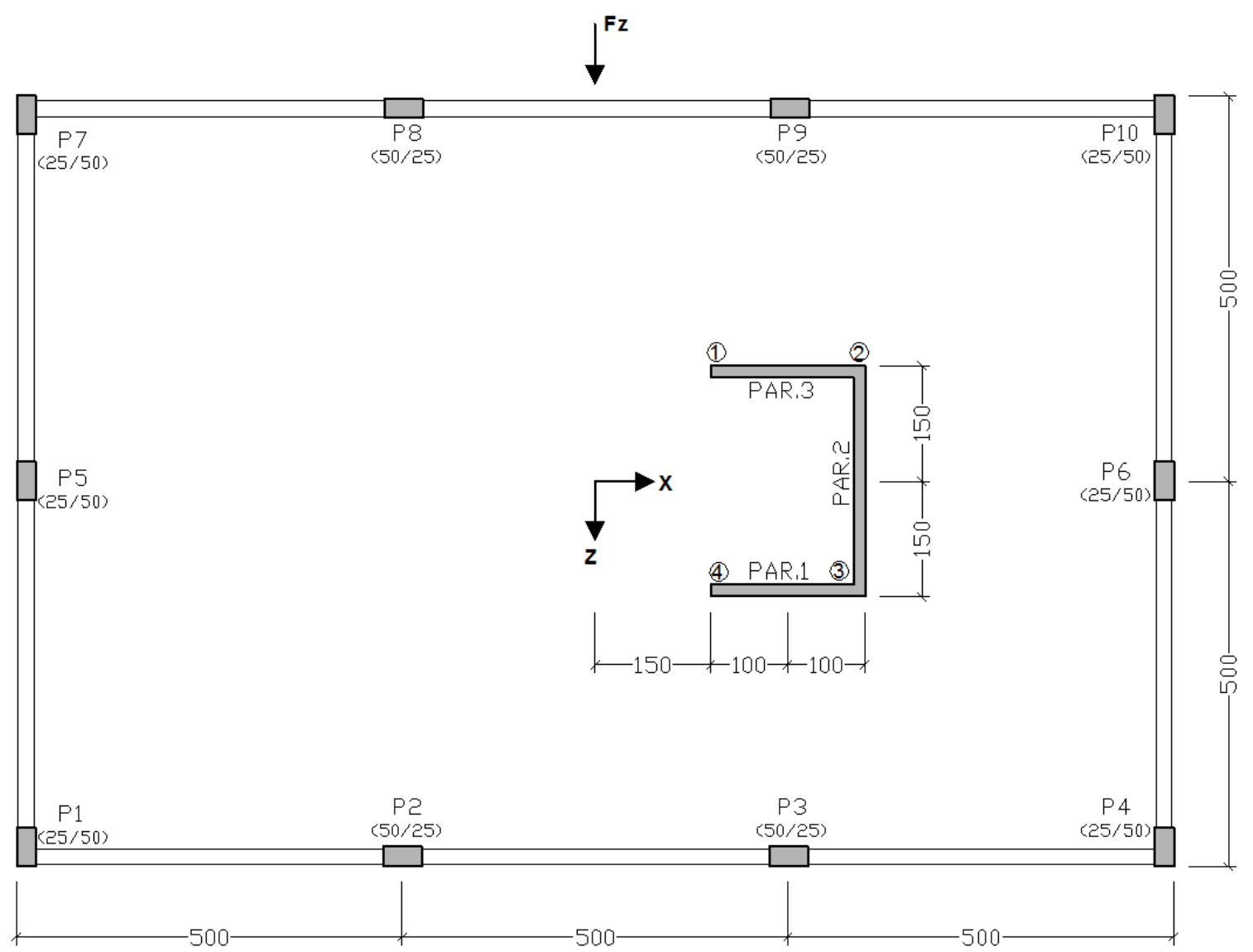

Figura 4.12: Planta de formas do edifício proposto por SILVA (1989).

Os deslocamentos na direção Z obtidos através de análises lineares são apresentados em centímetros na tabela 4.2: 
Tabela 4.2 - Deslocamentos dos pavimentos na direção Z.

\begin{tabular}{|c|c|c|c|c|c|}
\hline Pavimento & PEREIRA & SILVA & MATIAS & MARTINS & NUC NLGF \\
\hline 1 & 0,51 & 0,59 & 0,51 & 0,50 & 0,55 \\
\hline 2 & 1,47 & 1,64 & 1,49 & 1,48 & 1,60 \\
\hline 3 & 2,60 & 2,90 & 2,68 & 2,63 & 2,86 \\
\hline 4 & 3,83 & 4,27 & 4,00 & 3,95 & 4,25 \\
\hline 5 & 5,11 & 5,72 & 5,41 & 5,35 & 5,72 \\
\hline 6 & 6,40 & 7,19 & 6,85 & 6,78 & 7,21 \\
\hline 7 & 7,66 & 8,65 & 8,30 & 8,23 & 8,72 \\
\hline 8 & 8,88 & 10,09 & 9,37 & 9,65 & 10,19 \\
\hline 9 & 10,04 & 11,49 & 11,12 & 11,04 & 11,63 \\
\hline 10 & 11,12 & 12,81 & 12,44 & 12,36 & 13,00 \\
\hline 11 & 12,12 & 14,07 & 13,70 & 13,62 & 14,31 \\
\hline 12 & 13,04 & 15,25 & 14,89 & 14,81 & 15,54 \\
\hline 13 & 13,87 & 16,36 & 16,00 & 15,93 & 16,70 \\
\hline 14 & 14,63 & 17,39 & 17,05 & 16,98 & 17,79 \\
\hline 15 & 15,34 & 18,36 & 18,05 & 17,98 & 18,82 \\
\hline
\end{tabular}

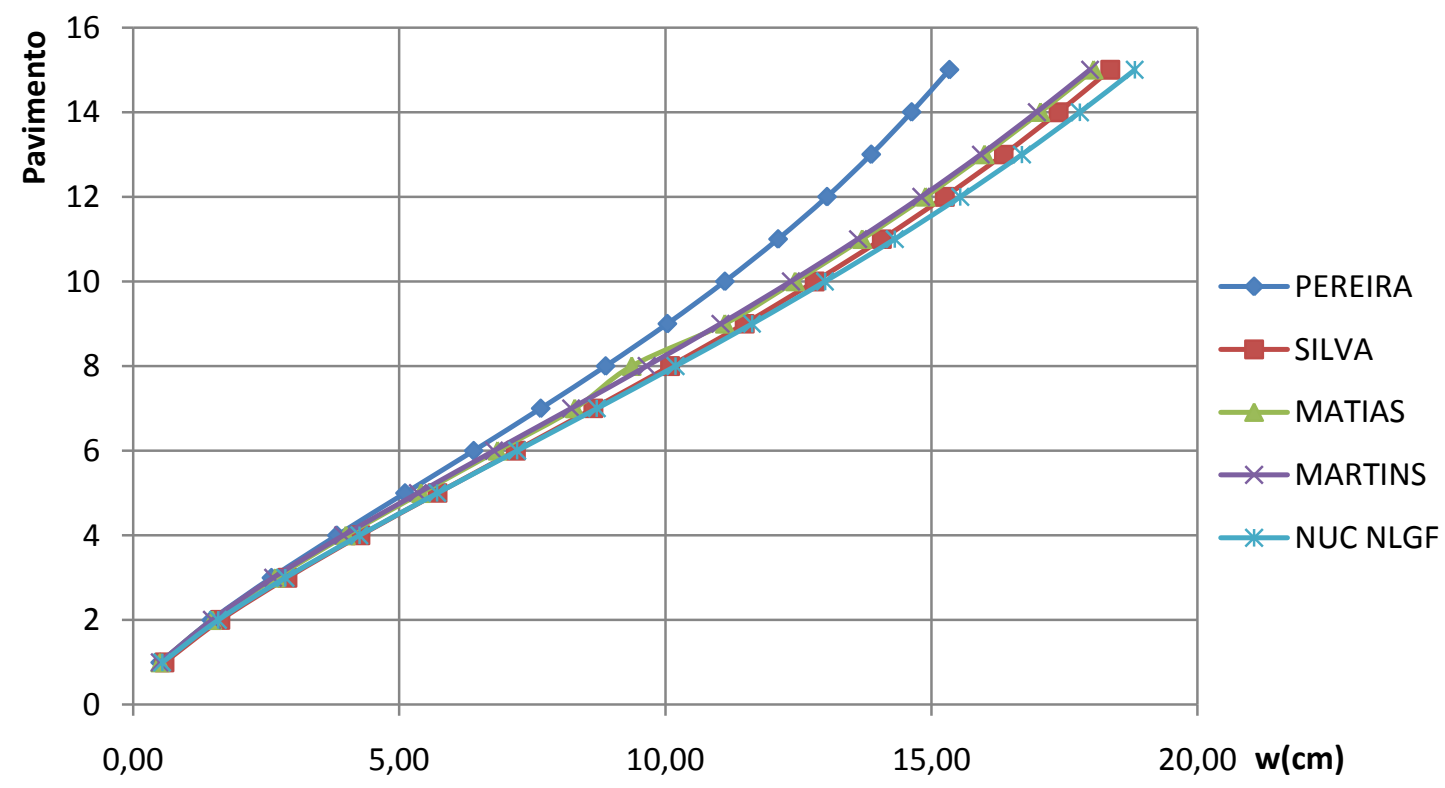

Figura 4.13: Deslocamentos dos pavimentos na direção Z. 
Os deslocamentos obtidos com o código desenvolvido neste trabalho são ligeiramente maiores que os obtidos pelas referências, isto decorre do fato de que na presente modelagem foi desprezada a rigidez á torção dos elementos verticais, o que é bastante razoável na análise de estruturas pertencentes a edifícios, sendo os momentos torçores aplicados pelas ações do vento absorvidas pelos binários providos pela estrutura de contraventamento. Nos demais trabalhos a rigidez á torção dos elementos verticais é considerada.

Os deslocamentos na direção $\mathrm{Z}$ obtidos através de análises não lineares geométricas são apresentados em centímetros na tabela 4.3:

Tabela 4.3 - Deslocamentos dos pavimentos na direção Z.

\begin{tabular}{|c|c|c|c|c|c|}
\hline Pavimento & PEREIRA & SILVA & MATIAS & MARTINS & NUC NLGF \\
\hline 1 & 0,54 & 0,64 & 0,55 & 0,54 & 0,60 \\
\hline 2 & 1,55 & 1,79 & 1,60 & 1,60 & 1,77 \\
\hline 3 & 2,74 & 3,17 & 2,88 & 2,90 & 3,18 \\
\hline 4 & 4,02 & 4,68 & 4,31 & 4,36 & 4,73 \\
\hline 5 & 5,35 & 6,26 & 5,82 & 5,90 & 6,37 \\
\hline 6 & 6,68 & 7,88 & 7,37 & 7,49 & 8,04 \\
\hline 7 & 7,97 & 9,48 & 8,93 & 9,08 & 9,71 \\
\hline 8 & 9,21 & 11,06 & 10,46 & 10,66 & 11,35 \\
\hline 9 & 10,39 & 12,57 & 11,95 & 12,11 & 12,94 \\
\hline 10 & 11,48 & 14,02 & 13,37 & 13,64 & 14,46 \\
\hline 11 & 12,48 & 15,39 & 14,72 & 15,03 & 15,91 \\
\hline 12 & 13,39 & 16,67 & 15,99 & 16,34 & 17,27 \\
\hline 13 & 14,21 & 17,87 & 17,18 & 17,57 & 18,55 \\
\hline 14 & 14,94 & 18,98 & 18,30 & 18,72 & 19,75 \\
\hline 15 & 15,63 & 20,04 & 19,37 & 19,82 & 20,89 \\
\hline
\end{tabular}




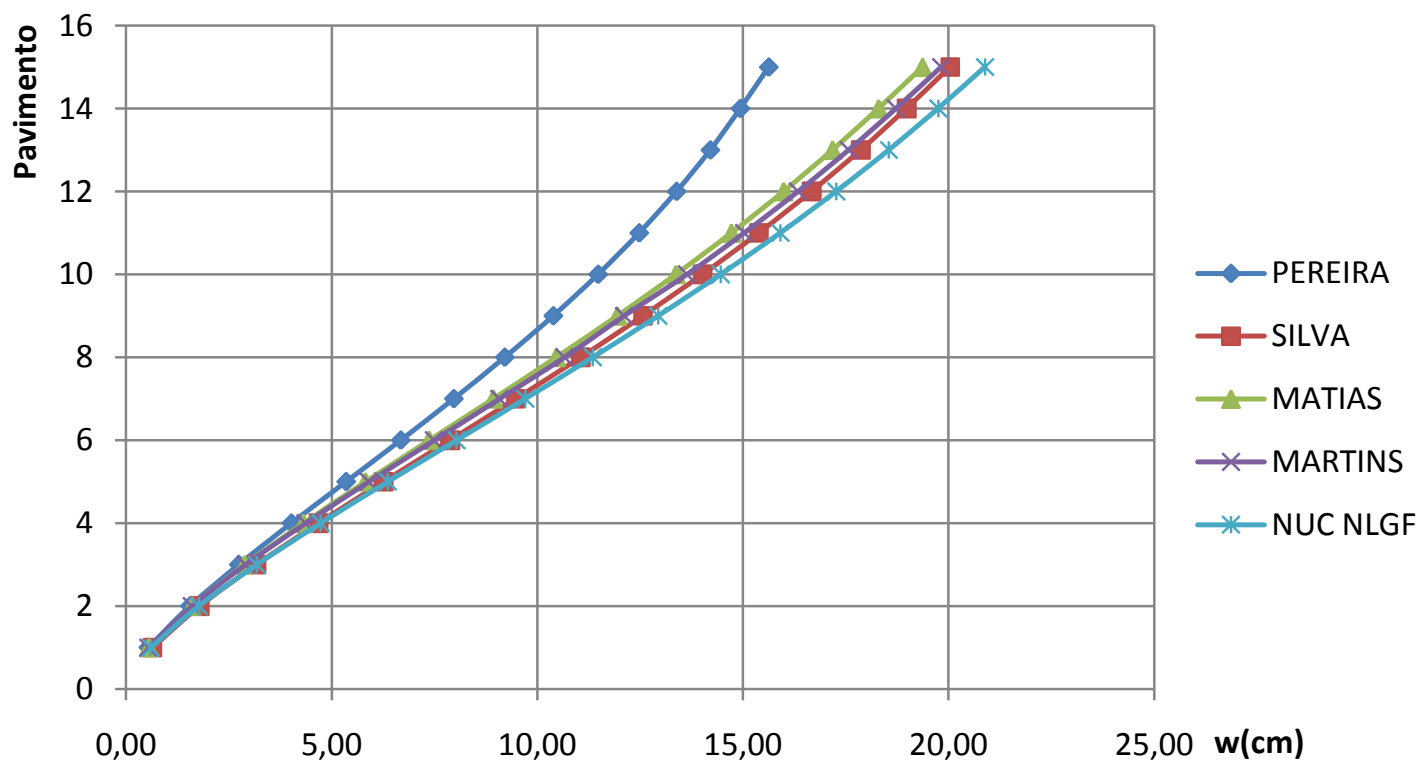

Figura 4.14: Deslocamentos dos pavimentos na direção Z.

$\mathrm{Na}$ análise não linear geométrica também são observados valores de deslocamentos ligeiramente maiores que os de referência. Provavelmente pela não consideração da rigidez á torção dos elementos verticais.

A formulação adotada para o tratamento da não linearidade geométrica é bastante consolidada e amplamente usada por vários outros autores do SET/EESC/USP. A boa representatividade dos deslocamentos obtidos através da formulação empregada pode ser observada nos exemplos ao longo deste capítulo.

A estratégia de solução do sistema não linear adotado foi o secante, com atualização da matriz de rigidez da estrutura a cada iteração. O controle da convergência é feito em forças e deslocamentos. Do ponto de vista computacional, a formulação apresenta excelente desempenho, mesmo para os exemplos com maior nível de não linearidade, bastaram algumas poucas iterações para a convergência dos deslocamentos e forças. 


\section{Capítulo 5 - Não linearidade física}

O tratamento da não linearidade física será feito através do método das fatias, o qual permite a aplicação de modelos constitutivos independendentes para cada material. Este método consiste na divisão da seção transversal do elemento em fatias de aço e concreto, paralelas à linha neutra, de tal forma que o somatório das contribuições de cada camada expresse o comportamento da seção. Tal procedimento possibilita a utilização de um modelo constitutivo independente para cada camada. Obviamente as relações suportadas para esse tratamento são uniaxiais, uma vez que ao longo da largura do elemento as propriedades físicas são consideradas constantes.

A integração ao longo da seção transversal será feita nas extremidades de cada elemento, através do somatório discreto das propriedades de cada camada .

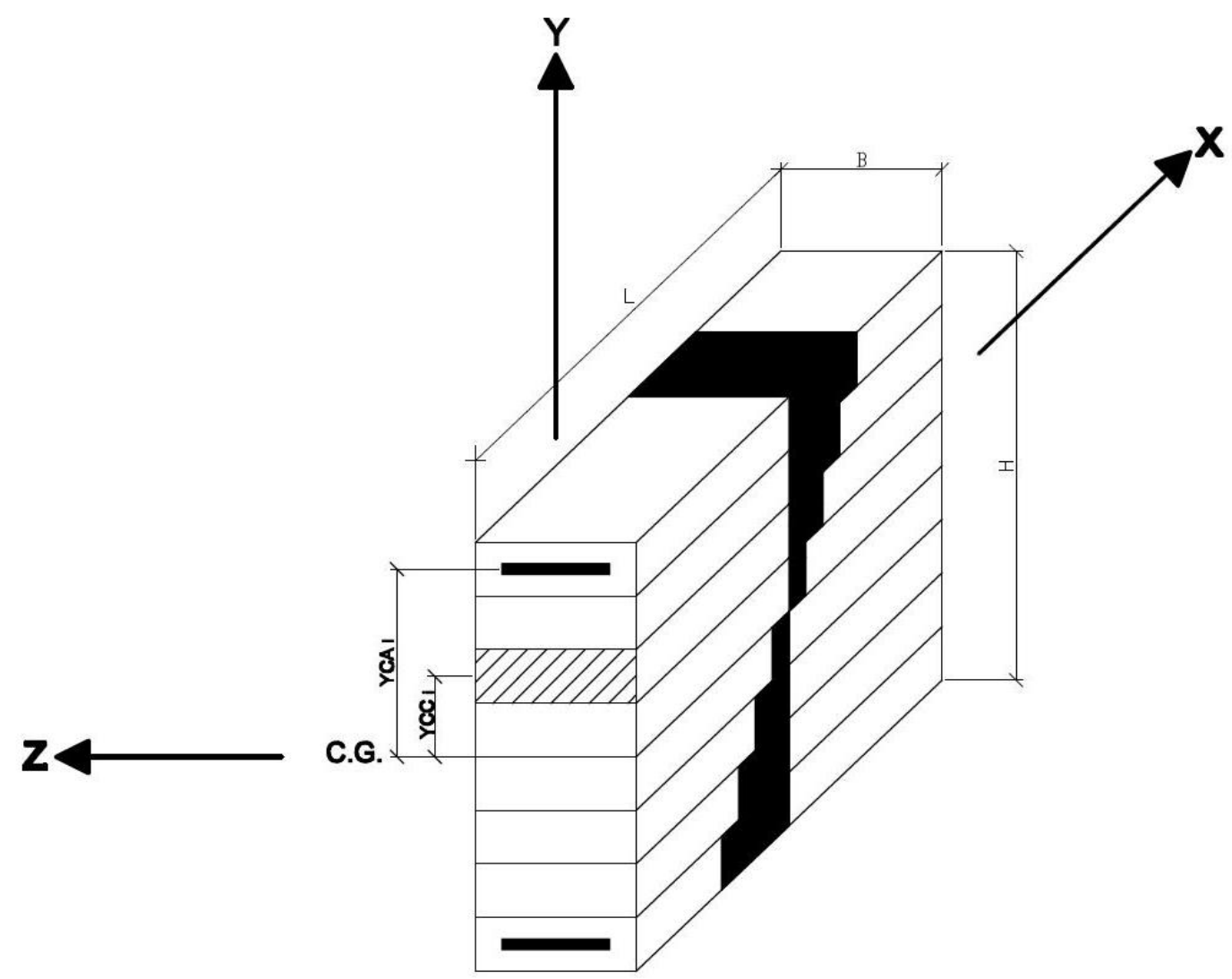

Figura 5.1: Divisão da seção transversal em fatias. 
De acordo com a figura 5.1, as propriedades da seção transversal ( $E A$ e $E I_{Z}$ ), são calculadas através do somatório discreto de cada fatia nos pontos de integração, neste caso, os extremos de cada elemento. Os esforços equilibrados pela seção (Força Normal e Momento Fletor), também são determinados através da soma das contribuições de cada fatia.

As propriedades da seção são dadas pelas seguintes relações:

$E A=\sum E_{i} \cdot A_{i}$

$E I_{z}=\sum E_{i} \cdot I_{z i}$

$E A_{y}=\sum E_{i} \cdot A_{i} \cdot Y_{i}$

$A_{i}=$ Área da fatia $i$

$E_{i}=$ Módulo de elasticidade da fatia $i$

$E A_{y}=$ Momento estático da seção

$I_{z i}=$ Inércia segundo o eixo $\mathrm{z}$ da fatia $i$

$L=$ Comprimento do elemento

Os incrementos de esforços solicitantes na seção são dados por:

$\Delta N=\sum \Delta \sigma_{i} \cdot A_{i}$

$\Delta N=\sum \Delta \varepsilon_{i} \cdot E_{i} \cdot A_{i}$ 
$\Delta M=\sum \Delta \sigma_{i} \cdot A_{i} \cdot y_{i}$

$\Delta M=\sum \Delta \varepsilon_{i} \cdot E_{i} \cdot A_{i} \cdot y_{i}$

Os esforços cortantes são obtidos através do equilíbrrio estático do elemento.

\subsection{Modelos constitutivos dos materiais.}

Para o concreto comprimido o modelo adotado é o proposto por KENT \& PARK (1971).

Esse modelo considera o confinamento promovido pelas armaduras transversais, o que permite que o programa seja usado em casos em que se utilize concreto de alta resistência.

A curva tensão deformação é composta por três trechos, como ilustrado na figura 5.2, assim divididos:

Região AB: O ramo ascendente da curva é representado por uma parábola do segundo grau, cuja forma não é afetada pelo efeito de confinamento. A deformação correspondente à máxima tensão é adotada com $\varepsilon_{0}=0,002$.

$\sigma=f_{c}^{\prime}\left[\frac{2 \epsilon_{c}}{\epsilon_{0}}-\left(\frac{\epsilon_{c}}{\epsilon_{0}}\right)^{2}\right]$

$f^{\prime}{ }_{c}=f c k+3,5(M P a)$

Onde:

$f^{\prime}{ }_{c}$ - Tensão de compressão máxima do concreto;

$\varepsilon_{0}$ - Deformação específica no concreto correspondente à máxima tensão; 
$\varepsilon c-$ Deformação específica no concreto;

$\sigma-$ Tensão no concreto correspondente à deformação $\varepsilon$.

Região BC: O ramo descendente da curva corresponde a uma reta cuja inclinação é definida determinando-se a deformação quando a tensão do concreto reduz-se a 50\% da tensão de pico. Para o concreto sem efeito de confinamento essa deformação é dada por:

$\varepsilon_{50 u}=\frac{3+0,002 \cdot f_{c}^{\prime}}{f_{c}^{\prime}-1000}$

Sendo a tensão $f^{\prime} c$ expressa em libras por polegada quadrada.

Para o concreto confinado por estribos retangulares, a inclinação do ramo descendente é reduzida, sendo relevantes as seguintes variáveis:

$A_{S}^{\prime \prime}$ - Área da seção transversal do estribo;

$s$ - Espaçamento entre os estribos;

$b$ " e d" - Largura e altura dos estribos b" $<\mathrm{d}$ ".

Dessa forma pode-se definir a taxa volumétrica de confinamento por estribos retangulares:

$\rho^{\prime \prime}=\frac{2\left(b^{\prime \prime}+d^{\prime \prime}\right) A s "}{b^{\prime \prime} d^{\prime \prime}}$

A equação do ramo descendente da curva pode ser escrita como:

$\sigma={f^{\prime}}_{c}\left[1-Z\left(\varepsilon_{c}-\varepsilon_{0}\right)\right]$

Sendo:

$Z=\frac{0,5}{\left(\varepsilon_{50 h}+\varepsilon_{50 u}-\varepsilon_{0}\right)}$ 
$\varepsilon_{50 h}=\frac{3}{4} \rho " \sqrt{\frac{\mathrm{b}^{\prime \prime}}{\mathrm{s}}}$

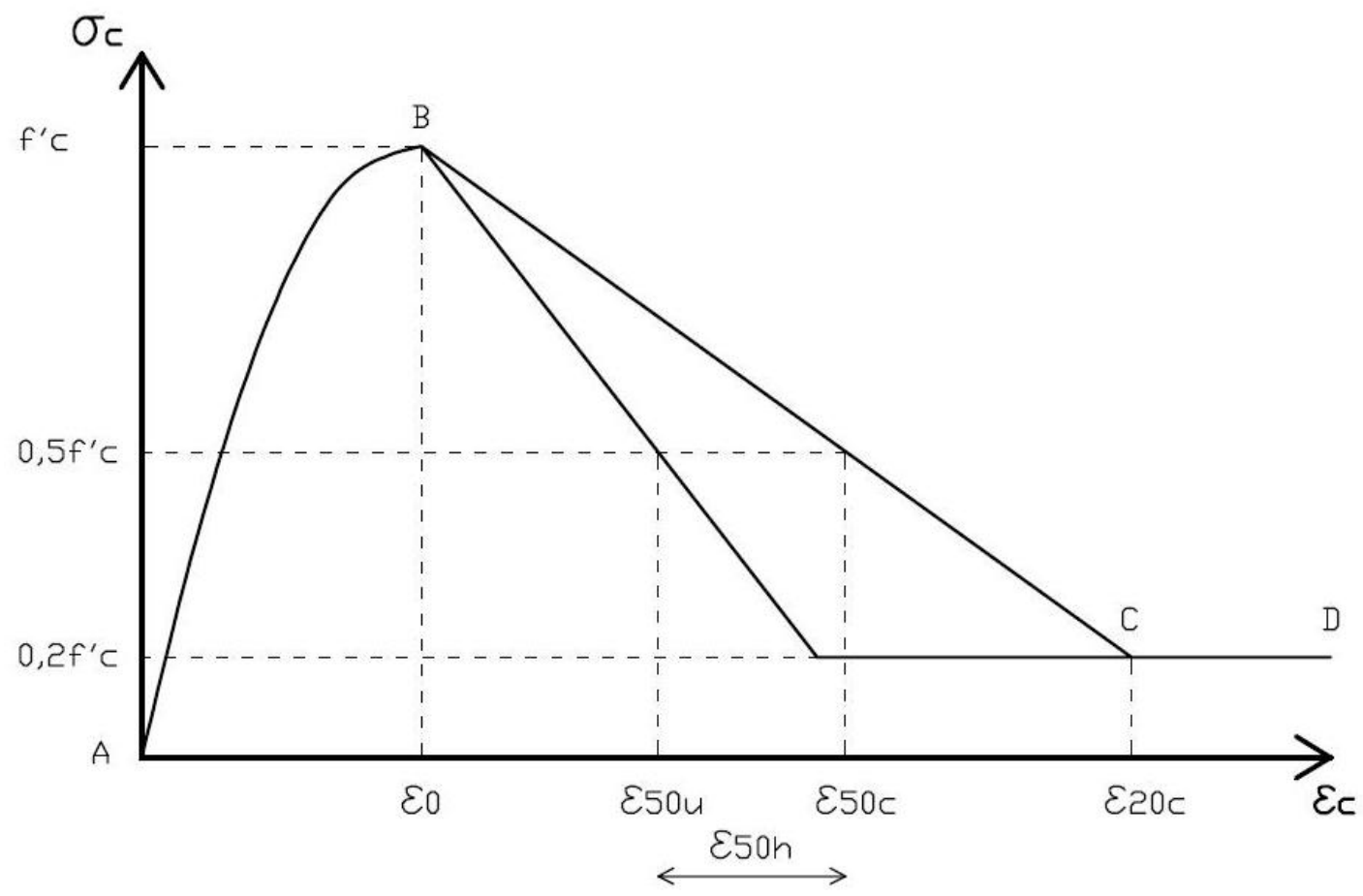

Figura 5.2: Curva Tensão versus Deformação do concreto sob compressão.

Região CD: Admite-se que o concreto mantém uma tensão de $0,2 f^{\prime} c$ indefinidamente.

Para o concreto tracionado, foi adotado o modelo proposto por FIGUEIRAS (1983). Nesse modelo o concreto tracionado se comporta de forma elástico-linear até a abertura da fissura. Depois de atingida a tensão última de tração, em função dos efeitos de aderência, o concreto intacto entre fissuras contribui para o enrijecimento da estrutura como um todo. Este efeito, conhecido como tension stiffening, pode ser considerado de forma indireta pela hipótese de que o concreto, após a fissuração, apresenta uma diminuição gradual na resistência à tração até não ser mais capaz de absorver mais tensões de tração.

Desse modo, pode-se expressar o comportamento do concreto na tração por:

$\sigma=\alpha f^{\prime}{ }_{t}\left(1-\frac{\varepsilon_{1}}{\varepsilon_{\mathrm{m}}}\right) \quad$ Se $\varepsilon_{t} \leq \varepsilon \leq \varepsilon_{m}$ 
$\sigma=\frac{f_{t}}{\varepsilon_{t}} \varepsilon \quad$ Se $\varepsilon \leq \varepsilon_{t}$

Sendo:

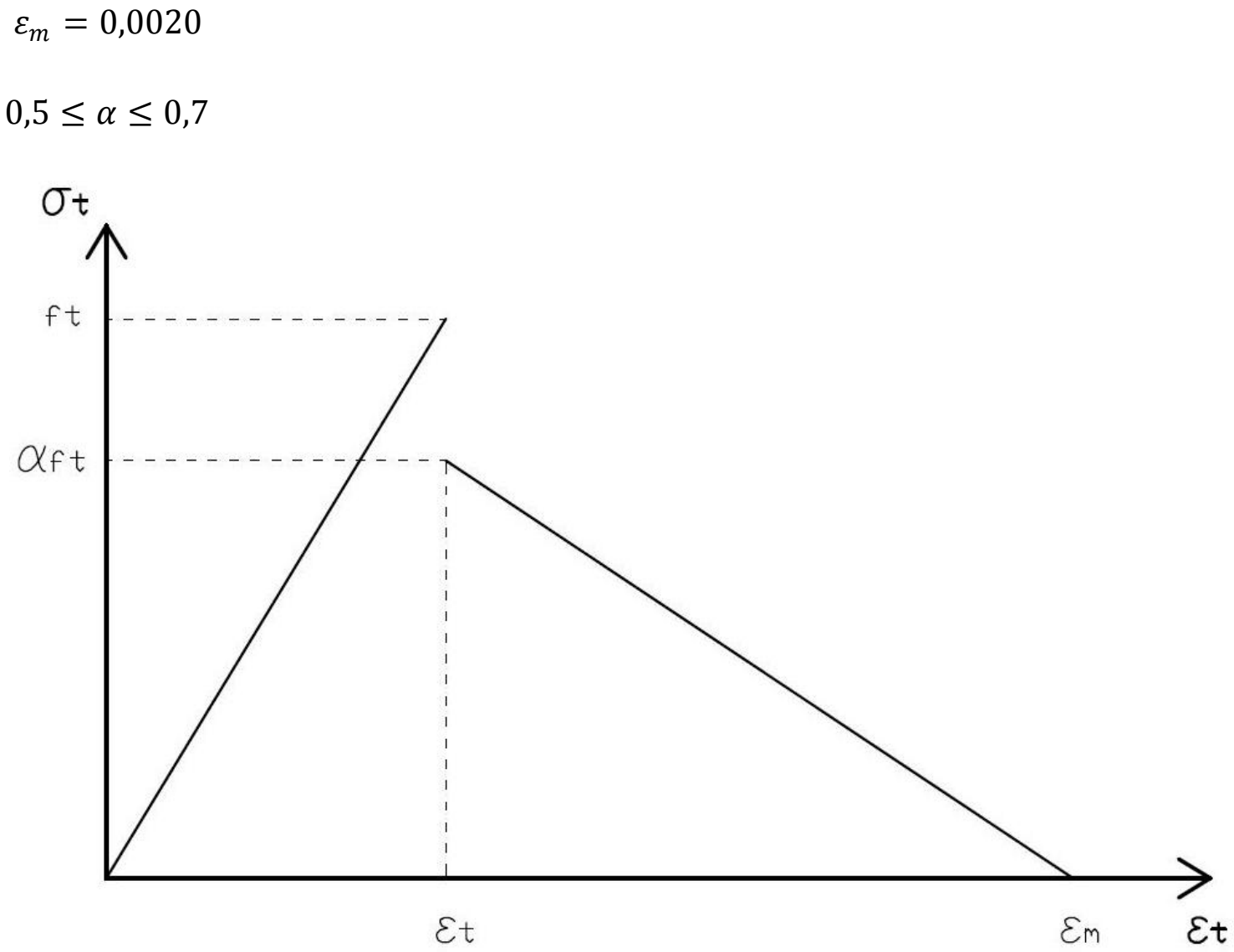

Figura 5.3: Curva Tensão versus Deformação do concreto sob tração.

Para o aço adotou-se um modelo elástico não-linear com a possibilidade de encruamento positivo, conforme diagrama da figura 5.4: 


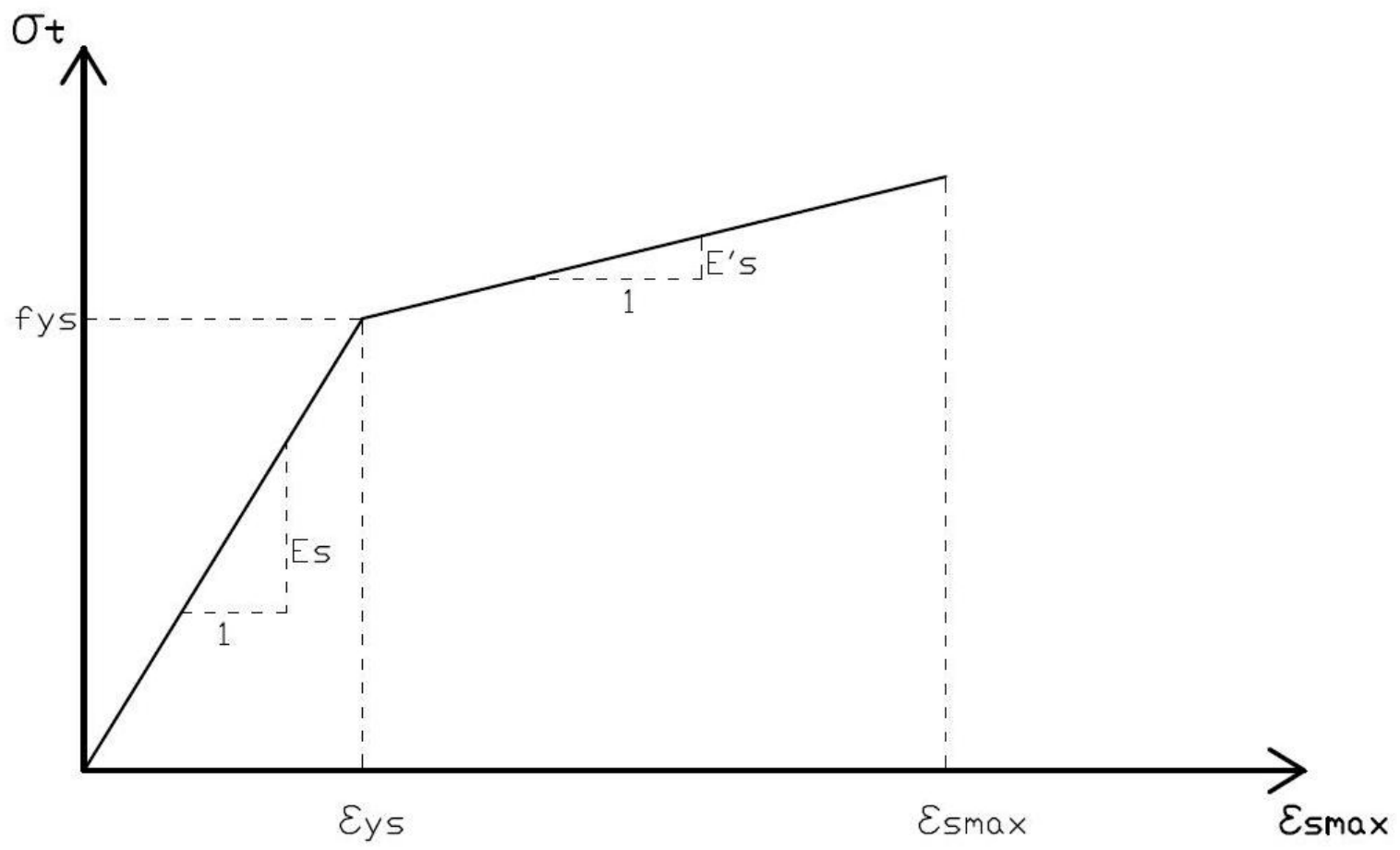

Figura 5.4: Curva Tensão versus Deformação do aço.

onde:

$f_{y s}$ - Tensão de escoamento do aço;

$\varepsilon_{y s}$ - Deformação específica no aço correspondente à tensão de escoamento;

$\varepsilon_{\text {smax }}-$ Deformação específica máxima permitida para o aço $(\varepsilon y u=0,010)$;

$E_{s}-$ Módulo de elasticidade do aço $(\mathrm{Es}=210000 \mathrm{MPa})$

$E_{s}^{\prime}-$ Módulo de elasticidade do aço após o escoamento.

\subsection{Relações entre módulo de elasticidade e deformação.}

A relação entre o módulo de elasticidade e deformação de cada fatia será determinada através da reta secante à curva Tensão versus Deformação no referido intervalo de deformações, o que resulta no módulo de elasticidade secante do material.

A relação $E=f(\varepsilon)$ é obtida a partir do modelo constitutivo de cada material:

$E=\frac{\Delta \sigma}{\Delta \varepsilon}$ 
Uma vez que o módulo de elasticidade é variável com as deformações, isso implica na necessidade de aplicação de incrementos de carga até que se atinja o nível de carregamento desejado. De acordo com os modelos apresentados para o concreto e para o aço, conhecidos os diagramas Tensão versus Deformação, para cada trecho do comportamento do material é possível a determinação do módulo de elasticidade.

Como os passos de carga são sempre crescentes até atingir o carregamento máximo, as deformações tendem sempre a crescer, dispensando assim uma análise do histórico do carregamento. Desta forma, cada valor de deformação corresponde a um único valor de tensão, sendo suficiente a relação entre Módulo de elasticidade e Deformação através da reta secante da curva Tensão versus Deformação do material. Não havendo ciclos de carregamento e descarregamento, a relação unívoca entre deformação e tensão fica atendida.

\subsection{Exemplos de validação.}

Para a validação do código NUC NLGF, em termos de não linearidade física e geométrica acopladas serão usados quatro exemplos. O primeiro deles se refere a um pórtico simples ensaiado por WILBY \& PANDIT (1967) e apresentado tanto por RASHEED \& DINNO (1994) como por PINTO (2002). O segundo trata-se de um pórtico com dois lances estudado por VECHIO \& EMARA (1992) e, posteriormente, por PINTO (2002). O terceiro exemplo é um pórtico simples estudado por SOLER (1995), SILVA (1996), e posteriormente por PAULA (2001).

O quarto exemplo trata-se de um pórtico com 8 pavimentos estudado por CAUVIN (1979), CILONI(1993), SILVA (1996) e posteriormente por PINTO (2002). 


\subsubsection{Pórtico simples com carregamento vertical.}

Neste exemplo, são comparados os resultados apresentados por PINTO (2002) através da ferramenta computacional PPNL, com discretização da estrutura em 12 e 15 elementos, além dos resultados experimentais apresentados por WILBY \& PANDIT (1967). A seção transversal (vide figura 5.6) foi dividida em 10 fatias, a geometria e discretização da estrutura são apresentadas nas figuras 5.5 e 5.7:

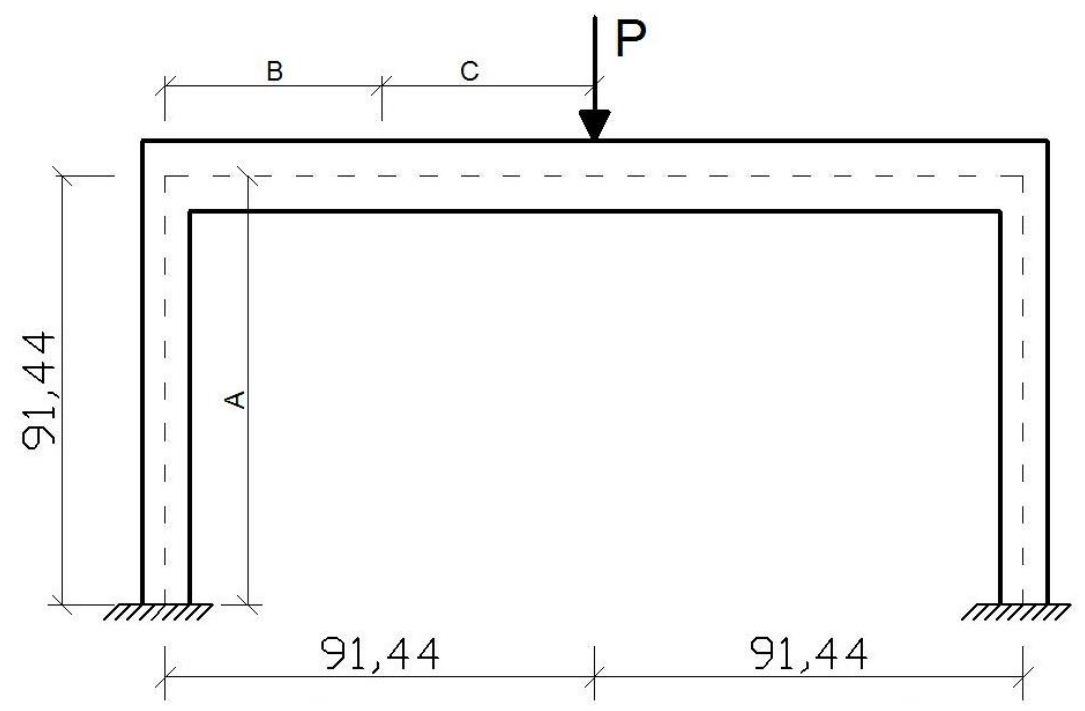

Figura 5.5: Geometria e carregamento do pórtico apresentado por WILBY \& PANDIT (1967).
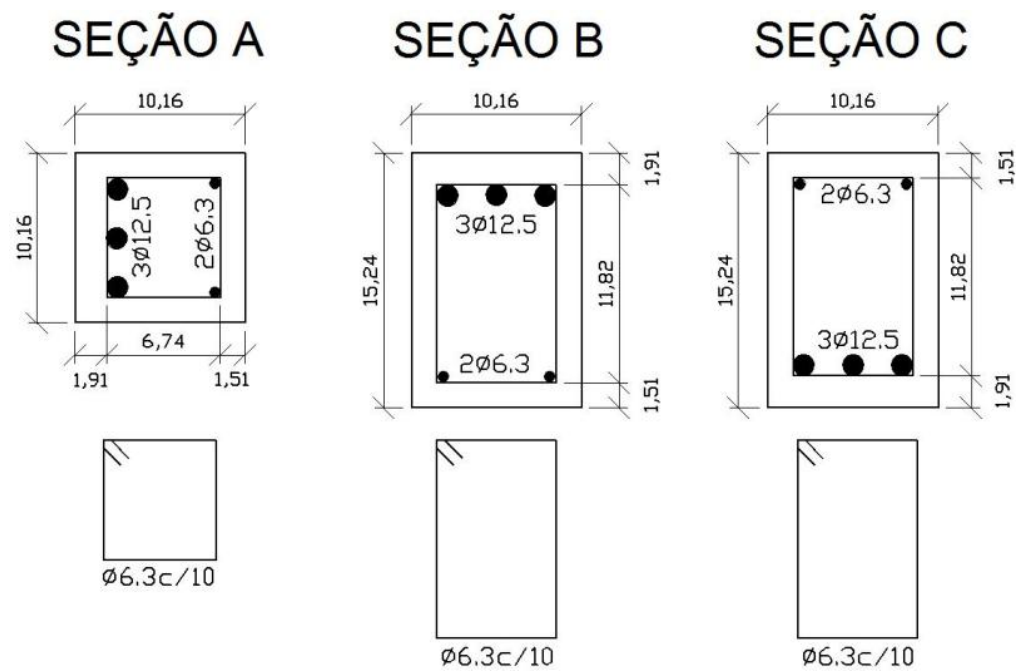

Figura 5.6: Seções transversais das barras do pórtico apresentado por WILBY \& PANDIT (1967). 
Os parâmetros dos materiais empregados são os seguintes:

Tabela 5.1 - Parâmetros físicos dos materiais.

\begin{tabular}{|c|c|c|c|}
\hline \multicolumn{4}{|c|}{ Parâmetros dos materiais } \\
\hline \multicolumn{2}{|c|}{ Concreto } & \multicolumn{2}{c|}{ Aço } \\
\hline$f^{\prime}{ }_{c}$ & $25.9 \mathrm{MPa}$ & $f_{y}$ & $303.6 \mathrm{MPa}$ \\
\hline$f_{t}$ & $2.53 \mathrm{MPa}$ & $\varepsilon_{y}$ & 0.00152 \\
\hline$\varepsilon_{m}$ & 0.00208 & $E_{s}$ & $200000 \mathrm{MPa}$ \\
\hline$\alpha$ & 0.7 & $E_{s}$ & $1000 \mathrm{MPa}$ \\
\hline
\end{tabular}

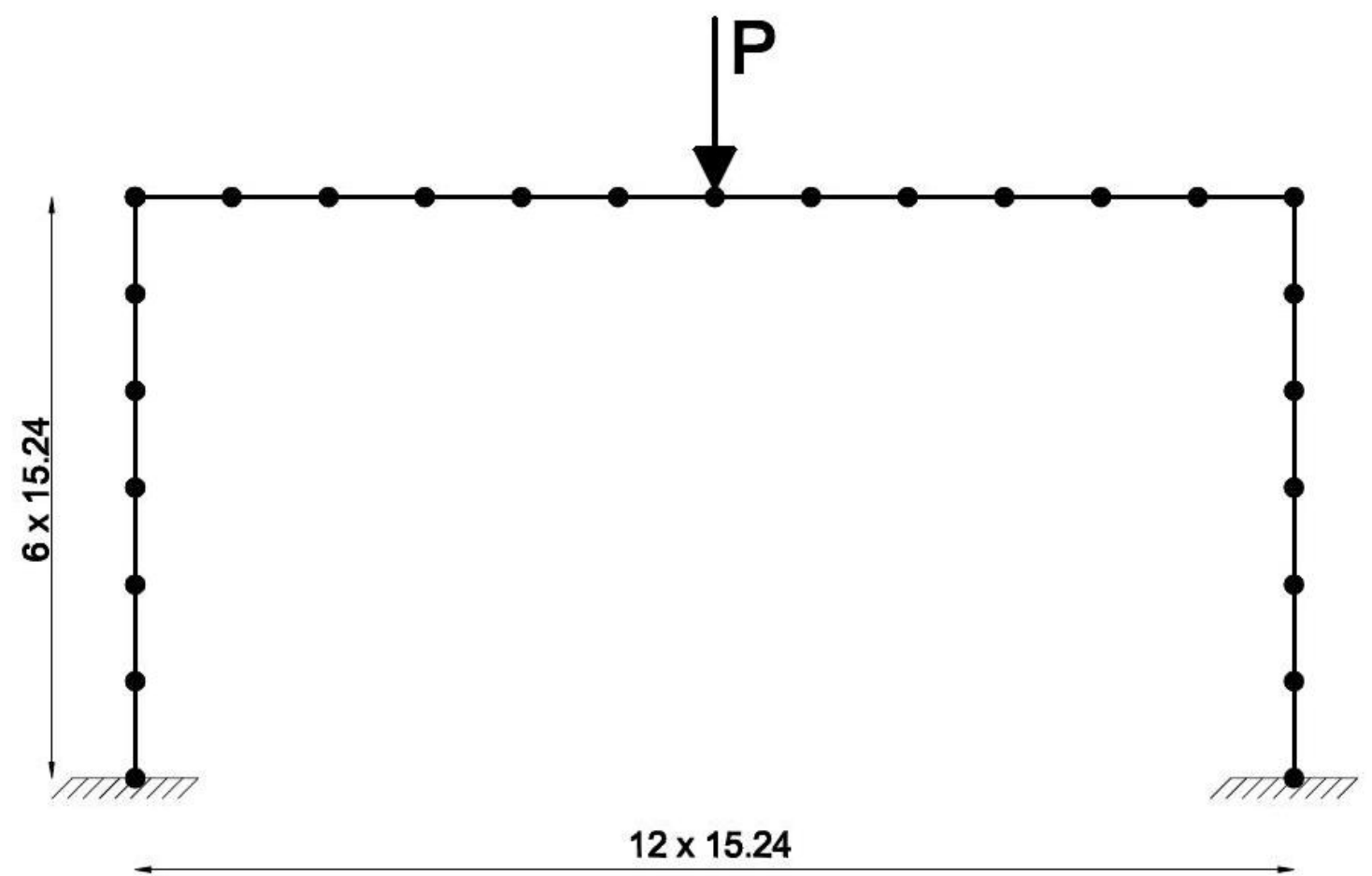

Figura 5.7: Discretização das barras do pórtico apresentado por WILBY \& PANDIT (1967).

Na figura 5.8 são mostradas as curvas força vertical versus deslocamento vertical no ponto de aplicação do carregamento. 


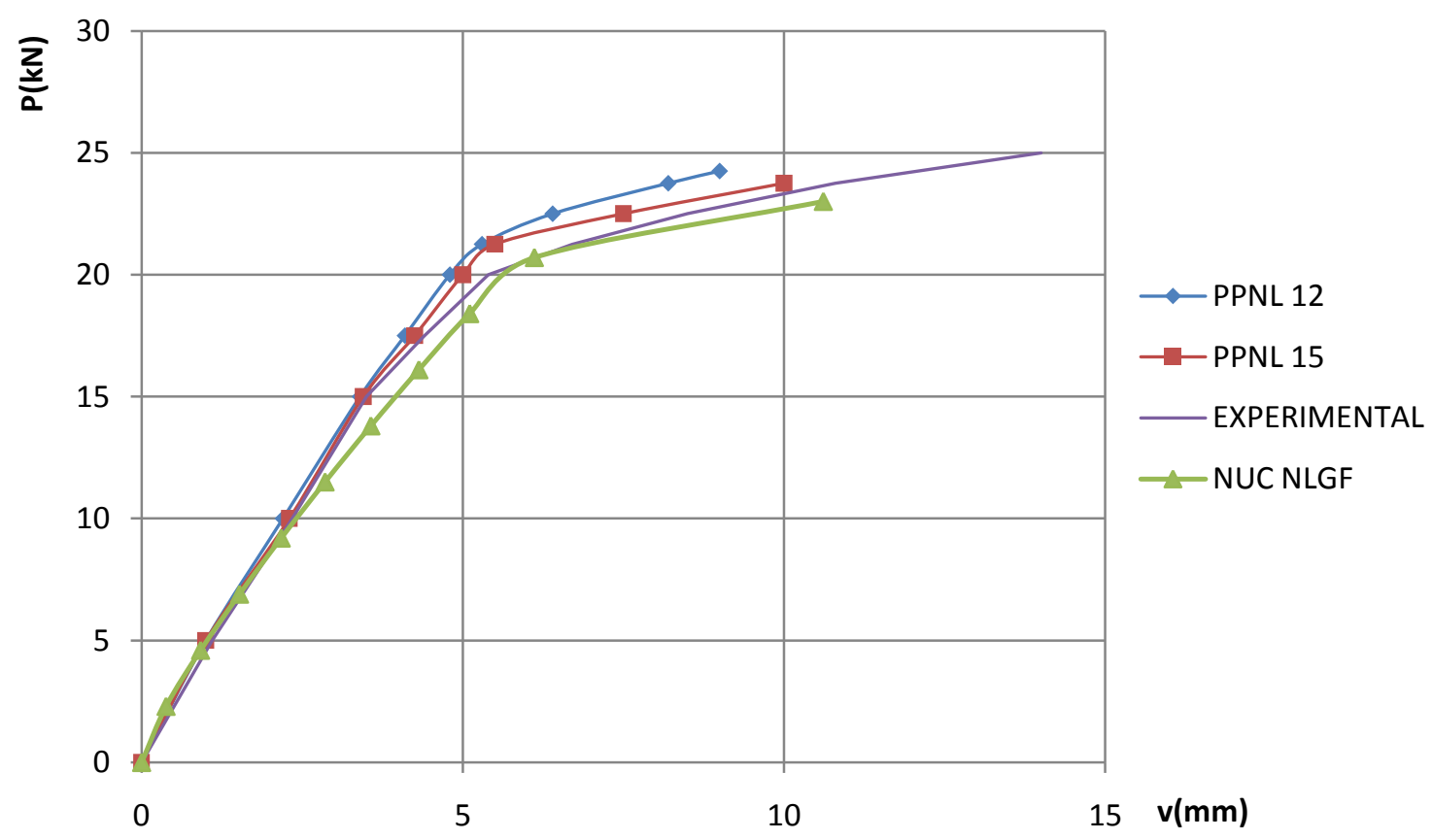

Figura 5.8: Deslocamento vertical versus carregamento aplicado.

Os deslocamentos obtidos com o código desenvolvido neste trabalho apresentam boa representatividade comparados aos das referências. Os pontos de inflexão e a carga máxima resistida pela estrutura estão bem representados. Assim como em PINTO (2002), foram empregados 10 passos de carregamento. Em análises paralelas e que não são mostradas no trabalho, foi investigada a influência do número de passos sobre os resultados. Para este exemplo, um número maior de passos não influiu nos resultados.

\subsubsection{Pórtico com dois lances.}

VECHIO \& EMARA (1992) fizeram uma análise numérica e experimental deste pórtico. Trata-se de um pórtico de concreto armado com dois lances, em que a carga vertical é mantida constante e a carga horizontal é aplicada de forma monotonicamente crescente até a ruptura. PINTO (2002) analisou a mesma estrutura para validação seu modelo numérico, sendo a seção transversal dividida em 10 fatias.

Os parâmetros dos materiais empregados são os seguintes: 
Tabela 5.2 - Parâmetros físicos dos materiais.

\begin{tabular}{|c|c|c|c|}
\hline \multicolumn{4}{|c|}{ Parâmetros dos materiais } \\
\hline \multicolumn{2}{|c|}{ Concreto } & \multicolumn{2}{c|}{ Aço } \\
\hline$f^{\prime}{ }_{c}$ & $30.0 \mathrm{MPa}$ & $f_{y}$ & $418.0 \mathrm{MPa}$ \\
\hline$f_{t}$ & $3.0 \mathrm{MPa}$ & $\varepsilon_{y}$ & 0.00152 \\
\hline$\varepsilon_{m}$ & 0.0018 & $E_{s}$ & $192500 \mathrm{MPa}$ \\
\hline$\alpha$ & 0.7 & $E_{s}{ }^{\prime}$ & $500 \mathrm{MPa}$ \\
\hline
\end{tabular}

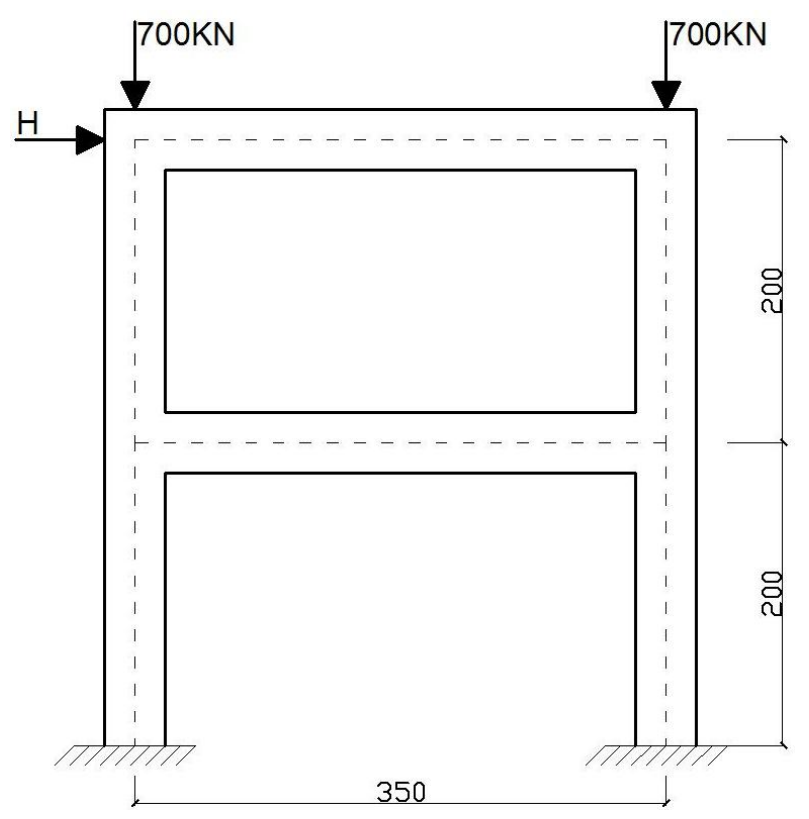

Figura 5.9: Geometria e carregamento do pórtico ensaiado por VECHIO \& EMARA (1992).
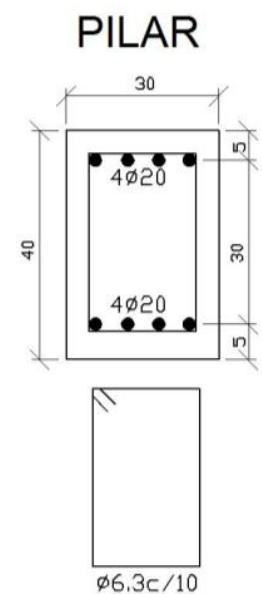

VIGA
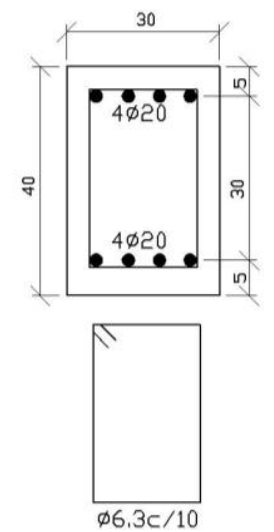

Figura 5.10: Seções transversais das barras do pórtico ensaiado por VECHIO \& EMARA (1992). 


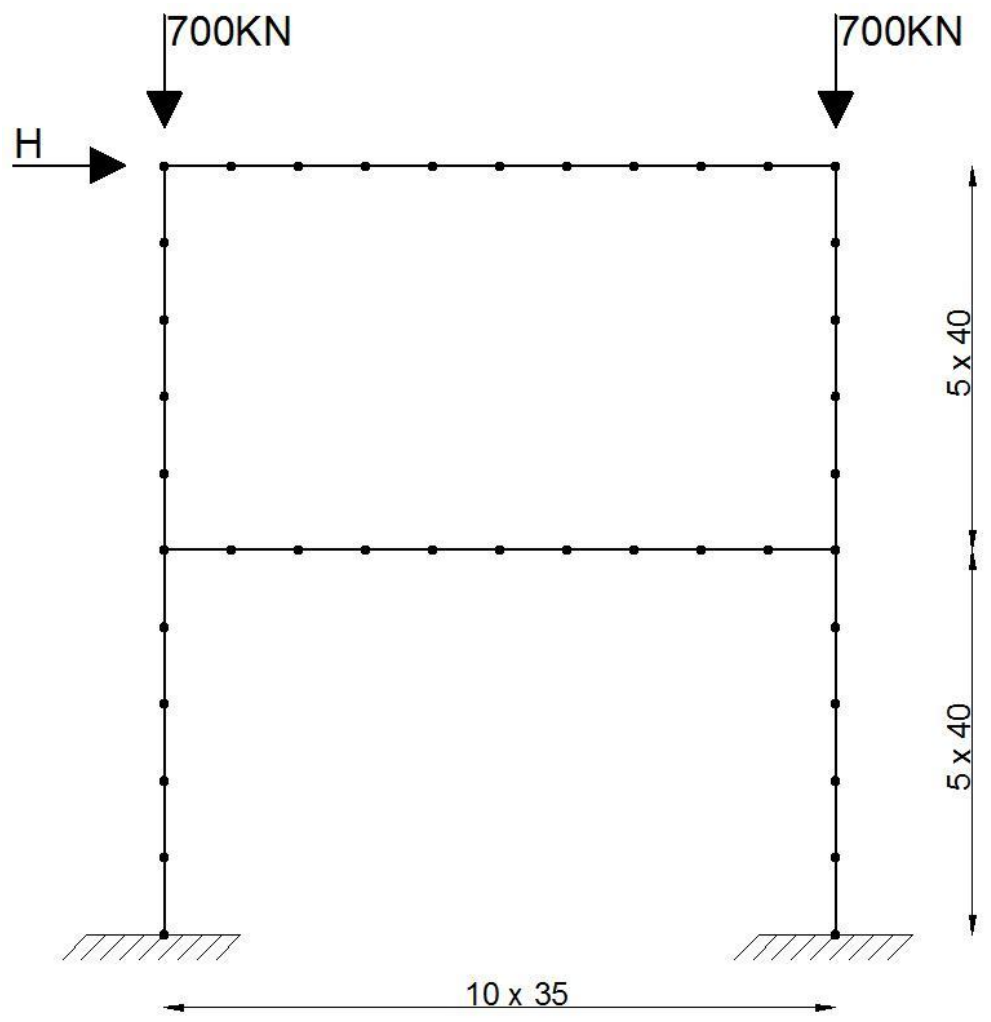

Figura 5.11: Discretização das barras do pórtico ensaiado por VECHIO \& EMARA (1992).

Na figura 5.12 são mostrados os deslocamentos horizontais do topo do pórtico.

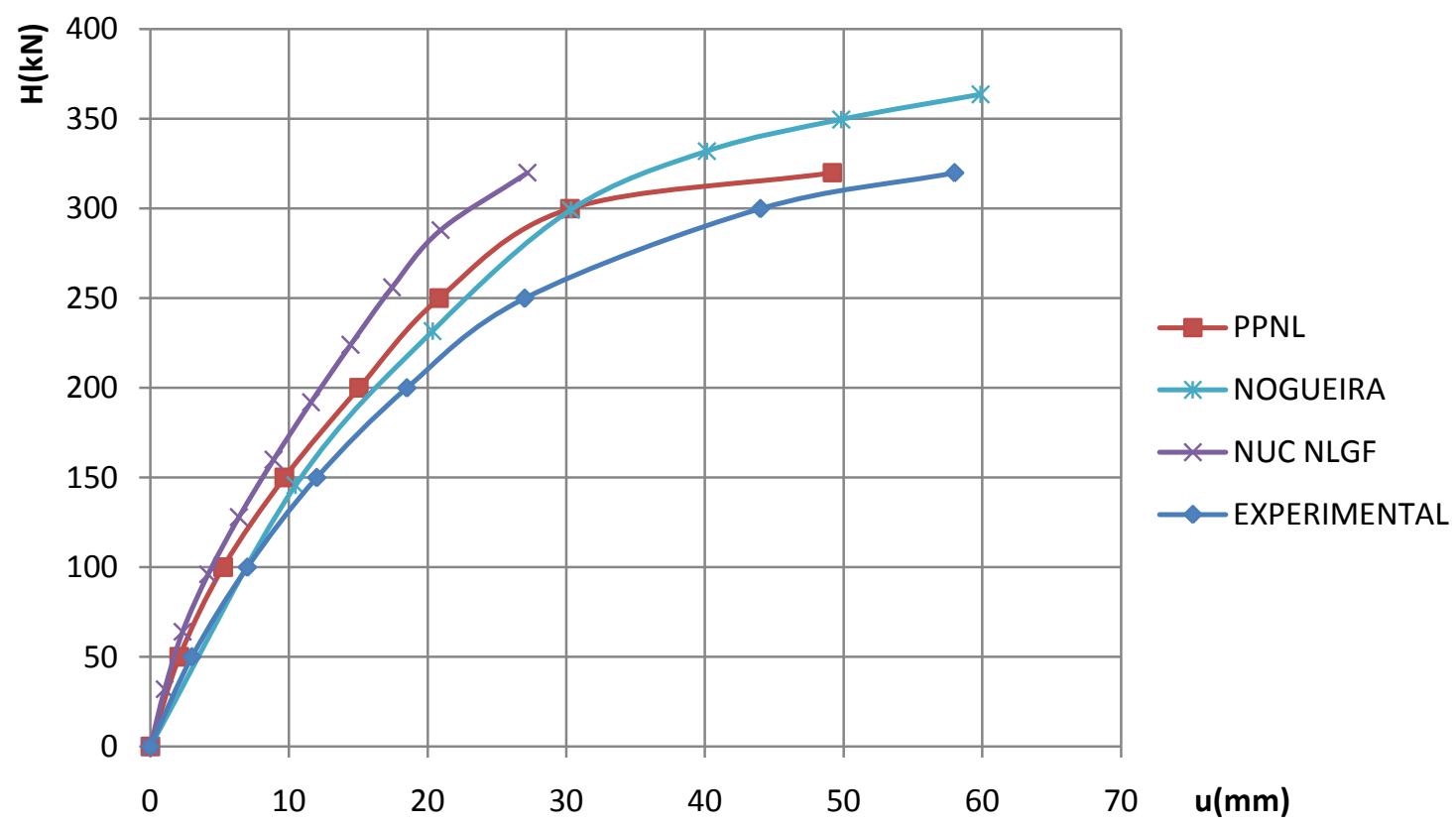

Figura 5.11: Força horizontal versus deslocamento horizontal do topo do pórtico ensaiado por VECHIO \& EMARA (1992). 
Neste exemplo, a análise realizada com o código desenvolvido neste trabalho apresenta deslocamentos menores que os das referências. Os resultados são considerados representativos, pois a carga máxima e os pontos de inflexão estão bem representados. Neste exemplo, assim como o anterior, o número de passos de carregamento não influenciou os resultados.

\subsubsection{Pórtico simples.}

Este exemplo refere-se a um pórtico simples modelado por SILVA (1996), empregando uma discretização em dez elementos para cada barra, sendo os pontos de integração coincidentes com os nós extremos de cada elemento. PAULA (2001), também analisou este mesmo exemplo, discretizando cada barra em dez elementos e utilizando seis pontos de integração ao longo de cada um deles. Em ambas as análises a seção transversal foi dividida em dez camadas.

Como parte da validação do código NUC NLGF, este exemplo teve suas 3 barras divididas em dez elementos, e seção transversal dividida em dez fatias.

Os parâmetros dos materiais empregados são apresentados na tabela 5.3:

Tabela 5.3 - Parâmetros físicos dos materiais.

\begin{tabular}{|c|l|c|l|}
\hline \multicolumn{4}{|c|}{ Parâmetros dos materiais } \\
\hline \multicolumn{3}{|c|}{ Concreto } & \multicolumn{2}{c|}{ Aço } \\
\hline$f_{c}^{\prime}$ & $17.5 \mathrm{MPa}$ & $f_{y}$ & $420 \mathrm{MPa}$ \\
\hline$f_{t}$ & $1.55 \mathrm{MPa}$ & $\varepsilon_{y}$ & 0.002 \\
\hline$\varepsilon_{m}$ & 0.0020 & $E_{s}$ & $210000 \mathrm{MPa}$ \\
\hline$\alpha$ & 0.7 & $E_{s}{ }^{\prime}$ & $1000 \mathrm{MPa}$ \\
\hline
\end{tabular}




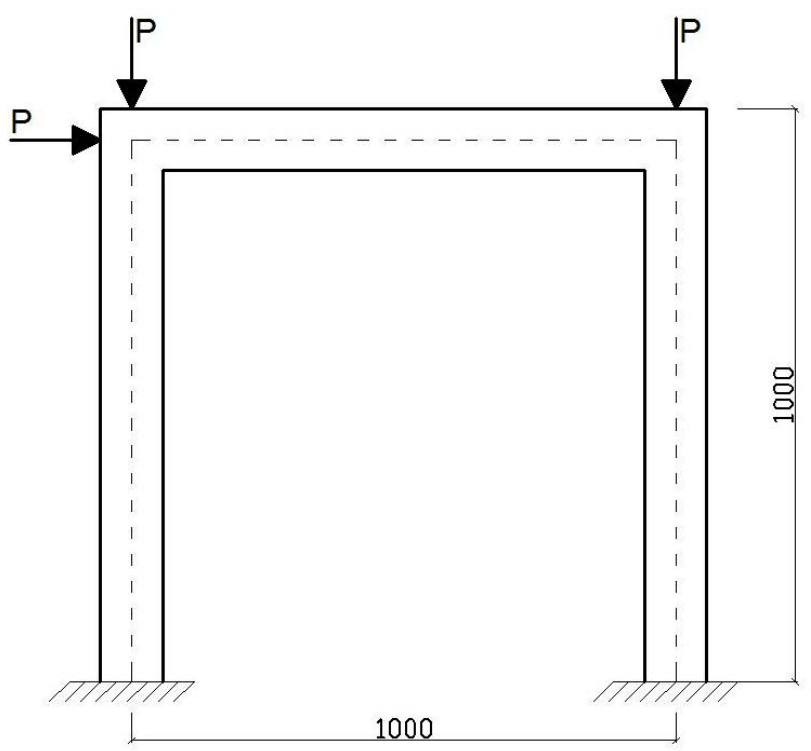

Figura 5.12: Geometria e carregamento do pórtico proposto por SILVA (1996).
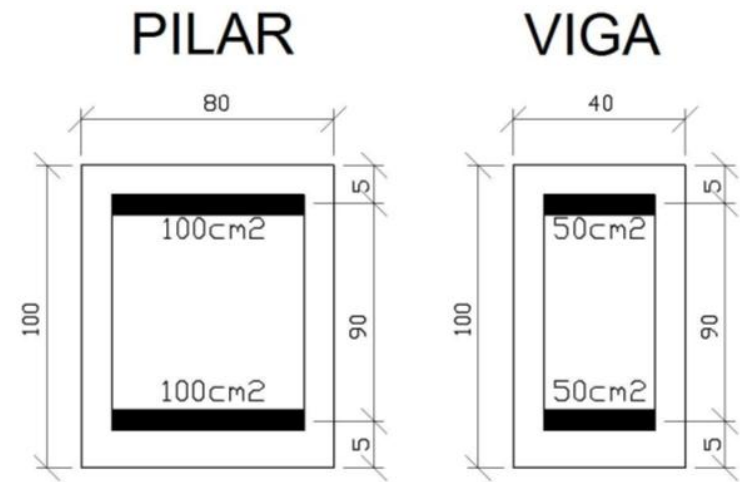

Figura 5.13: Seções transversais das barras do pórtico proposto por SILVA (1996).

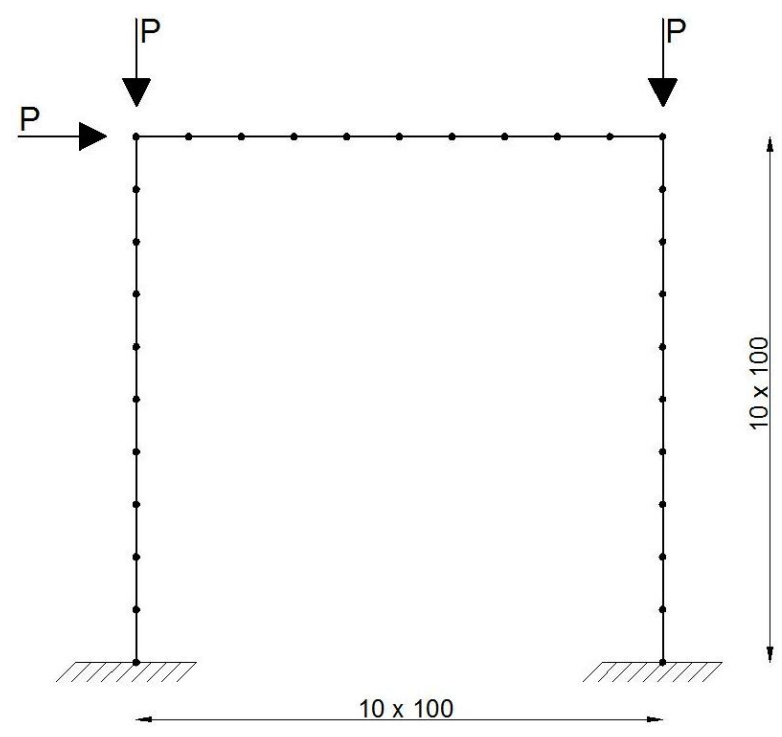

Figura 5.13: Discretização das barras do pórtico proposto por SILVA (1996). 
A seguir são mostradas as curvas Força $\mathrm{P}$ versus deslocamento horizontal do topo do pórtico.

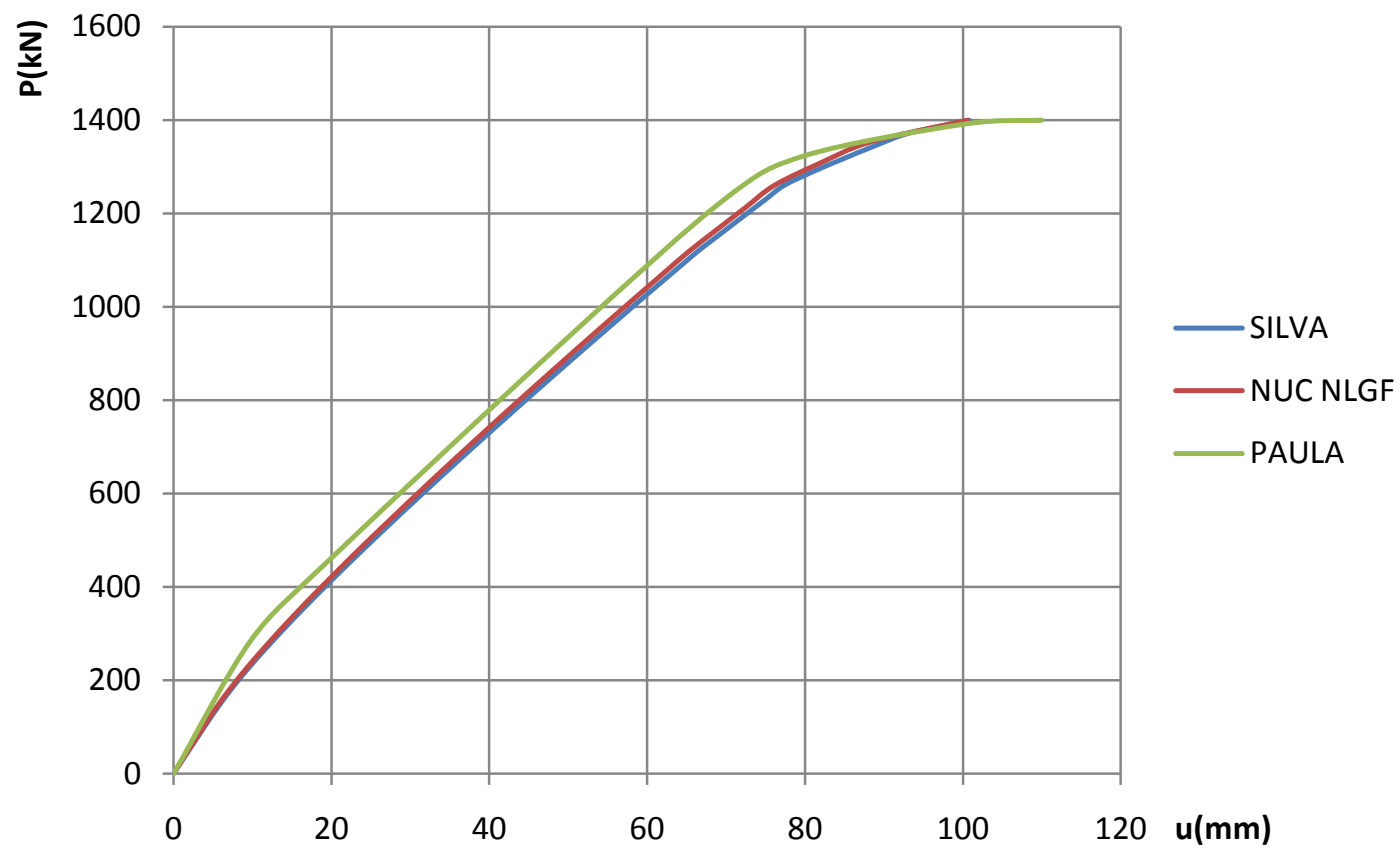

Figura 5.13: Força $P$ versus deslocamento horizontal do pórtico proposto por SILVA (1996).

Neste exemplo, os deslocamentos são praticamente iguais aos apresentados pelas referências, os pontos de inflexão e carga máxima também estão bem representados. $\mathrm{O}$ número de passos de carga mais uma vez não influenciou os resultados.

\subsubsection{Pórtico com 8 pavimentos.}

Este quarto exemplo, da mesma forma que os anteriores, foi estudado por vários pesquisadores. Trata-se de uma estrutura mais próxima das encontradas em edifícios correntes, com dimensões e carregamentos usuais.

O dimensionamento desta estrutura, de acordo com PINTO (2002), foi feito segundo a NB-1/78. Para uma mesma geometria e carregamento foram obtidas três situações de dimensionamento, nas quais as dimensões dos elementos foram concebidas de forma a 
apresentar três taxas de armadura diferentes, uma próxima à mínima, uma próxima à média, em torno de $2 \%$ para os pilares, e uma próxima à máxima permitida pela NBR 6118.

Os carregamentos verticais e horizontais foram aplicados simultaneamente. A situação que corresponde ao Estado Limite Último, aqui chamado ELU, é aquela em que um fator multiplicador igual a 1,4 é aplicado sobre todos os carregamentos. O estado Limite de Serviço, aqui chamado ELS, é aquele no qual os carregamentos são aplicados com seu valor integral igual ao apresentado nas figuras 5.14 e 5.15 .

Os casos designados pela letra A têm as menores taxas de armadura, os designados por $\mathrm{B}$ têm taxas médias, e os indicados pela letra $\mathrm{C}$ têm taxas próximas á máxima. A seguir são mostrados geometria, carregamentos e discretização da estrutura. As dimensões nas figuras 5.14 e 5.15 são dadas em $\mathrm{cm}$. O detalhamento dos elementos é mostrado no anexo A.

Os parâmetros dos materiais empregados são apresentados na tabela 5.4:

Tabela 5.4 - Parâmetros físicos dos materiais.

\begin{tabular}{|c|c|c|c|}
\hline \multicolumn{4}{|c|}{ Parâmetros dos materiais } \\
\hline \multicolumn{2}{|c|}{ Concreto } & \multicolumn{2}{c|}{ Aço } \\
\hline$f^{\prime}{ }_{c}$ & $23.5 \mathrm{MPa}$ & $f_{y}$ & $500 \mathrm{MPa}$ \\
\hline$f_{t}$ & $2.2 \mathrm{MPa}$ & $\varepsilon_{y}$ & 0.002 \\
\hline$\varepsilon_{m}$ & 0.0020 & $E_{s}$ & $210000 \mathrm{MPa}$ \\
\hline$\alpha$ & 0.7 & $E_{s}{ }^{\prime}$ & $1000 \mathrm{MPa}$ \\
\hline
\end{tabular}



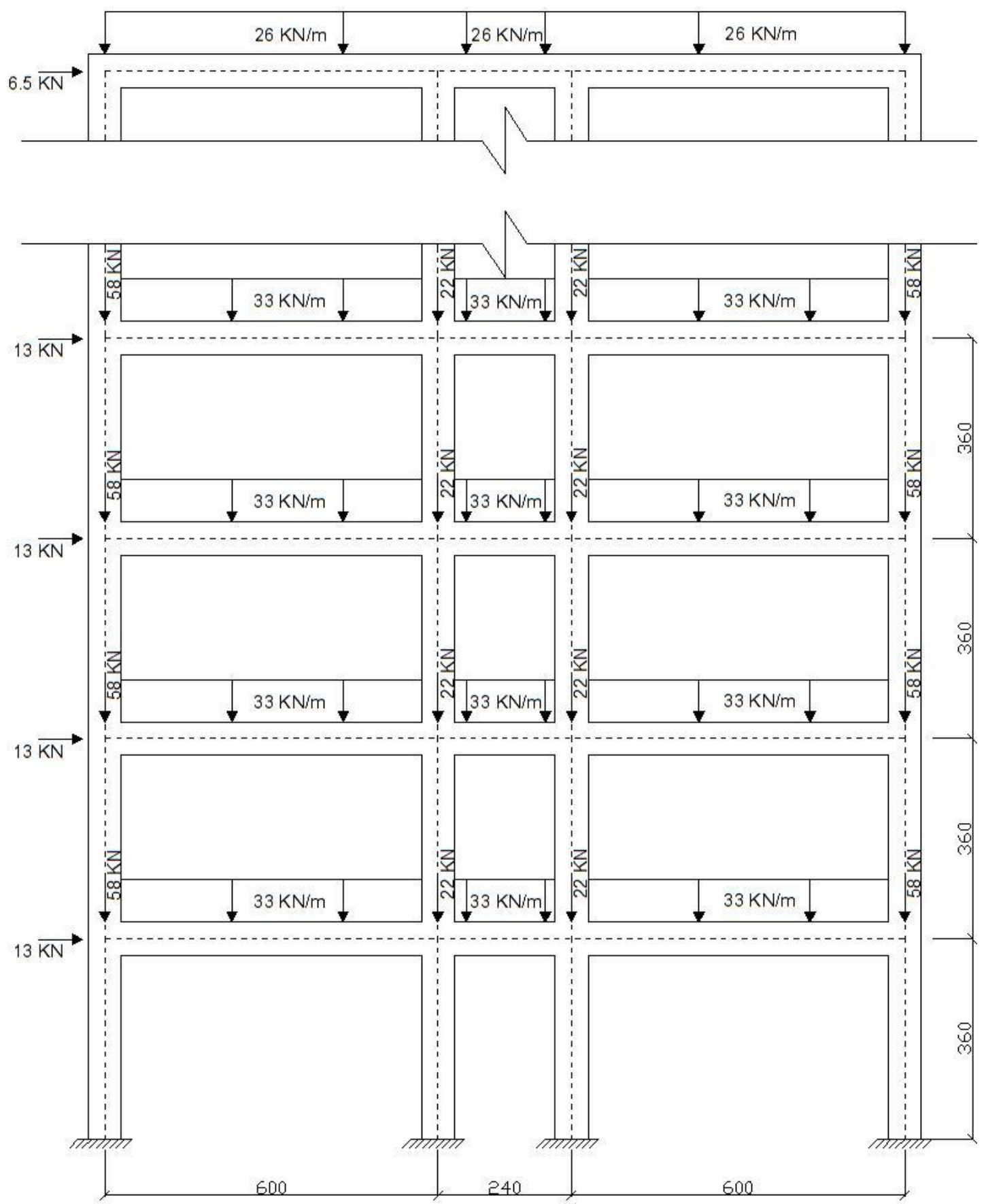

Figura 5.14: Geometria e carregamento do pórtico apresentado em PINTO (2002). 

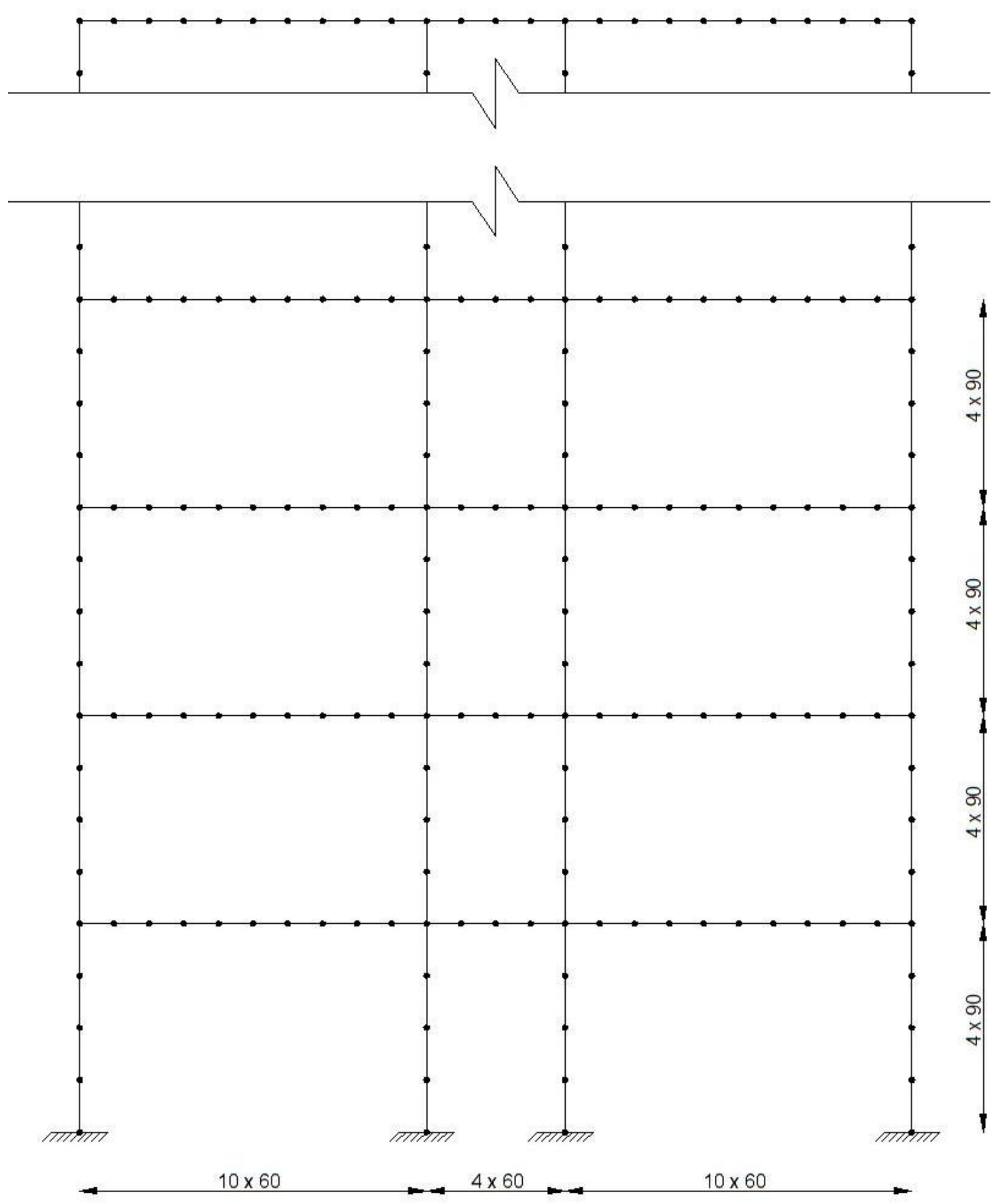

Figura 5.15: Discretização das barras do pórtico apresentado em PINTO (2002). 
Tabela 5.5 - Deslocamentos horizontais dos pavimentos do pórtico apresentado em PINTO (2002).

\begin{tabular}{|c|c|c|c|c|c|c|c|c|c|c|c|c|}
\hline \multirow{2}{*}{ Pav. } & \multicolumn{9}{|c|}{ Deslocamentos (cm) PINTO (2002) } & \multicolumn{3}{c|}{ Deslocamentos (cm) NUC NLGF } \\
\cline { 2 - 14 } & \multicolumn{2}{|c|}{ A } & \multicolumn{2}{|c|}{ B } & \multicolumn{2}{c|}{ C } & \multicolumn{2}{|c|}{ A } & \multicolumn{2}{|c|}{ B } & \multicolumn{2}{c|}{ C } \\
\cline { 2 - 13 } & ELS & ELU & ELS & ELU & ELS & ELU & ELS & ELU & ELS & ELU & ELS & ELU \\
\hline FUND. & 0,00 & 0,00 & 0,00 & 0,00 & 0,00 & 0,00 & 0,00 & 0,00 & 0,00 & 0,00 & 0,00 & 0,00 \\
\hline 1 & 0,20 & 0,31 & 0,49 & 0,85 & 0,64 & 1,09 & 0,18 & 0,29 & 0,40 & 0,71 & 0,60 & 0,95 \\
\hline 2 & 0,50 & 0,78 & 1,11 & 1,93 & 1,43 & 2,42 & 0,48 & 0,78 & 1,02 & 1,76 & 1,43 & 2,32 \\
\hline 3 & 0,78 & 1,31 & 1,66 & 2,84 & 2,16 & 3,63 & 0,76 & 1,24 & 1,59 & 2,70 & 2,19 & 3,56 \\
\hline 4 & 1,03 & 1,65 & 2,11 & 3,59 & 2,75 & 4,66 & 1,00 & 1,64 & 2,06 & 3,47 & 2,84 & 4,60 \\
\hline 5 & 1,22 & 1,98 & 2,48 & 4,20 & 3,24 & 5,44 & 1,19 & 1,97 & 2,44 & 4,08 & 3,38 & 5,45 \\
\hline 6 & 1,37 & 2,22 & 2,75 & 4,63 & 3,60 & 6,01 & 1,35 & 2,23 & 2,73 & 4,55 & 3,78 & 6,08 \\
\hline 7 & 1,48 & 2,38 & 2,95 & 4,96 & 3,85 & 6,42 & 1,46 & 2,42 & 2,93 & 4,87 & 4,05 & 6,51 \\
\hline 8 & 1,54 & 2,48 & 3,08 & 5,19 & 4,02 & 6,72 & 1,53 & 2,56 & 3,05 & 5,06 & 4,19 & 6,74 \\
\hline
\end{tabular}

Nos gráficos a seguir são mostrados os deslocamentos horizontais de cada pavimento, estes são comparados com os mostrados em PINTO (2002). Os nomes dos exemplos acompanhados de NUC NLGF são referentes aos obtidos com o código desenvolvido neste trabalho, os demais são oriundos da referência acima citada.

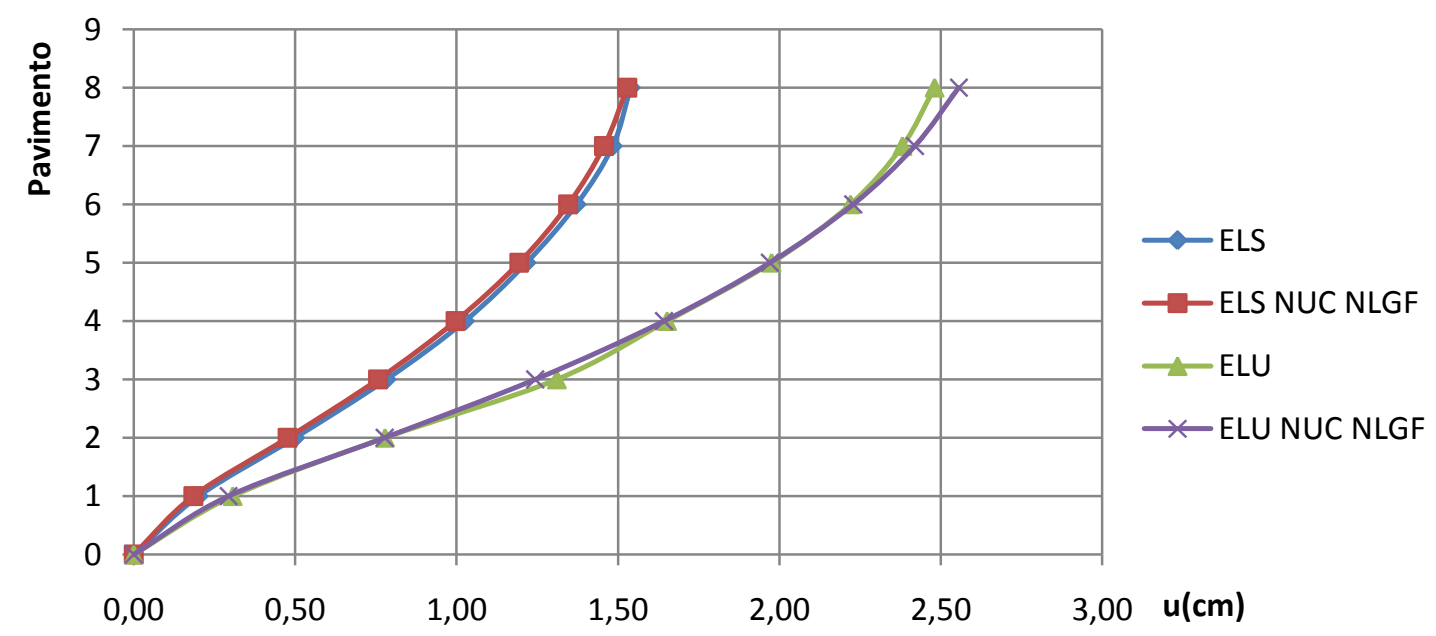

Figura 5.16: Deslocamento horizontal ao nível de cada pavimento: A. 


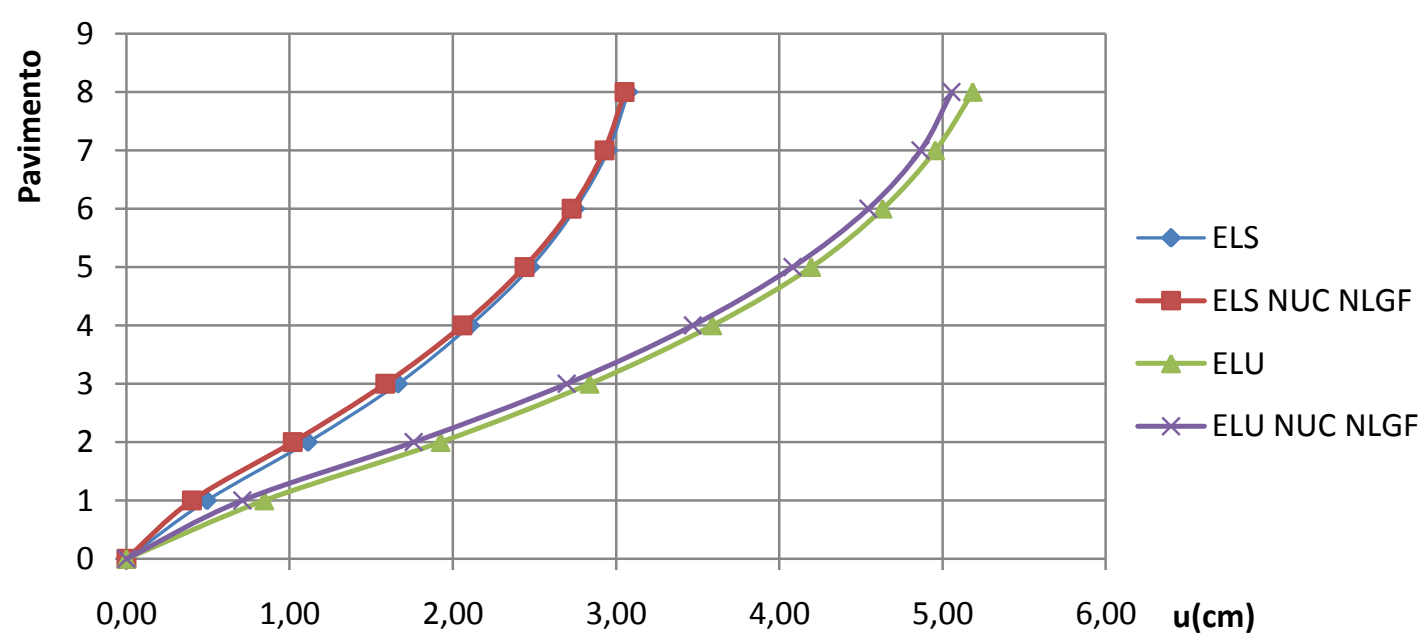

Figura 5.17: Deslocamento horizontal ao nível de cada pavimento: B.

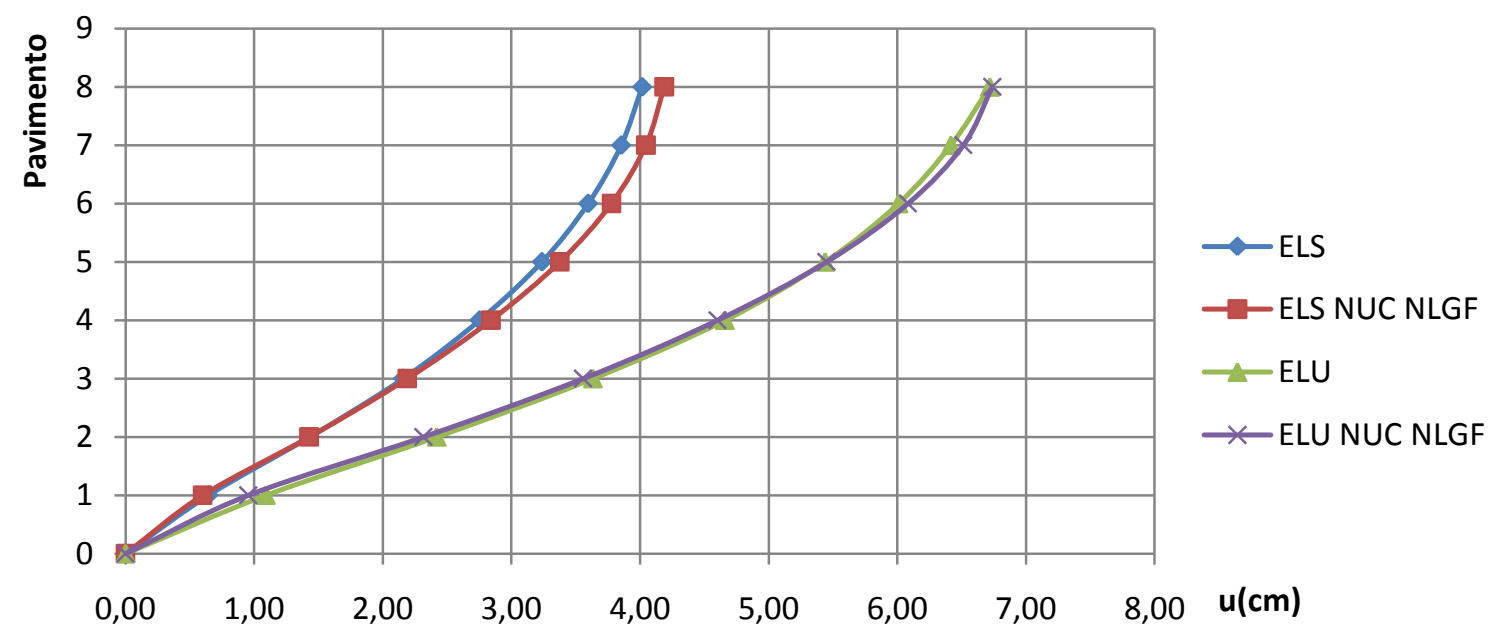

Figura 5.18: Deslocamento horizontal ao nível de cada pavimento: $\mathrm{C}$.

Neste exemplo onde são estudadas estruturas mais próximas àquelas usualmente empregadas em edifícios, os deslocamentos obtidos com o código desenvolvido neste trabalho são muito próximos dos mostrados pela referência. Para as três situações de taxa de armadura o nível de representatividade foi praticamente o mesmo, independente do nível de carregamento aplicado, ELS ou ELU. 
Ao longo do capítulo foram apresentados resultados obtidos por várias referências, em todos os exemplos houve boa correspondência entre os deslocamentos obtidos com a formulação proposta neste trabalho e os mostrados pelas referências.

Comparada ás demais, esta formulação é relativamente simples. A divisão dos membros da estrutura em 4 ou 5 elementos, assim como feito por outros autores levou a bons resultados, dispensando uma discretização mais rica da estrutura. O número de passos de carga exigido para bons resultados também foi muito próximo os observados pelas referências. Do ponto de vista computacional mostrou boa eficiência, chegando à convergência em forças e deslocamentos com número pequeno de iterações em cada passo de carga.

Durante a fase de desenvolvimento e validação das rotinas de cálculo para a consideração da não linearidade física foram feitas algumas análises complementares que não são mostradas no decorrer do trabalho, nos próximos dois parágrafos são citadas algumas conclusões a respeito.

A influência do confinamento conferido pelos estribos mostra pequena influência para os exemplos onde a não linearidade é bastante acentuada, e em situações de carregamento próximo ao crítico. Para as estruturas mais próximas às presentes em edifícios, a influência é desprezível, pois a taxa volumétrica dos estribos é muito pequena.

A consideração da resistência à tração do concreto mostra significativa influência sobre os deslocamentos para aqueles exemplos onde o nível de carregamento é muito alto, porém não influencia de forma significativa na carga máxima obtida. Para as estruturas mais próximas as usuais a influência foi mínima. 


\section{Capítulo 6 - Exemplos}

Neste capítulo, são estudados 3 exemplos, as estruturas são adaptadas de SILVA (1989).

Todos os exemplos são iguais em planta, a distinção entre eles está no número de pavimentos. Os exemplos possuem 12, 16 e 20 pavimentos. Cada exemplo é dividido em 3 situações de dimensionamento, de forma a apresentarem 3 taxas de armadura. Todos os pavimentos são iguais em planta. As características comuns á todos os exemplos são dadas a seguir:

Pé direito dos andares: $H=300 \mathrm{~cm}$

Número de pavimentos: $N=(12,16$ e 20)

Dimensões do pilares: 25 x $50 \mathrm{~cm}$

Dimensões das vigas: 20 x $60 \mathrm{~cm}$

Para o último pavimento os carregamentos são os seguintes:

Carregamento vertical distribuído nas vigas: $Q=10 \mathrm{kN} / \mathrm{m}$

Cargas verticais aplicadas nos pontos 1, 2, 3 e 4 na seção transversal do núcleo:

Ponto 1: $P=35 \mathrm{kN}$

Ponto 2: $P=90 \mathrm{kN}$

Ponto 3: $P=90 \mathrm{kN}$

Ponto 4: $P=35 k N$

Ação do vento concentrada no último pavimento: $F_{Z}=25 \mathrm{kN}$

Para os demais pavimentos os carregamentos são os seguintes:

Carregamento vertical distribuído nas vigas: $Q=20 \mathrm{kN} / \mathrm{m}$

Cargas verticais aplicadas nos pontos 1, 2, 3 e 4 na seção transversal do núcleo:

Ponto 1: $P=70 \mathrm{kN}$

Ponto 2: $P=180 \mathrm{kN}$

Ponto 3: $P=180 \mathrm{kN}$

Ponto 4: $P=70 \mathrm{kN}$

Ação do vento concentrada nos demais pavimento: $F_{Z}=51 \mathrm{kN}$ 
As dimensões da planta de formas estão em $\mathrm{cm}$.

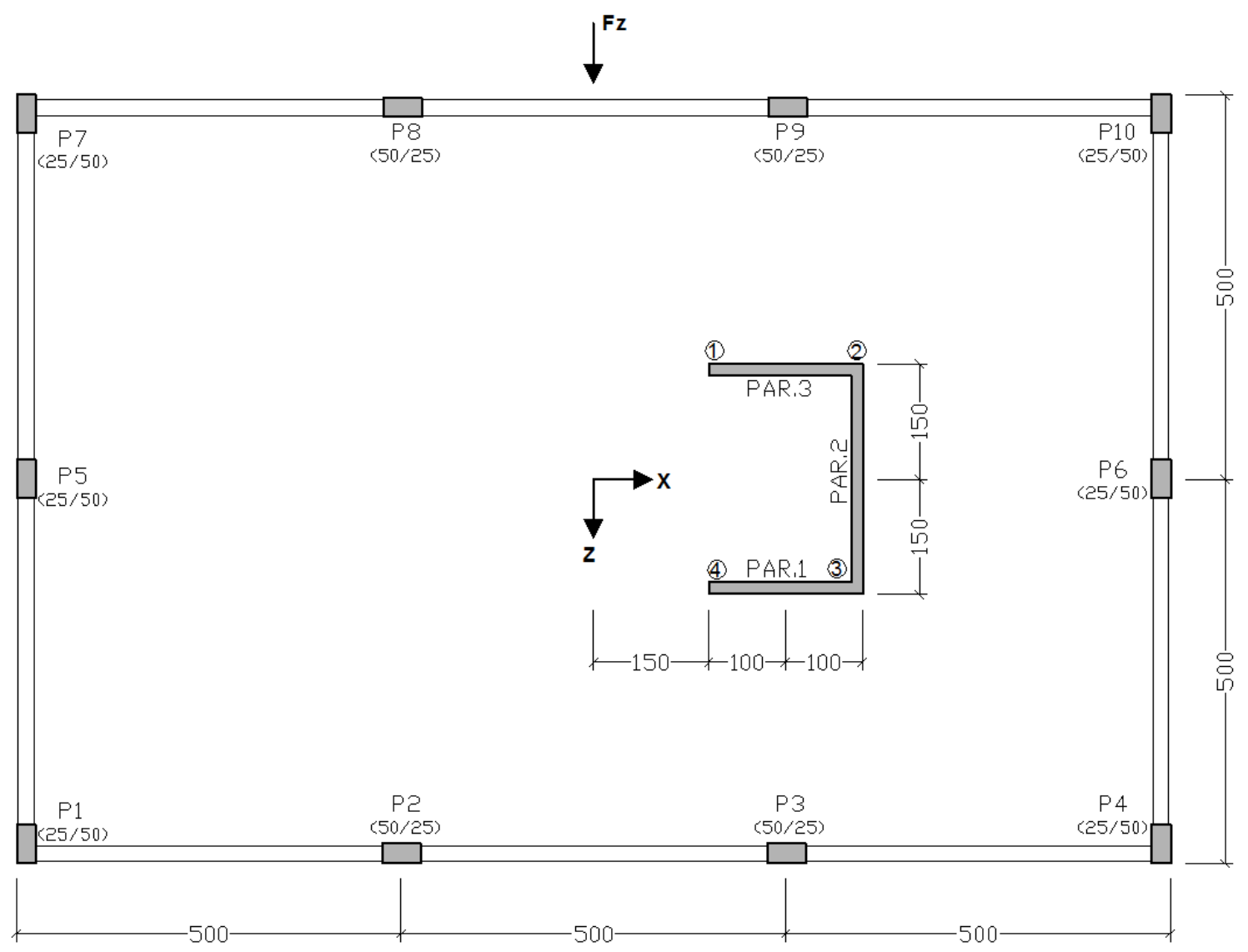

Figura 6.1: Planta de formas do edifício proposto por SILVA (1989).

\subsection{Dimensionamento.}

Para a determinação das armaduras e espessuras das paredes dos núcleos, procede-se de forma semelhante ao mostrado em PINTO (2002). O dimensionamento é feito de forma a obter taxas de armadura, próximas à mínima, à média e á máxima.

Para o dimensionamento será considerada a não linearidade geométrica, as deformações por esforço cortante são desprezadas, e a não linearidade física é considerada de forma simplificada de acordo com a NBR 6118, adotando um coeficiente multiplicador da rigidez de todos os elementos igual a 0,70 . Os demais aspectos do dimensionamento, inclusive os efeitos de segunda ordem local são tratados de acordo com a NBR 6118. Este procedimento leva a 3 configurações da estrutura para cada exemplo, a nomenclatura destas é feita de acordo com a taxa de armadura, a situação com menor taxa de armadura é chamada $\mathrm{A}$, média $\mathrm{B}$ e maior $\mathrm{C}$, precedidas pelo número de pavimentos. Os detalhamentos das armaduras dos núcleos serão apresentados no anexo B. 


\subsection{Análises efetuadas.}

Para a avaliação da não linearidade física dos núcleos, é realizada uma análise não linear geométrica, combinada com uma análise não linear física rigorosa para os elementos que compõem os núcleos e consideração de $70 \%$ da inércia dos demais elementos.

Além da avaliação da não linearidade nos núcleos, são realizadas mais 3 análises para efeito de comparação dos deslocamentos dos pavimentos. A nomenclatura e considerações sobre cada análise são dadas a seguir:

Linear: Análise linear, análise não linear física simplificada considerando $70 \%$ da inércia de todos os elementos. Não é considerada a deformação por esforço cortante.

Linear Tim.: Análise linear, análise não linear física simplificada considerando $70 \%$ da inércia de todos os elementos. É considerada a deformação por esforço cortante, (hipótese de Timoshenko).

NLG: Análise não linear geométrica considerando $70 \%$ da rigidez á flexão de todos os elementos, não é considerada a deformação por esforço cortante.

NLG Tim.: Análise não linear geométrica, análise não linear física simplificada considerando $70 \%$ da inércia de todos os elementos. É considerada a deformação por esforço cortante, (hipótese de Timoshenko).

NLG-NLF: Análise não linear geométrica, consideração de $70 \%$ da rigidez à flexão para vigas e pilares e consideração da não linearidade física de forma rigorosa para as paredes dos núcleos. Não é considerada a deformação por esforço cortante. 


\subsection{Coeficiente redução de inércia das paredes dos núcleos.}

A busca por um coeficiente redutor de inércia para as paredes dos núcleos é feita de forma a representar os deslocamentos da estrutura o mais próximos possível daqueles obtidos a partir de uma análise não linear rigorosa. Para tanto, são realizadas várias análises não linear geométrica e física simplificada, aplicando diferentes coeficientes redutores ás paredes. Baseado nos resultados apresentados na análise NLG-NLF, ao final de cada exemplo é apresentada uma sugestão de coeficiente redutor de inércia para os elementos que compõem os núcleos. 


\subsection{Edifício com 12 pavimentos.}

Este exemplo apresenta as seguintes características particulares:

Número de pavimentos: 12

Espessura das paredes do núcleo: 14, 16 e $18 \mathrm{~cm}$

Dados da análise não linear geométrica, e física simplificada:

Tabela 6.1 - Parâmetros físicos do concreto.

\begin{tabular}{|c|c|}
\hline \multicolumn{2}{|c|}{ Concreto } \\
\hline$f c k$ & $20.0 \mathrm{MPa}$ \\
\hline$E_{\text {Sec. }}$ & $21287.4 \mathrm{MPa}$ \\
\hline$G$ & $8869.7 \mathrm{MPa}$ \\
\hline$v$ & 0.20 \\
\hline
\end{tabular}

Parâmetros dos materiais empregados na análise não linear geométrica, e física rigorosa: Tabela 6.2 - Parâmetros físicos dos materiais.

\begin{tabular}{|c|c|c|c|}
\hline \multicolumn{4}{|c|}{ Parâmetros dos materiais } \\
\hline \multicolumn{2}{|c|}{ Concreto } & \multicolumn{2}{c|}{ Aço } \\
\hline$f_{c}^{\prime}$ & $23.5 \mathrm{MPa}$ & $f_{y}$ & $434.8 \mathrm{MPa}$ \\
\hline$f_{t}$ & $2.35 \mathrm{MPa}$ & $\varepsilon_{y}$ & 0.00207 \\
\hline$\varepsilon_{m}$ & 0.0020 & $E_{s}$ & $210000 \mathrm{MPa}$ \\
\hline$\alpha$ & 0.7 & $E_{s}{ }^{\prime}$ & $1000 \mathrm{MPa}$ \\
\hline
\end{tabular}

É mostrada a seguir a tabela resumo das armaduras obtidas nas 3 situações de dimensionamento. 
Tabela 6.3 - Resumo de armadura das paredes PAR 1 e PAR 3.

\begin{tabular}{|c|c|c|c|c|c|c|c|c|c|}
\hline \multirow{2}{*}{ Pav. } & \multicolumn{3}{|c|}{ A (t =18cm) } & \multicolumn{3}{c|}{ B (t =16cm) } & \multicolumn{3}{c|}{ C (t =14cm) } \\
\cline { 2 - 11 } & $\boldsymbol{\phi}(\mathbf{m m})$ & Esp. $(\mathbf{c m})$ & Quant. & $\boldsymbol{\phi}(\mathbf{m m})$ & Esp. (cm) & Quant. & $\boldsymbol{\phi}(\mathbf{m m})$ & Esp. (cm) & Quant. \\
\hline 1 & 12,5 & 10 & 40 & 16 & 9 & 44 & 16 & 7 & 58 \\
\hline 2 & 12,5 & 15 & 26 & 16 & 13 & 30 & 16 & 7 & 58 \\
\hline 3 & 10 & 20 & 20 & 16 & 15 & 26 & 16 & 11 & 36 \\
\hline 4 & 10 & 22 & 18 & 10 & 14 & 28 & 16 & 15 & 26 \\
\hline 5 & 10 & 22 & 18 & 10 & 25 & 16 & 10 & 10 & 40 \\
\hline 6 & 10 & 22 & 18 & 10 & 25 & 16 & 10 & 28 & 14 \\
\hline 7 & 10 & 22 & 18 & 10 & 25 & 16 & 10 & 28 & 14 \\
\hline 8 & 10 & 22 & 18 & 10 & 25 & 16 & 10 & 28 & 14 \\
\hline 9 & 10 & 22 & 18 & 10 & 25 & 16 & 10 & 28 & 14 \\
\hline 10 & 10 & 22 & 18 & 10 & 25 & 16 & 10 & 28 & 14 \\
\hline 11 & 10 & 22 & 18 & 10 & 25 & 16 & 10 & 28 & 14 \\
\hline 12 & 10 & 22 & 18 & 10 & 25 & 16 & 10 & 28 & 14 \\
\hline
\end{tabular}

Tabela 6.4 - Resumo de armadura da parede PAR 2.

\begin{tabular}{|c|c|c|c|c|c|c|c|c|c|}
\hline \multirow{2}{*}{ Pav. } & \multicolumn{3}{|c|}{$\mathbf{A}(\mathbf{t}=\mathbf{1 8 c m})$} & \multicolumn{3}{c|}{ B (t=16cm) } & \multicolumn{3}{c|}{ C (t =14cm) } \\
\cline { 2 - 11 } & $\boldsymbol{\phi ( \mathbf { m m } )}$ & Esp. (cm) & Quant. & $\boldsymbol{\phi}(\mathbf{m m})$ & Esp. $(\mathbf{c m})$ & Quant. & $\boldsymbol{\phi}(\mathbf{m m})$ & Esp. (cm) & Quant. \\
\hline 1 & 10 & 22 & 28 & 10 & 25 & 24 & 10 & 24 & 26 \\
\hline 2 & 10 & 22 & 28 & 10 & 25 & 24 & 10 & 28 & 22 \\
\hline 3 & 10 & 22 & 28 & 10 & 25 & 24 & 10 & 28 & 22 \\
\hline 4 & 10 & 22 & 28 & 10 & 25 & 24 & 10 & 28 & 22 \\
\hline 5 & 10 & 22 & 28 & 10 & 25 & 24 & 10 & 28 & 22 \\
\hline 6 & 10 & 22 & 28 & 10 & 25 & 24 & 10 & 28 & 22 \\
\hline 7 & 10 & 22 & 28 & 10 & 25 & 24 & 10 & 28 & 22 \\
\hline 8 & 10 & 22 & 28 & 10 & 25 & 24 & 10 & 28 & 22 \\
\hline 9 & 10 & 22 & 28 & 10 & 25 & 24 & 10 & 28 & 22 \\
\hline 10 & 10 & 22 & 28 & 10 & 25 & 24 & 10 & 28 & 22 \\
\hline 11 & 10 & 22 & 28 & 10 & 25 & 24 & 10 & 28 & 22 \\
\hline 12 & 10 & 22 & 28 & 10 & 25 & 24 & 10 & 28 & 22 \\
\hline
\end{tabular}

A seguir são mostrados os resultados referentes aos deslocamentos do nó mestre de cada pavimento. 
Translações dos pavimentos na direção X:

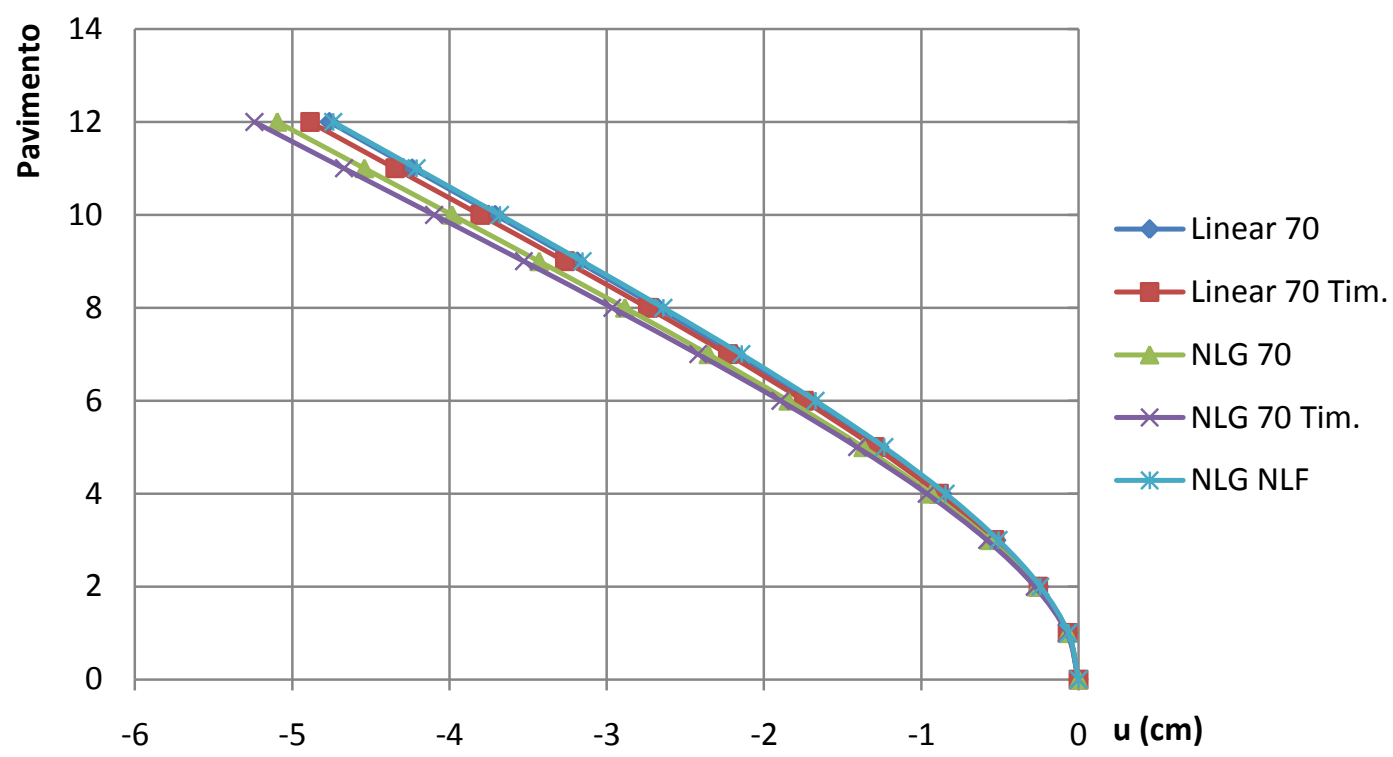

Figura 6.2: Deslocamento do pavimento na direção X: $12 \mathrm{~A}$.

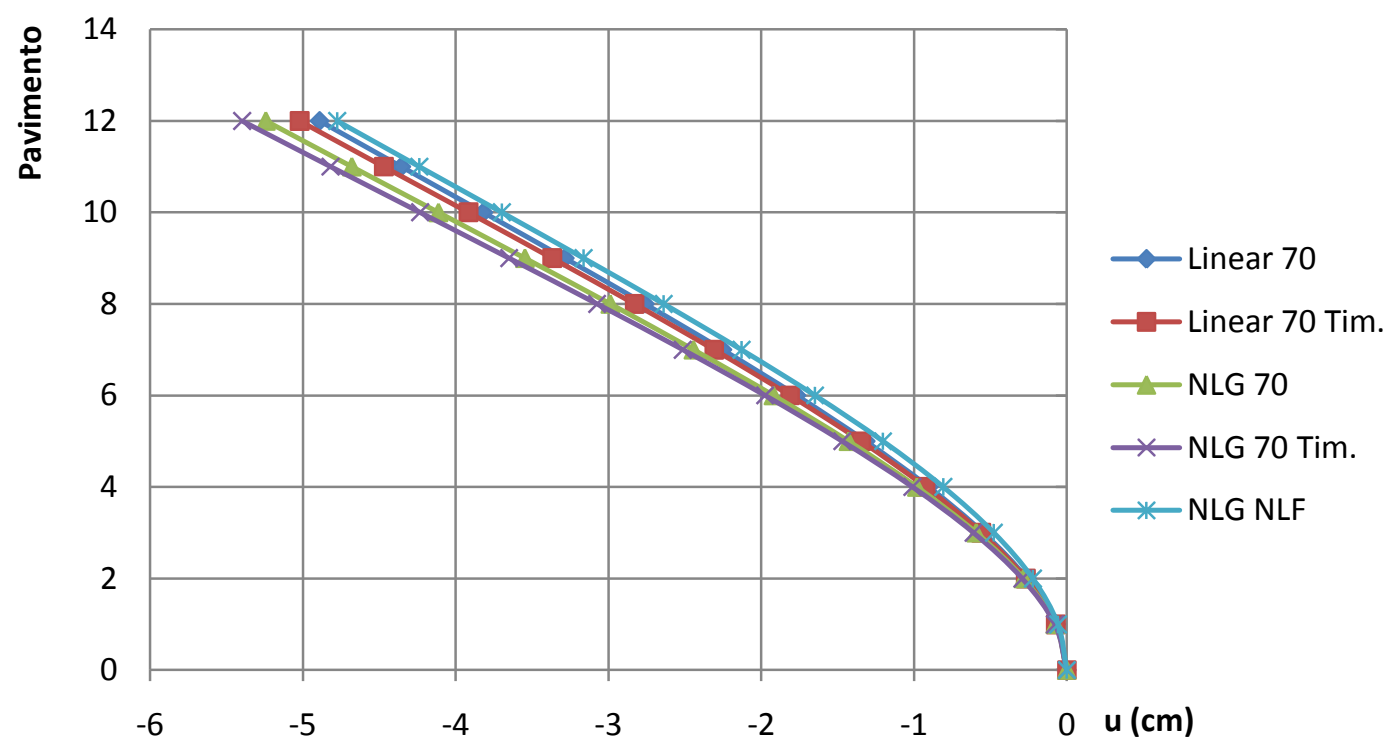

Figura 6.3: Deslocamento do pavimento na direção $X: 12 B$. 


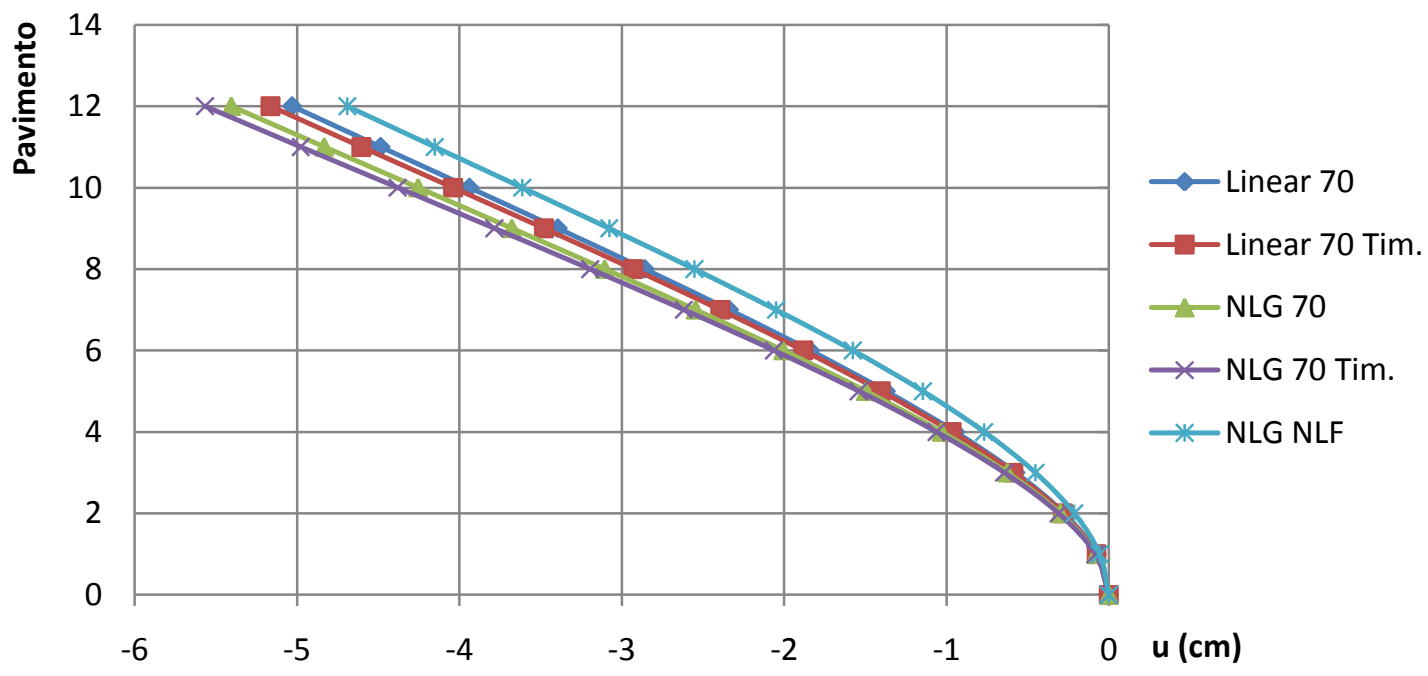

Figura 6.4: Deslocamento do pavimento na direção X: 12C.

Translações dos pavimentos na direção Z:

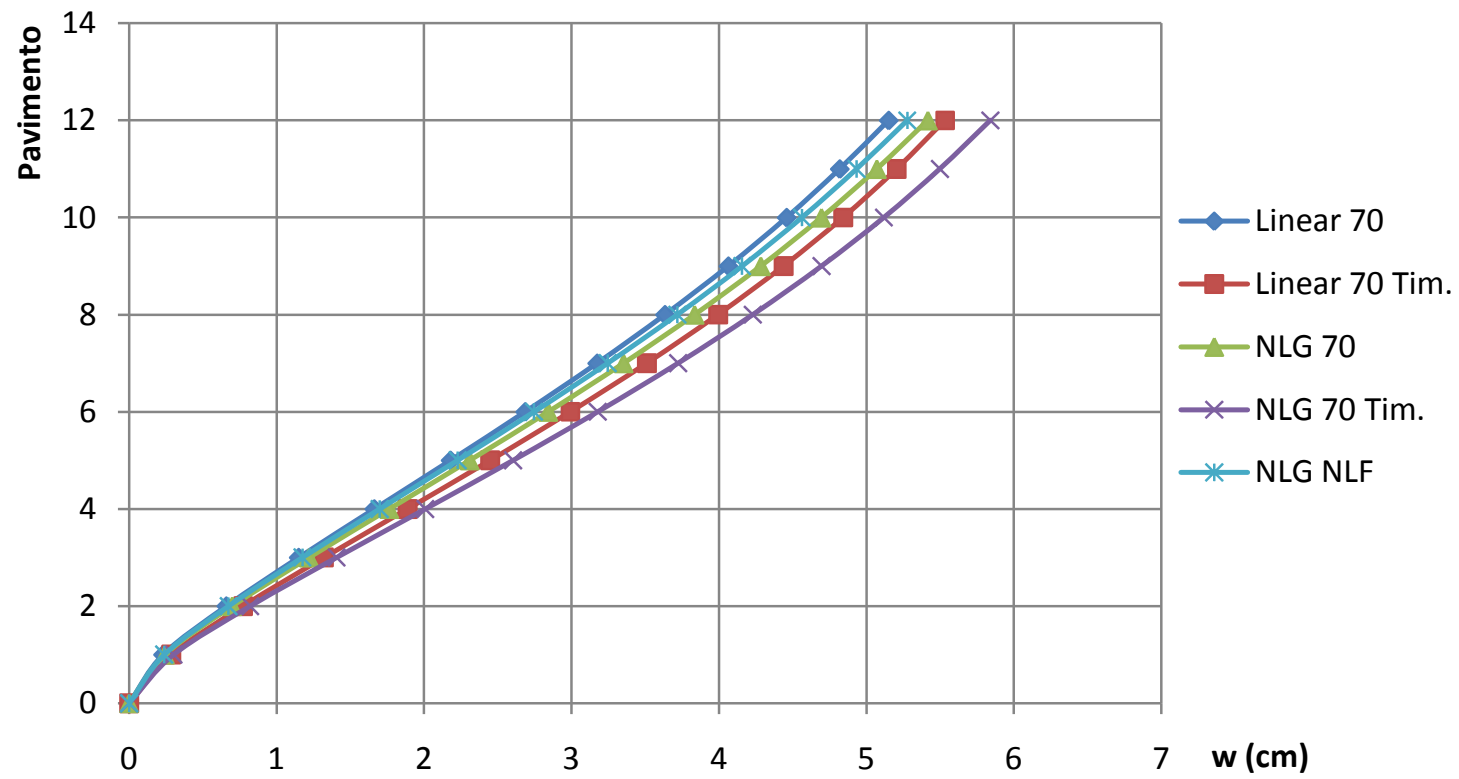

Figura 6.5: Deslocamento do pavimento na direção Z: $12 \mathrm{~A}$. 


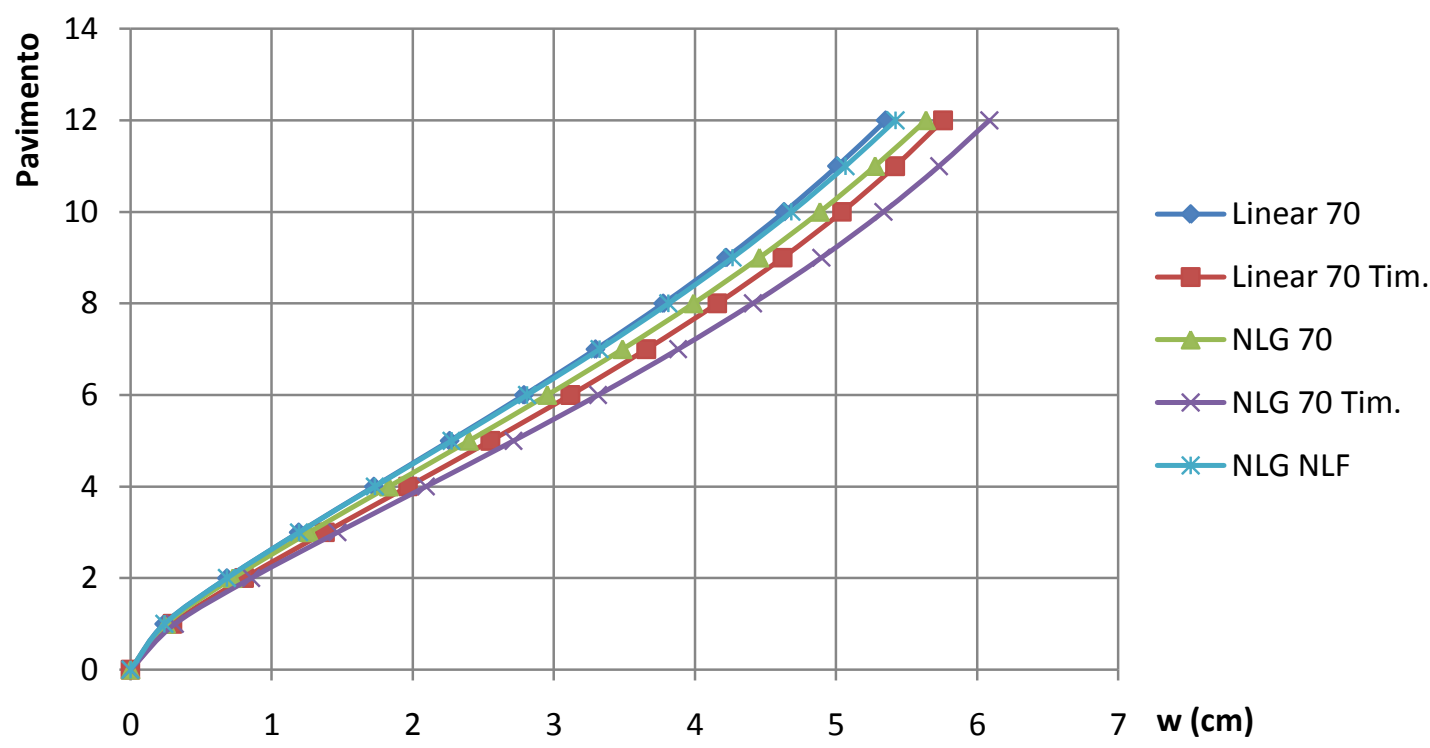

Figura 6.6: Deslocamento do pavimento na direção Z: 12B.

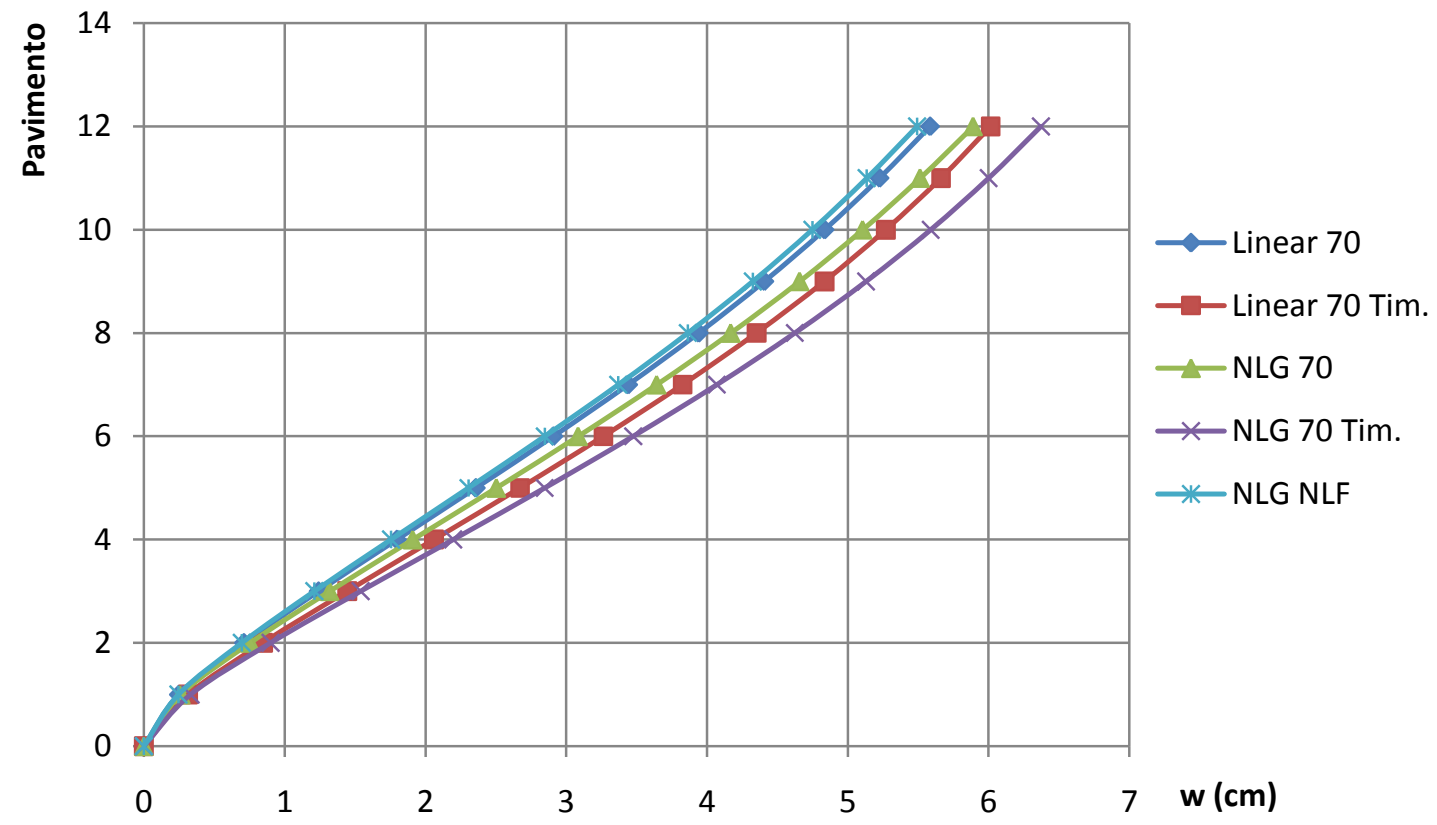

Figura 6.7: Deslocamento do pavimento na direção Z: 12C. 
Rotações dos pavimentos em torno do eixo Y.

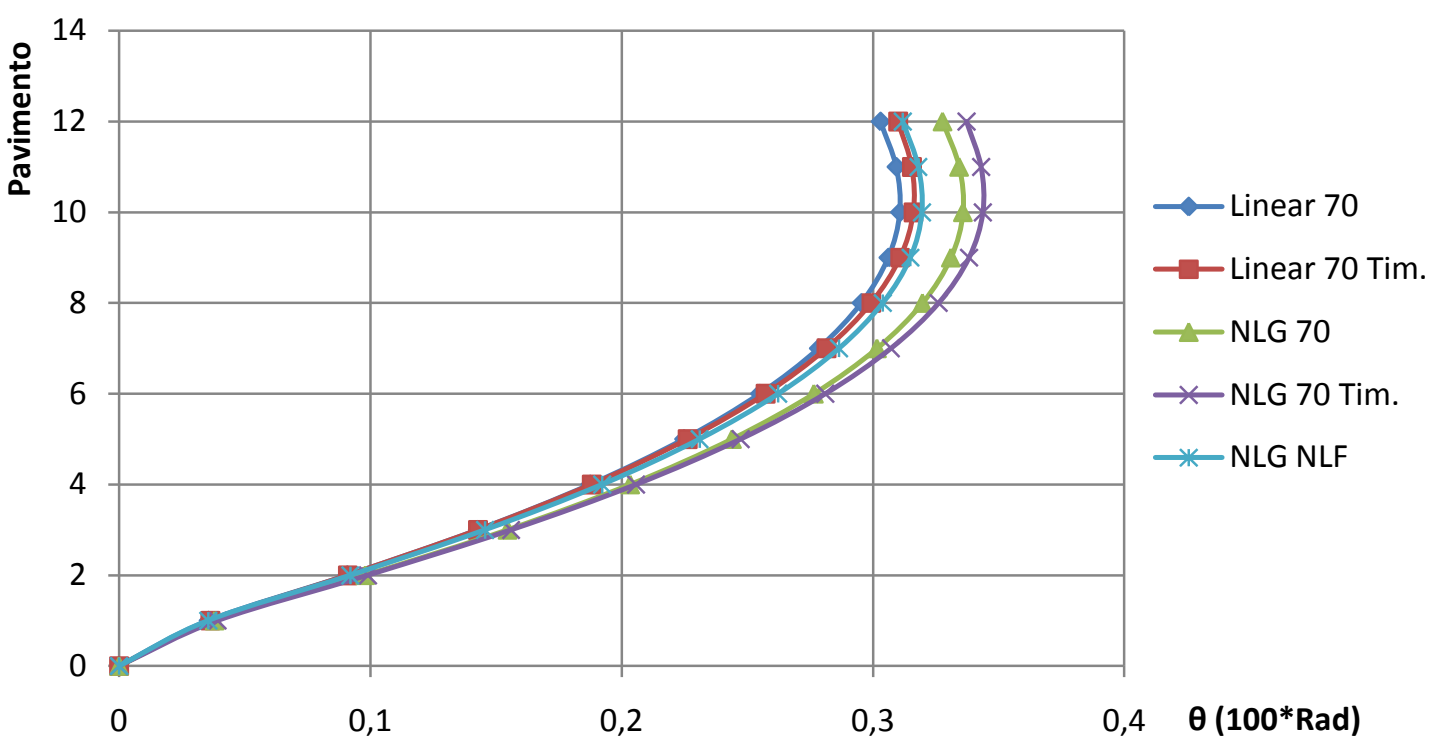

Figura 6.8: Rotação do pavimento em torno do eixo Y: 12A.

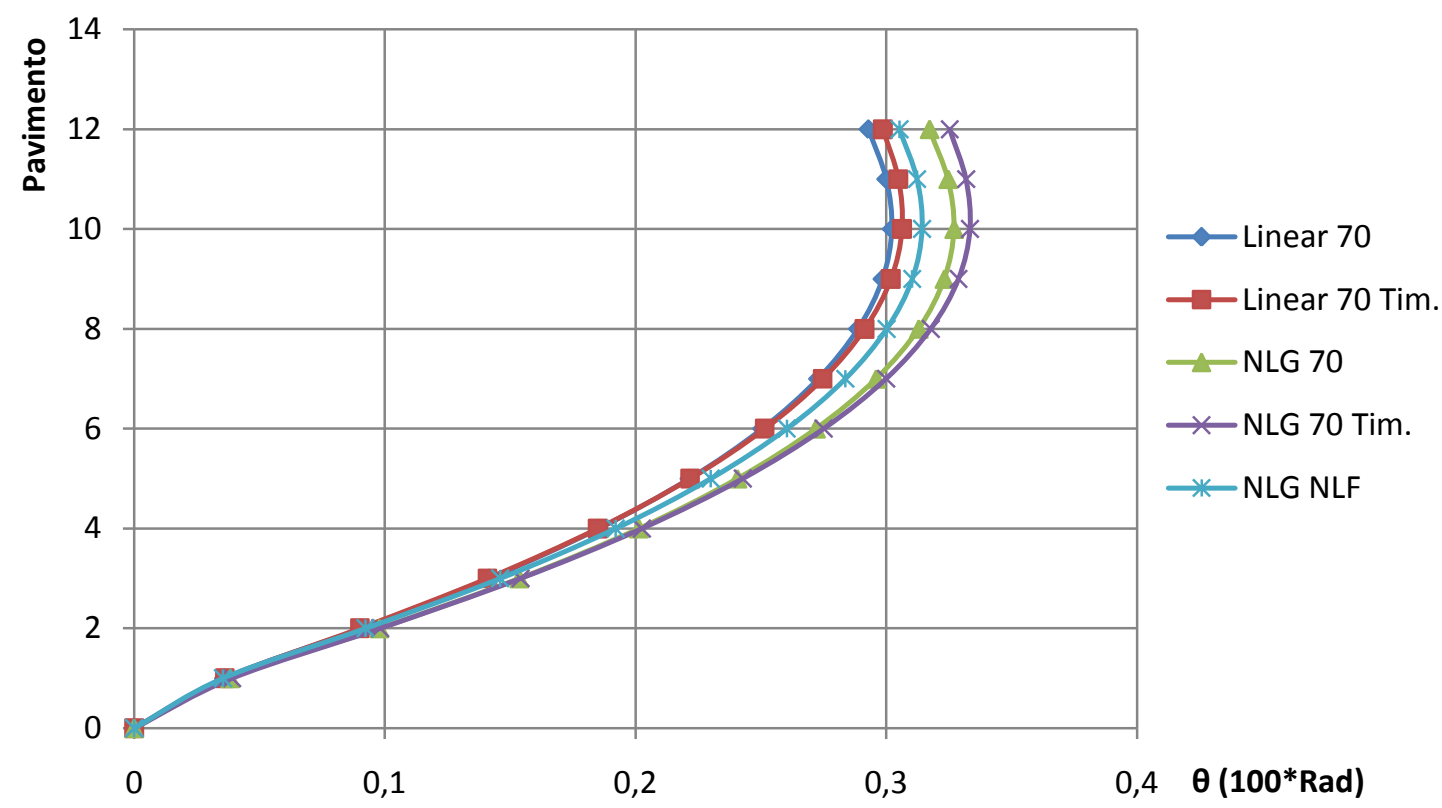

Figura 6.9: Rotação do pavimento em torno do eixo Y: $12 B$. 


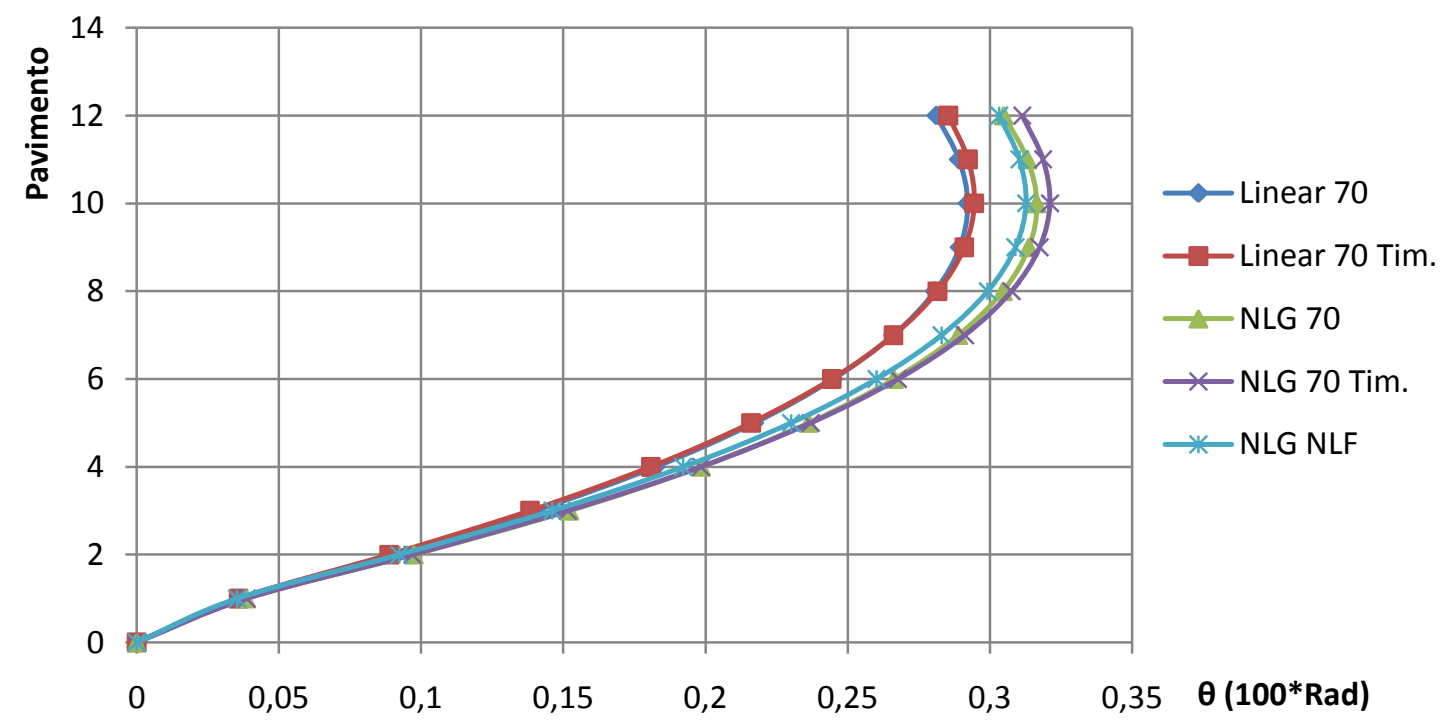

Figura 6.10: Rotação do pavimento em torno do eixo Y: 12C.

Independente da análise realizada é mostrada uma vista superior da configuração deformada típica da estrutura, através de um pós-processador desenvolvido no SET/EESC/USP.

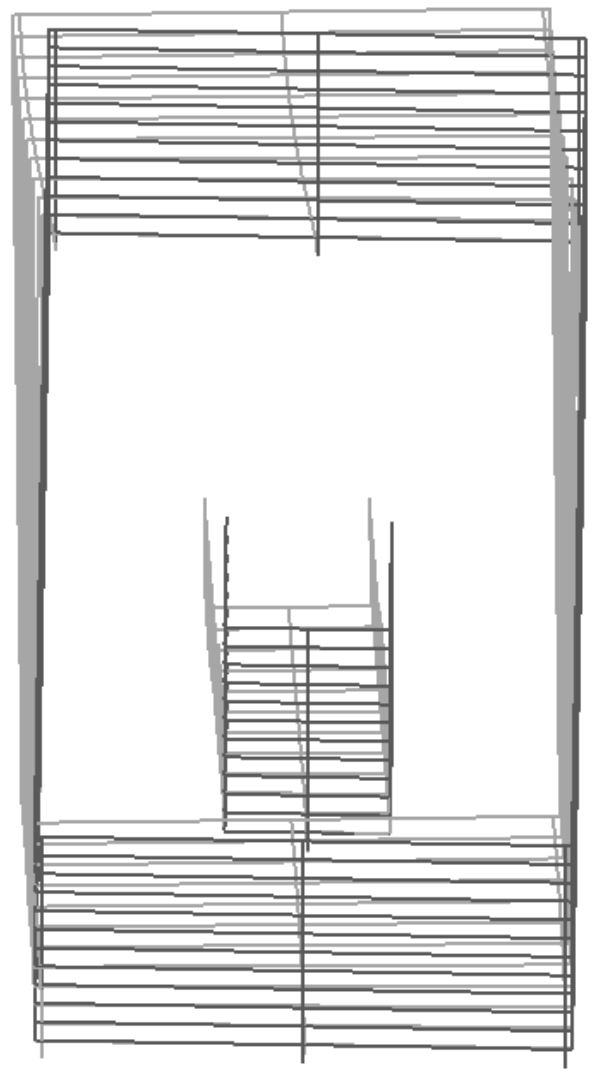

Figura 6.10: Configuração deformada típica da estrutura com 12 pavimentos. 
O intuito da realização destas análises adicionais, é mostrar que além da consideração das não linearidades de forma rigorosa, existem outras considerações de grande importância na modelagem de estruturas com núcleos de rigidez.

Devido á grande rigidez das estruturas estudadas neste exemplo, a influência das não linearidades geométrica e física é pequena, e a diferença nos resultados considerando a não linearidade física de forma rigorosa ou simplificada não são expressivos.

A consideração da deformação por esforço cortante, assim como concluído por TORRES (1999) em sua dissertação de mestrado, mostrou diferenças significativas nos deslocamentos considerando ou não a não linearidade geométrica. Para os deslocamentos na direção Z, a análise linear considerando a deformação por esforço cortante são maiores que os apresentados por uma análise não linear geométrica desprezando estas deformações. Para a situação de análise não linear geométrica, a consideração da deformação por esforço cortante apresenta deslocamentos ainda maiores.

\section{Sugestão para coeficiente redutor de inércia.}

Para este exemplo um coeficiente redutor igual a 0,90 para as paredes do núcleo representou de forma satisfatória os deslocamentos da estrutura. A seguir é mostrado com maiores detalhes os resultados obtidos com as análises não linear rigorosa, e as não lineares simplificadas, usando coeficientes redutores iguais 0,70 e 0,90 para as paredes dos núcleos. Os valores dos deslocamentos obtidos em cada uma das análises são mostrados no anexo C. 


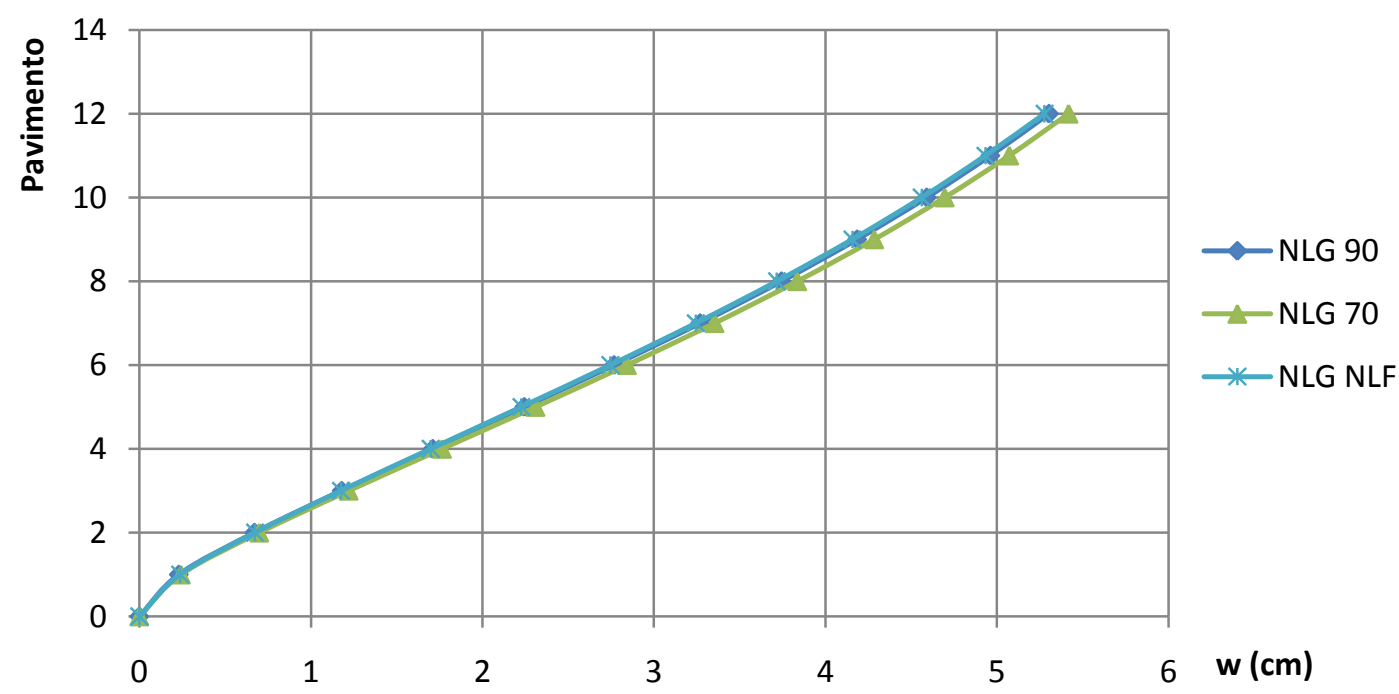

Figura 6.11: Deslocamento do pavimento na direção Z: 12A.

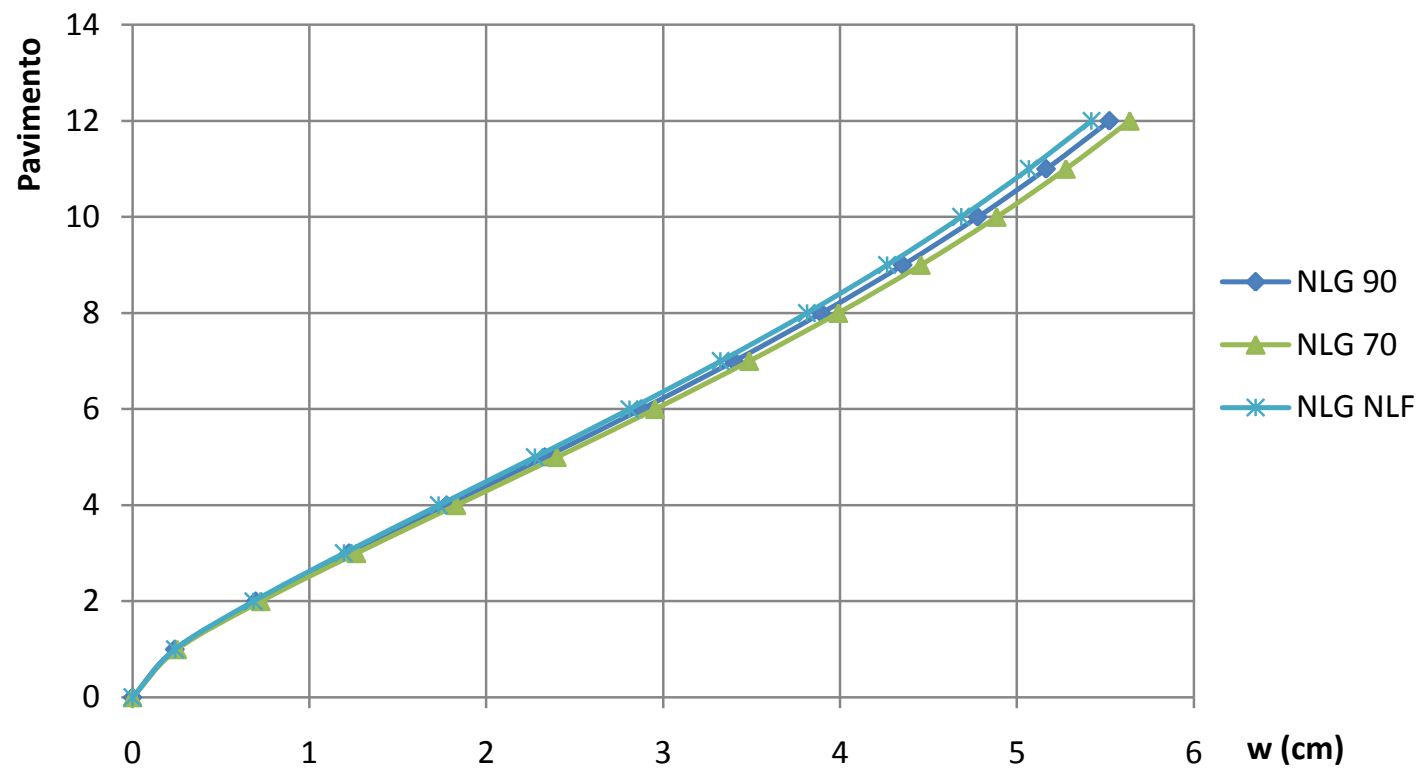

Figura 6.12: Deslocamento do pavimento na direção Z: 12B. 


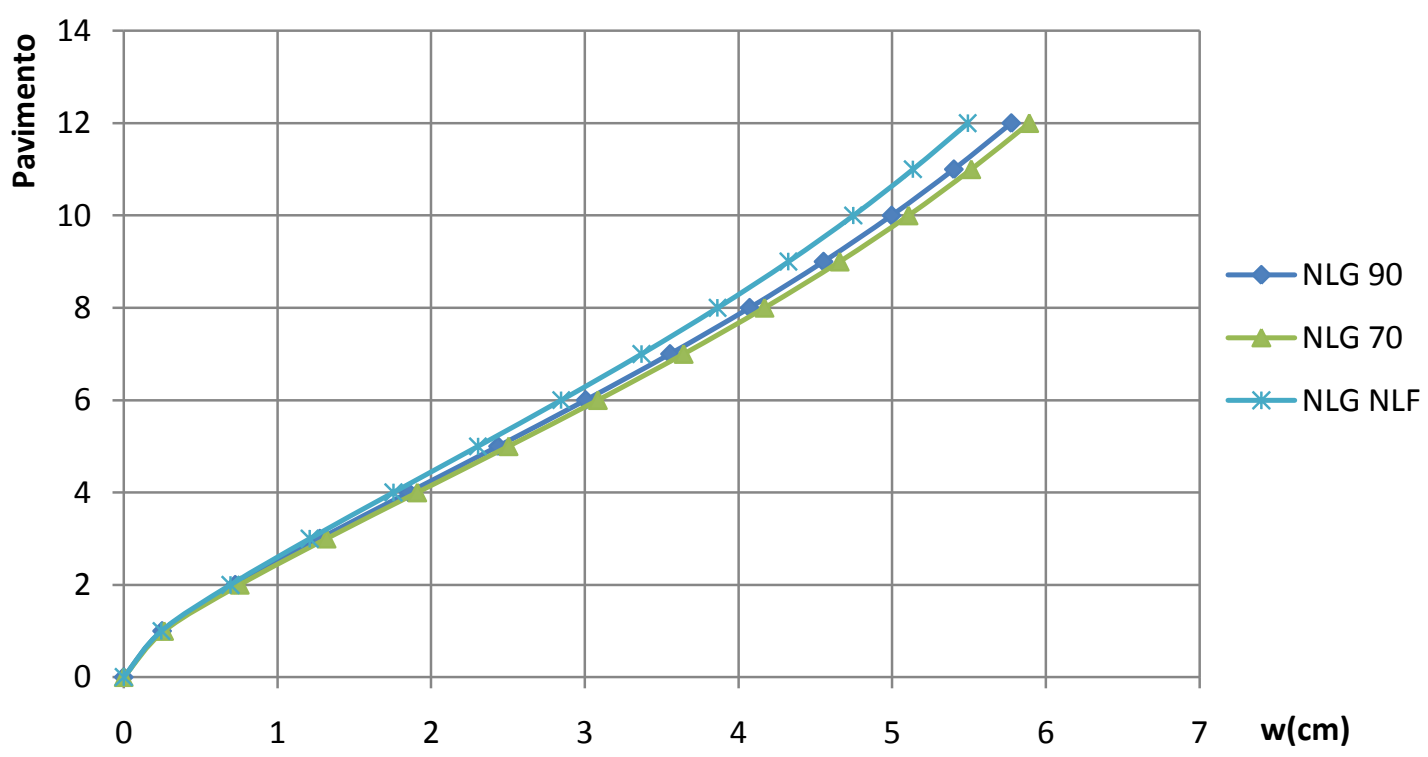

Figura 6.13: Deslocamento do pavimento na direção Z: 12C.

A boa representatividade do coeficiente redutor de inércia é verificada nos diagramas das figuras 6.11, 6.12 e 6.13. Devido ao baixo nível de não linearidade física observada nos modelos, para a situação $12 \mathrm{C}$, com maior taxa de armadura, a rigidez efetiva foi maior que aquela proposta pelo coeficiente redutor. Fatos justificado pelo aumento de rigidez conferido pela presença maior de barras de armadura. Para os 3 casos as deformações nas camadas de concreto foram muito pequenas, não penalizando assim de forma significativa o módulo de elasticidade do concreto.

Com o intuito de verificar a influência da não linearidade física sobre os esforços solicitantes, é feita uma comparação entre os momentos atuantes na direção de maior inércia da parede PAR 2. Serão comparados os resultados apresentados na análise não linear rigorosa, não linear simplificada com coeficientes redutores iguais a 0,70 e 0,90. Assim as análises serão chamadas NLG NLF, NLG 70, e NLG 90, respectivamente. 
Momentos nas paredes dos núcleos:

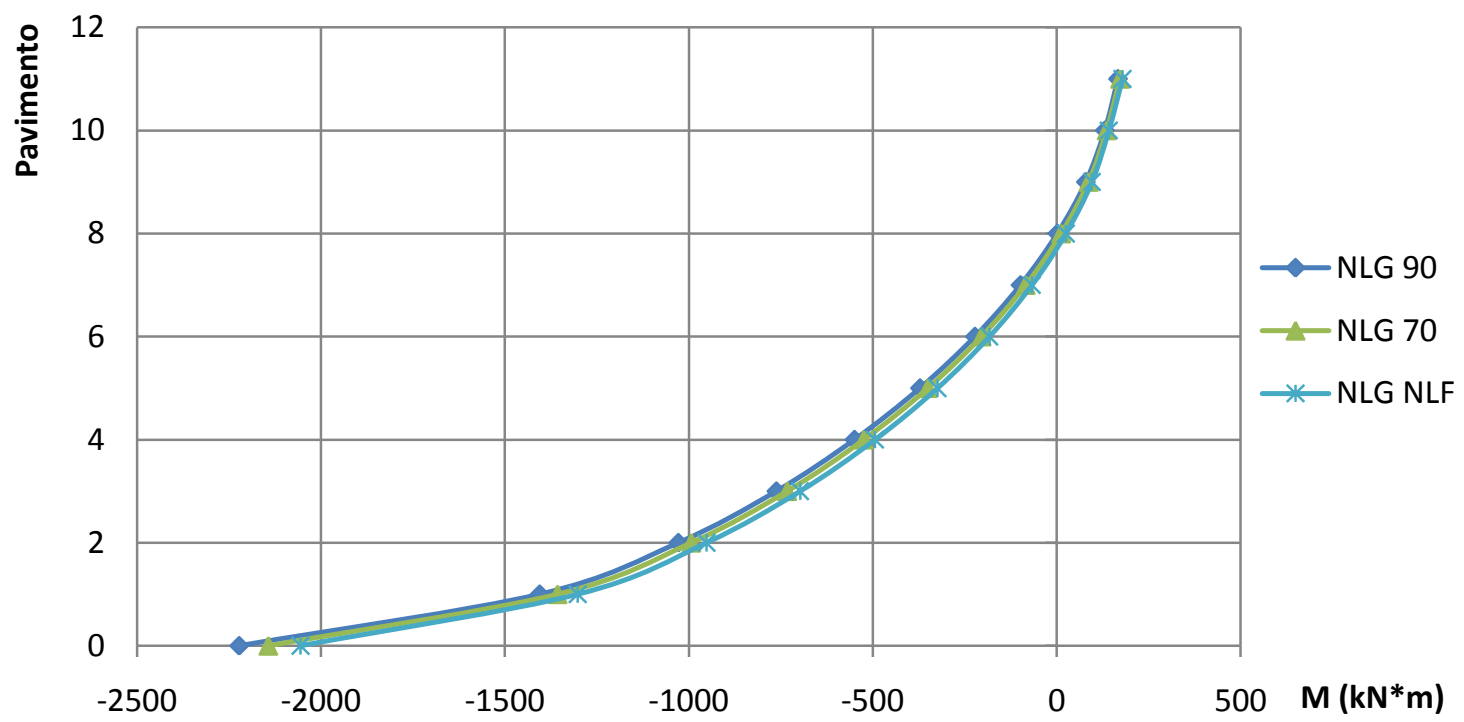

Figura 6.14: Momento em torno do eixo X da parede PAR 2: 12A.

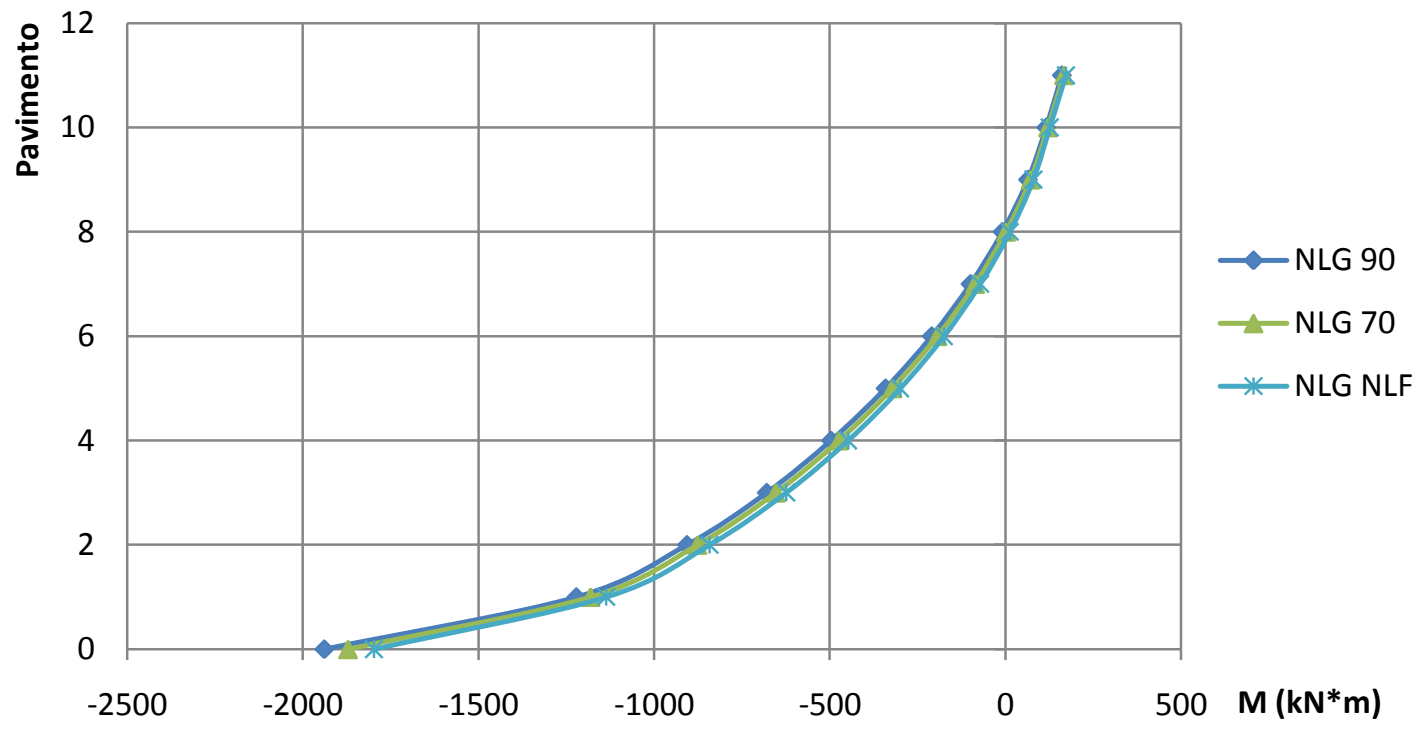

Figura 6.15: Momento em torno do eixo $X$ da parede PAR 2: $12 B$. 


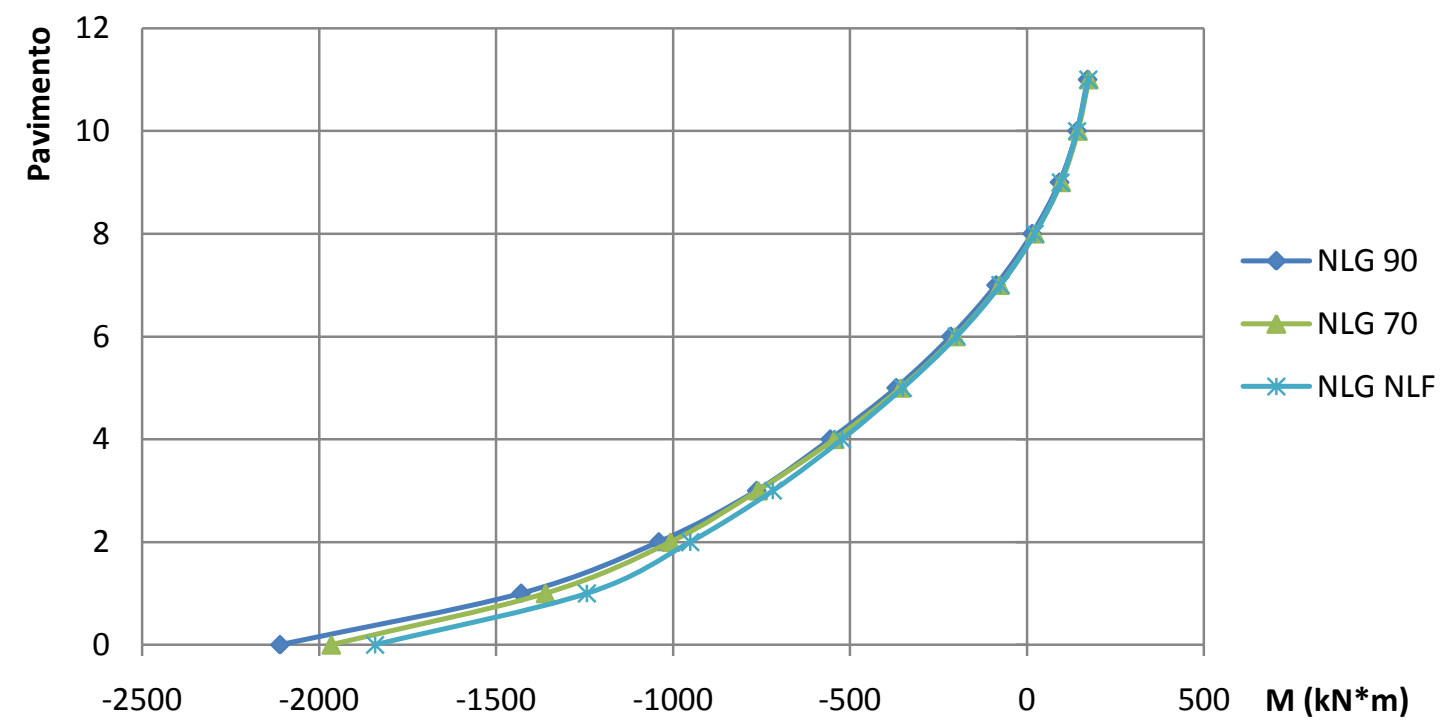

Figura 6.16: Momento em torno do eixo X da parede PAR 2: 12C.

Apesar da boa representatividade do coeficiente redutor proposto em termos de deslocamentos, esta mesma não é verificada com o mesmo nível para os esforços. Nos exemplos estudados, a rigidez efetiva das paredes é variável ao longo da altura do edifício. Desta forma para as paredes pertencentes aos primeiros andares, há uma maior diminuição da rigidez, enquanto para as paredes dos andares superiores a rigidez efetiva é maior devido ao menor nível de solicitação. Mesmo dispondo a armadura mínima, o nível de deformações nestas paredes não leva a diminuição da rigidez efetiva.

O caso que sofre maior influência da variação da rigidez efetiva ao longo da altura do edifício é aquele com maior taxa de armadura, 12C. Pois a diminuição da rigidez nas paredes dos andares inferiores é maior que nos casos com taxas de armadura média ou mínima. Para as situações com taxas de armadura mínima ou média, existe maior uniformidade da rigidez efetiva ao longo da altura do edifício, o que justifica melhor representatividade dos esforços através de um coeficiente redutor único para todas as paredes.

Para este exemplo, tomando como referência a análise não linear rigorosa, as simplificadas apresentam valores de momento ligeiramente maiores, sendo a análise considerando $90 \%$ da inércia o mais eficiente. 


\subsection{Edifício com 16 pavimentos}

Além das características comuns aos 3 exemplos, este exemplo apresenta as seguintes características particulares:

Número de pavimentos: 16

Espessura das paredes do núcleo: 15, 17 e $19 \mathrm{~cm}$

Dados da análise não linear geométrica:

Tabela 6.5 - Parâmetros físicos do concreto.

\begin{tabular}{|c|c|}
\hline \multicolumn{2}{|c|}{ Concreto } \\
\hline$f c k$ & $25.0 \mathrm{MPA}$ \\
\hline$E_{\text {Sec. }}$ & $23800.0 \mathrm{MPa}$ \\
\hline$G$ & $9916,7 \mathrm{MPa}$ \\
\hline$v$ & 0.20 \\
\hline
\end{tabular}

Parâmetros dos materiais empregados na análise não linear física e geométrica:

Tabela 6.6 - Parâmetros físicos dos materiais.

\begin{tabular}{|c|c|c|c|}
\hline \multicolumn{4}{|c|}{ Parâmetros dos materiais } \\
\hline \multicolumn{2}{|c|}{ Concreto } & \multicolumn{2}{c|}{ Aço } \\
\hline$f_{c}^{\prime}{ }_{c}$ & $28.5 \mathrm{MPa}$ & $f_{y}$ & $434.8 \mathrm{MPa}$ \\
\hline$f_{t}$ & $2.5 \mathrm{MPa}$ & $\varepsilon_{y}$ & 0.00207 \\
\hline$\varepsilon_{m}$ & 0.0020 & $E_{s}$ & $210000 \mathrm{MPa}$ \\
\hline$\alpha$ & 0.7 & $E_{s}{ }^{\prime}$ & $1000 \mathrm{MPa}$ \\
\hline
\end{tabular}


Tabela 6.7 - Resumo de armadura das paredes PAR 1 e PAR 3.

\begin{tabular}{|c|c|c|c|c|c|c|c|c|c|}
\hline \multirow{2}{*}{ Pav. } & \multicolumn{3}{|c|}{ A (t =19cm) } & \multicolumn{3}{c|}{ B (t =17cm) } & \multicolumn{3}{c|}{ C (t =15cm) } \\
\cline { 2 - 11 } & $\boldsymbol{\phi}(\mathbf{m m})$ & Esp. $(\mathbf{c m})$ & Quant. & $\boldsymbol{\phi ( \mathbf { m m } )}$ & Esp. $(\mathbf{c m})$ & Quant. & $\boldsymbol{\phi}(\mathbf{m m})$ & Esp. $(\mathbf{c m})$ & Quant. \\
\hline 1 & 12,5 & 11 & 36 & 16 & 7 & 58 & 16 & 6 & 66 \\
\hline 2 & 12,5 & 11 & 36 & 16 & 9 & 44 & 16 & 6 & 66 \\
\hline 3 & 12,5 & 15 & 26 & 12,5 & 9 & 44 & 16 & 7 & 58 \\
\hline 4 & 12,5 & 15 & 26 & 12,5 & 10 & 40 & 16 & 8 & 50 \\
\hline 5 & 10 & 14 & 28 & 10 & 16 & 26 & 16 & 12 & 34 \\
\hline 6 & 10 & 21 & 20 & 10 & 16 & 26 & 10 & 10 & 40 \\
\hline 7 & 10 & 21 & 20 & 10 & 23 & 18 & 10 & 26 & 16 \\
\hline 8 & 10 & 21 & 20 & 10 & 23 & 18 & 10 & 26 & 16 \\
\hline 9 & 10 & 21 & 20 & 10 & 23 & 18 & 10 & 26 & 16 \\
\hline 10 & 10 & 21 & 20 & 10 & 23 & 18 & 10 & 26 & 16 \\
\hline 11 & 10 & 21 & 20 & 10 & 23 & 18 & 10 & 26 & 16 \\
\hline 12 & 10 & 21 & 20 & 10 & 23 & 18 & 10 & 26 & 16 \\
\hline 13 & 10 & 21 & 20 & 10 & 23 & 18 & 10 & 26 & 16 \\
\hline 14 & 10 & 21 & 20 & 10 & 23 & 18 & 10 & 26 & 16 \\
\hline 15 & 10 & 21 & 20 & 10 & 23 & 18 & 10 & 26 & 16 \\
\hline 16 & 10 & 21 & 20 & 10 & 23 & 18 & 10 & 26 & 16 \\
\hline
\end{tabular}

Tabela 6.8 - Resumo de armadura da parede PAR 2.

\begin{tabular}{|c|c|c|c|c|c|c|c|c|c|}
\hline \multirow{2}{*}{ Pav. } & \multicolumn{3}{|c|}{ A (t=19cm) } & \multicolumn{3}{c|}{ B (t =17cm) } & \multicolumn{3}{c|}{ C (t =15cm) } \\
\cline { 2 - 11 } & $\boldsymbol{\phi}$ (mm) & Esp. (cm) & Quant. & $\boldsymbol{\phi ( m m )}$ & Esp. (cm) & Quant. & $\boldsymbol{\phi ( m m )}$ & Esp. (cm) & Quant. \\
\hline 1 & 10 & 21 & 28 & 10 & 16 & 38 & 10 & 18 & 34 \\
\hline 2 & 10 & 21 & 28 & 10 & 23 & 26 & 10 & 26 & 24 \\
\hline 3 & 10 & 21 & 28 & 10 & 23 & 26 & 10 & 26 & 24 \\
\hline 4 & 10 & 21 & 28 & 10 & 23 & 26 & 10 & 26 & 24 \\
\hline 5 & 10 & 21 & 28 & 10 & 23 & 26 & 10 & 26 & 24 \\
\hline 6 & 10 & 21 & 28 & 10 & 23 & 26 & 10 & 26 & 24 \\
\hline 7 & 10 & 21 & 28 & 10 & 23 & 26 & 10 & 26 & 24 \\
\hline 8 & 10 & 21 & 28 & 10 & 23 & 26 & 10 & 26 & 24 \\
\hline 9 & 10 & 21 & 28 & 10 & 23 & 26 & 10 & 26 & 24 \\
\hline 10 & 10 & 21 & 28 & 10 & 23 & 26 & 10 & 26 & 24 \\
\hline 11 & 10 & 21 & 28 & 10 & 23 & 26 & 10 & 26 & 24 \\
\hline 12 & 10 & 21 & 28 & 10 & 23 & 26 & 10 & 26 & 24 \\
\hline 13 & 10 & 21 & 28 & 10 & 23 & 26 & 10 & 26 & 24 \\
\hline 14 & 10 & 21 & 28 & 10 & 23 & 26 & 10 & 26 & 24 \\
\hline 15 & 10 & 21 & 28 & 10 & 23 & 26 & 10 & 26 & 24 \\
\hline 16 & 10 & 21 & 28 & 10 & 23 & 26 & 10 & 26 & 24 \\
\hline
\end{tabular}


Translações dos pavimentos na direção X.

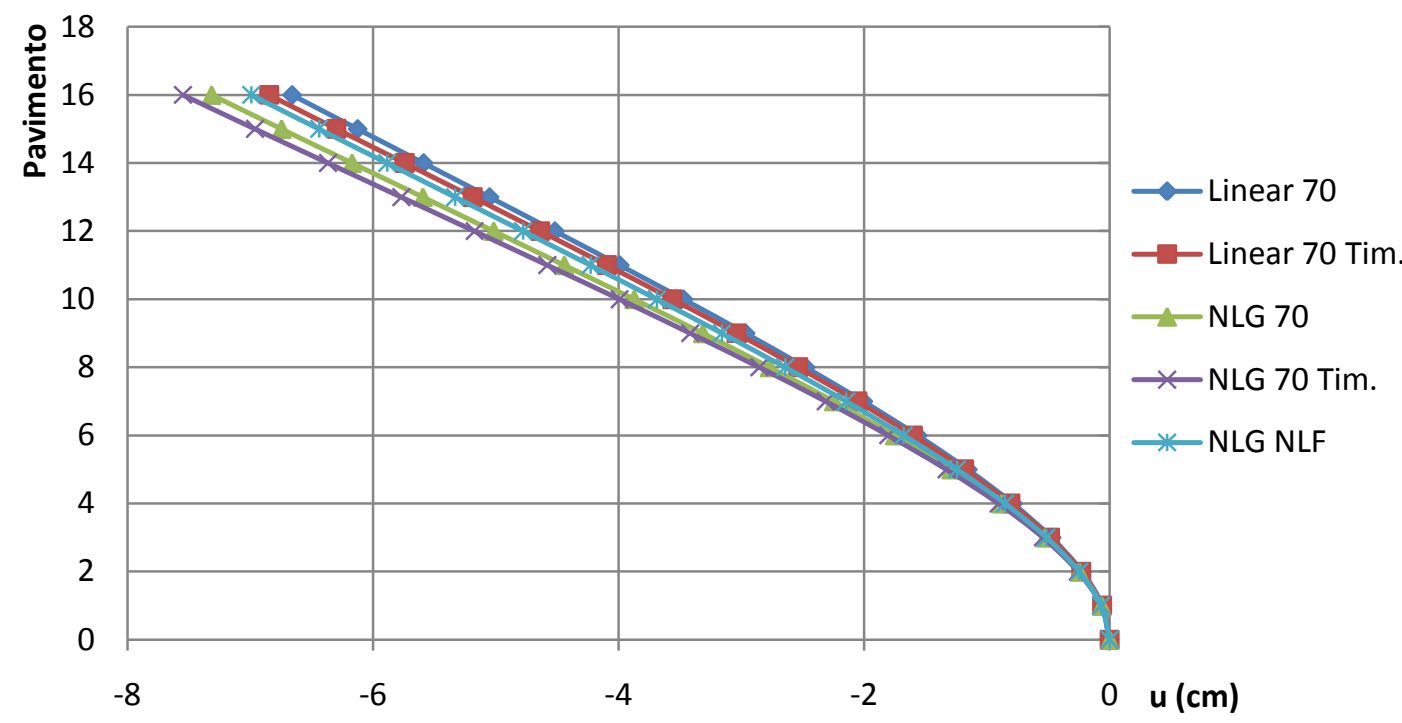

Figura 6.17: Deslocamento do pavimento na direção $X$ : 16A.

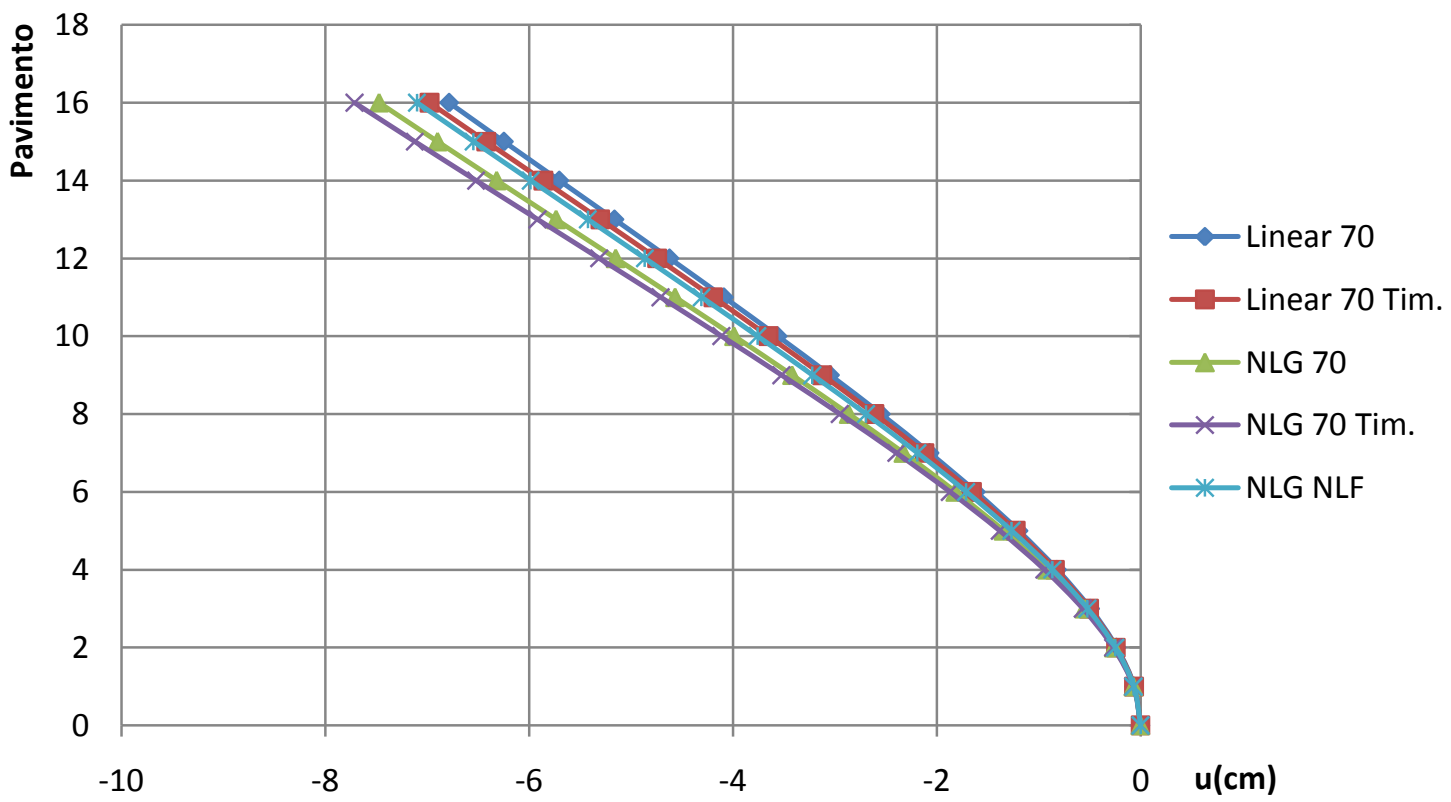

Figura 6.18: Deslocamento do pavimento na direção X: $16 B$. 


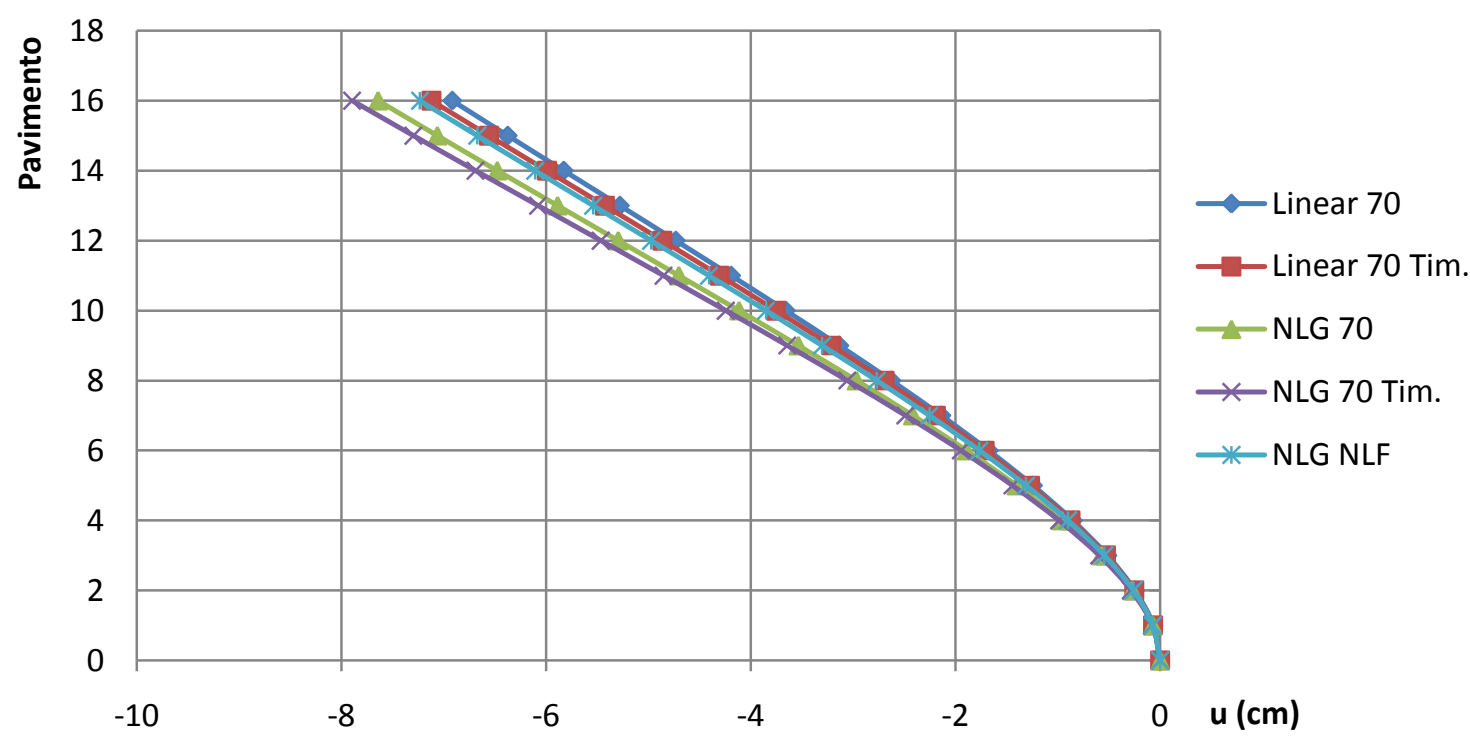

Figura 6.19: Deslocamento do pavimento na direção X: 16C.

Translações dos pavimentos na direção Z.

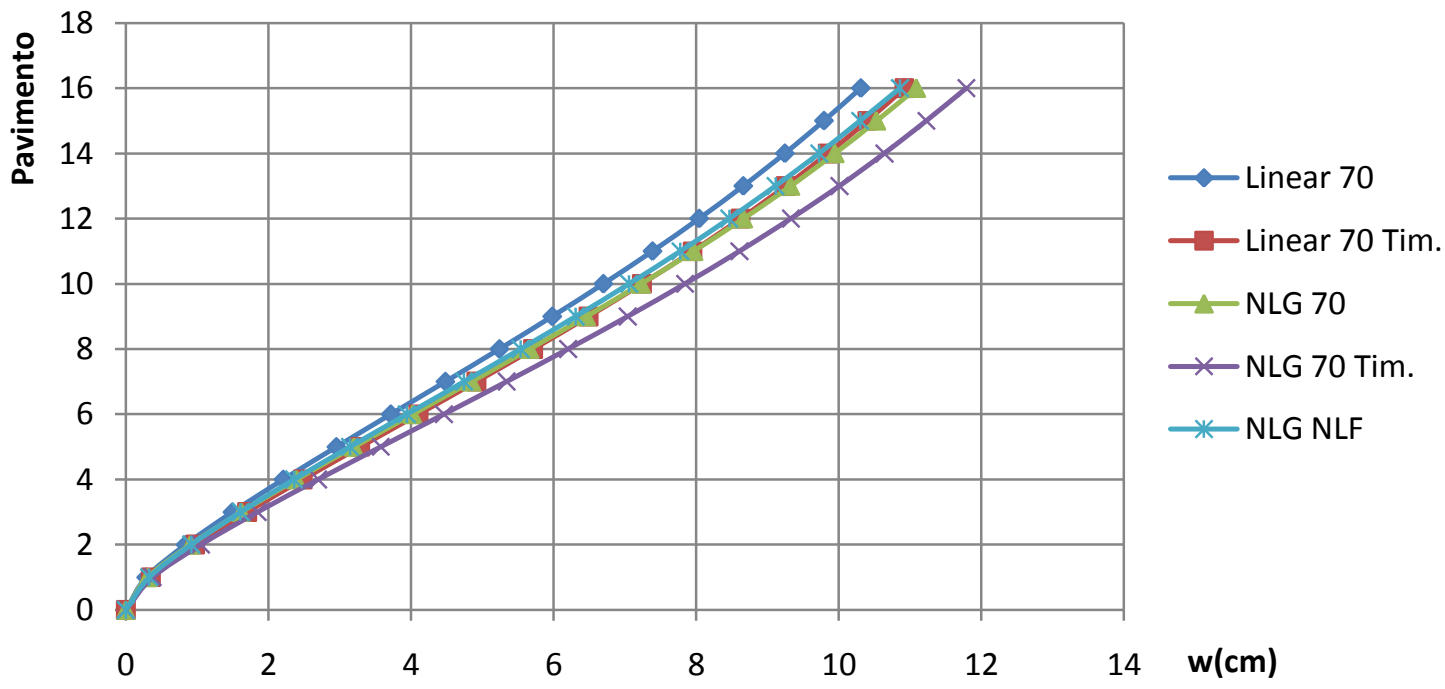

Figura 6.20: Deslocamento do pavimento na direção Z: 16A. 


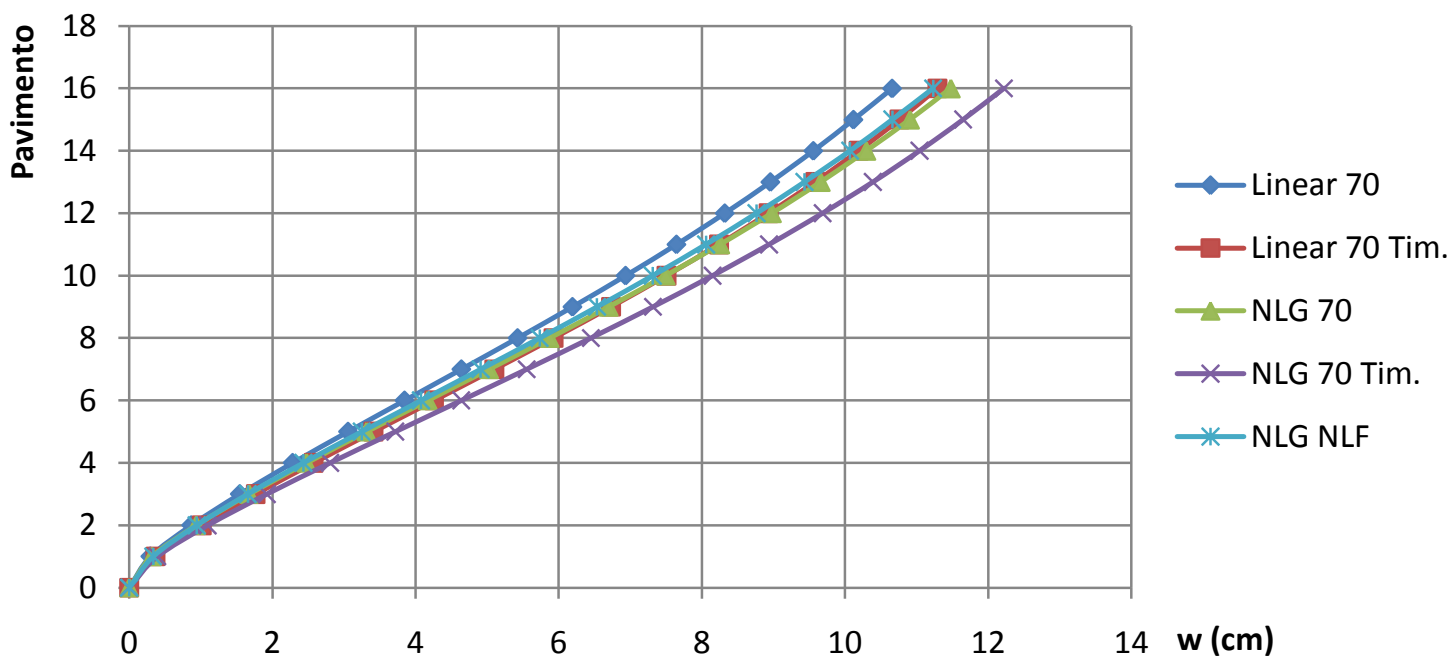

Figura 6.21: Deslocamento do pavimento na direção Z: 16B.

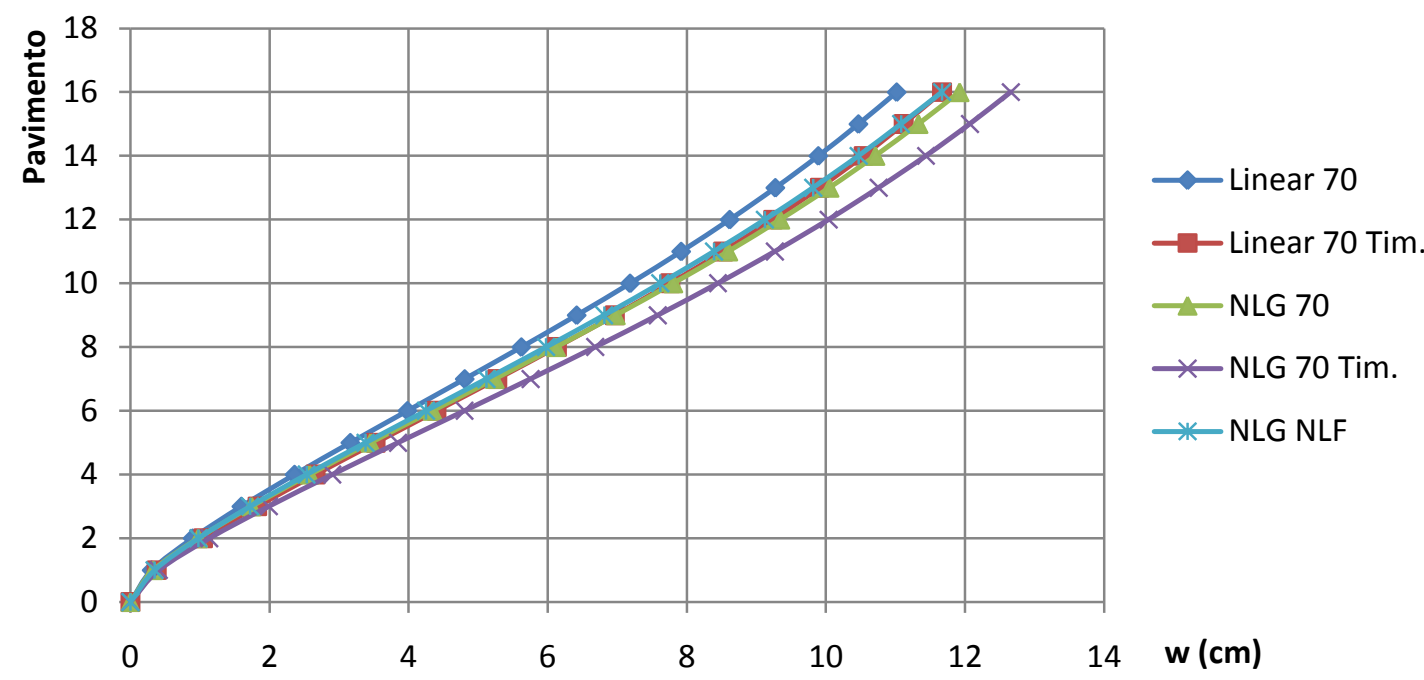

Figura 6.22: Deslocamento do pavimento na direção Z: 16C. 
Rotações dos pavimentos em torno do eixo Y.

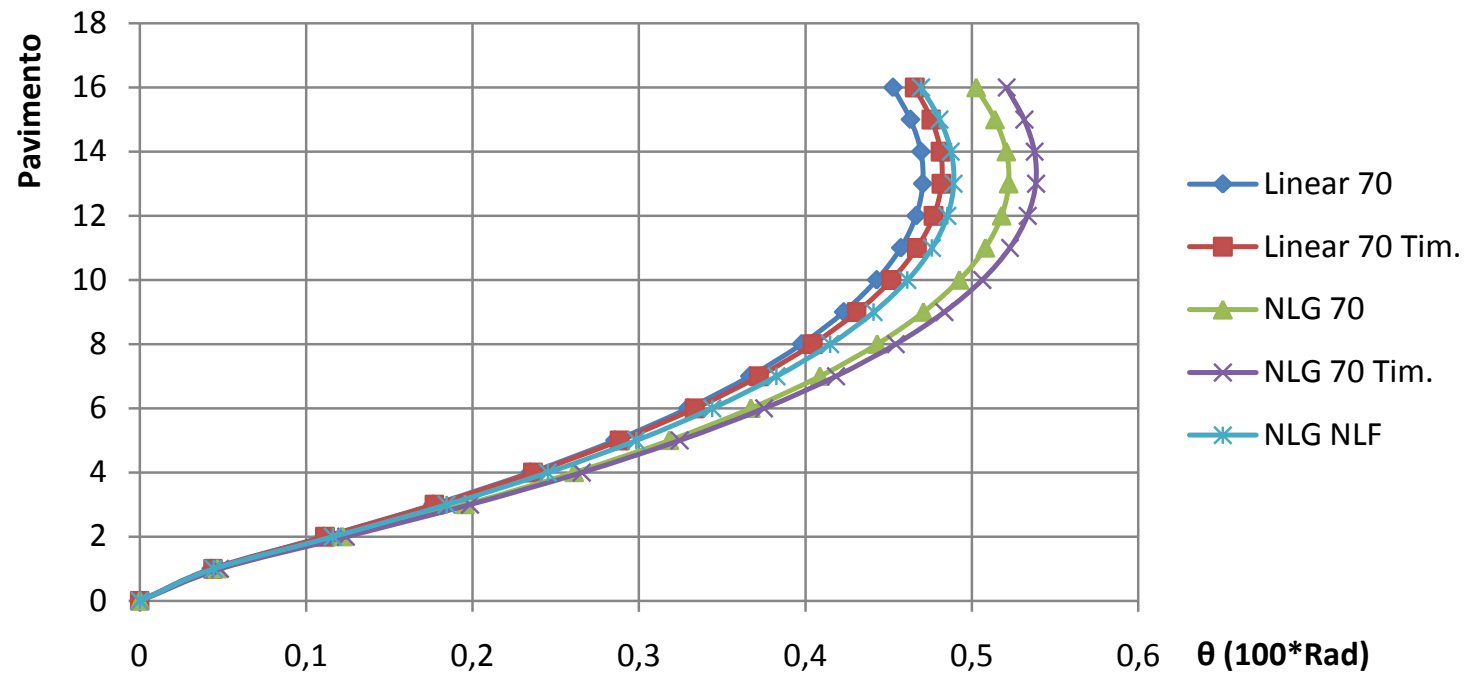

Figura 6.23: Rotação do pavimento em torno do eixo Y: 16A.

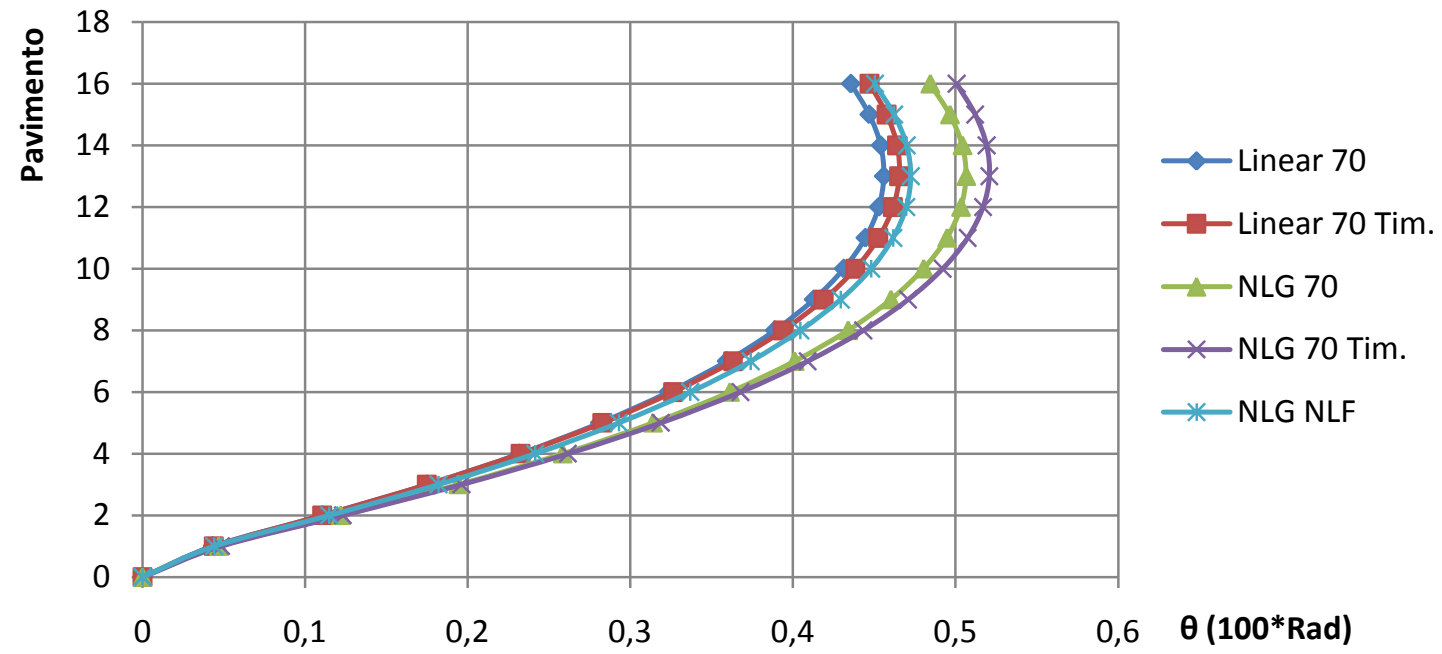

Figura 6.24: Rotação do pavimento em torno do eixo Y: $16 B$. 


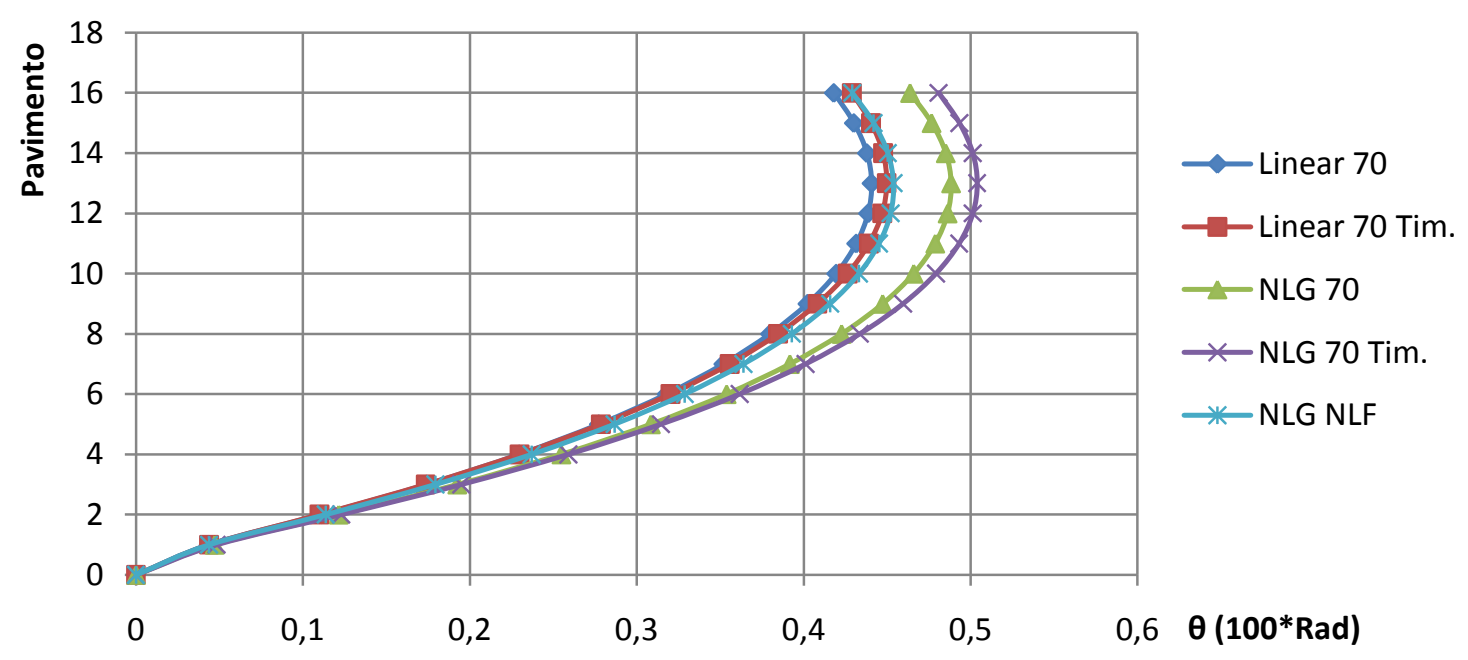

Figura 6.25: Rotação do pavimento em torno do eixo Y: 16C.

A comparação entre as diferentes análises levam a conclusões semelhantes ás mostradas no exemplo 1, a menos de algumas particularidades discutidas no próximo parágrafo.

Neste exemplo, a não linearidade geométrica tem uma influência um pouco maior que no exemplo anterior, a consideração da não linearidade física de forma simplificada está mais bem representada que no exemplo anterior. A influência da consideração por esforço cortante mais uma vez leva a deslocamentos significativamente maiores que aqueles obtidos das análises que as desprezam. Na figura 6.26 é mostrada a configuração deformada típica da estrutura. 


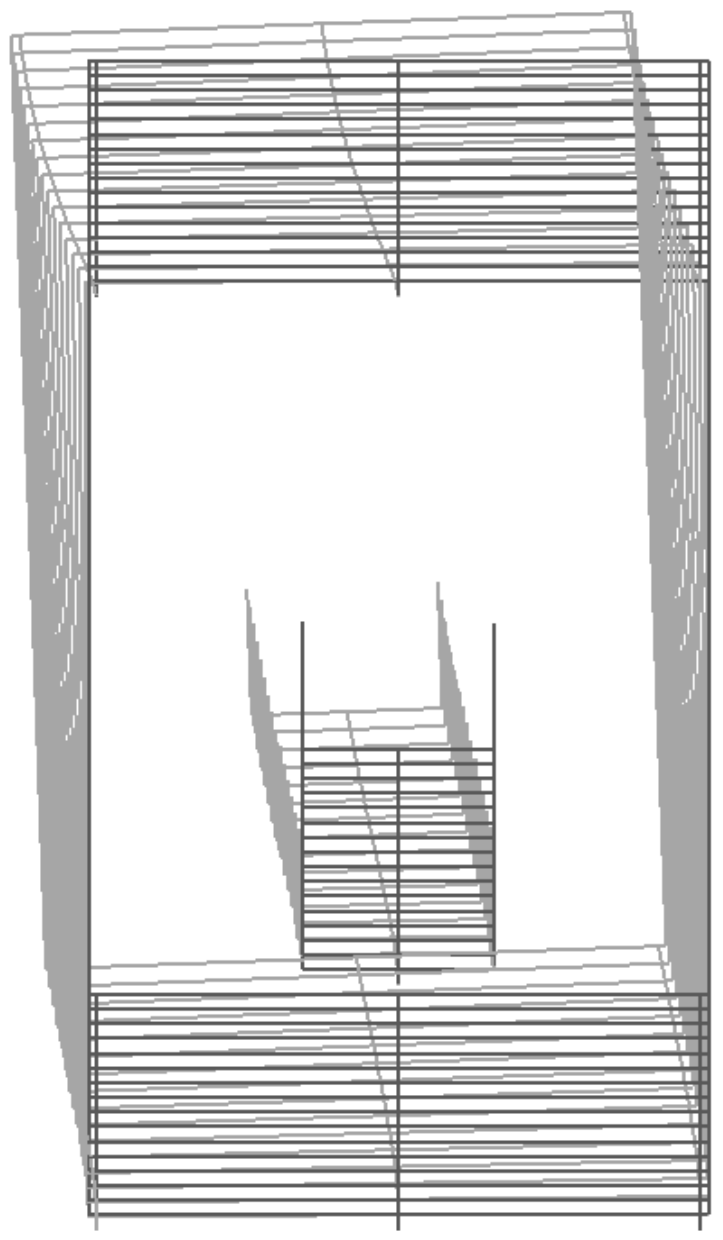

Figura 6.26: Configuração deformada típica da estrutura com 16 pavimentos.

\section{Sugestão para coeficiente redutor de inércia:}

Para este exemplo um coeficiente redutor igual a 0,90 representou de forma satisfatória os deslocamentos da estrutura, enquanto no exemplo anterior, para a situação com maior taxa de armadura há uma menor diminuição da rigidez, neste exemplo a diminuição de rigidez se apresenta uniforme para as 3 situações de taxa de armadura. A seguir é mostrado com maiores detalhes os resultados obtidos com as análises não linear rigorosa, e as não lineares simplificadas, usando coeficientes redutores iguais 0,70 e 0,90 para as paredes dos núcleos. Os valores dos deslocamentos obtidos em cada uma das análises são mostrados no anexo C. 


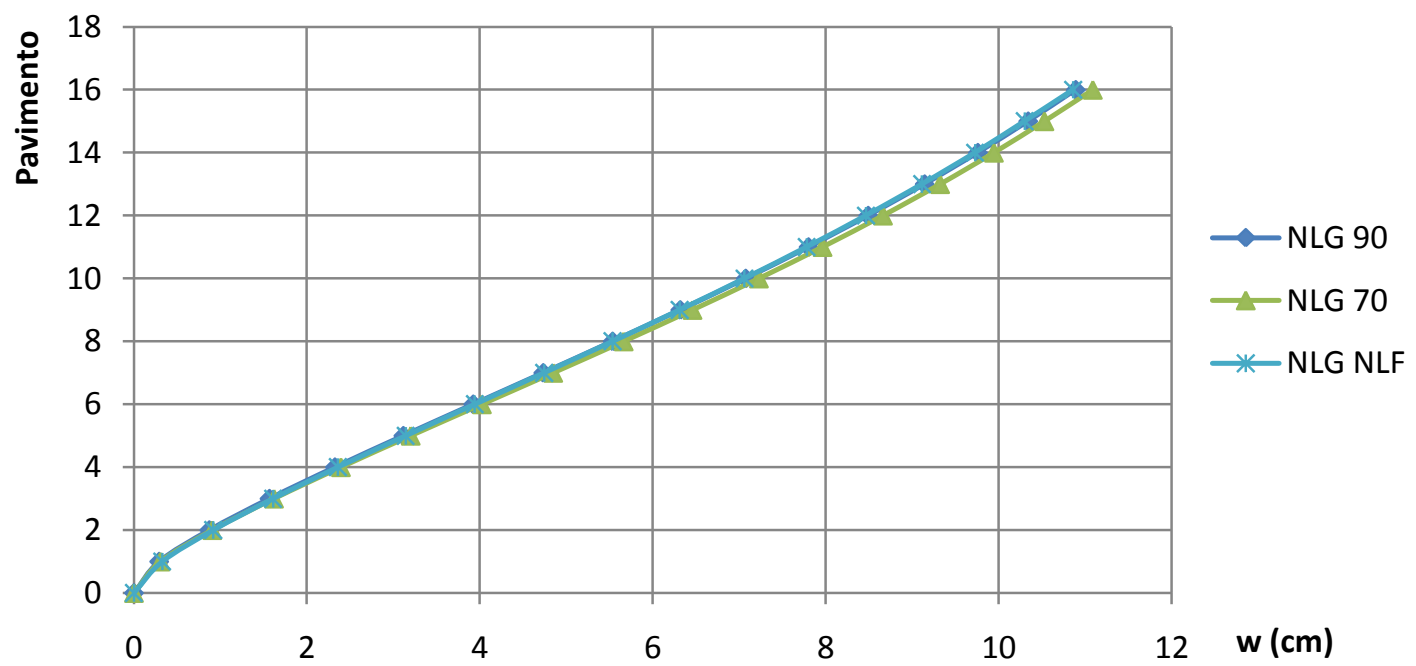

Figura 6.27: Deslocamento do pavimento na direção Z: 16A.

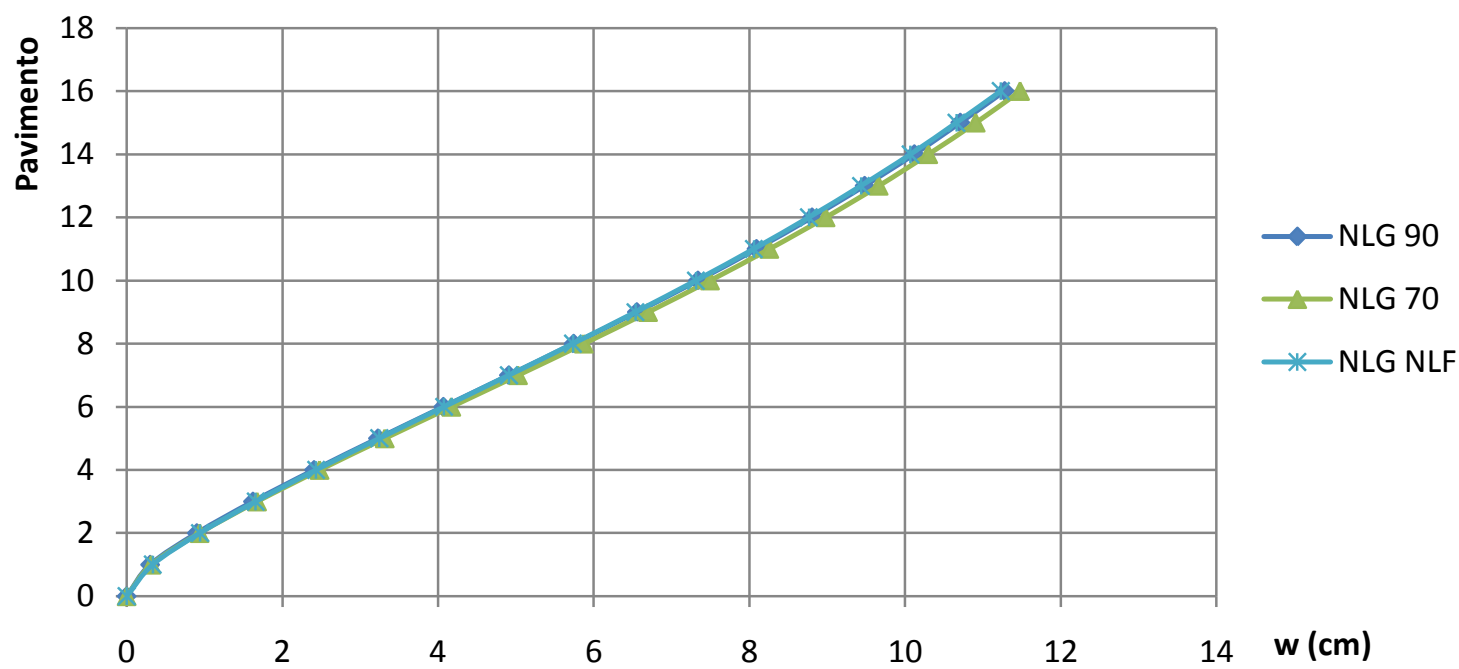

Figura 6.28: Deslocamento do pavimento na direção Z: $16 B$. 


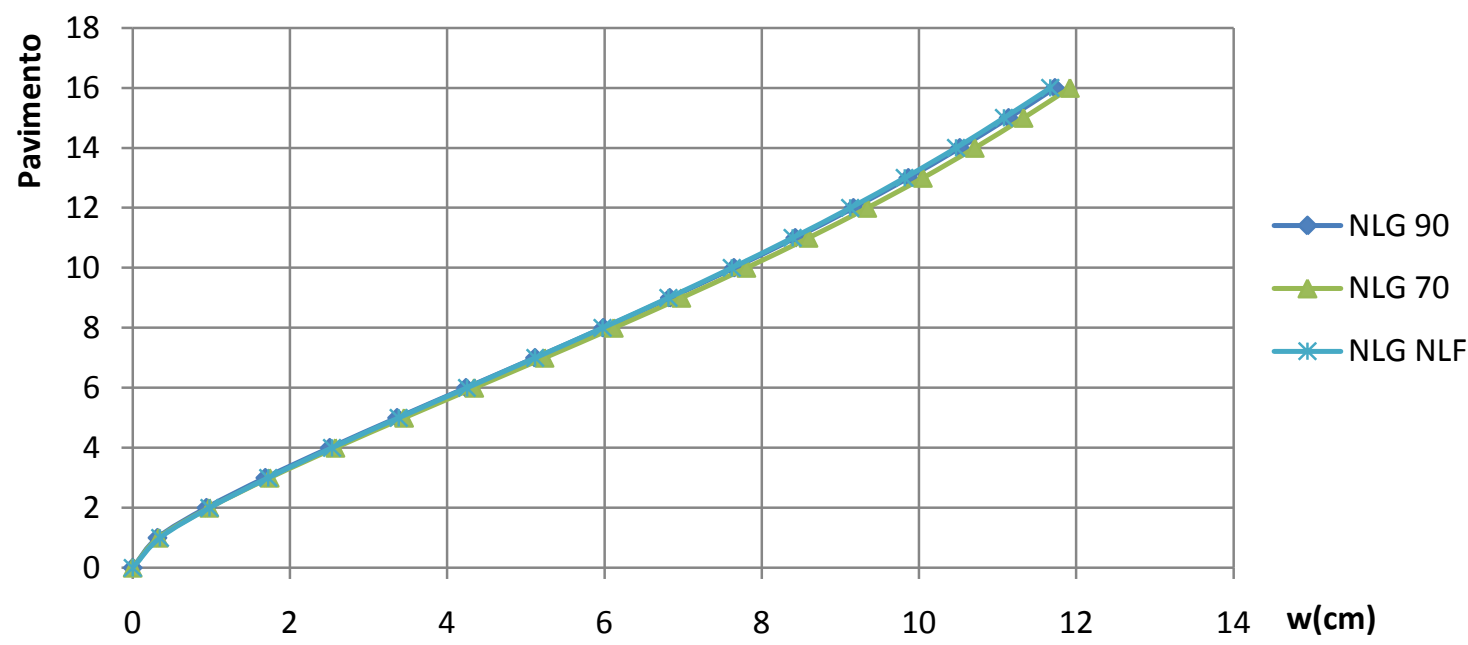

Figura 6.29: Deslocamento do pavimento na direção Z: 16C.

Representatividade do coeficiente redutor de inércia é verificada nos diagramas das figuras $6.27,6.28$ e 6.29. Para este exemplo o nível de representatividade do coeficiente redutor foi o mesmo para as 3 situações de taxas de armadura.

\section{Momentos nas paredes dos núcleos:}

Com o intuito de verificar a influência da não linearidade física sobre os esforços solicitantes, é feita uma comparação entre os momentos atuantes na direção de maior inércia da parede PAR 2. Serão comparados os resultados apresentados na análise não linear rigorosa, não linear simplificada com coeficientes redutores iguais a 0,70 e 0,90 . Assim as análises serão chamadas NLG NLF, NLG 70, e NLG 90, respectivamente. 


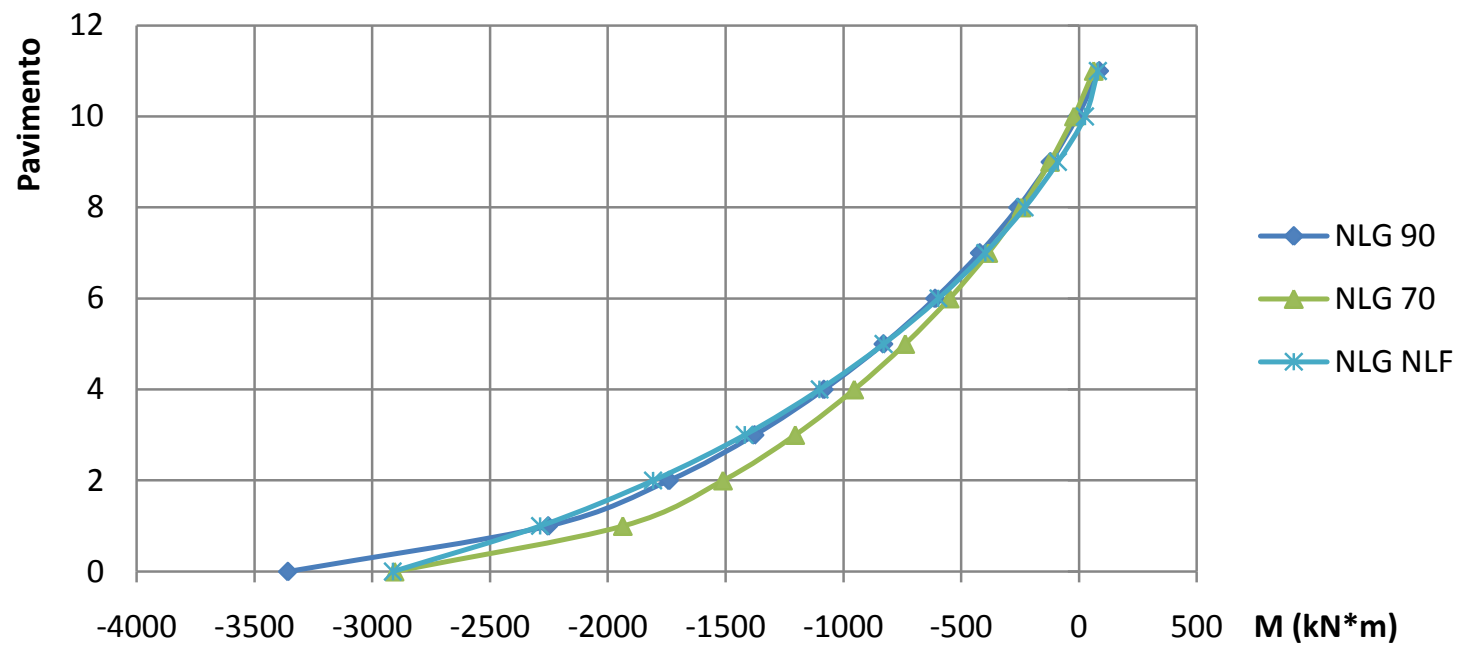

Figura 6.30: Momento em torno do eixo X da parede PAR 2: 16A.

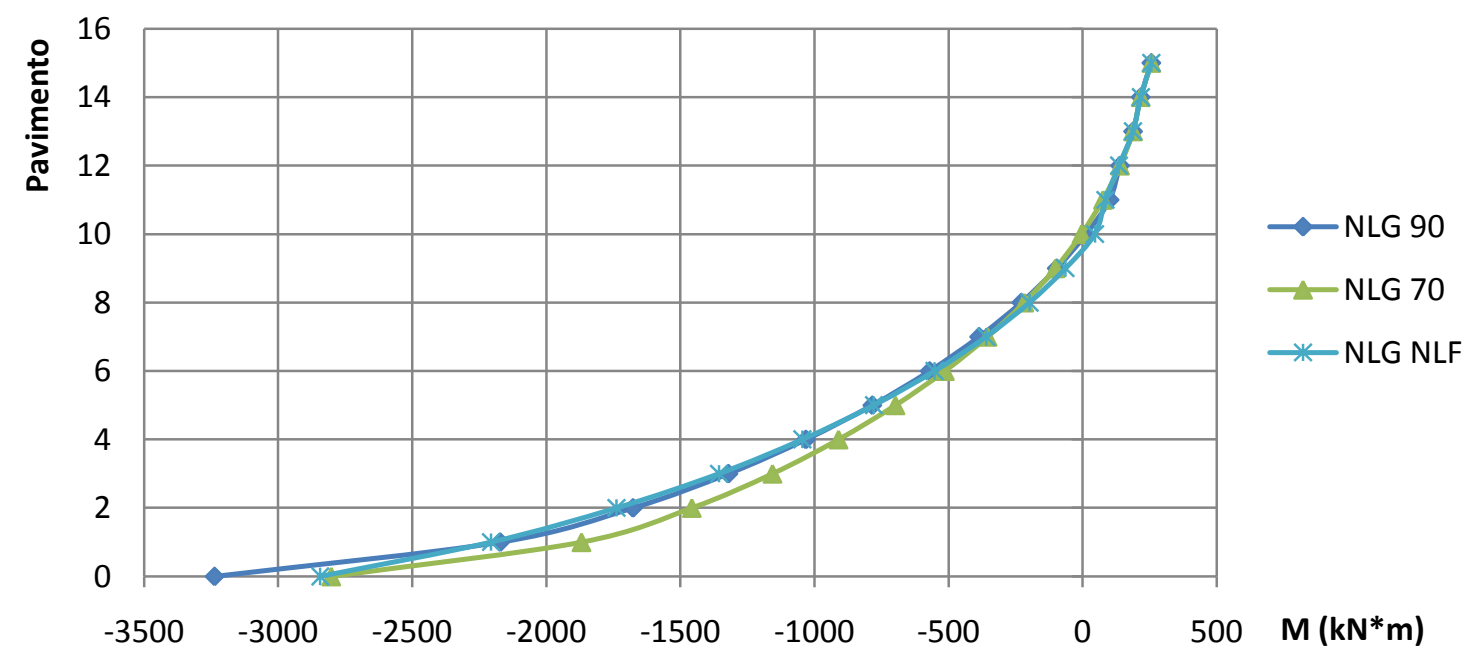

Figura 6.31: Momento em torno do eixo X da parede PAR 2: $16 B$. 


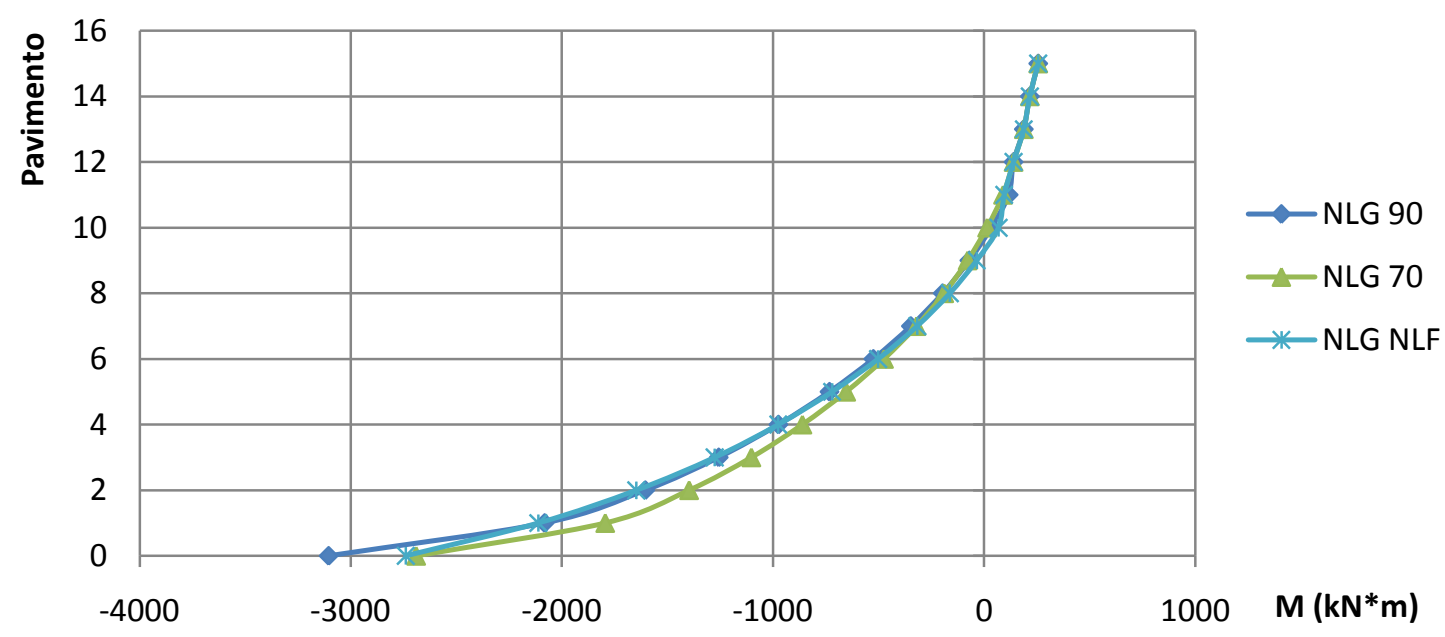

Figura 6.32: Momento em torno do eixo X da parede PAR 2: 16C.

Neste exemplo, a representatividade dos esforços fornecidos pelas análises simplificadas tem diferenças maiores que as do exemplo anterior. Devido a uma maior variação da rigidez efetiva ao longo da altura do edifício, os coeficientes de redução usados nas análises simplificadas levam a momentos com significativa diferença. A seguir são comentadas as diferenças apresentadas.

A boa representatividade da análise simplificada usando $90 \%$ da inércia é verificada nas 3 situações de taxas de armadura, para o primeiro andar, nas 3 situações, o momento obtido desta análise é maior que aquele obtido na análise rigorosa. Para as análises usando $70 \%$ da inércia, os valores dos momentos são menores que os obtidos na análise rigorosa nos seis primeiros andares para as 3 situações, sendo a diferença maior no caso com menor taxa de armadura. 


\subsection{Edifício com 20 pavimentos.}

Além das características comuns aos 3 exemplos, este exemplo apresenta as seguintes características particulares:

Número de pavimentos: 20

Espessura das paredes do núcleo: 17, 19 e $21 \mathrm{~cm}$

Dados da análise não linear geométrica:

Tabela 6.9 - Parâmetros físicos do concreto.

\begin{tabular}{|c|c|}
\hline \multicolumn{2}{|c|}{ Concreto } \\
\hline$f c k$ & $30.0 \mathrm{MPa}$ \\
\hline$E_{\text {Sec. }}$ & $26071.6 \mathrm{MPa}$ \\
\hline$G$ & $10866.2 \mathrm{MPa}$ \\
\hline$v$ & 0.20 \\
\hline
\end{tabular}

Parâmetros dos materiais empregados na análise não linear física e geométrica:

Tabela 6.10 - Parâmetros físicos dos materiais.

\begin{tabular}{|c|c|c|c|}
\hline \multicolumn{4}{|c|}{ Parâmetros dos materiais } \\
\hline \multicolumn{2}{|c|}{ Concreto } & \multicolumn{2}{c|}{ Aço } \\
\hline$f^{\prime}{ }_{c}$ & $33.5 \mathrm{MPa}$ & $f_{y}$ & $434.8 \mathrm{MPa}$ \\
\hline$f_{t}$ & $3.0 \mathrm{MPa}$ & $\varepsilon_{y}$ & 0.00207 \\
\hline$\varepsilon_{m}$ & 0.0020 & $E_{s}$ & $210000 \mathrm{MPa}$ \\
\hline$\alpha$ & 0.7 & $E_{s}{ }^{\prime}$ & $1000 \mathrm{MPa}$ \\
\hline
\end{tabular}


Tabela 6.11 - Resumo de armadura das paredes PAR 1 e PAR 3.

\begin{tabular}{|c|c|c|c|c|c|c|c|c|c|}
\hline \multirow{2}{*}{ Pav. } & \multicolumn{3}{|c|}{$A(t=21 \mathrm{~cm})$} & \multicolumn{3}{|c|}{$B(t=19 \mathrm{~cm})$} & \multicolumn{3}{|c|}{$\mathrm{C}(\mathrm{t}=17 \mathrm{~cm})$} \\
\hline & $\phi(\mathbf{m m})$ & Esp. (cm) & Quant. & $\phi(\mathbf{m m})$ & Esp. (cm) & Quant. & $\phi(\mathbf{m m})$ & Esp. (cm) & Quant. \\
\hline 1 & 12,5 & 9 & 44 & 16 & 10 & 40 & 16 & 6 & 66 \\
\hline 2 & 12,5 & 17 & 24 & 16 & 10 & 40 & 16 & 6 & 66 \\
\hline 3 & 12,5 & 17 & 24 & 16 & 12 & 34 & 16 & 7 & 58 \\
\hline 4 & 12,5 & 17 & 24 & 12,5 & 12 & 34 & 12,5 & 7 & 58 \\
\hline 5 & 10 & 19 & 22 & 10 & 21 & 20 & 12,5 & 9 & 44 \\
\hline 6 & 10 & 19 & 22 & 10 & 21 & 20 & 10 & 13 & 30 \\
\hline 7 & 10 & 19 & 22 & 10 & 21 & 20 & 10 & 23 & 18 \\
\hline 8 & 10 & 19 & 22 & 10 & 21 & 20 & 10 & 23 & 18 \\
\hline 9 & 10 & 19 & 22 & 10 & 21 & 20 & 10 & 23 & 18 \\
\hline 10 & 10 & 19 & 22 & 10 & 21 & 20 & 10 & 23 & 18 \\
\hline 11 & 10 & 19 & 22 & 10 & 21 & 20 & 10 & 23 & 18 \\
\hline 12 & 10 & 19 & 22 & 10 & 21 & 20 & 10 & 23 & 18 \\
\hline 13 & 10 & 19 & 22 & 10 & 21 & 20 & 10 & 23 & 18 \\
\hline 14 & 10 & 19 & 22 & 10 & 21 & 20 & 10 & 23 & 18 \\
\hline 15 & 10 & 19 & 22 & 10 & 21 & 20 & 10 & 23 & 18 \\
\hline 16 & 10 & 19 & 22 & 10 & 21 & 20 & 10 & 23 & 18 \\
\hline 17 & 10 & 19 & 22 & 10 & 21 & 20 & 10 & 23 & 18 \\
\hline 18 & 10 & 19 & 22 & 10 & 21 & 20 & 10 & 23 & 18 \\
\hline 19 & 10 & 19 & 22 & 10 & 21 & 20 & 10 & 23 & 18 \\
\hline 20 & 10 & 19 & 22 & 10 & 21 & 20 & 10 & 23 & 18 \\
\hline
\end{tabular}


Tabela 6.12 - Resumo de armadura da parede PAR 2.

\begin{tabular}{|c|c|c|c|c|c|c|c|c|c|}
\hline \multirow{2}{*}{ Pav. } & \multicolumn{3}{|c|}{ A } & \multicolumn{3}{c|}{ B } & \multicolumn{3}{c|}{ C } \\
\cline { 2 - 10 } & $\boldsymbol{\phi}(\mathbf{m m})$ & Esp. (cm) & Quant. & $\boldsymbol{\phi}(\mathbf{m m})$ & Esp. (cm) & Quant. & $\boldsymbol{\phi}(\mathbf{m m})$ & Esp. (cm) & Quant. \\
\hline 1 & 10 & 19 & 32 & 10 & 13 & 46 & 10 & 13 & 46 \\
\hline 2 & 10 & 19 & 32 & 10 & 21 & 28 & 10 & 23 & 26 \\
\hline 3 & 10 & 19 & 32 & 10 & 21 & 28 & 10 & 23 & 26 \\
\hline 4 & 10 & 19 & 32 & 10 & 21 & 28 & 10 & 23 & 26 \\
\hline 5 & 10 & 19 & 32 & 10 & 21 & 28 & 10 & 23 & 26 \\
\hline 6 & 10 & 19 & 32 & 10 & 21 & 28 & 10 & 23 & 26 \\
\hline 7 & 10 & 19 & 32 & 10 & 21 & 28 & 10 & 23 & 26 \\
\hline 8 & 10 & 19 & 32 & 10 & 21 & 28 & 10 & 23 & 26 \\
\hline 9 & 10 & 19 & 32 & 10 & 21 & 28 & 10 & 23 & 26 \\
\hline 10 & 10 & 19 & 32 & 10 & 21 & 28 & 10 & 23 & 26 \\
\hline 11 & 10 & 19 & 32 & 10 & 21 & 28 & 10 & 23 & 26 \\
\hline 12 & 10 & 19 & 32 & 10 & 21 & 28 & 10 & 23 & 26 \\
\hline 13 & 10 & 19 & 32 & 10 & 21 & 28 & 10 & 23 & 26 \\
\hline 14 & 10 & 19 & 32 & 10 & 21 & 28 & 10 & 23 & 26 \\
\hline 15 & 10 & 19 & 32 & 10 & 21 & 28 & 10 & 23 & 26 \\
\hline 16 & 10 & 19 & 32 & 10 & 21 & 28 & 10 & 23 & 26 \\
\hline 17 & 10 & 19 & 32 & 10 & 21 & 28 & 10 & 23 & 26 \\
\hline 18 & 10 & 19 & 32 & 10 & 21 & 28 & 10 & 23 & 26 \\
\hline 19 & 10 & 19 & 32 & 10 & 21 & 28 & 10 & 23 & 26 \\
\hline 20 & 10 & 19 & 32 & 10 & 21 & 28 & 10 & 23 & 26 \\
\hline
\end{tabular}

A seguir são mostrados os resultados referentes aos deslocamentos do nó mestre de cada pavimento. Os valores dos deslocamentos podem ser consultados no anexo C.

Translações dos pavimentos na direção X.

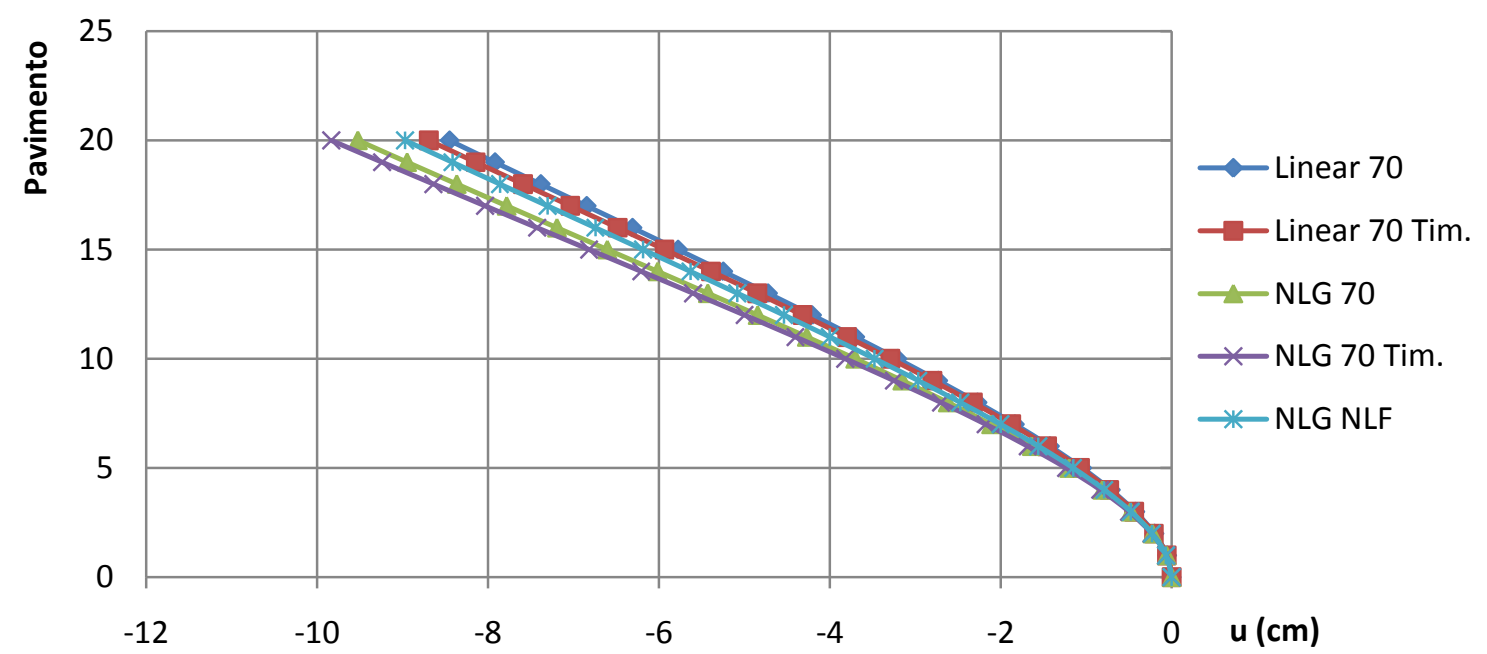

Figura 6.37: Deslocamento do pavimento na direção X: 20A. 


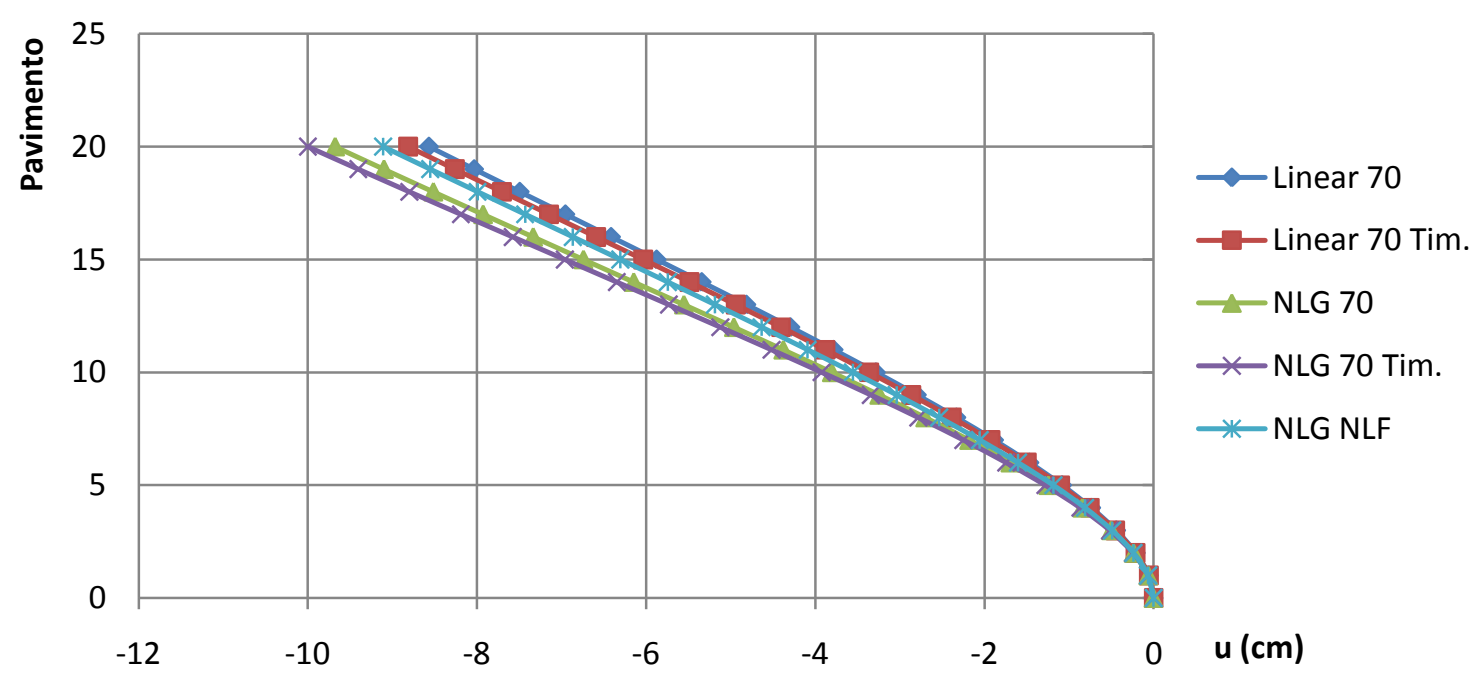

Figura 6.38: Deslocamento do pavimento na direção X: 20B.

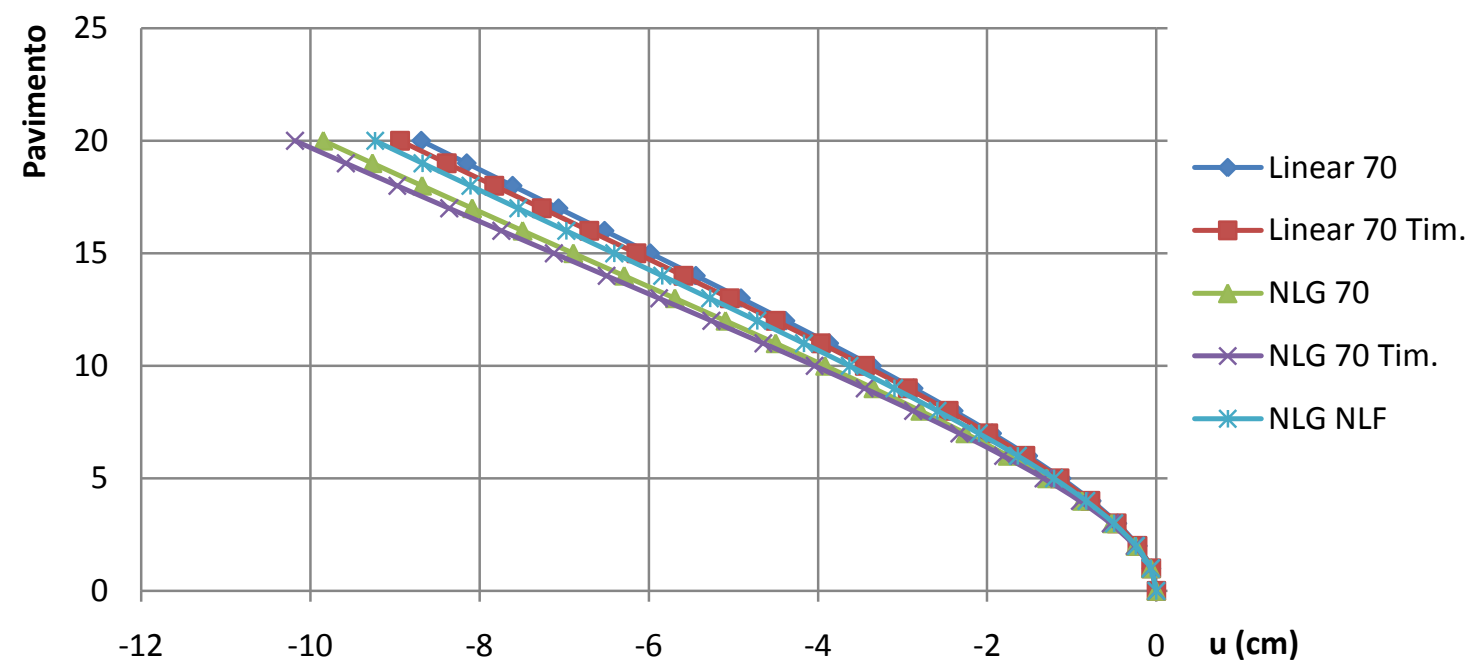

Figura 6.39: Deslocamento do pavimento na direção X: 20C. 
Translações dos pavimentos na direção Z.

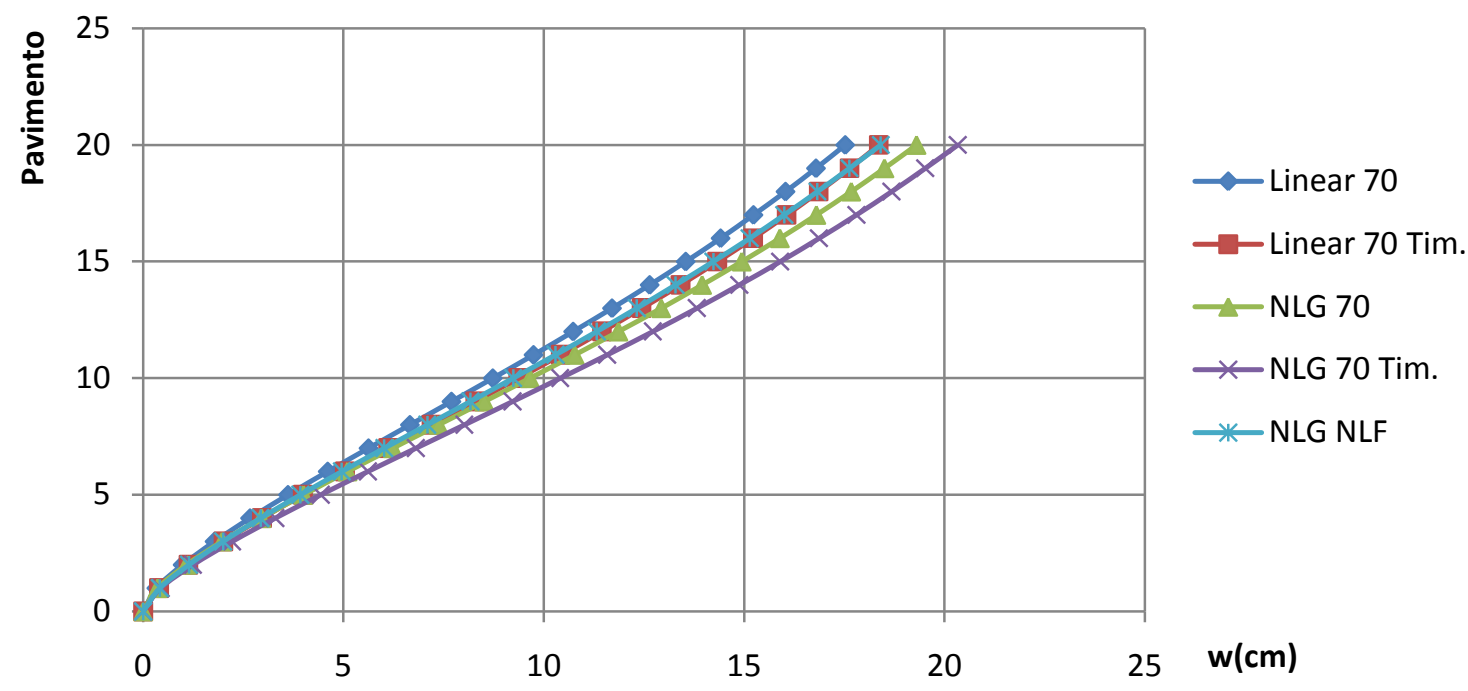

Figura 6.40: Deslocamento do pavimento na direção Z: 20A.

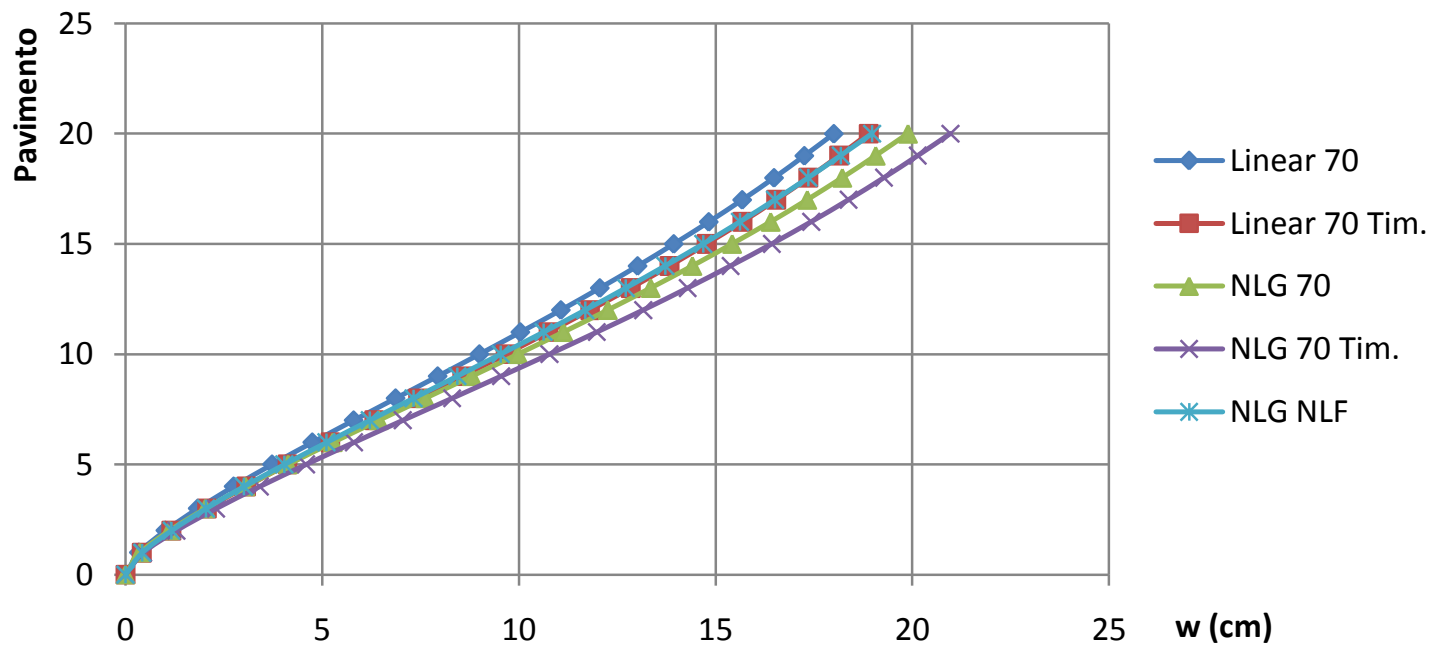

Figura 6.41: Deslocamento do pavimento na direção Z: 20B. 


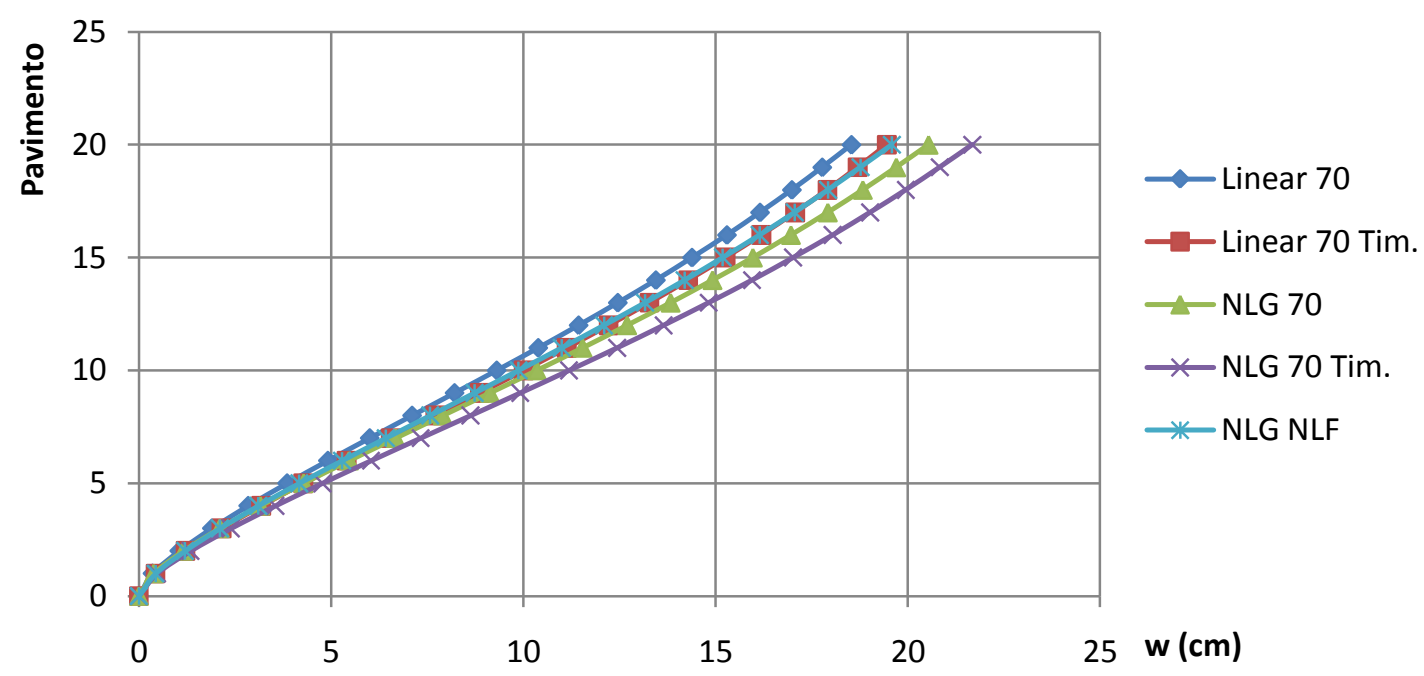

Figura 6.42: Deslocamento do pavimento na direção Z: 20C.

Rotações dos pavimentos em torno do eixo Y.

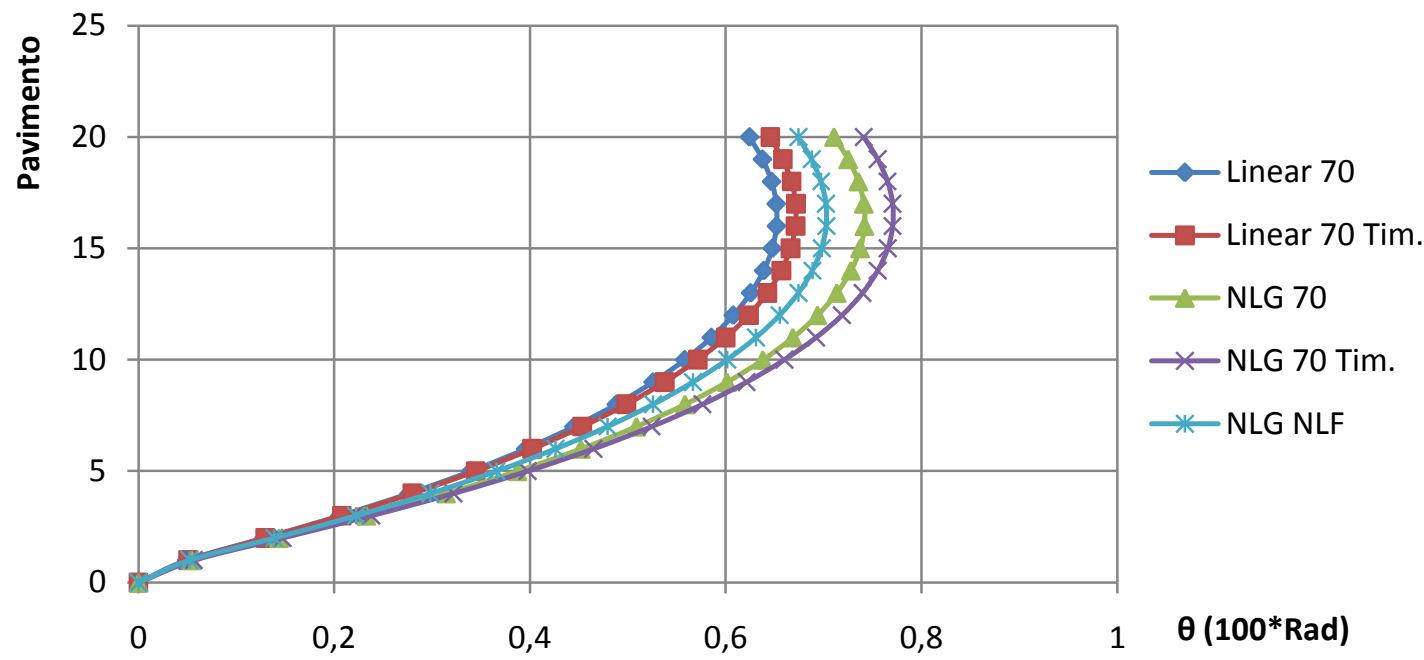

Figura 6.43: Rotação do pavimento em torno do eixo Y: 20A. 


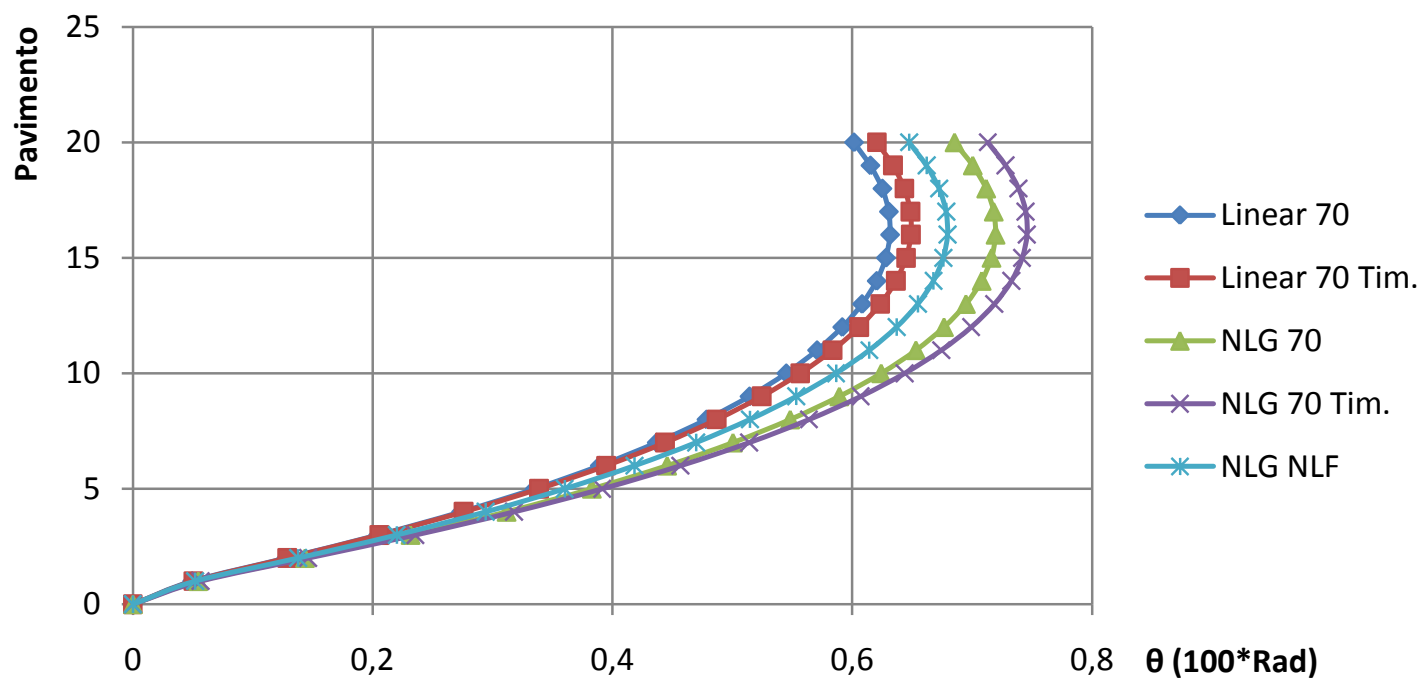

Figura 6.44: Rotação do pavimento em torno do eixo Y: $20 B$.

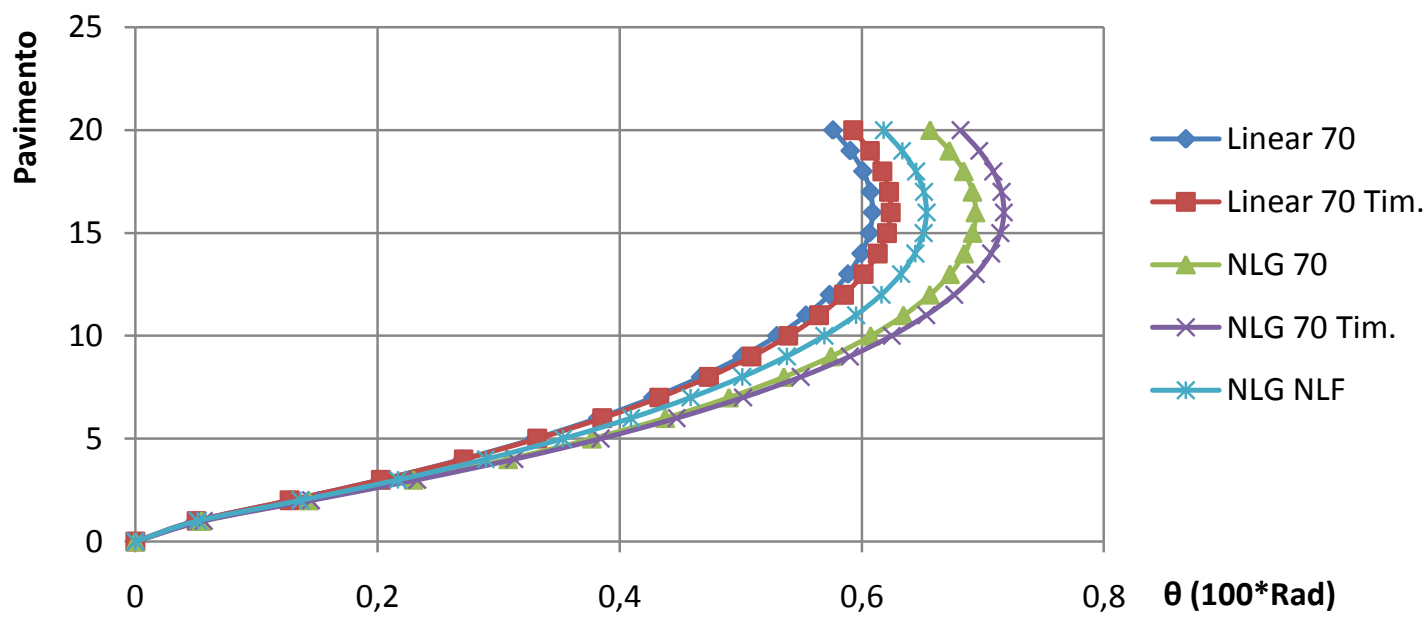

Figura 6.45: Rotação do pavimento em torno do eixo Y: 20C.

A análise comparativa dos deslocamentos deste exemplo, além do aumento da influência da não linearidade geométrica, confirma a tendência de comportamento mostrada nos exemplos anteriores. Na figura 6.46 é mostrada a configuração deformada típica da estrutura: 


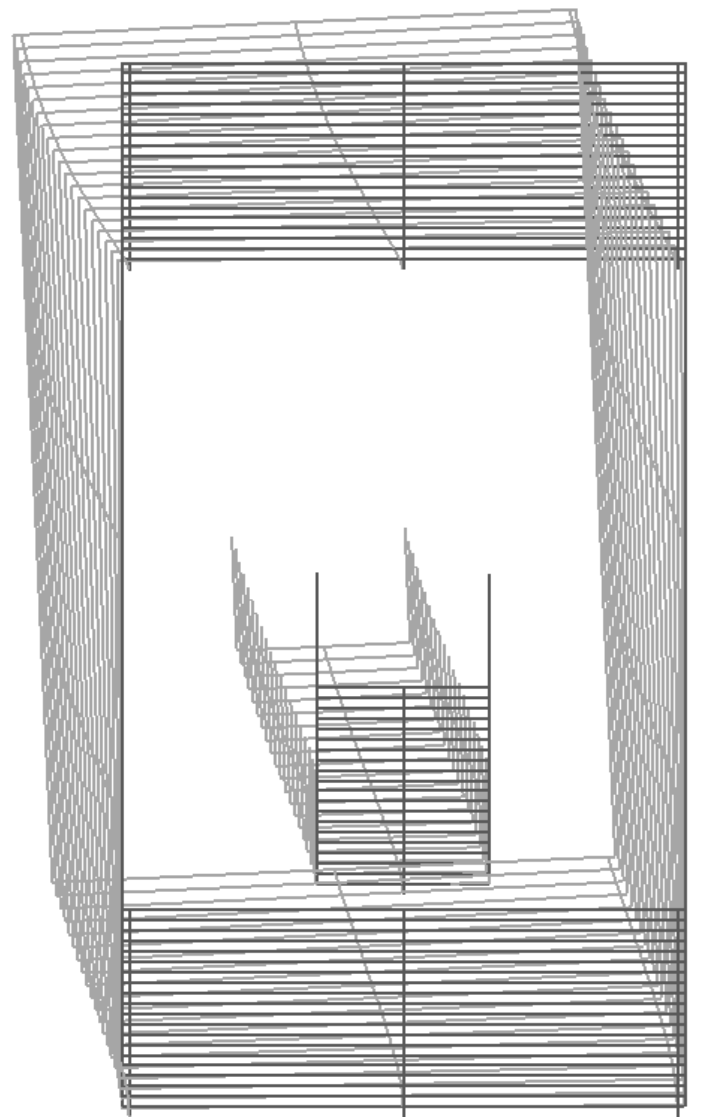

Figura 6.46: Configuração deformada típica da estrutura com 20 pavimentos.

\section{Sugestão de coeficiente redutor de inércia:}

Para este exemplo um coeficiente redutor igual a 0,90 representou de forma satisfatória os deslocamentos da estrutura até o $15^{\circ}$ pavimento. Coeficientes maiores representaram melhor o deslocamento dos últimos pavimentos, mas subestimaram os deslocamentos dos demais pavimentos. A adoção do coeficiente igual a 0,90 é justificada pelo fato de que para esta estrutura, nos últimos pavimentos, devido á grande inércia das paredes em relação ás solicitações, a rigidez efetiva é maior que a rigidez calculada usando a inércia bruta da seção.

A seguir são mostrados com maiores detalhes os resultados obtidos com as análises não linear rigorosa, e as não lineares simplificadas, usando coeficientes redutores iguais a 0,70 e 0,90 para as paredes dos núcleos. Os valores dos deslocamentos obtidos em cada uma das análises são mostrados no anexo C. 


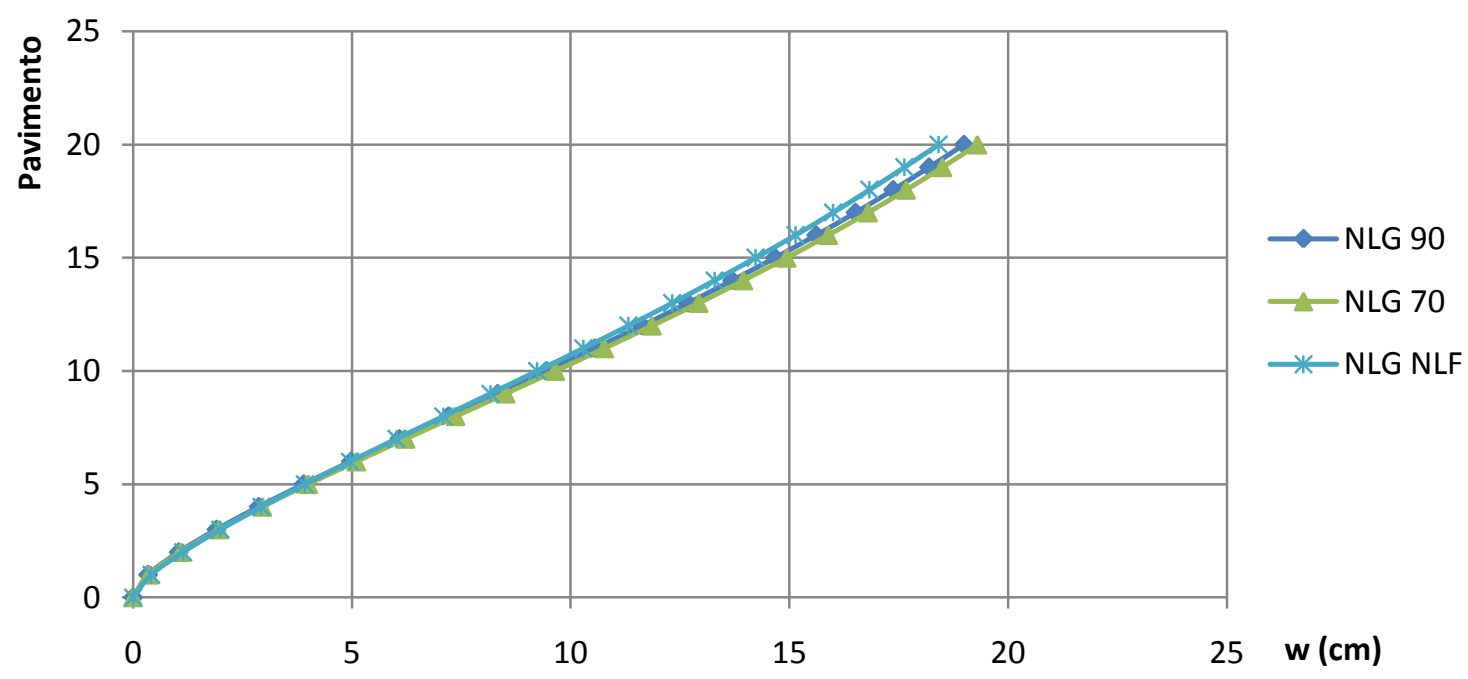

Figura 6.47: Deslocamento do pavimento na direção Z: 20A.

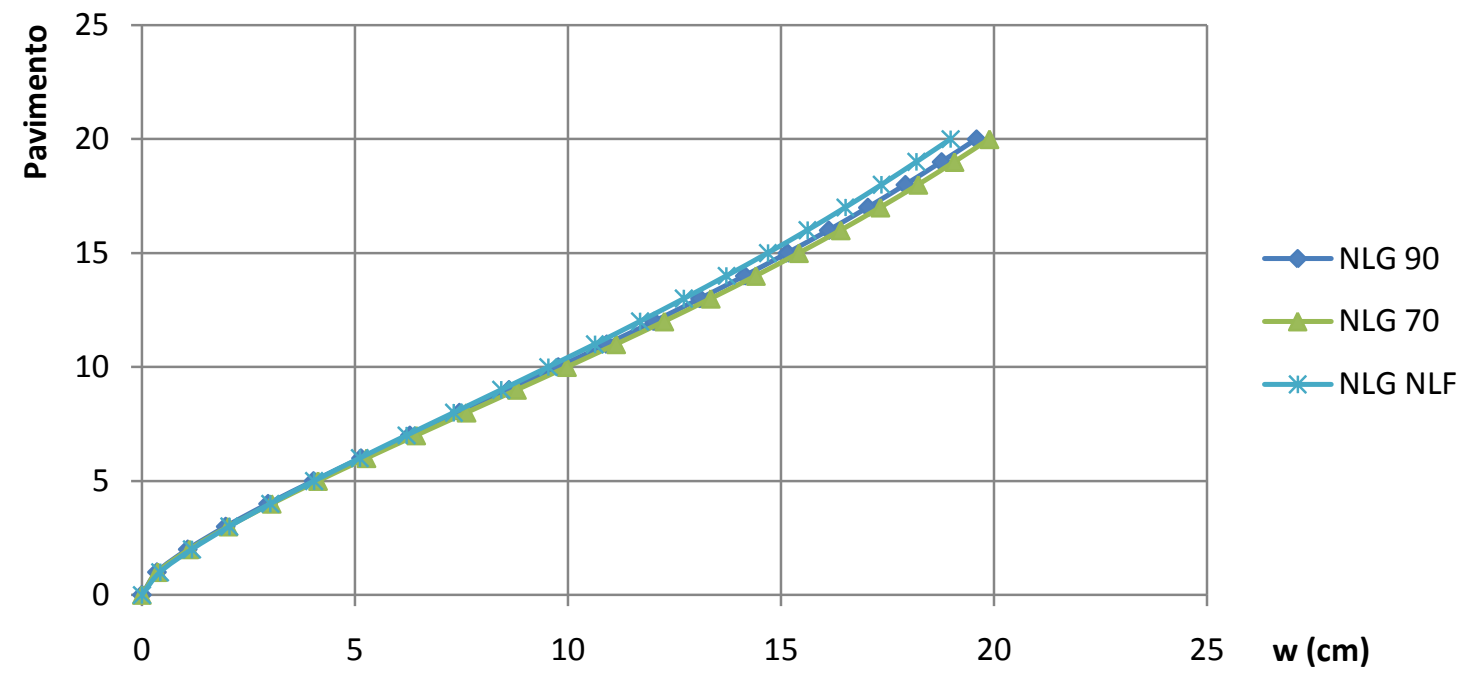

Figura 6.48: Deslocamento do pavimento na direção Z: 20B. 


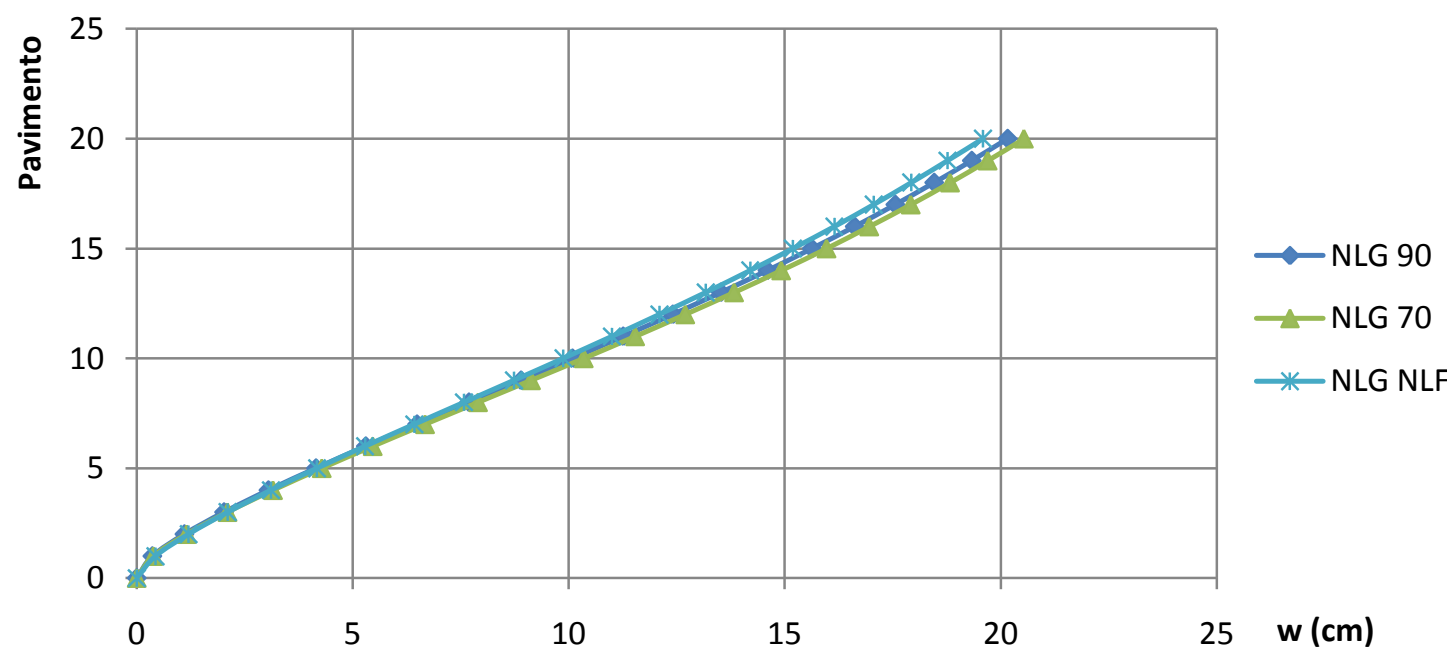

Figura 6.49: Deslocamento do pavimento na direção Z: 20C.

O coeficiente redutor, conforme comentado acima, apresenta boa representatividade para os deslocamentos nas 3 situações até o $15^{\circ}$ pavimento.

\section{Momentos nas paredes dos núcleos:}

Com o intuito de verificar a influência da não linearidade física sobre os esforços solicitantes, é feita uma comparação entre os momentos atuantes na direção de maior inércia da parede PAR 2. Serão comparados os resultados apresentados na análise não linear rigorosa, não linear simplificada com coeficientes redutores iguais a 0,70 e 0,90. Assim as análises serão chamadas NLG NLF, NLG 70, e NLG 90, respectivamente. 


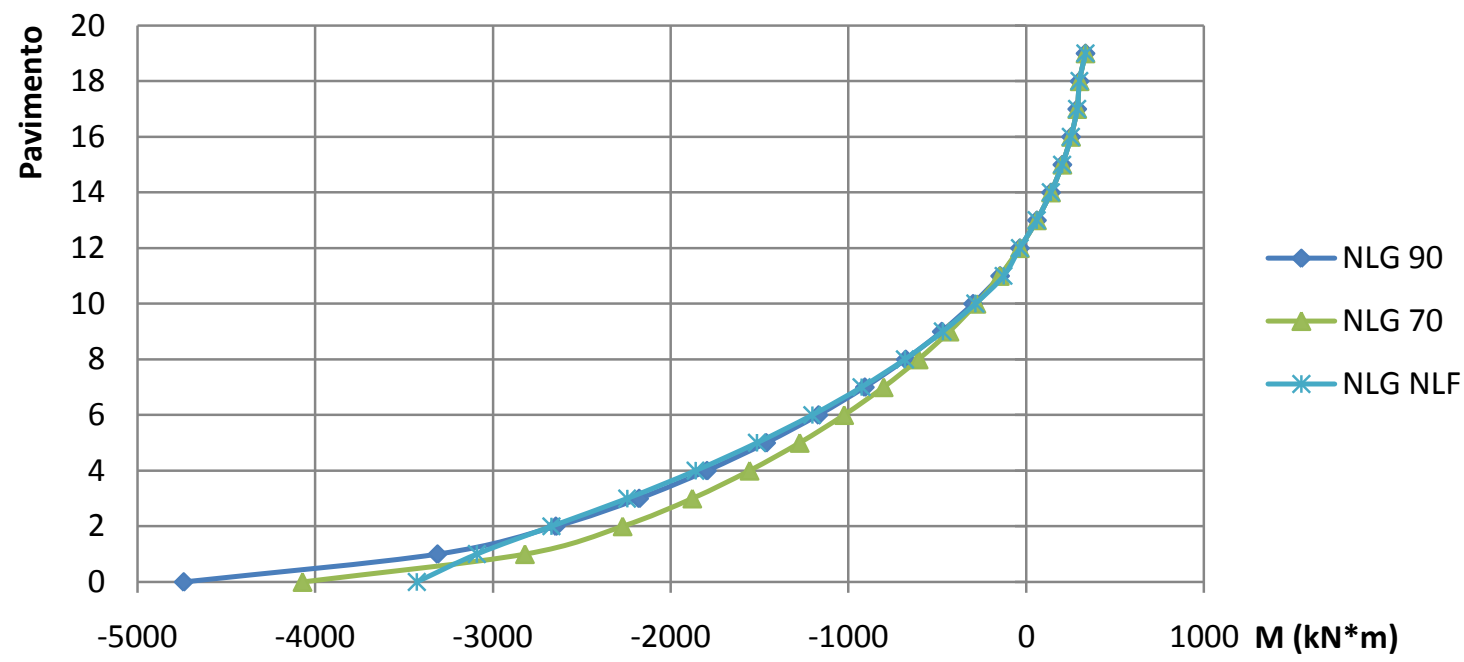

Figura 6.49: Momento em torno do eixo $X$ da parede PAR 2: 20A.

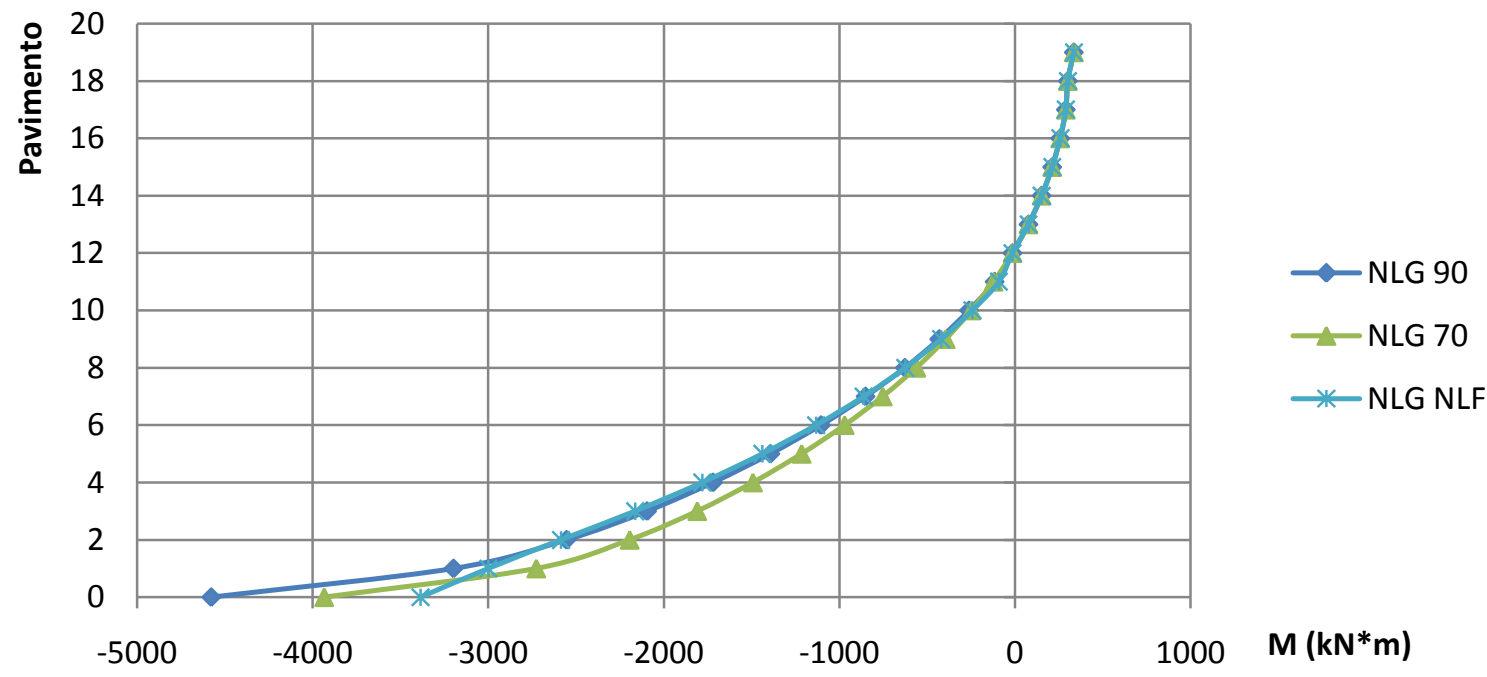

Figura 6.50: Momento em torno do eixo $X$ da parede PAR 2: $20 B$. 


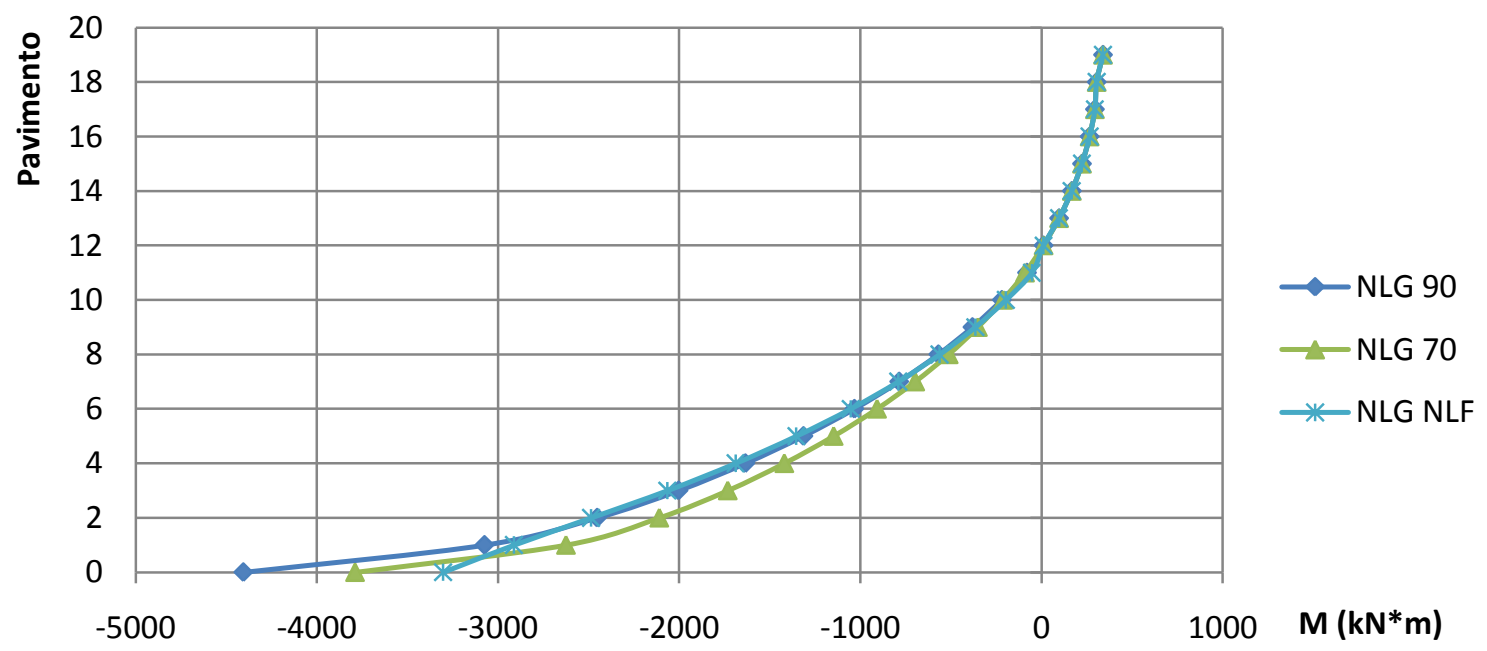

Figura 6.51: Momento em torno do eixo X da parede PAR 2: 20C.

Neste exemplo a representatividade dos esforços fornecidos pelas análises simplificadas têm diferenças maiores que as dos exemplos anteriores. Devido a uma maior variação da rigidez efetiva ao longo da altura do edifício, os coeficientes de redução usados nas análises simplificadas levam a momentos com significativa diferença na base do edifício.

A boa representatividade da análise simplificada usando $90 \%$ da inércia é verificada nas três situações de taxas de armadura, exceto para as paredes dos dois primeiros andares, onde a rigidez efetiva é menor. Para os primeiros andares, nas três situações, o momento obtido desta análise é maior que aquele obtido na análise rigorosa. Para a análise usando $70 \%$ da rigidez, para as três situações, o momento obtido é maior que aquele apresentado pela análise rigorosa apenas no primeiro andar, para os demais andares, esta análise leva a momentos menores que os obtidos na análise rigorosa.

Os três exemplos estudados neste capítulo apresentaram comportamentos muito semelhantes, os resultados das diferentes análises apresentam as mesmas tendências em todos os exemplos. Em todos os exemplos são observados alguns aspectos comuns, são eles: 
a) Os efeitos da não linearidade geométrica são pequenos, em alguns casos menores que os efeitos devido à deformação por esforço cortante;

b) Os efeitos da deformação por esforço cortante são relativamente altos e merecem maior atenção;

c) A análise não linear rigorosa apresenta maior rigidez efetiva para as paredes dos núcleos que a análise simplificada proposta pela NBR 6118.

d) $\mathrm{O}$ coeficiente redutor de inércia adotado apresenta praticamente a mesma representatividade em termos de deslocamentos para todos os exemplos.

As diferenças em esforços aparecem no edifício com 20 pavimentos, sujeito a um maior nível de não linearidade. Para este caso, existem diferenças significativas entre os momentos obtidos pelas três análises não lineares. 


\section{Capítulo 7 - Conclusões e sugestões para trabalhos futuros}

\section{Conclusões.}

Este trabalho acopla teorias bastante consolidadas para a análise não linear física e geométrica de núcleos rígidos pertencentes às estruturas de contraventamento de edifícios altos de concreto. As formulações e considerações sobre os modelos empregados apresentaram resultados satisfatórios.

Os resultados mostrados ao longo do trabalho mostram que o acoplamento das não linearidades física e geométrica ao modelo de YAGUI é viável e eficiente.

A consideração da deformação por esforço cortante levou a sensível aumento nos deslocamentos, sendo que, para os edifícios mais rígidos, o acréscimo de deslocamentos é maior que os provocados pelos efeitos não lineares físico e geométrico.

Os exemplos estudados no capítulo seis mostram que a rigidez efetiva das paredes dos núcleos é maior que aquela obtida usando o coeficiente redutor de inércia igual a 0,70 proposto pela NBR 6118.

As análises NLG-NLF, em termos de deslocamento dos pavimentos, foram bem representadas por uma análise não linear simplificada usando um coeficiente redutor de inércia igual a 0,90 para as paredes dos núcleos e de 0,70 para os demais elementos.

A rigidez efetiva das paredes dos núcleos não é constante ao longo da altura do edifício. Para os exemplos em que o nível de não linearidade é maior, apresenta maior variabilidade.

Tomando como referência a análise não linear rigorosa, os valores dos momentos fletores correspondentes às análises não lineares simplificadas apresentam significativa diferença para os primeiros pavimentos dos edifícios com maior nível de não linearidade. A partir do segundo pavimento, os valores destes são muito próximos aos obtidos pela análise empregando coeficiente redutor de inércia das paredes dos núcleos igual a 0,90 . 


\section{Sugestões para trabalhos futuros.}

Durante o desenvolvimento deste trabalho, foram notados alguns aspectos importantes a serem estudados em trabalhos futuros, a seguir são citados alguns de maior relevância.

A consideração da deformação por esforço cortante acoplado às não linearidades física e geométrica de forma consistente.

Ampliação do estudo realizado, considerando um maior número de estruturas, com variabilidade de planta de formas, número de pavimentos e de seção dos núcleos.

Influência do tipo de consideração da não linearidade física dos núcleos sobre os demais elementos da estrutura.

Extensão da análise não linear rigorosa aos demais elementos da estrutura e implementação da análise não linear rigorosa para a flexão oblíqua.

Considerar a modelagem dos núcleos através de elementos planos. Assim como a adoção de modelos constitutivos biaxiais para o concreto das paredes dos núcleos. 


\section{Capítulo 8 - Referências Bibliográficas}

ALWIS, W. A. M. Trilinear moment-curvature relationship for reinforced concrete beams. ACI Structural Journal, p. 276-283, May-June, 1990

ANTUNES, H.M.C.C.,(1978). Carregamento crítico de instabilidade geral para estruturas tridimensionais de edifícios altos. Tese (Doutorado) - Escola de Engenharia de São Carlos - EESC -USP.

ARGYRIS, J. H.. Continua and Discontinua. Pro. Conf. On Matrix Methods in Structural Mechanicis Wright-Patterson ${ }^{\mathrm{a}}$ F.B., Ohio, p.11-185, October.1965

ARGYRIS, J. H., DUNNE, P. C.., SCHARPF, D. W. ; On large displacement -small strain analysis os structures with rotation degrees of freedom; Comput. Meths. Appl. Mech. Engrg.; 14; 401-451; 1978.

ASSOCIAÇÃO BRASILEIRA DE NORMAS TÉCNICAS (2003). NBR 6118: Projeto de estruturas de concreto - procedimento. Rio de Janeiro.

BATHE, K. J. (1996). Finite element procedures. New Jersey, Prentice Hall. REDDY, J. N. (1997). On locking-free shear deformable beam finite elements.Comp Meth. App. Mech. Eng. ,149,9p113-132.

BECKER, E.P., (1989). Edifícios altos: interação tridimensional das peças de contraventamento. Dissertação (Mestrado) - Escola de Engenharia de São Carlos ESC- USP.

BRANSON, D. E. (1963). Instantaneous and time dependent deflections of simple and continuous reinforced concrete beams. Ala. Hwy. Res. Rep. no 7, Bureau of Public Roads.

CAUVIN, A. (1979). Non linear analisys of a multistorey sway frame according to CEB model code. CEB: Bulletin D'Information, n.134, p83-107.

CILONI, A. D. (1993). Sobre o comportamento em serviço de estruturas planas de concreto armado. São Carlos. Tese (Doutorado) - Escola de Engenharia de São Carlos, Universidade de São Paulo.

CORRÊA, M.R.S. (1991). Aperfeiçoamento de modelos usualmente empregados no projeto de sistemas estruturais de edifícios. São Carlos. 331p. Tese (Doutorado) Escola de Engenharia de São Carlos, Universidade de São Paulo.

ELIAS, Z.M. (1986). Theory and methods of structural analysis. John Wiley \& Sons.

FIGUEIRAS, J.A. (1983). Ultimate Load analysis of anisotropic and reinforced concrete plates and shells. Swansea. Ph.D. Thesis, - Department of Civil Engeneering, University College of Swansea. 
GERE, J. M. \& WEAVER Jr,W. (1987). Análise de estruturas reticuladas. Guanabara Rio de Janeiro, RJ

HEIDEBRECHT, A. C. ; SWIFT, R. D. (1971). Analysis of asymmetrical coupled shear walls. Journal of the Structural Division, Proc. ASCE, v. 97, n. ST5 , p. 1407-1422, May.

JENNINGS, A. (1968). Frame analysis including change of geometry. Journal of the Structural Division ASCE, v. 94, c. St 3, p. 627-694, March.

KENT, D. C.; PARK, R. (1971). Flexural members with confined concrete. Journal of Structural Division ASCE, v.97, n. ST7, p1969-1990, July.

KENT, D. C.; PARK, R. (1971). Flexural members with confined concrete. Journal of Structural Division (ASCE), v.97, n. ST7, p1969-1990, July.

MALLET, R. , MARÇAL, P. V. ; Finite element analysis of nonlinear structures; J. Struct. Div., ASCE; 94; 2081-2105; 1968

MARTIN, H. C. ; Fininte elements and the analysis of geometrically nonlinear problens; In Gallagher, R. H. et al, ed, Recent Advances In Matrix Methods of Structural Analysis and Design; The University of Alabama Press; Alabama; 343$381 ; 1969$

MARTINS, C. H. (2001). Análise não linear de estruturas tridimensionais de edifícios de andares múltiplos com núcleos resistentes, considerando a rigidez transversal à flexão das lajes. São Carlos. Tese ( Doutorado ) - Escola de Engenharia de São Carlos,Universidade de São Paulo.

MATIAS JR., I.G.; MORI, D.D. Núcleos resistentes sobre fundações flexíveis. In: JORNADAS SUL-AMERICANAS DE ENGENHARIA ESTRUTURAL, 28., São Carlos, 1-5 set. 1997. Estruturas e fundações. São Carlos, Departamento de Engenharia de Estruturas-EESC-USP / Associação Sulamericana de Engenharia Estrutural, 1997. v.4, p.1387-1396.

MATIAS JUNIOR, I.G. (1997). Análise não-linear de estruturas tridimensionais de edifícios altos com núcleos resistentes sobre fundações flexíveis. Dissertação (Mestrado - Escola de Engenharia de São Carlos, Universidade de São Paulo.

MORI, D. D. (1992); Os núcleos estruturais e a não-linearidade geométrica na análise de estruturas tridimensionais de edifícios altos. Tese (Doutorado), EESCUSP

NARAYANASWAMI, R. \& ADELMAN, H. M. Inclusion of transverse shear deformation in finite element displacement formulation. AIAA Journal vol.12 n'11.P1613-1614 New York, John Wiley.

NICKEL, R. E. ; SECOR, G. A. (1972). Convergence of consistently derived Timoshenko beam finite elements. International Journal for Numerical Methods in Engineering, v. 5, p. 243-253. 
NÓBREGA, S. H. S. (1997). Sobre o desenvolvimento de elementos finitos de casca. Uma classe de formulações mistas. Tese (Doutorado) - EPUSP

NOGUEIRA, C. G. (2005). Um modelo de confiabilidade e otimização aplicado às estruturas de barras de concreto armado. Dissertação (Mestrado) - Escola de

ORAN, C. ; Tangente stiffness in space frames; J. Struct. Div. , ASCE; 99; 987-1001; 1973

PAULA, C. F. (2001). Contribuição ao estudo das respostas numéricas não-lineares estática e dinâmica de estruturas reticuladas planas. Tese (doutorado) - Escola de Engenharia de São Carlos, Universidade de São Paulo.

PAULA, C.F. (1997). Estudo das descrições lagrangiana e euleriana na análise nãolinear geométrica com o emprego do método dos elementos finitos. São Carlos. 112p. Dissertação (Mestrado) - Escola de Engenharia de São Carlos, Universidade de São Paulo.

PEREIRA, A. C. O. (2000). Estudo da influência da modelagem estrutural do núcleo nos painéis de contraventamento de edifícios altos. São Carlos, 2000. 148p. Dissertação (Mestrado) - Escola de Engenharia de São Carlos, Universidade de São Paulo.

PEREIRA, G. S., (1997). Contribuições à Análise de Estruturas de Contraventamento de Edifícios em Concreto Armado; Dissertação de Mestrado, EESC-USP

PIMENTA, P. M. (1986). Análise não-linear de pórticos planos. São Paulo, EPUSP. Boletim técnico do departamento de engenharia de estruturas e Fundações, 8611.

PINTO, R.S. (2002). Análise não-linear das estruturas de contraventamento de edifícios em concreto armado. Tese (Doutorado) - Escola de Engenharia de São Carlos, Universidade de São Paulo, São Carlos. 2002.

POWELL, G. H. ; Theory of nonlinear elastic structures; J. Struct. Div. , ASCE: 95; 2687-2701; 1969

PROENÇA, S.P.B. (1988). Sobre modelos matemáticos do comportamento não linear do concreto: análise crítica e contribuições. São Carlos. 330p. Tese (Doutorado) - Escola de Engenharia de São Carlos, Universidade de São Paulo.

RASHEED, H. A. S.; DINNO, K. S. (1994). An efficient nonlinear analisys of RC sections. Computers and Strutures, v. 53, n. 3, p. 613-623.

RASHEED, H. A. S.; DINNO, K. S. (1994). An improved nonlinear analisys of reinforced concrete frames. Computers and Strutures, v. 53, n. 3, p. 625-636.

REDDY, J. N. (1984). Energy and variational methods in applied mechanics. 
RIGINATO, A. C. (1998). Contribuição para a determinação de matrizes de rigidez e vetores de ações nodais equivalentes com o emprego da formulação hermitiana livre. Tese de doutorado - EESC/USP.

SCANLON, A.; MURRAY, D. W. (1974). Time dependent reinforced concrete slab deflection. Journal of Structural Division (ASCE), v.100(9), p. 1911-1924.

SILVA, R. M. (1989). Análise de estruturas tridimensionais de edifícios altos com núcleo resistentes considerando o efeito P-Delta. Dissertação (Mestrado) - Escola de Engenharia de São Carlos - EESC-USP

SILVA, R. M. (1996). Análise não-linear de pórticos planos de concreto armado: modelagem numérica e avaliação dos métodos aproximados. São Carlos. Tese (Doutorado) - Escola de Engenharia de São Carlos - USP.

SMITH, B.S., TARANATH, B.S. The analysis of tall core-supported structures subject to torsion. Proc. Institution of Civil Engineers, v.53, p.173-87, Sept.1972.

SOLER, J. G. M. (1995) Análise não-linear de pórticos espaciais de concreto armado. São Paulo. Tese (Doutorado) - Escola Politécnica, Universidade de São Paulo.

SORIANO, H. L., (1971). Cálculo automático do efeito do vento em estruturas de edifícios. Dissertação (Mestrado). Universidade Federal do Rio de Janeiro- COPPE.

TARANATH, B.S. Analysis of interconnected open section shear wall structures. Journal of the Structural Division, ASCE, v.101, p.2367-84, Nov. 1975.

TESSLER, A. ; DONG, S. B. (1981). On a hierarchy of conforming Timoshenko beam elements. Computers \& Structures, v. 14, n. 3-4, p.335-344.

TIMOSHENKO, S. P. ; GERE, J. M. (1984). Teoria da elasticidade. 2. ed. New York, Graw-Hill.

TORRES, I. (1999). Efeito da deformação por cortante no cálculo de edifícios de andares múltiplos com núcleos estruturais. Dissertação (mestrado) - Escola de Engenharia de São Carlos - EESC - USP

TURNER, M. J. ;DILL,E.H.; MARTIN, H. C.; TOPP,L.J. Stiffnes and Deflection analysis of Complex Structures. J. Areospace Sciences;23, 805-224. 1965

TURNER, M. J.; CLOGH,R.W.; MARTIN, H. C.; MELSOSH,R.J . Large Deflection on Structures Sunjected to Heating and External Loads AND Deflection Analysis of Complex Structures. J. Areospace sciences; 27. 1960.

VASCONCELOS, G.M.A. (2005). Verificação simultânea dos estados limites últimos e de serviços em análises não-lineares de peças de concreto armado submetidas à flexão pura. Dissertação (Mestrado) - Escola de Engenharia de São Carlos, Universidade de São Paulo. 
VECHIO, F.J ; EMARA, M. B. (1992). Shear deformations in reiforced concrete frames. ACI Structural Journal, v.89, No. 1, January-February 1992.

VLASSOV, B.Z. Pieces longues en voiles minces. Paris: Eyrolles, 1962. 655p.

WANG(1995).Timoshenko beam bending solutions in terms of Euler-Bernoulli solutions. Journal of Engineering Mechanics, vol. 121,p763-765,1995.

WEN, R.K.; RAHIMZADEH, J. (1983). Nonlinear elastic frame analysis by finite element. Journal of Structural Engineering, v.109, n.8, p.1952-1971.

WILBY, C. B.; PANDIT, T. (1967). Inelastic behavior of reinforced concrete singlebay potal frames. Civil Engineering Pub. Works Rev. 62, 331-336.

YAGUI , T., (1971). Estruturas constituídas de paredes delgadas com diafragmas transversais. Tese (Doutorado) - Escola de Engenharia de São Carlos - EESC - USP. 
Anexo A

\section{EX1A-VIGAS}

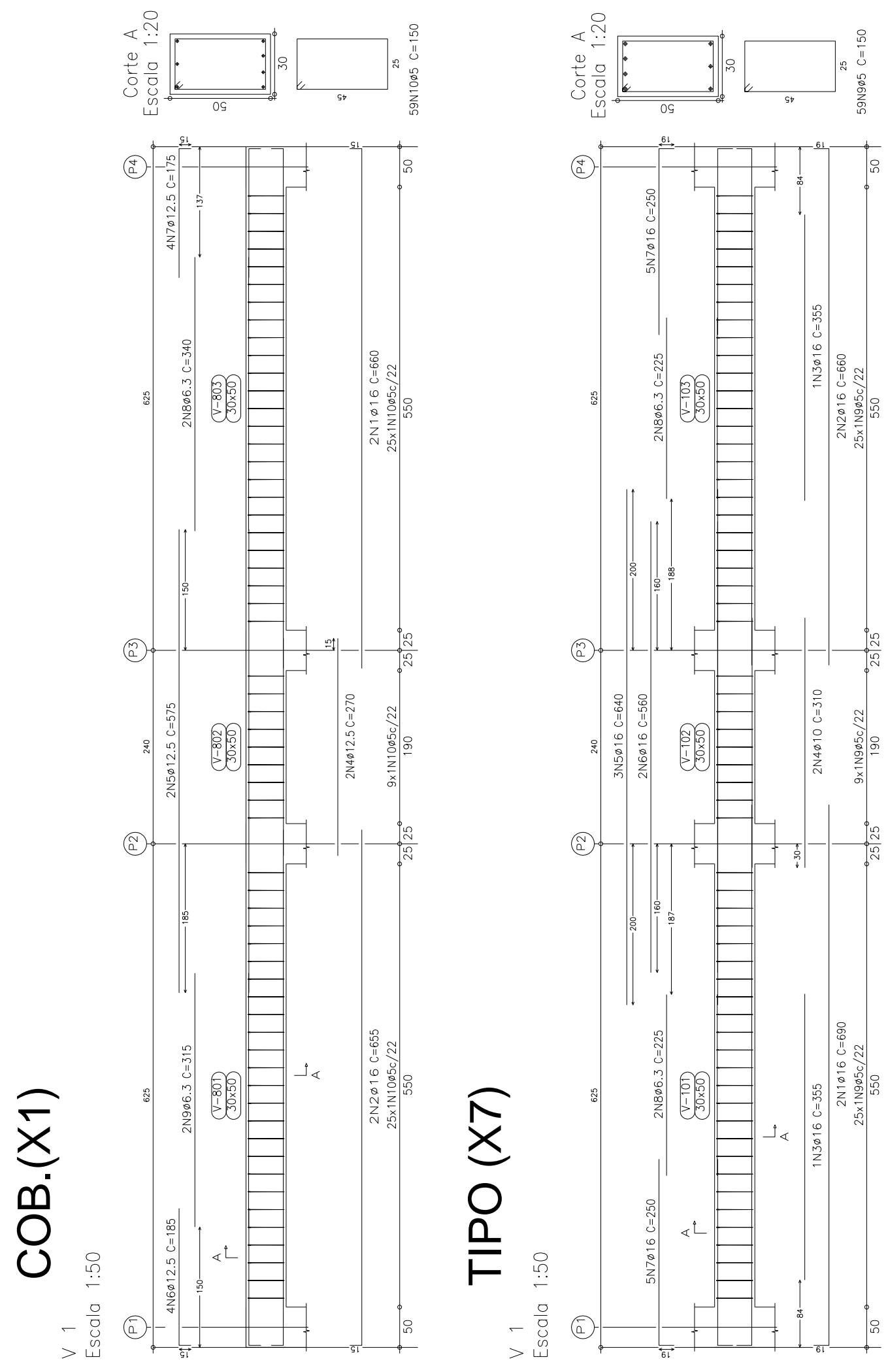




\section{EX1A - PILARES}
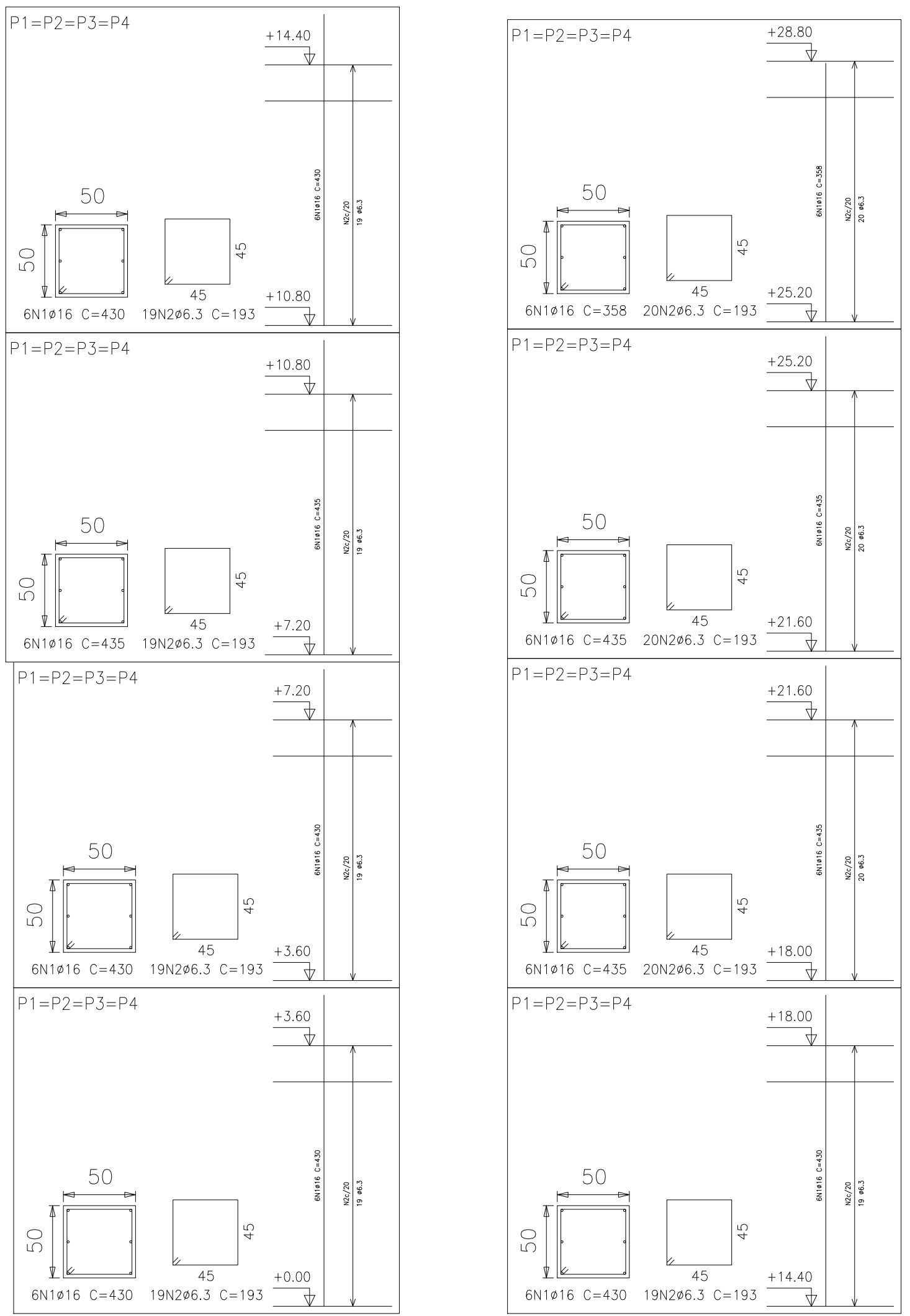


\section{EX1B - VIGAS}

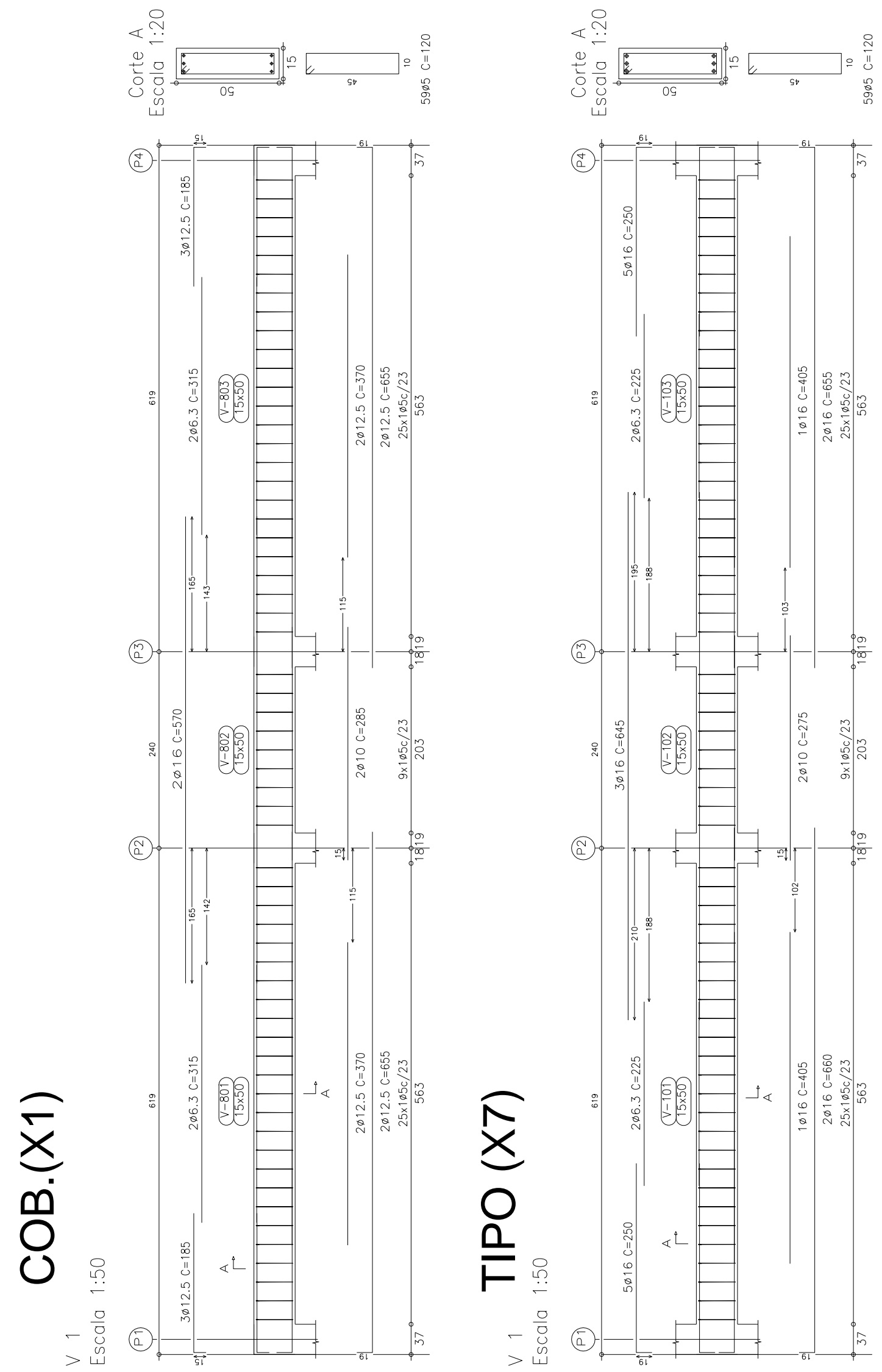




\section{EX1B - PILARES}
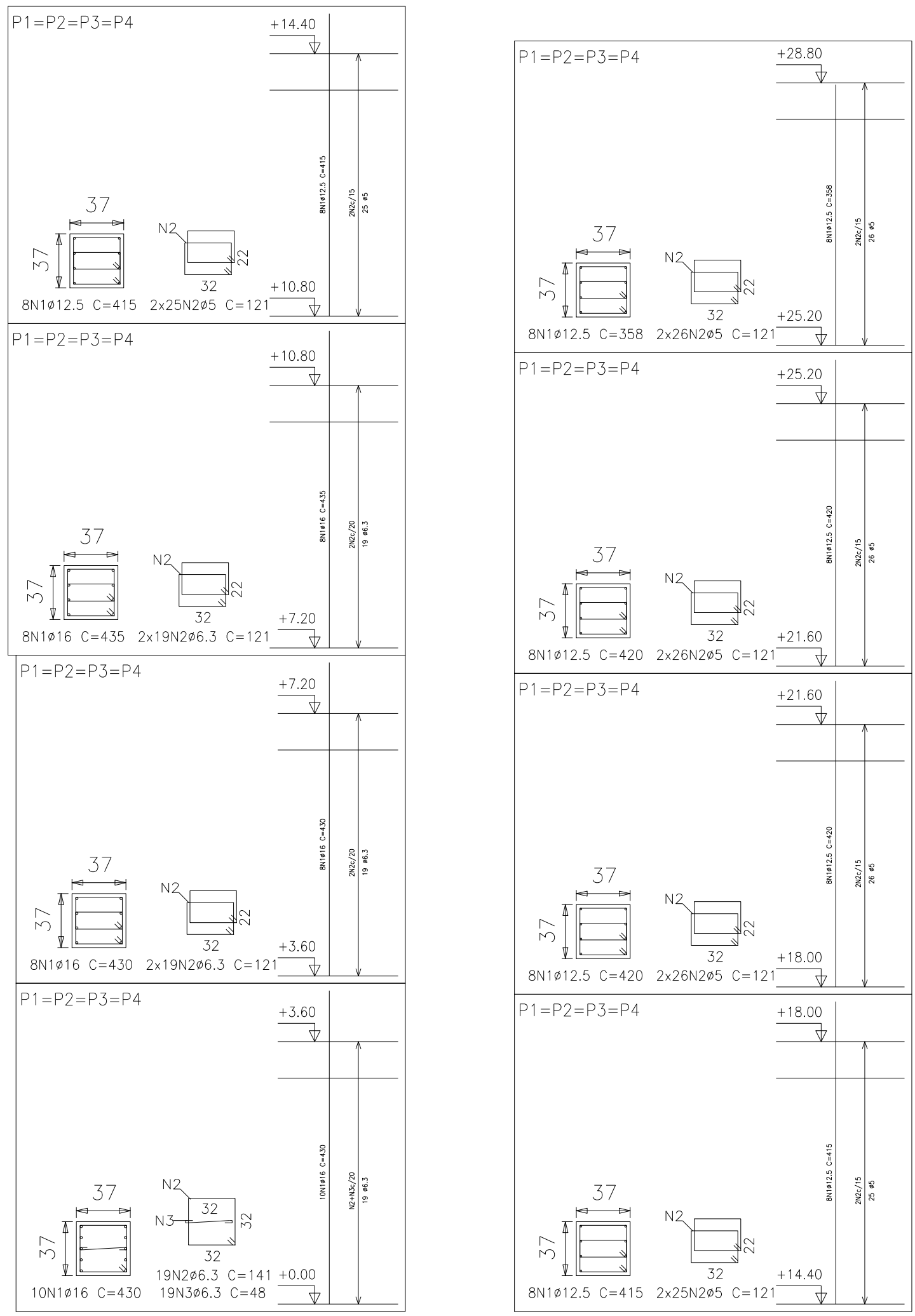


\section{EX1C - VIGAS}

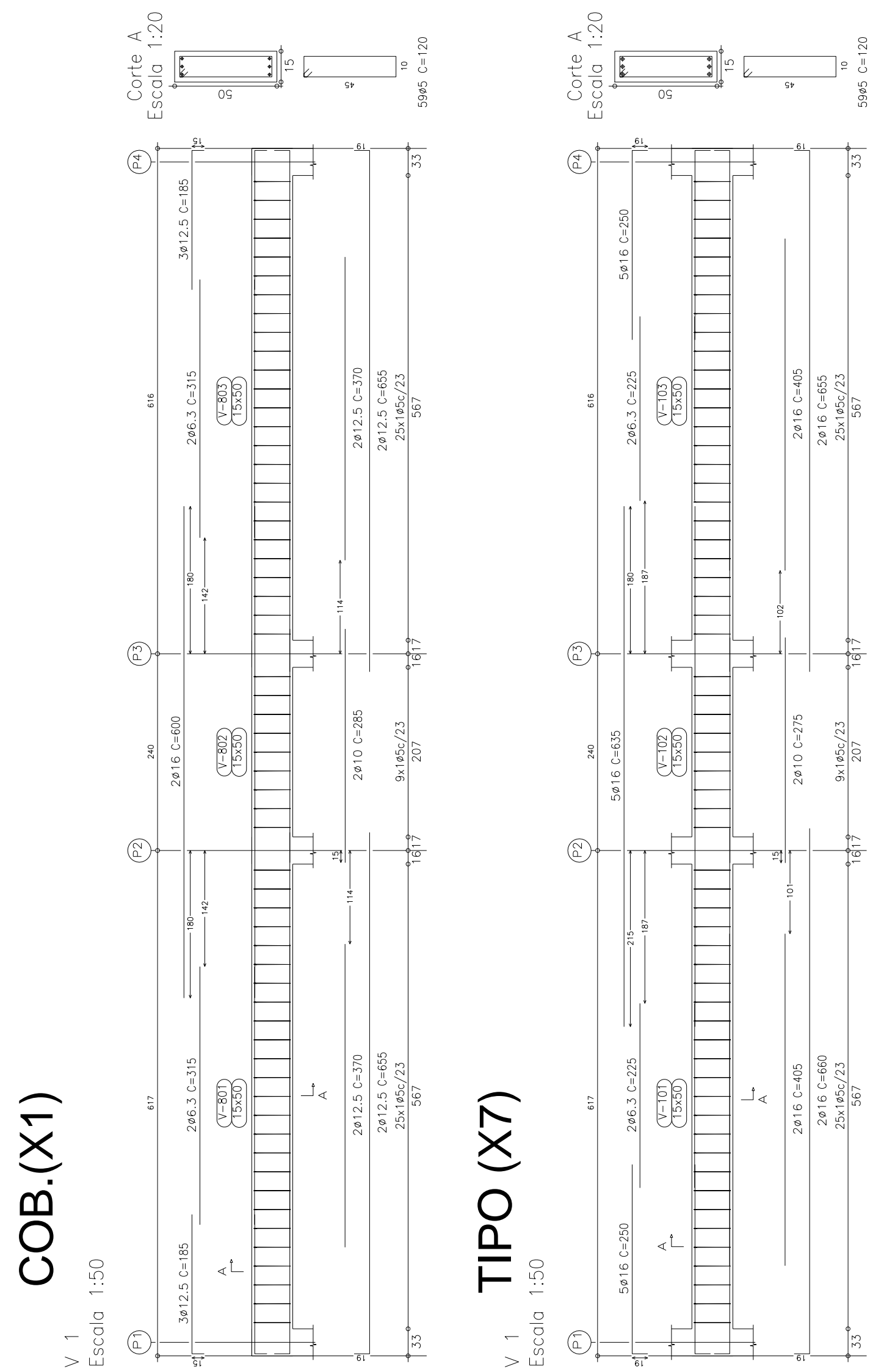




\section{EX1C - PILARES}
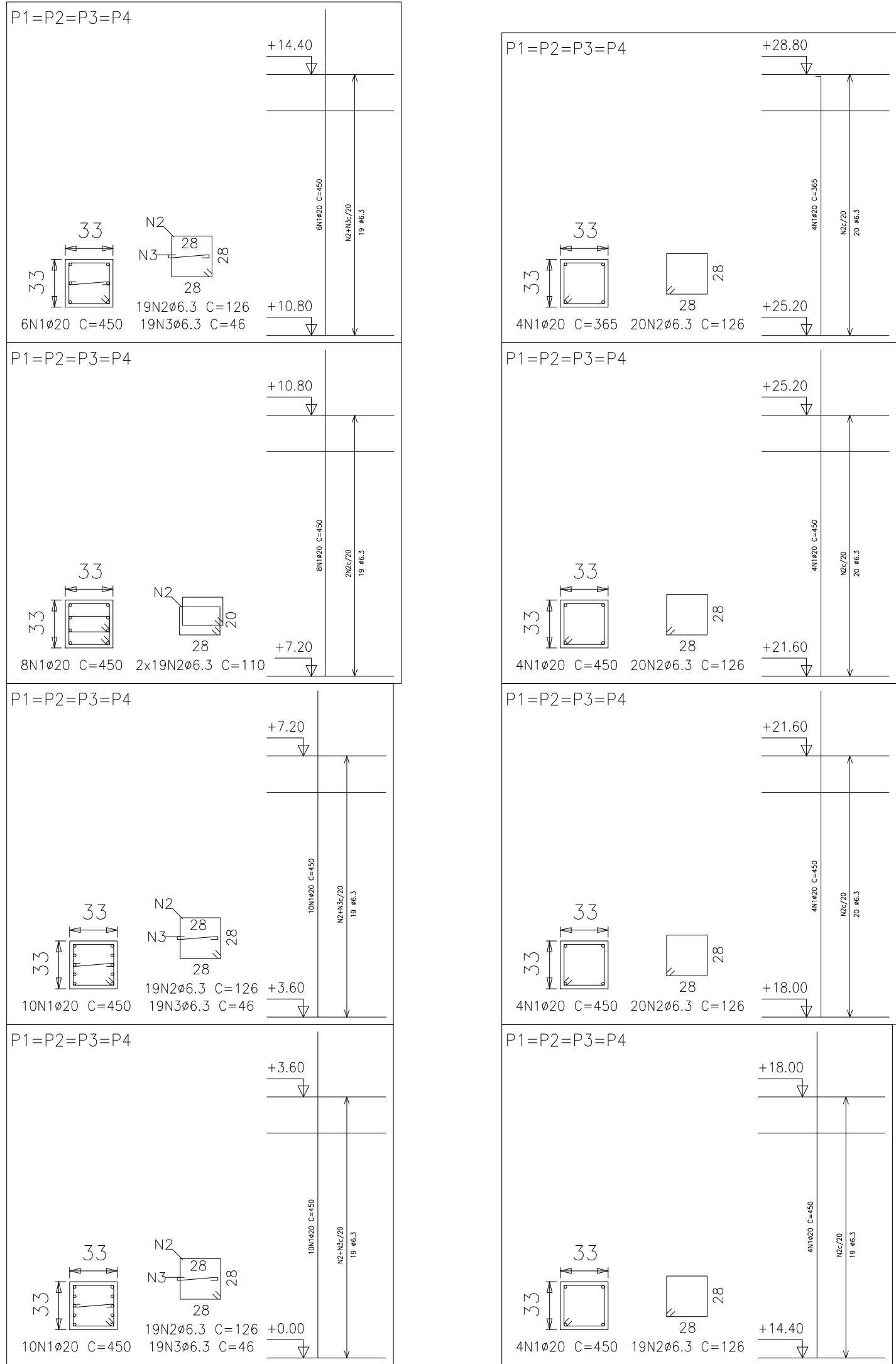


\section{ANEXO B}

Neste anexo são mostrados, de forma simplificada as seções e barras de aço longitudinais dos núcleos. As cotas se referem ao eixo de cada parede e são dadas em $\mathrm{cm}$.

$12 \mathrm{~A}$
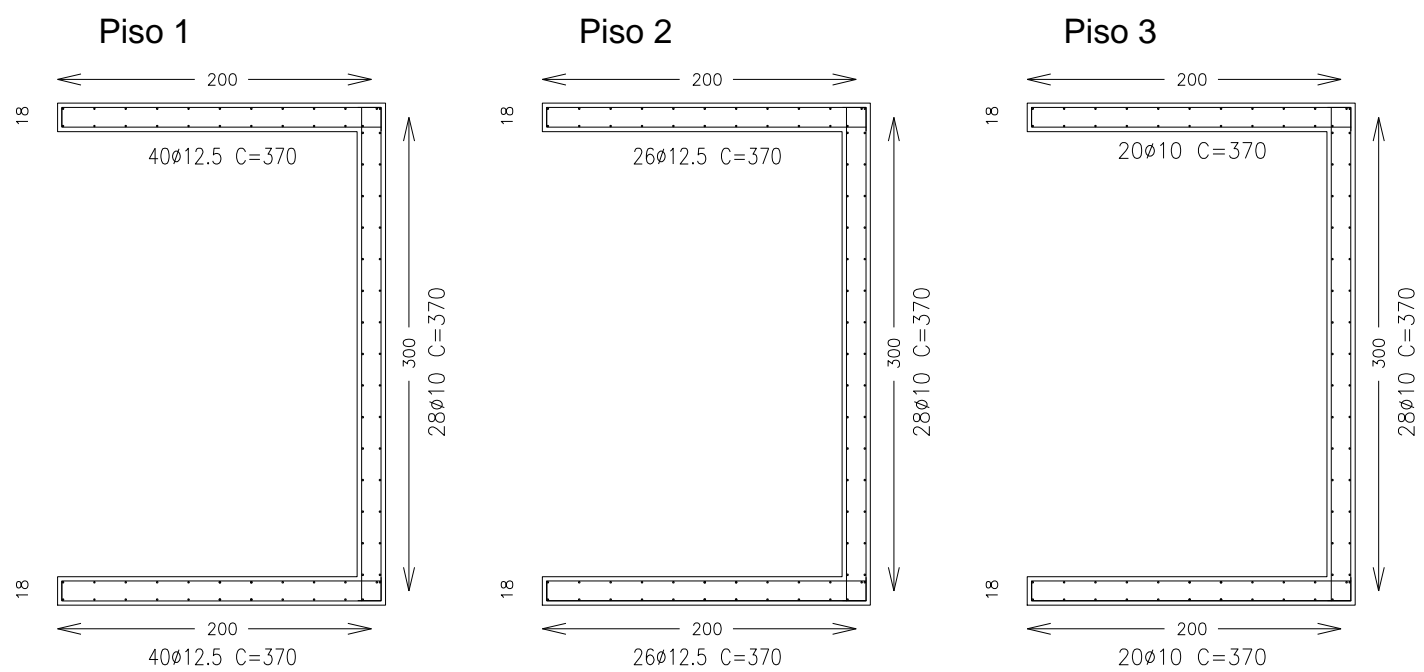

Piso 4-12

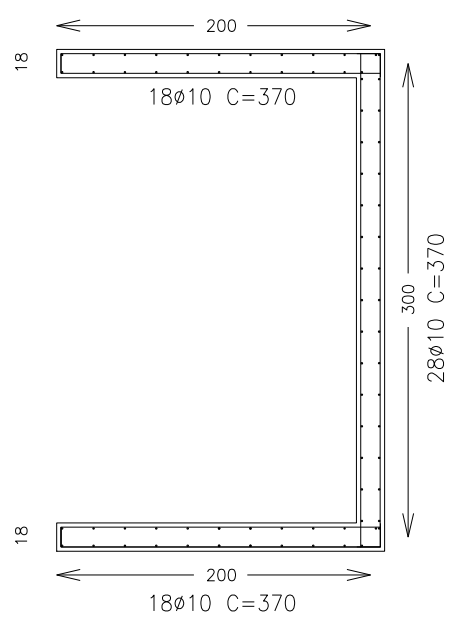


12 B

Piso 1

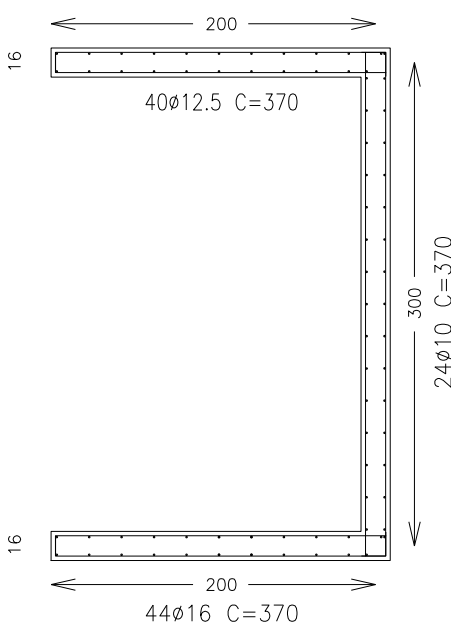

Piso 4

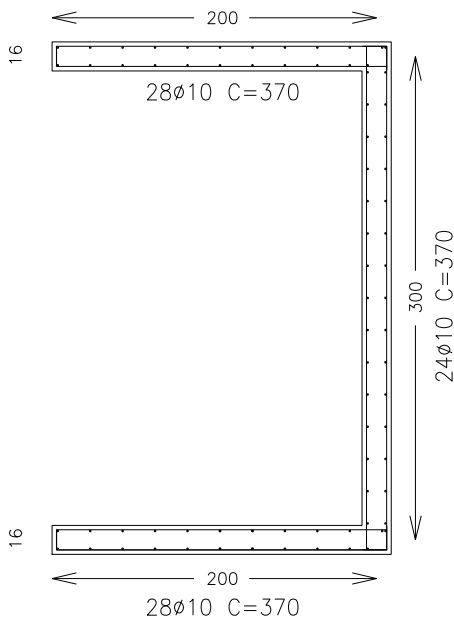

Piso 2

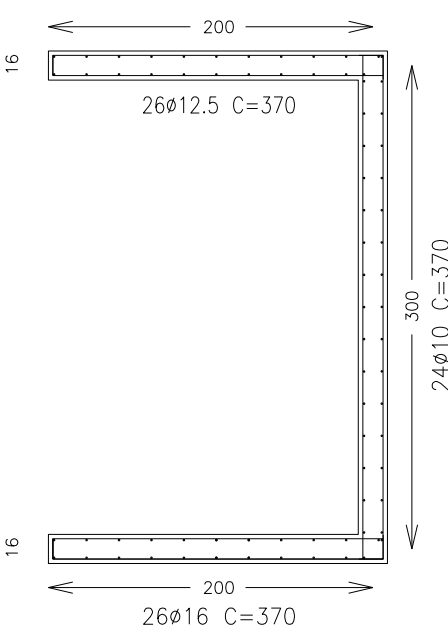

Piso 5-12

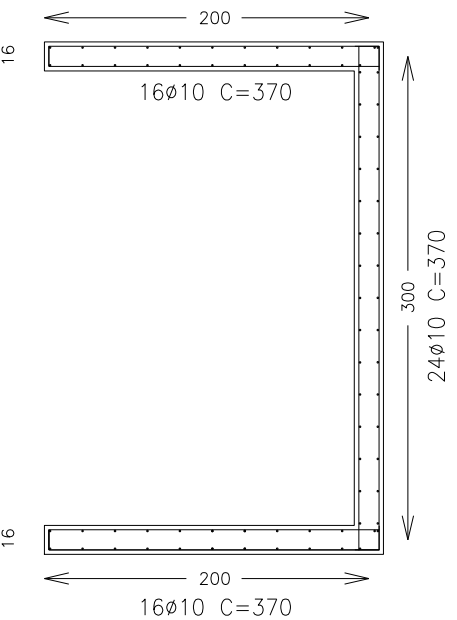

Piso 3

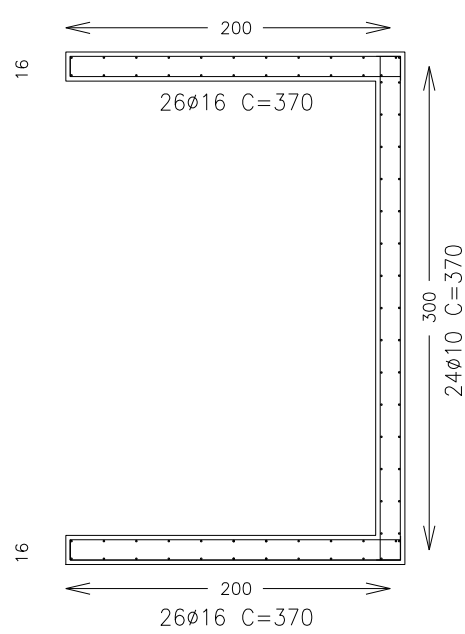

$26016 \mathrm{C}=370$ 


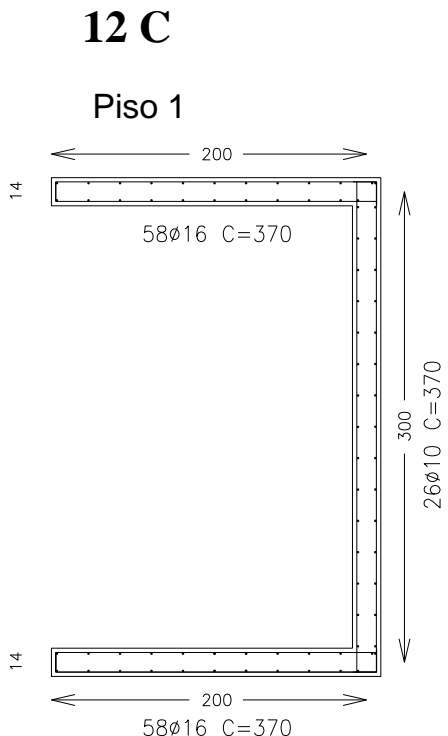

Piso 4

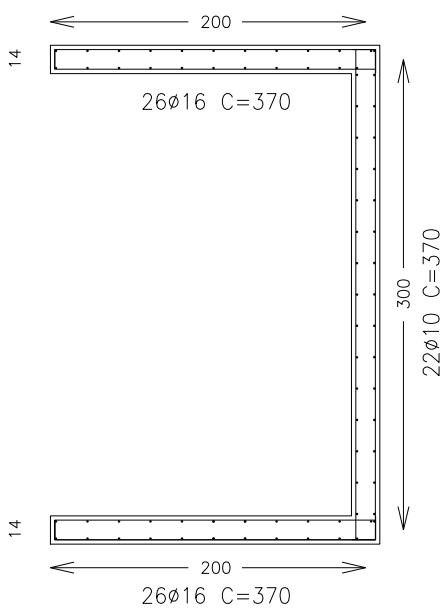

Piso 2

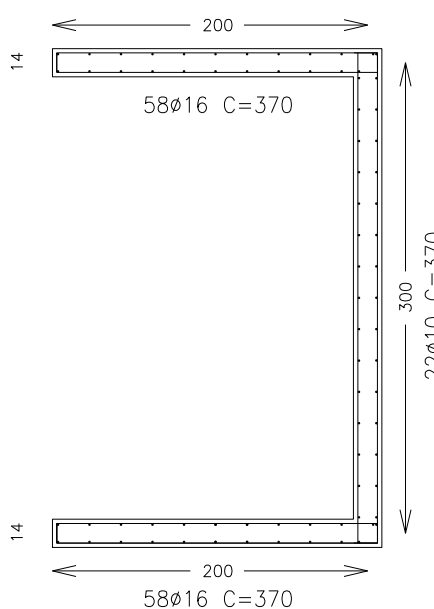

Piso 5

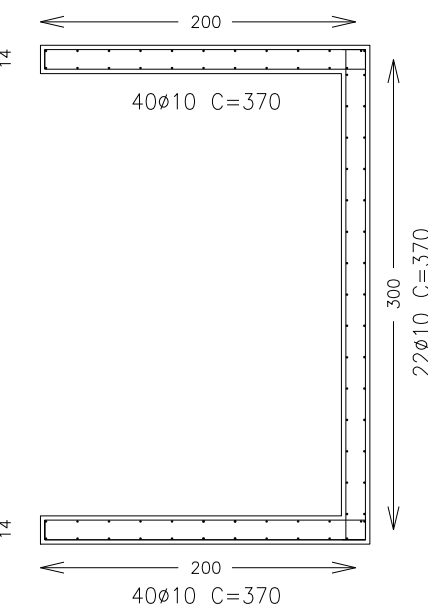

Piso 3

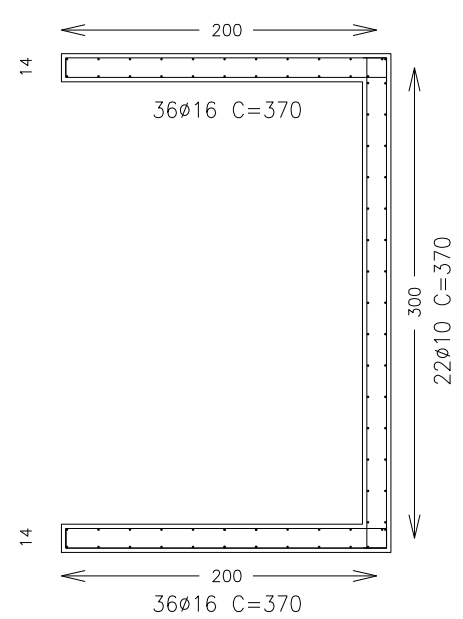

Piso 6-12

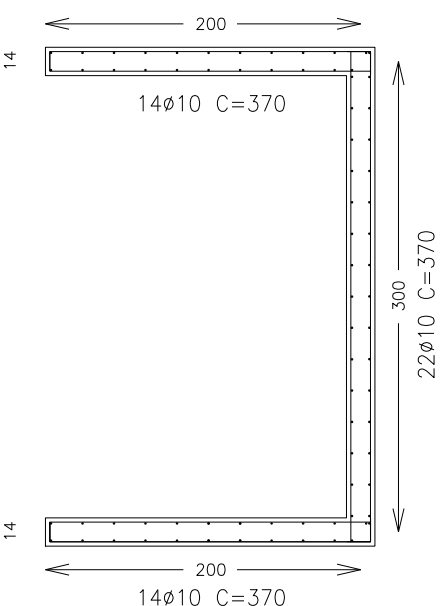


16A
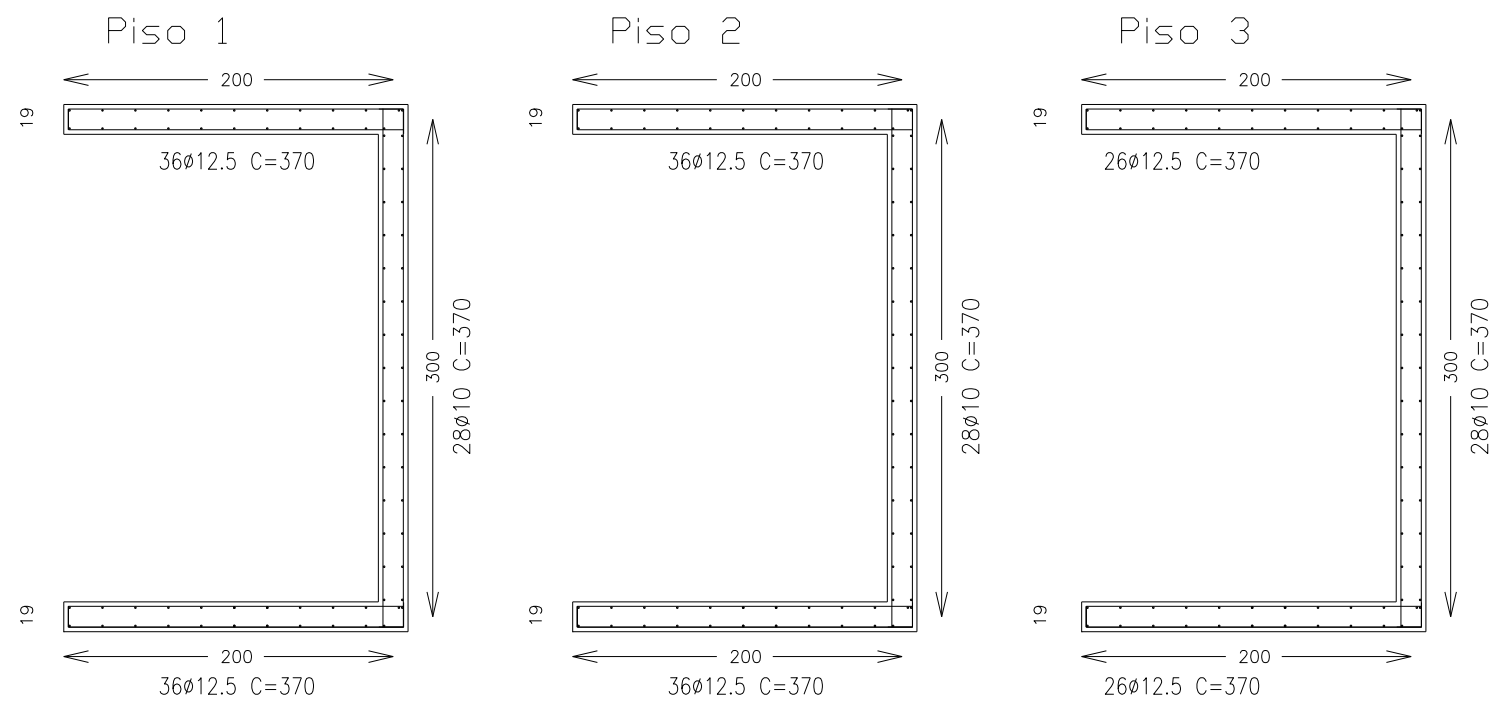

Piso 4

Piso 5

Piso 6-16
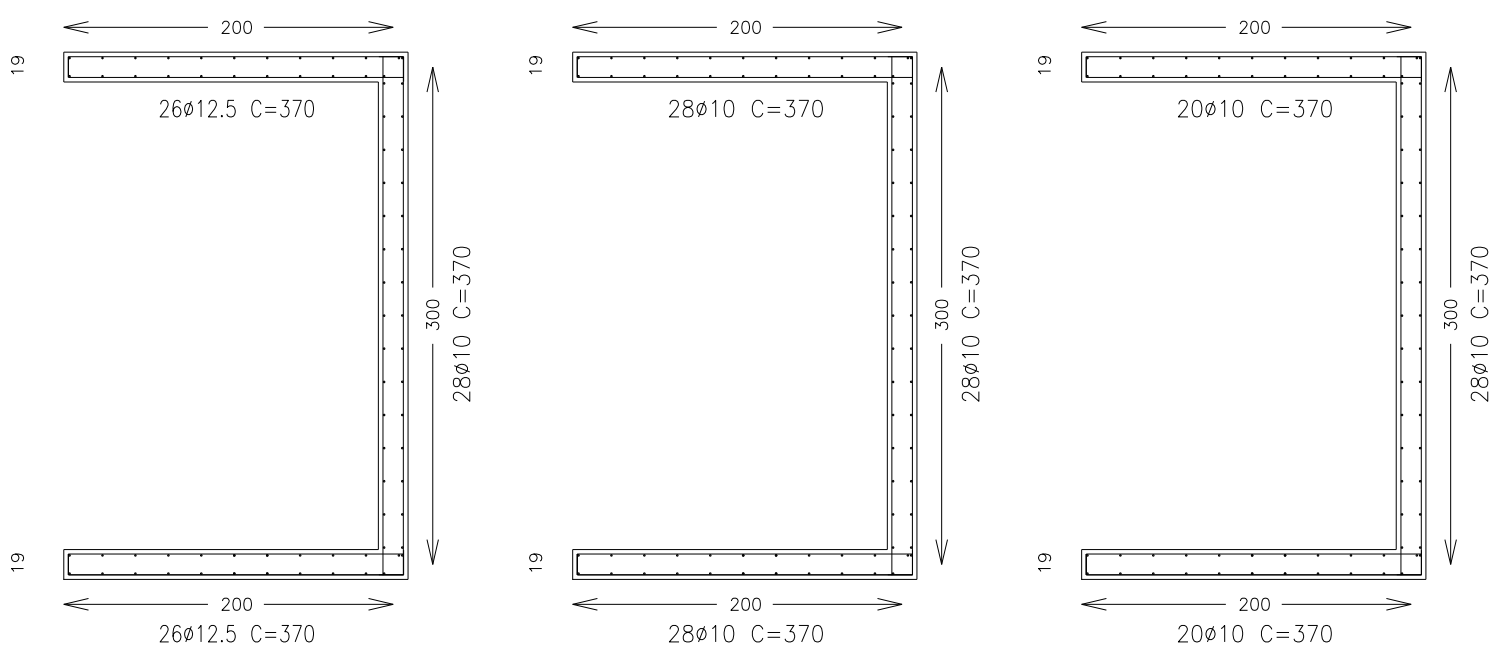


\section{B}
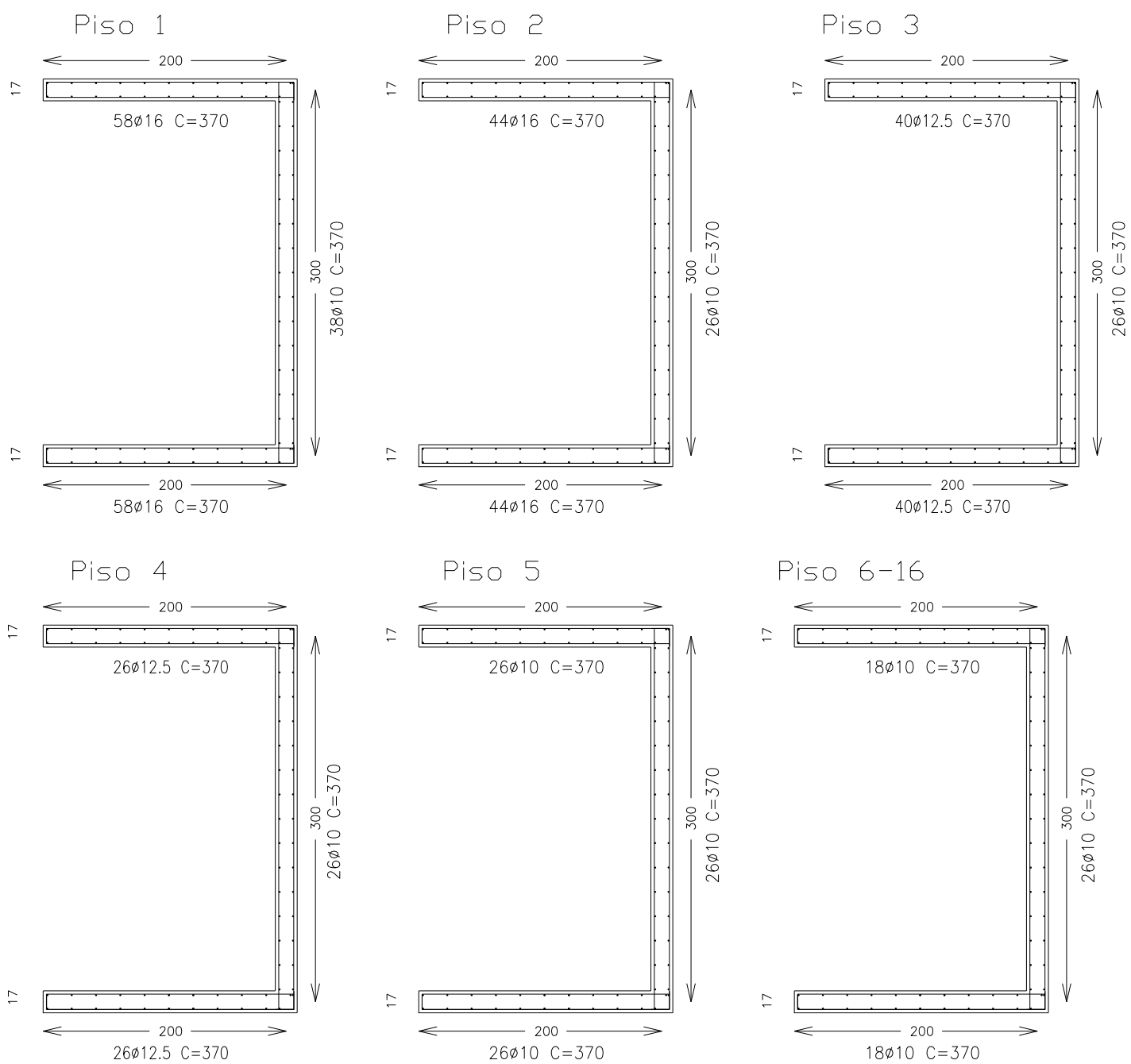
$16 \mathrm{C}$
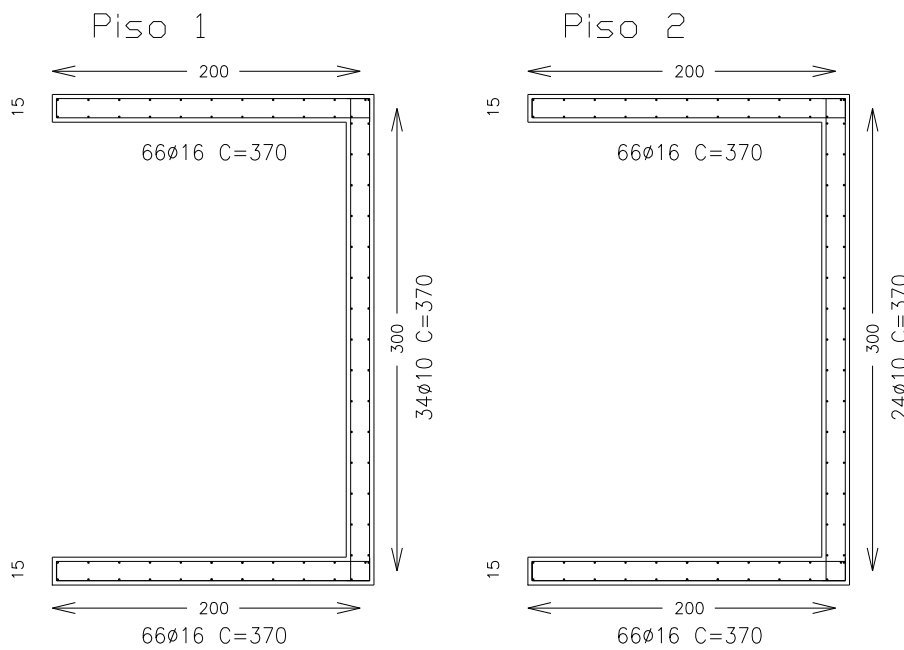

Piso 3

Piso 4

Piso 5

$\stackrel{2}{-}$
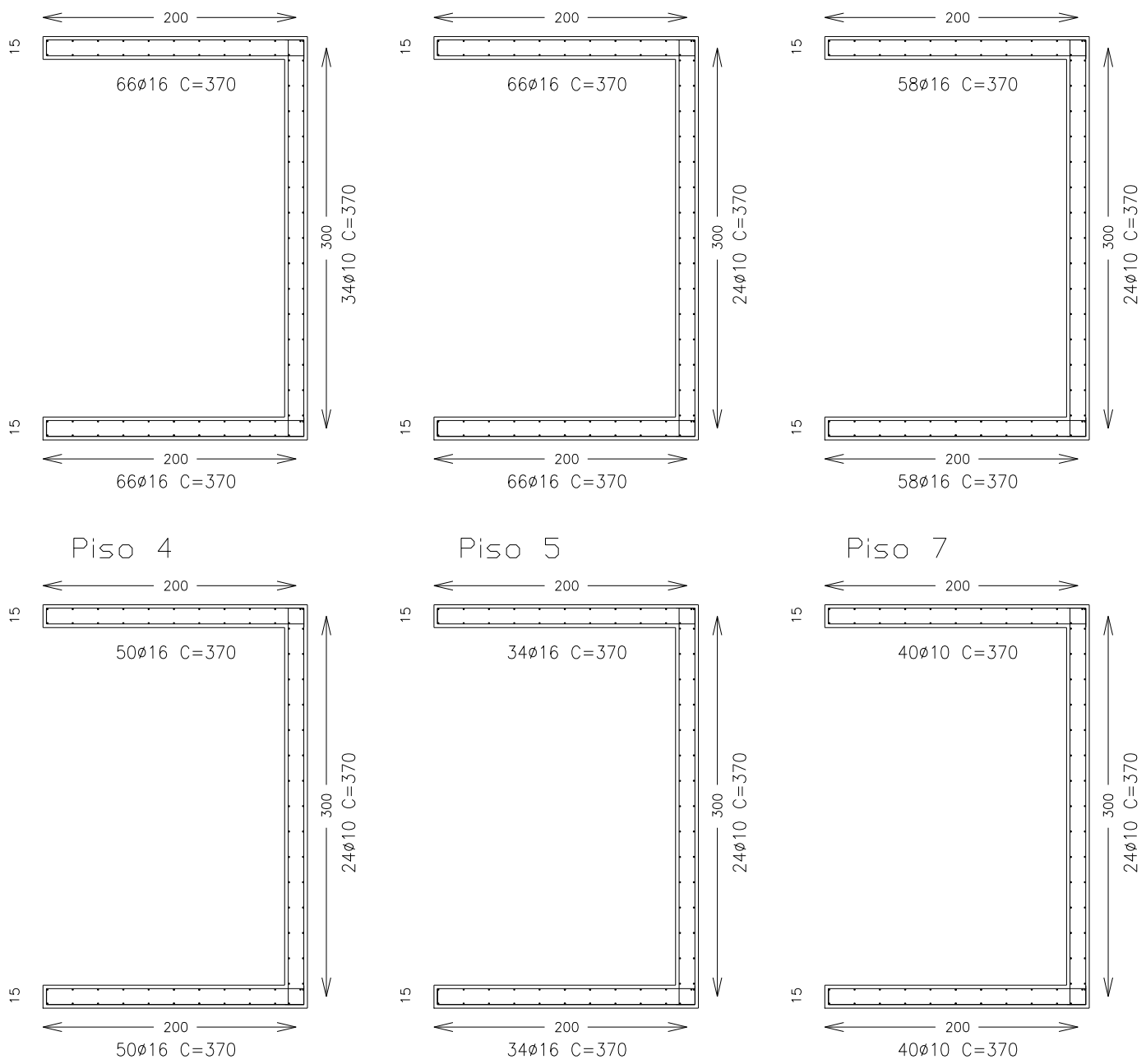

는
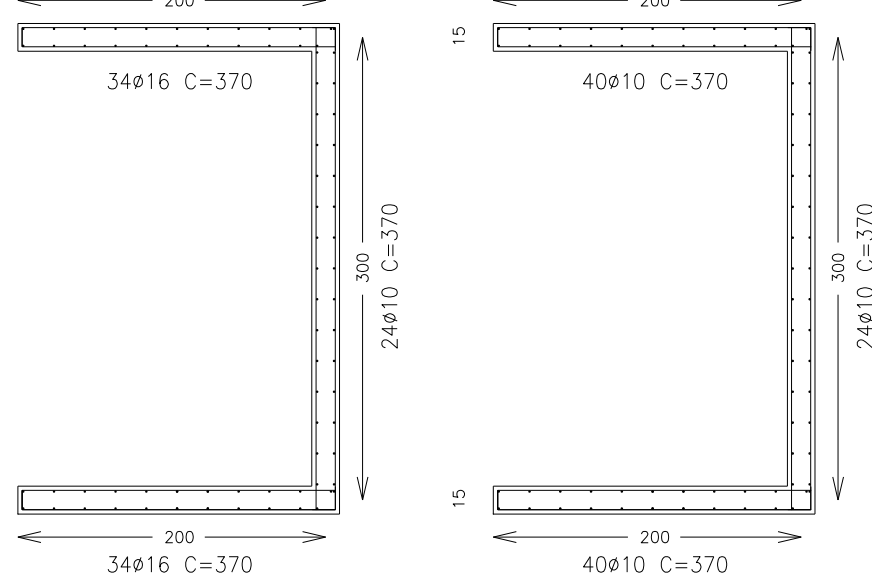

Piso 7-16

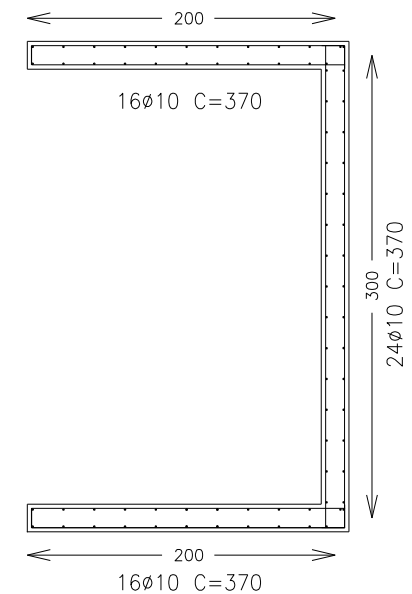


20A
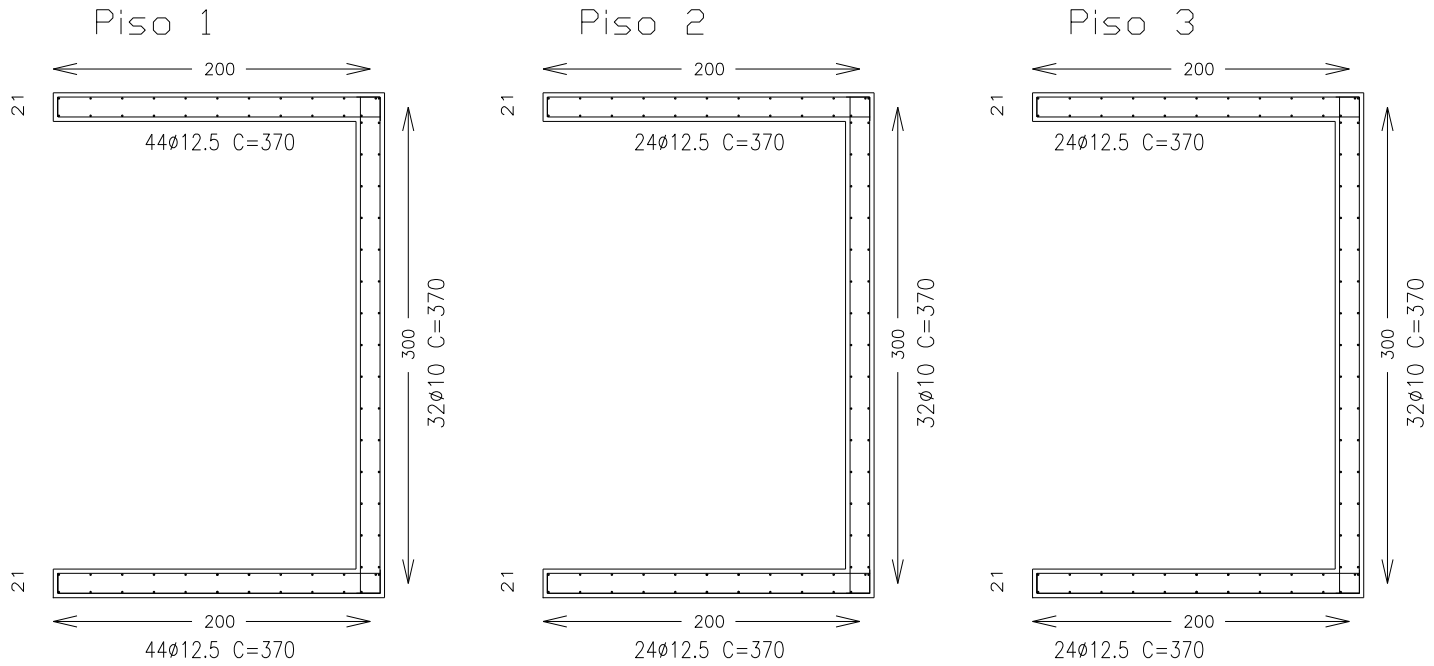

Piso 4

Piso 5-20
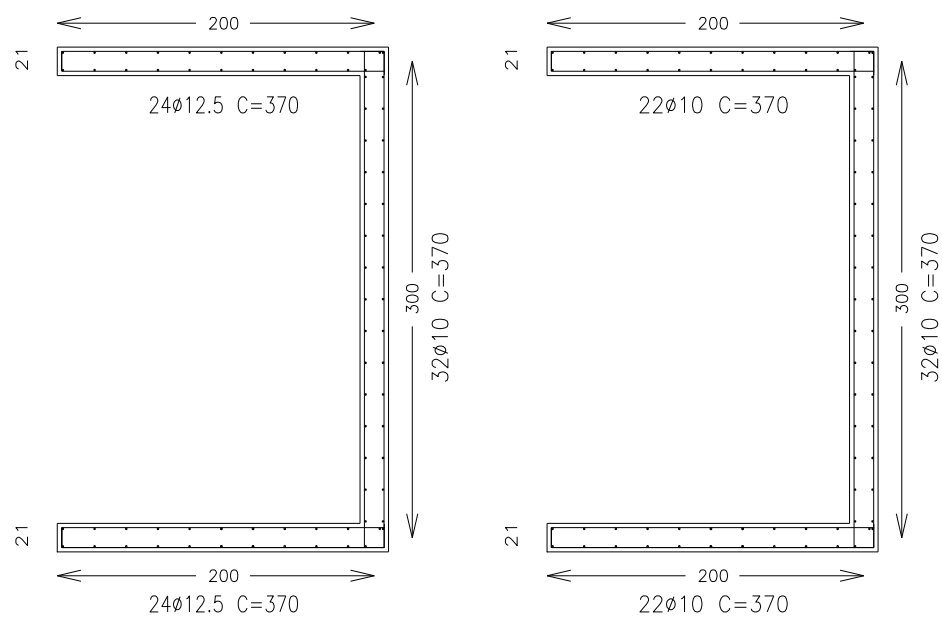
20B
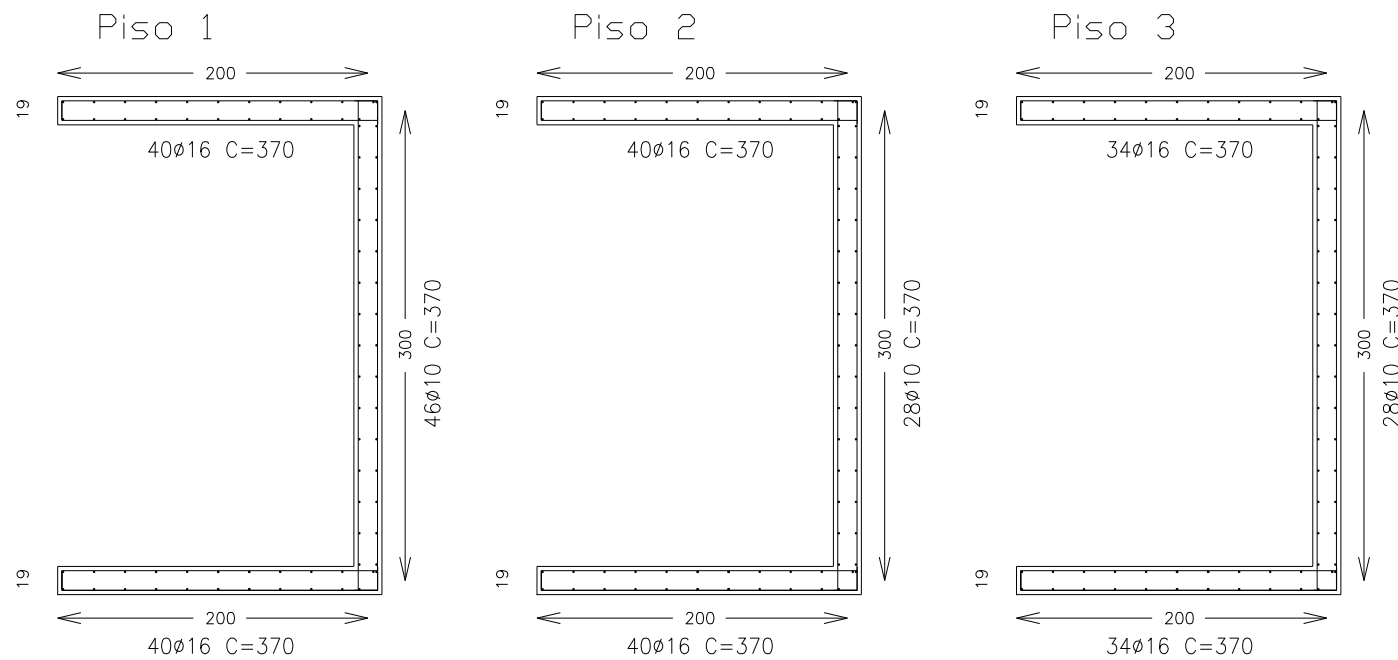

Piso 4

Piso 5-20
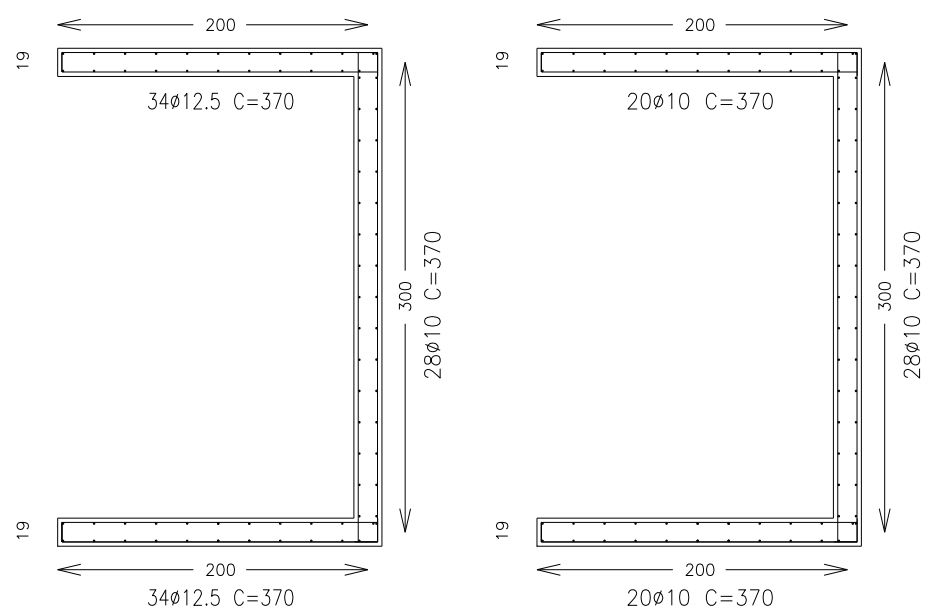
$20 \mathrm{C}$
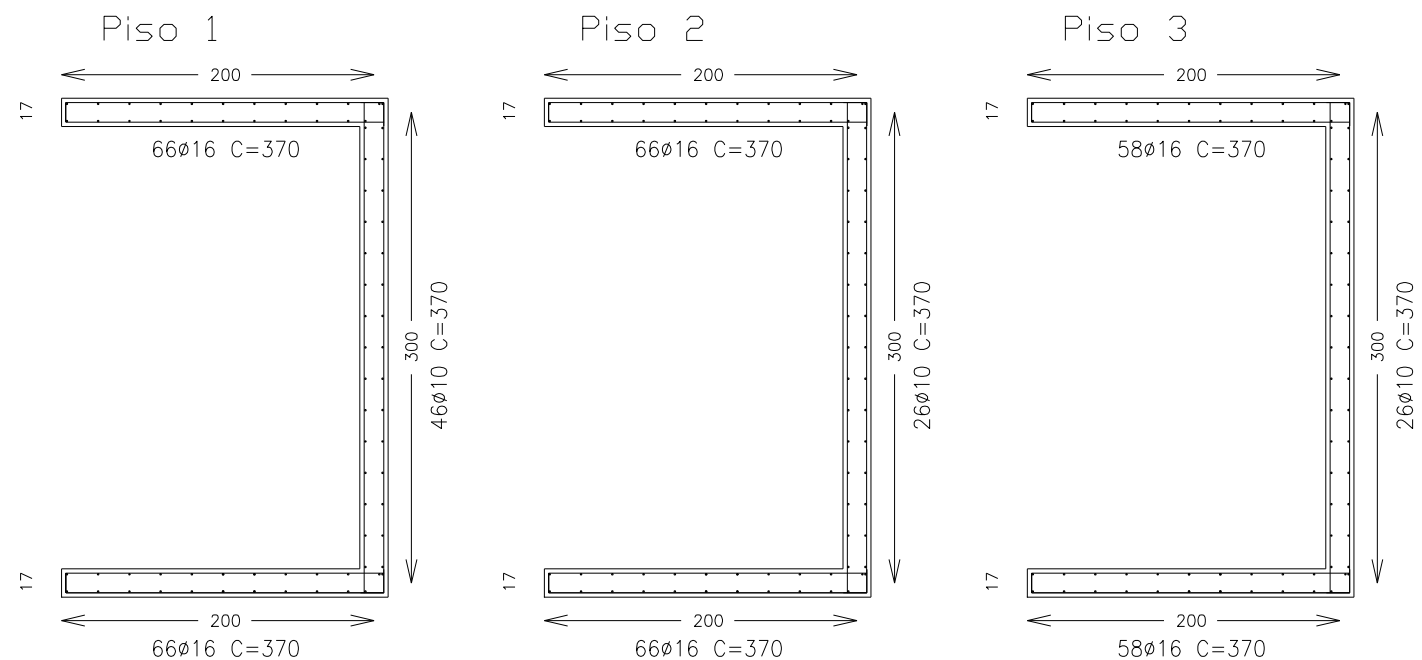

Piso 4

Piso 5

Piso 6
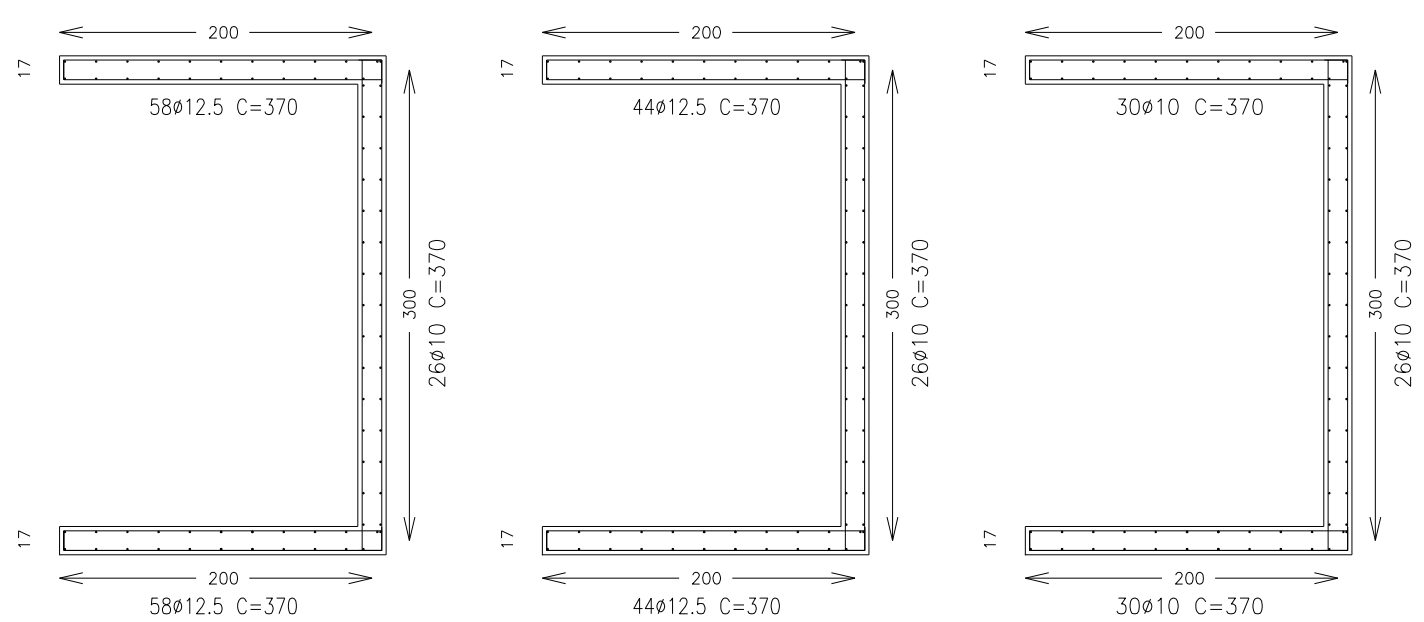

Piso 7-20

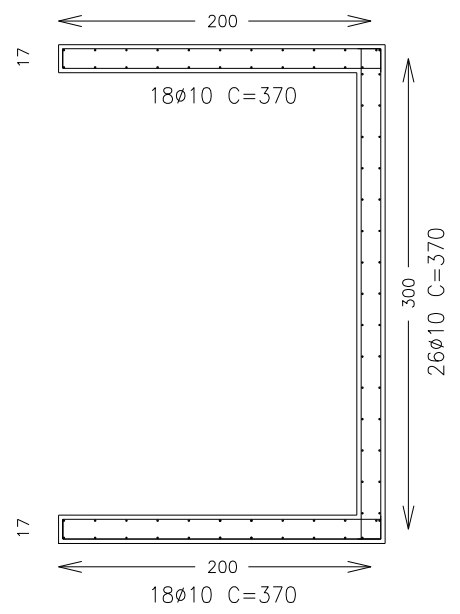




\section{Anexo C}

Neste anexo são mostrados os valores dos deslocamentos na direção do eixo $\mathrm{Z}$ das análises NLG NLF, NLG 70 e NLG 90. Os deslocamentos são dados em cm.

\section{Exemplo 1: Edifício com 12 pavimentos:}

Tabela C.1 - Deslocamentos dos pavimentos: edifício com 12 pavimentos.

\begin{tabular}{|c|c|c|c|c|c|c|c|c|c|}
\hline & \multicolumn{3}{|c|}{$12 \mathrm{~A}$} & \multicolumn{3}{c|}{$12 \mathrm{~B}$} & \multicolumn{3}{c|}{$12 \mathrm{C}$} \\
\cline { 2 - 11 } PAV & NLGF & NLG 70 & NLG 90 & NLGF & NLG 70 & NLG 90 & NLGF & NLG 70 & NLG 90 \\
\hline 1 & 0,2379 & 0,2429 & 0,2303 & 0,2411 & 0,2521 & 0,2393 & 0,2457 & 0,2629 & 0,2499 \\
\hline 2 & 0,6741 & 0,6995 & 0,6713 & 0,6841 & 0,7249 & 0,6962 & 0,6952 & 0,7551 & 0,7257 \\
\hline 3 & 1,175 & 1,221 & 1,18 & 1,195 & 1,266 & 1,224 & 1,211 & 1,32 & 1,276 \\
\hline 4 & 1,699 & 1,765 & 1,711 & 1,732 & 1,831 & 1,776 & 1,755 & 1,91 & 1,854 \\
\hline 5 & 2,227 & 2,31 & 2,245 & 2,275 & 2,399 & 2,332 & 2,305 & 2,504 & 2,436 \\
\hline 6 & 2,746 & 2,843 & 2,768 & 2,81 & 2,954 & 2,877 & 2,847 & 3,085 & 3,006 \\
\hline 7 & 3,245 & 3,354 & 3,27 & 3,325 & 3,487 & 3,401 & 3,37 & 3,643 & 3,555 \\
\hline 8 & 3,717 & 3,836 & 3,744 & 3,813 & 3,99 & 3,895 & 3,864 & 4,169 & 4,073 \\
\hline 9 & 4,157 & 4,285 & 4,185 & 4,267 & 4,457 & 4,355 & 4,325 & 4,658 & 4,554 \\
\hline 10 & 4,562 & 4,696 & 4,591 & 4,685 & 4,886 & 4,779 & 4,748 & 5,106 & 4,997 \\
\hline 11 & 4,933 & 5,072 & 4,962 & 5,068 & 5,277 & 5,166 & 5,135 & 5,514 & 5,402 \\
\hline 12 & 5,277 & 5,418 & 5,304 & 5,422 & 5,638 & 5,524 & 5,492 & 5,891 & 5,776 \\
\hline
\end{tabular}




\section{Exemplo 2: Edifício com 16 pavimentos:}

Tabela C. 2 - Deslocamentos dos pavimentos: edifício com 16 pavimentos.

\begin{tabular}{|c|c|c|c|c|c|c|c|c|c|}
\hline \multirow{2}{*}{ PAV } & \multicolumn{3}{|c|}{$16 \mathrm{~A}$} & \multicolumn{3}{c|}{$16 \mathrm{~B}$} & \multicolumn{3}{c|}{$16 \mathrm{C}$} \\
\cline { 2 - 11 } & NLGF & NLG 70 & NLG 90 & NLGF & NLG 70 & NLG 90 & NLGF & NLG 70 & NLG 90 \\
\hline 1 & 0,3282 & 0,307 & 0,2915 & 0,3344 & 0,3179 & 0,3023 & 0,3479 & 0,3308 & 0,3149 \\
\hline 2 & 0,9178 & 0,9065 & 0,8712 & 0,9407 & 0,9377 & 0,902 & 0,978 & 0,9743 & 0,9379 \\
\hline 3 & 1,61 & 1,62 & 1,567 & 1,656 & 1,676 & 1,623 & 1,723 & 1,742 & 1,687 \\
\hline 4 & 2,359 & 2,394 & 2,324 & 2,433 & 2,479 & 2,408 & 2,534 & 2,578 & 2,506 \\
\hline 5 & 3,143 & 3,201 & 3,115 & 3,246 & 3,317 & 3,229 & 3,383 & 3,452 & 3,363 \\
\hline 6 & 3,942 & 4,024 & 3,923 & 4,077 & 4,172 & 4,069 & 4,25 & 4,344 & 4,239 \\
\hline 7 & 4,744 & 4,849 & 4,733 & 4,91 & 5,029 & 4,911 & 5,119 & 5,238 & 5,117 \\
\hline 8 & 5,536 & 5,664 & 5,535 & 5,733 & 5,875 & 5,743 & 5,977 & 6,119 & 5,985 \\
\hline 9 & 6,311 & 6,46 & 6,317 & 6,536 & 6,7 & 6,555 & 6,813 & 6,978 & 6,831 \\
\hline 10 & 7,06 & 7,228 & 7,074 & 7,313 & 7,496 & 7,34 & 7,62 & 7,805 & 7,647 \\
\hline 11 & 7,779 & 7,964 & 7,8 & 8,057 & 8,258 & 8,092 & 8,392 & 8,595 & 8,427 \\
\hline 12 & 8,464 & 8,663 & 8,49 & 8,764 & 8,981 & 8,806 & 9,125 & 9,343 & 9,167 \\
\hline 13 & 9,113 & 9,324 & 9,143 & 9,434 & 9,663 & 9,481 & 9,817 & 10,05 & 9,865 \\
\hline 14 & 9,726 & 9,946 & 9,758 & 10,07 & 10,3 & 10,12 & 10,47 & 10,71 & 10,52 \\
\hline 15 & 10,3 & 10,53 & 10,34 & 10,66 & 10,91 & 10,71 & 11,08 & 11,33 & 11,14 \\
\hline 16 & 10,86 & 11,09 & 10,89 & 11,23 & 11,48 & 11,28 & 11,67 & 11,92 & 11,73 \\
\hline
\end{tabular}


Exemplo 3: Edifício com 20 pavimentos:

Tabela C. 3 - Deslocamentos dos pavimentos: edifício com 20 pavimentos.

\begin{tabular}{|c|c|c|c|c|c|c|c|c|c|}
\hline \multirow{2}{*}{ PAV } & \multicolumn{3}{|c|}{$20 \mathrm{~A}$} & \multicolumn{3}{c|}{ 202B } & \multicolumn{3}{c|}{ 20C } \\
\cline { 2 - 11 } & NLGF & NLG 70 & NLG 90 & NLGF & NLG 70 & NLG 90 & NLGF & NLG 70 & NLG 90 \\
\hline 1 & 0,4159 & 0,3602 & 0,3422 & 0,4244 & 0,3719 & 0,3538 & 0,4347 & 0,3852 & 0,3629 \\
\hline 2 & 1,144 & 1,084 & 1,042 & 1,171 & 1,118 & 1,076 & 1,202 & 1,157 & 1,105 \\
\hline 3 & 1,996 & 1,969 & 1,906 & 2,049 & 2,031 & 1,967 & 2,108 & 2,102 & 2,022 \\
\hline 4 & 2,931 & 2,953 & 2,868 & 3,014 & 3,047 & 2,962 & 3,108 & 3,156 & 3,049 \\
\hline 5 & 3,925 & 4,004 & 3,899 & 4,042 & 4,134 & 4,028 & 4,174 & 4,284 & 4,151 \\
\hline 6 & 4,959 & 5,101 & 4,976 & 5,112 & 5,27 & 5,143 & 5,285 & 5,464 & 5,304 \\
\hline 7 & 6,02 & 6,229 & 6,083 & 6,21 & 6,437 & 6,289 & 6,425 & 6,676 & 6,49 \\
\hline 8 & 7,093 & 7,371 & 7,206 & 7,321 & 7,619 & 7,452 & 7,578 & 7,902 & 7,692 \\
\hline 9 & 8,168 & 8,515 & 8,332 & 8,434 & 8,802 & 8,616 & 8,732 & 9,129 & 8,896 \\
\hline 10 & 9,236 & 9,651 & 9,45 & 9,538 & 9,976 & 9,773 & 9,876 & 10,35 & 10,09 \\
\hline 11 & 10,29 & 10,77 & 10,55 & 10,63 & 11,13 & 10,91 & 11 & 11,54 & 11,26 \\
\hline 12 & 11,32 & 11,86 & 11,63 & 11,69 & 12,26 & 12,02 & 12,1 & 12,7 & 12,41 \\
\hline 13 & 12,32 & 12,93 & 12,68 & 12,72 & 13,35 & 13,1 & 13,17 & 13,83 & 13,52 \\
\hline 14 & 13,29 & 13,95 & 13,69 & 13,72 & 14,41 & 14,15 & 14,2 & 14,92 & 14,6 \\
\hline 15 & 14,23 & 14,94 & 14,67 & 14,69 & 15,42 & 15,15 & 15,19 & 15,97 & 15,63 \\
\hline 16 & 15,14 & 15,89 & 15,61 & 15,62 & 16,4 & 16,12 & 16,15 & 16,96 & 16,62 \\
\hline 17 & 16 & 16,8 & 16,51 & 16,51 & 17,33 & 17,04 & 17,06 & 17,92 & 17,56 \\
\hline 18 & 16,83 & 17,67 & 17,37 & 17,36 & 18,22 & 17,92 & 17,93 & 18,83 & 18,46 \\
\hline 19 & 17,63 & 18,5 & 18,19 & 18,18 & 19,07 & 18,77 & 18,77 & 19,7 & 19,33 \\
\hline 20 & 18,41 & 19,3 & 18,99 & 18,98 & 19,89 & 19,59 & 19,59 & 20,54 & 20,16 \\
\hline & & & & & & & & & \\
\hline
\end{tabular}

